doi.org/10.3114/fuse.2019.04.08

\title{
A revision of the genus Psathyrella, with a focus on subsection Spadiceogriseae
}

\author{
P. Voto ${ }^{1}$, F. Dovana 2 , M. Garbelotto ${ }^{3}$ \\ ${ }^{1}$ Via Garibaldi 173, 45010 Villadose, Italy \\ ${ }^{2}$ Department of Life Sciences and Systems Biology, University of Torino, Viale P.A. Mattioli 25, I-10125, Torino, Italy \\ ${ }^{3}$ Department of Environmental Science, Policy, and Management; University of California, Berkeley, CA 94720, USA \\ *Corresponding author: matteog@berkeley.edu
}

Key words:

key

molecular phylogenetics

new taxa

systematics

taxonomy

\begin{abstract}
Specimens belonging to taxa traditionally assigned to the subsection Spadiceogriseae of the genus Psathyrella were analyzed both morphologically and molecularly. Samples included mainly European collections, selected GenBank accessions, and specimens of various North American taxa described by Smith (1972) and deposited at the Herbarium of the University of Michigan (MICH). Three additional taxa from Africa and Central America were also included. Bayesian and Maximum Likelihood analyses of two loci (ITS and Tef-1 $\alpha$ ) independently and together supported the monophyletic nature of the subsection Spadiceogriseae, and identified nine statistically supported clades within the subsection. North American and European species often fell within the same clade, suggesting a relatively recent origin of the subsection or human induced intercontinental movement. While this study determines for the first time that the presence of a white veil is diagnostic for the entire subsection, very few morphological traits were associated with individual clades, but clades were often distinctively different in terms of habitat association, suggesting that trophic interactions may have driven the evolution of this group of fungi.

Combined, morphological and DNA analyses revealed both expected and unexpected synonymies. The new combinations $P$. vesiculosa, $P$. ochrofulva and $P$. sanjuanensis are proposed, and the new species $P$. rogersiae is described. New information is provided on the taxonomic status and distribution of several species including $P$. agrariella, P. albescens, P. atrifolia, P. bivelata, P. fatua, P. kauffmanii, P. aff. kauffmanii, P. incondita, P. infida, P. nitens, $P$. niveobadia, $P$. phegophila, $P$. pseudocorrugis sensu Kits van Waveren, $P$. subnuda. In total, 13 synonymies were proposed. Based on DNA data, five species of uncertain validity were confirmed as valid, while six species may be ambiguous and may require an in-depth re-analysis. The information gathered in this study was used to generate a key to the species of the subsection Spadiceogriseae.
\end{abstract}

Effectively published online: 21 June 2019.

\section{INTRODUCTION}

In the morphology-based infrageneric classification of the genus Psathyrella by Kits van Waveren (1985), the section Spadiceogriseae (subgenus Psathyra), type species $P$. spadiceogrisea, includes taxa with spores of medium dimension, pleurocystidia not muricate and mainly utriform with rounded to obtuse apex, and a veil neither granulose nor strongly fibrillose-squamulose. In the same 1985 study, Kits van Waveren further split the section in the two subsections Spadiceogriseae and Lutenses. Species with gill edges predominantly lined by large numbers of conspicuous sphaeropedunculate to clavate cells, here called paracystidia, amidst a minority of pleurocystidioid cells were placed in the first subsection. Based on this study (see discussion), we include a white veil as an additional morphological trait relevant for species within the subsection.

As we demonstrate in this paper, Kits van Waveren's subsection Spadiceogriseae is a well constructed taxonomic unit which has the important advantage to receive full recognition by the molecular evidence, even when applied on a worldwide scale. This subsection only needs to be integrated with $P$. ammophila which, evidently because of its large and dark spores, the Dutch author placed in the subgenus Psathyrella, keeping and emending Morgan's (1907) taxon Deconica Ammophilae [section Ammophilae (Morgan) Kits van Wav. emend., monospecific].

In the earlier work by Romagnesi (1944) the species of this homogenous group are placed in section Fatuae (characterized by colorless gill trama) subsection Spadiceogriseae Romagn. (type species Drosophila spadiceogrisea), but not all of them as Drosophila frustulenta sensu Romagnesi which, fide Kits van Waveren (1985), corresponds to $P$. clivensis, is the type species assigned to section Hydrophilae (defined on pigmented gill trama) subsection Frustulentae. Therefore, Romagnesi (1944) only partially realized the importance of the parameter of dominating paracystidia (which he used for the delimitation of subsection Spadiceogriseae inside section Fatuae) placing it at a lower level than that of the gill trama pigmentation.

Recently, Örstadius \& Knudsen (2012) and Örstadius et al. (2015) have published important studies on the genus Psathyrella including a modern revision of some species belonging to subsection Spadiceogriseae. However, they have not treated this subsection directly; in their keys formal supraspecific taxa are 
ignored and dichotomic steps are primarily based on partitions of spore length.

When we started this study, a number of ambiguities about European species morphologically belonging to subsection Spadiceogriseae, many of which present in Kits van Waveren's monograph (1985), and not resolved by the two modern works aforementioned, were still awaiting a definitive formal recognition by the scientific community (e.g. P. agraria, $P$. casca, $P$. niveobadia, $P$. phaseolispora, $P$. phegophila, and $P$. pseudocorrugis sensu Kits van Waveren).

More complex and unresolved is the taxonomy of North American species within the subsection Spadiceogriseae, mostly because the taxonomic work by Smith (1972) on North American specimens predated that of Kits van Waveren (1985) by over a decade. Predominance of paracystidia had no recognition at any supraspecific level in his systematic plan. He used the taxon subgenus Psathyrella section Fatuae for species with spores of medium length and pleurocystidia utriform to broadly rounded at apex, and used the subsection Fatuae only to delimit the terrestrial species. Psathyrella kauffmanii, for instance, is in subgenus Pseudostropharia because of being annulate. The formal species descriptions themselves show that Smith was not aware of the taxonomical importance of the morphological feature of the dominance of paracystidia later used by his European colleague to define the subsection Spadiceogriseae. Hence, while he noted the presence of both types of cystidia on gill edges, he did not define their exact frequency ratio, save for those cases when clavate cystidia were exceedingly prevalent. The first aim of this work, therefore, was to search through Smith's monograph for those descriptions revealing a possible inclusion of North American taxa in the subsection Spadiceogriseae.

As should be expected, the differences in taxonomic approach by the two systematists resulted in the definition of species that may be difficult to compare based on their original description. Thus, the second aim of this study was to provide a unified classification of a good selection of North American and European taxa.

Finally, our study attempts to clarify the taxonomic position of some of the species described by Smith, either characterized by ambiguously shaped pleurocystidial apices, a trait that makes uncertain their assignment within sections Spadiceogriseae or Pennatae, or characterized by unclear gills edge patterns, a trait that makes uncertain their assignment to subsections Spadiceogriseae or Lutenses.

\section{MATERIALS AND METHODS}

\section{Samples analyzed}

Table 1 lists all of the specimens described included in the study. In brief, morphological and molecular analyses were attempted on a total of 98 samples, including 60 North American, one Central American, 35 European and two African specimens. A total of 47 holotypes and five paratypes were included in this study.

We note that due to limited sample size, types vouchers of the following taxa could not be obtained from the Herbarium at the University of Michigan (MICH): P. ambusta, P. flexuosipes, $P$. incondita, $P$. carolinensis, $P$. lactobrunnescens, $P$. latispora, $P$. praecox and $P$. subcinerascens. Paratypes of $P$. flexuosipes, $P$. incondita and $P$. praecox were loaned to us. Unfortunately, the type vouchers of some European species, e.g. P. niveobadia, P. phaseolispora, P. phegophila, and of the South American species $P$. macquariensis could not be obtained. Finally, although we obtained a type for the following species, they failed to produce a DNA sequence: $P$. affinis, $P$. almerensis, $P$. ovaticystis, P. psammophila, P. rugulosa, $P$. solheimii, $P$. solheimii var. sanjuanensis, $P$. tenacipes, $P$. velibrunnescens, $P$. yaoundeana. Table 2 lists all additional sequences used in the ITS phylogenetic analysis and retrieved both from GenBank or UNITE.

\section{Morphology}

Spore color was assessed in water suspensions. Dried material was first imbibed with either $5 \% \mathrm{KOH}$ or $10 \% \mathrm{NH}_{4} \mathrm{OH}$. A $5 \%$ $\mathrm{KOH}$ stain was used to determine pigmentation of the marginal cystidia and of the underlying cells. A $10 \% \mathrm{NH}_{4} \mathrm{OH}$ dilution was used to determine traits of pleurocystidia including wall thickness, presence of incrustation, and pigmentation. Congo red was used for staining and picture-documentation of microscopical features of interest.

A number of words in Smith's monograph that are not used in the European terminology were interpreted as follows. Inequilateral (spore shape in profile) = amygdaliform. Terete (spore shape) = bidimensional, in contrast to flattened tridimensional spores which need to be described in length, width in side view, and width in profile. Acute, obtuse, rounded and truncate (spore pole and cystidial apex): we maintain Smith's description of four levels of rotundity, from sharp (acute) through midway (obtuse) to broadly curved (rounded) or flat (truncate). Distant, close and crowded (frequency of gills): we substitute the term 'close' with the expression 'moderately crowded'.

When observed in $10 \% \mathrm{NH}_{4} \mathrm{OH}$, pleurocystidia may show an irrelevant greenish tint, only yellowish to brownish pigments are considered relevant. The cystidial cells on the gill edge in Psathyrella are often of two types; cheilocystidia and paracystidia. We call cheilocystidia those resembling pleurocystidia, while we call paracystidia, sensu Huijsman (1955), those having an apically undifferentiated shape (that is clavate, spheropedunculate, obpyriform, sometimes slender and more or less cylindrical); the term "dominating" in the text is used to indicate the predominance on gills edges of either one of the two types of cells described above. However, two ambiguous cases can sometimes occur, i.e. either some marginal cells may have an intermediate shape with a subtle differentiation at the apex, or the pleurocystidia themselves may also be undifferentiated in shape, e.g. ellipsoid to clavate. In both cases, a clear-cut distinction between the two types of marginal cells is not possible. The shape of cheilocystidia is usually omitted in our descriptions because it generally mirrors that of the pleurocystidia, except for a tendency to bear somewhat smaller dimensions. Sometimes, they may be partially described if they conspicuously deviate from the main pleurocystidial pattern; however, cheilocystidia may be characterized by a narrower apex or a slenderer neck than pleurocystidia.

Presence of a germ pore is assessed in $\mathrm{KOH}$, while its shape is assessed in water, as it may tend to swell when observed in alkali. The letter $Q$ indicates the quotient of bidimensional spores, that is the ratio length/breadth, but when the spores are tridimensional, the symbols $f Q$ and $p Q$ are used instead to indicate the quotient in front and, respectively, in profile view

The term avQ stands for the average value of $Q$. 


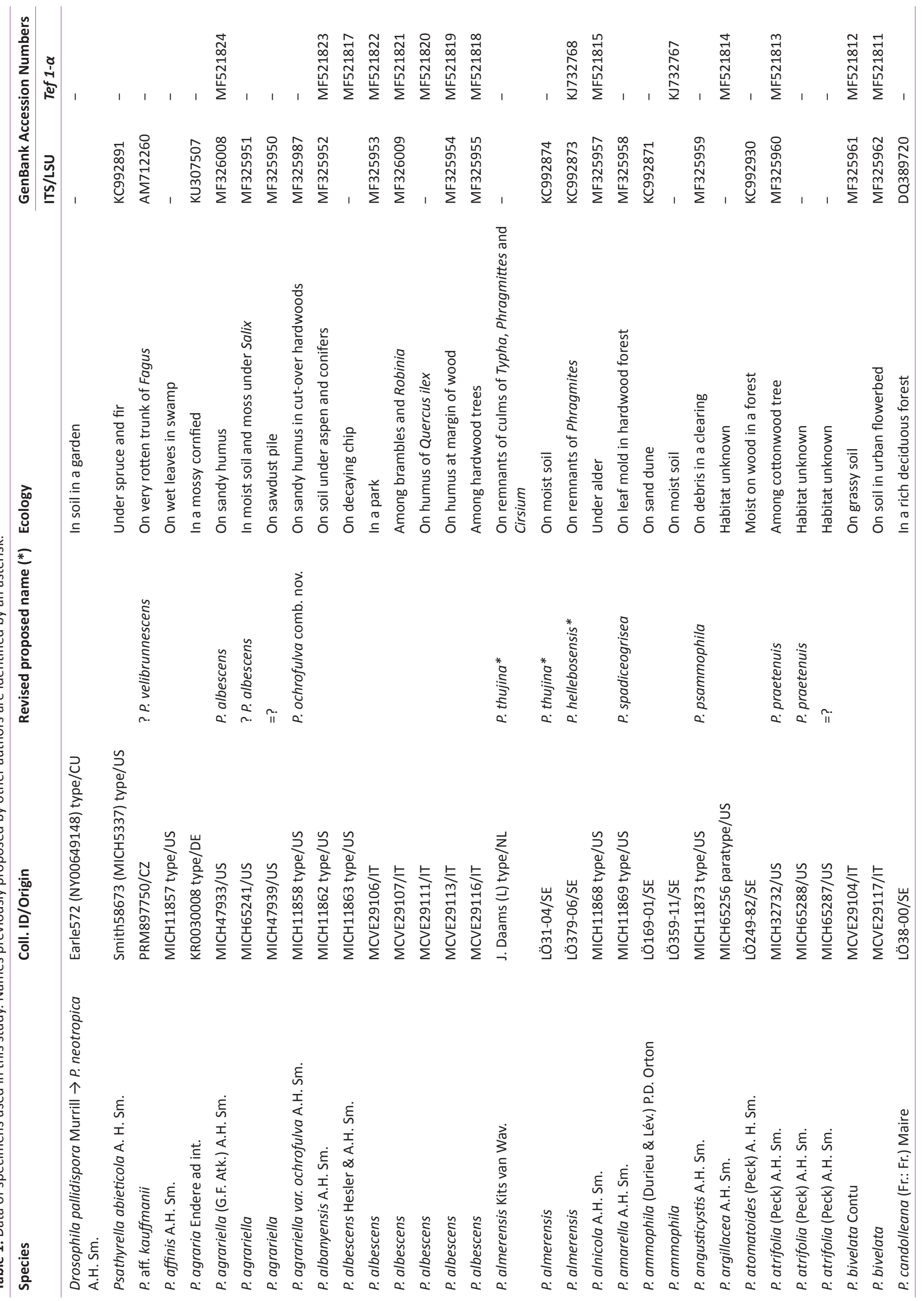




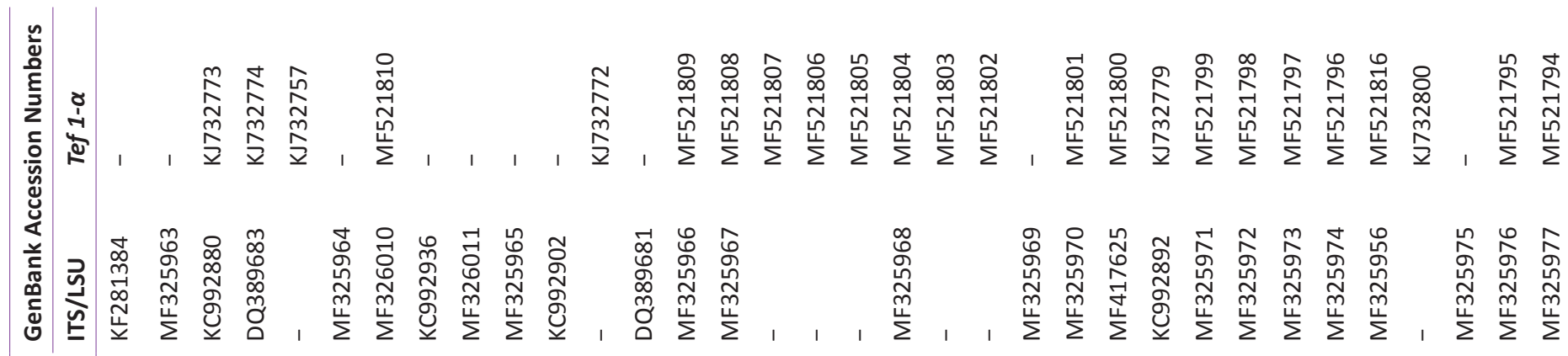

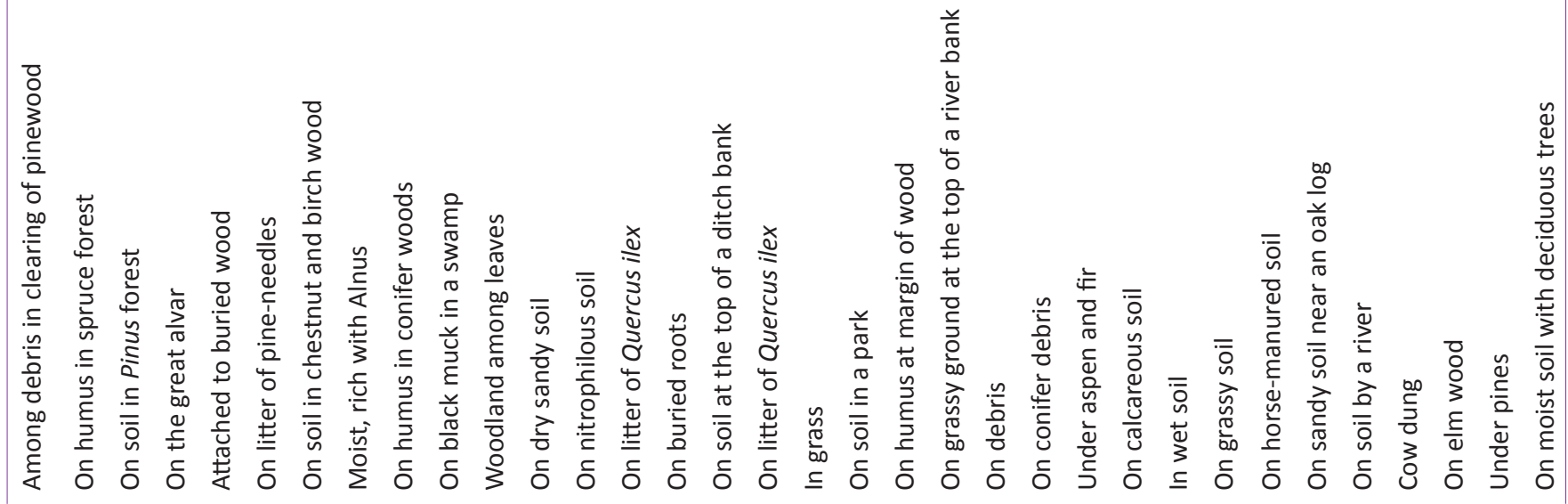

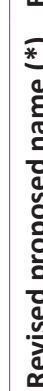

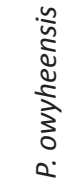

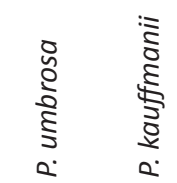

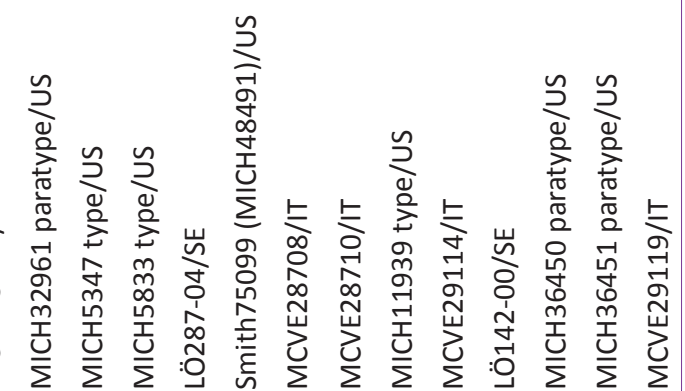




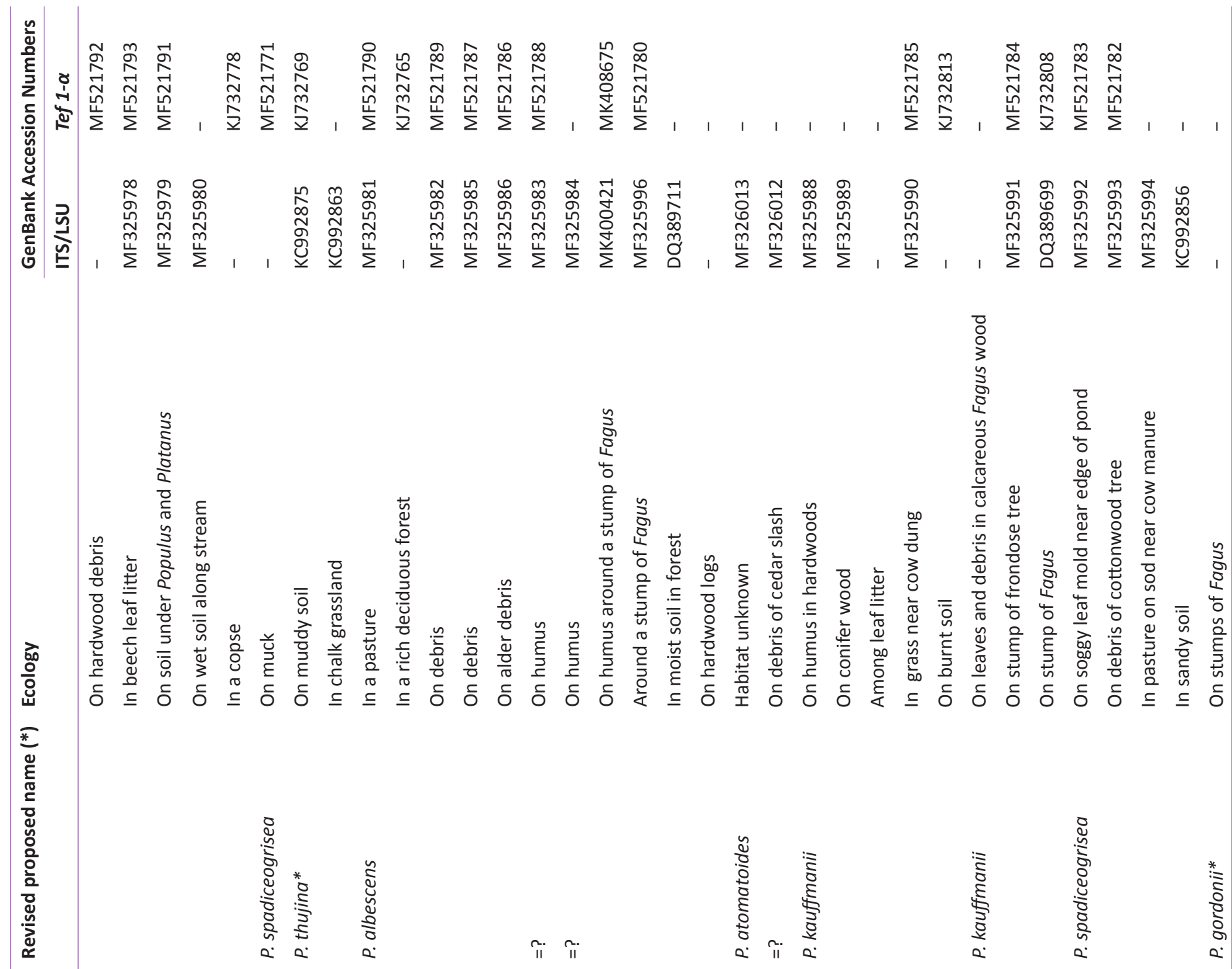

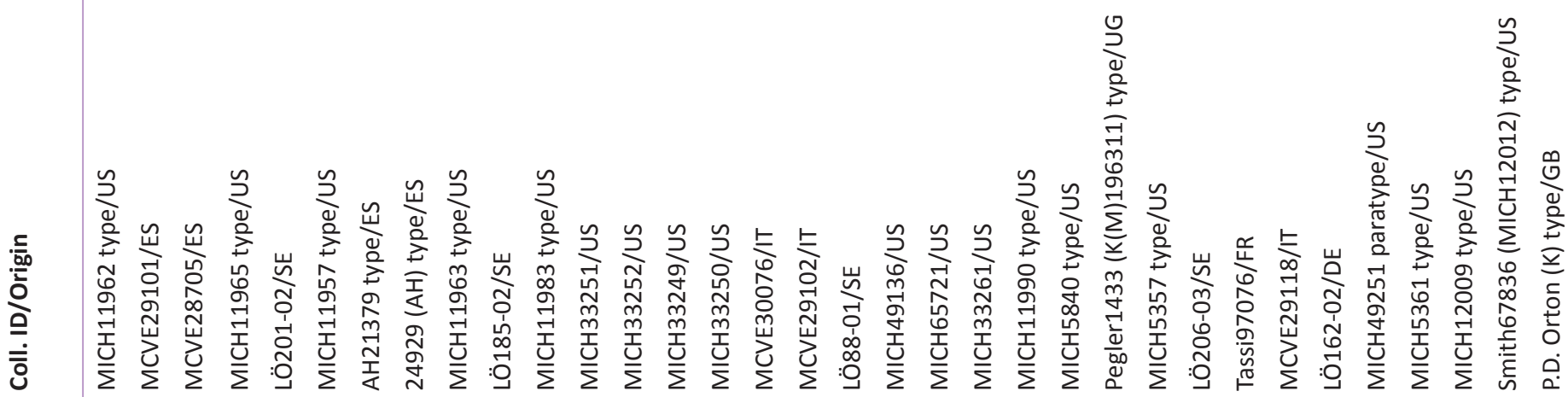

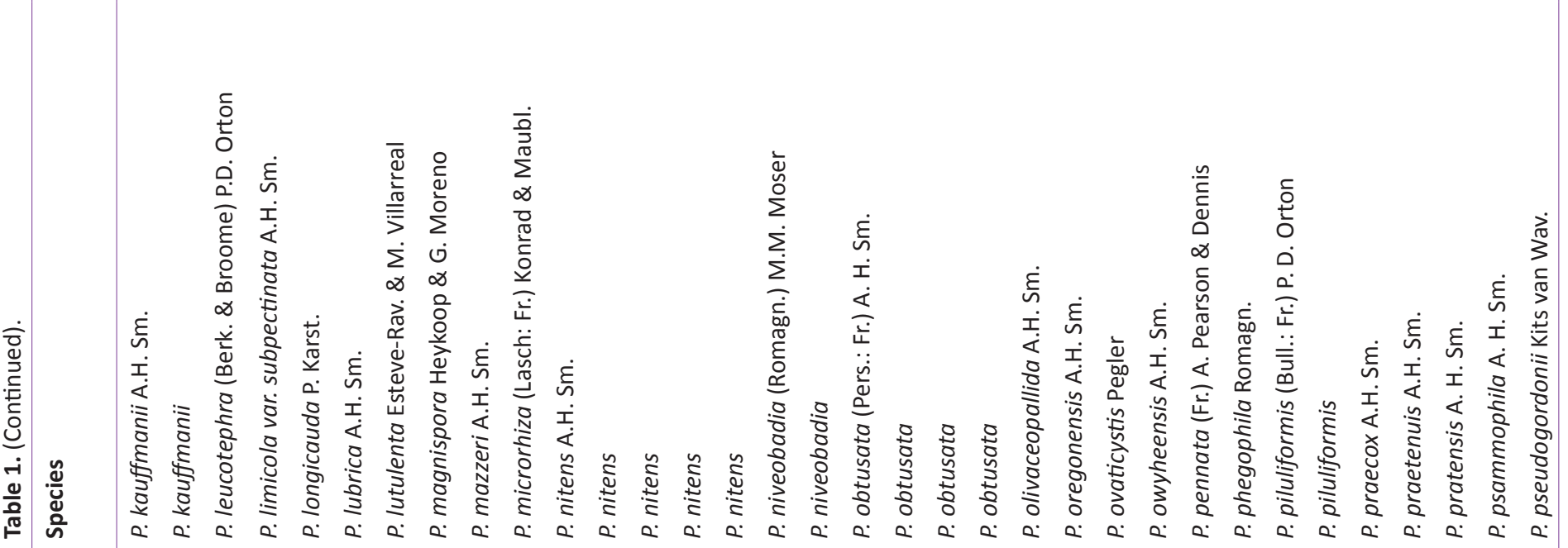




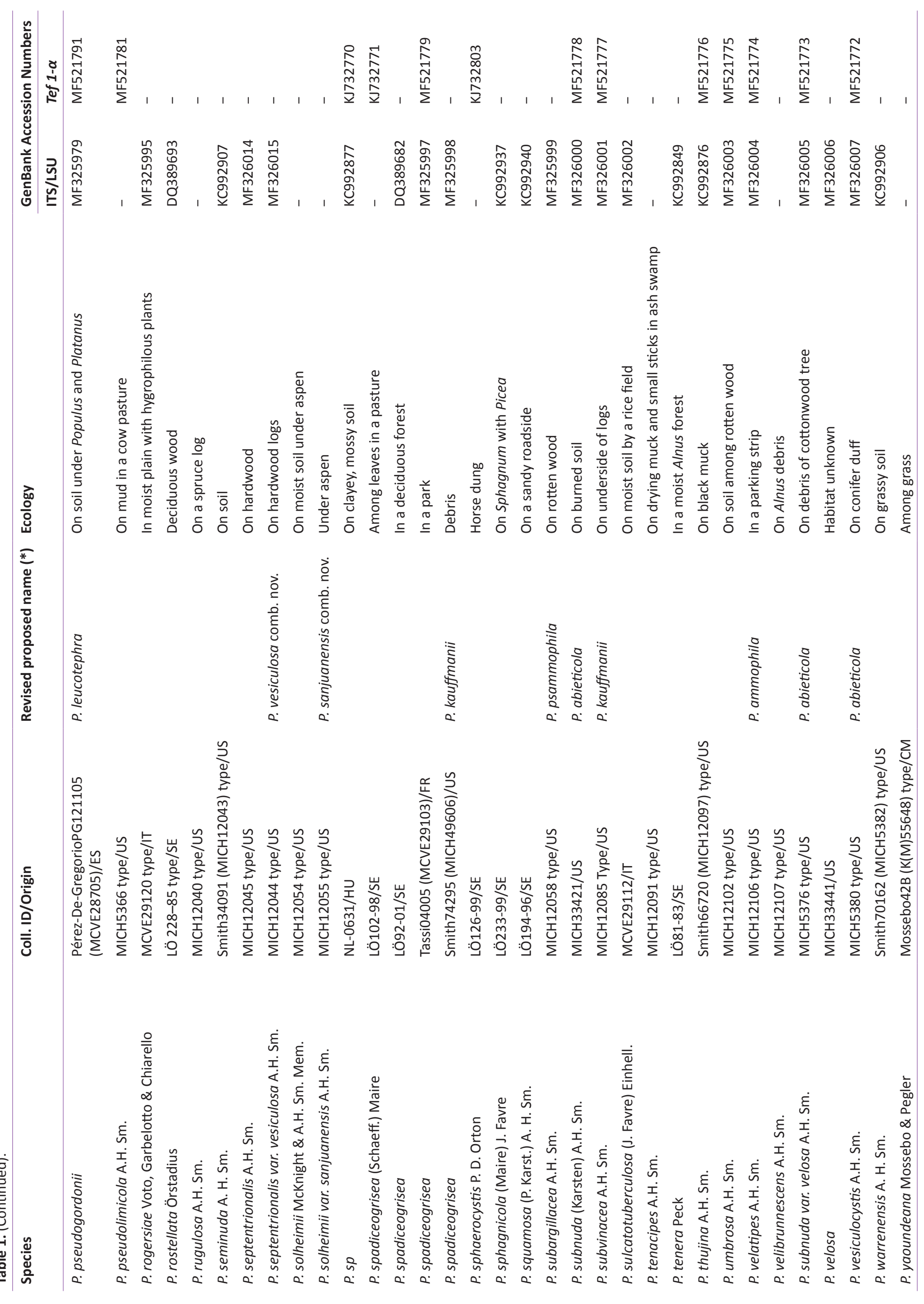


Table 2. List of sequences used in the ITS analysis without matching morphological analysis, including original Collection ID, origin when available, and GenBank or UNITE accession number.

\begin{tabular}{|c|c|c|}
\hline Species & Coll. ID/Origin & GenBank/UNITE Accession Numbers \\
\hline Psathyrella ammophila & O-F-253115/NO & UDB037642 \\
\hline Psathyrella ammophila & LO99/NO & UDB017672 \\
\hline Psathyrella ammophila & $\mathrm{AH}: 947 / \mathrm{ES}$ & KY350223 \\
\hline Psathyrella ammophila & SZMCNL 3398 & FN396112 \\
\hline Psathyrella ammophila & $\mathrm{AH} 24456$ & KY350224 \\
\hline Psathyrella ammophila & LO169-01/SE & KC992871 \\
\hline Psathyrella ammophila & AH947 & MF966506 \\
\hline Psathyrella ammophila & $\mathrm{AH} 24456$ & MF966486 \\
\hline Psathyrella casca & AM1814/DE & MF668177 \\
\hline Psathyrella cascoides & AV080419/DE & MK045734 \\
\hline Psathyrella cascoides & DW170430/DE & МK026744 \\
\hline Psathyrella cf. gracilis & SOC997/US & FJ235146 \\
\hline Psathyrella clivensis & AM1913/FR & MK129249 \\
\hline Psathyrella fatua & DD8849/BE & MK182811 \\
\hline Psathyrella fatua & DW160426/DE & MH997496 \\
\hline Psathyrella fatua & SZMC-NL-0603 & FN396142 \\
\hline Psathyrella fatua & AM1726/DE & МK072832 \\
\hline Psathyrella fatua & DD0223/BE & MK182825 \\
\hline Psathyrella fatua & AH33718 & MF966492 \\
\hline Psathyrella fatua & $\mathrm{AH}: 33718 / \mathrm{ES}$ & KY350222 \\
\hline Psathyrella fatua & DD2601/BE & MK182826 \\
\hline Psathyrella fatua & DD2602/BE & MK182822 \\
\hline Psathyrella fatua & DD0222/BE & MK182821 \\
\hline Psathyrella fatua & $\mathrm{AH} 22059$ & MF966485 \\
\hline Psathyrella fatua & LO231-08 & KC992879 \\
\hline Psathyrella fatua & AM445/DE & МК045704 \\
\hline Psathyrella jacobssonii & LO256-92/SE & KC992855 \\
\hline Psathyrella mammifera & HMJAU21908/CN & MG734734 \\
\hline Psathyrella mammifera & HMJAU 37882/CN & MG734740 \\
\hline Psathyrella marquana & AM1693/DE & MF668178 \\
\hline Psathyrella microrhiza & TU106657/EE & UDB011850 \\
\hline Psathyrella microrhiza & TU106614/EE & UDB011827 \\
\hline Psathyrella phegophila & AH45940/ES & KY350219 \\
\hline Psathyrella phegophila & HMJAU 28267/CN & MG734728 \\
\hline Psathyrella phegophila & BRNM705637 & AM712277 \\
\hline Psathyrella phegophila & HMJAU 37848/CN & MG734738 \\
\hline Psathyrella prona & $303322 /$ US & MK607583 \\
\hline Psathyrella pseudogracilis & TU106565/EE & UDB011802 \\
\hline Psathyrella spadiceogrisea & TU118645/EE & UDB018041 \\
\hline Psathyrella spadiceogrisea & TU106529/EE & UDB011718 \\
\hline Psathyrella spadiceogrisea & TU106528/EE & UDB011717 \\
\hline Psathyrella spadiceogrisea & TU106574/EE & UDB011808 \\
\hline Psathyrella spadiceogrisea & TENN:068273/US & KY744152 \\
\hline Psathyrella spadiceogrisea & AM1244/DE & МК045702 \\
\hline Psathyrella spadiceogrisea & BRNM705637/CZ & AM712276 \\
\hline Psathyrella spadiceogrisea & GENT JR3565/BE & МК045679 \\
\hline Psathyrella spadiceogrisea & AM1242/DE & МК045696 \\
\hline
\end{tabular}


Table 2. (Continued).

\begin{tabular}{lll}
\hline Species & Coll. ID/Origin & GenBank/UNITE Accession Numbers \\
\hline Psathyrella spadiceogrisea & LO102-98/SE & KC992878 \\
Psathyrella spadiceogrisea & AM1671/DE & MK045698 \\
Psathyrella spadiceogrisea & HIAS120608/DE & MK045697 \\
Psathyrella spadiceogrisea & SZMC-NL-0440 & FM878024 \\
Psathyrella spadiceogrisea & AM1581/ES & MK045703 \\
Psathyrella spadiceogrisea & CBS 171.47/PT & MH856203 \\
Psathyrella striatoannulata & INB3978642/CR & KY350221 \\
Psathyrella striatoannulata & INB4162132 & KY350220 \\
Psathyrella sublatispora & AH40381/ES & MF966502 \\
Psathyrella sublatispora & LO190-97/SE & KC992854 \\
Psathyrella subspadiceogrisea & HMJAU 35992 type/CN & KY678465 \\
Psathyrella subspadiceogrisea & HMJAU 35996/CN & KY678466 \\
Psathyrella thujina & AM1656 & KY680791 \\
Psathyrella thujina & AM1849 & KY680792 \\
\hline
\end{tabular}

Pictures of pleurocystidia and marginal cells are used to show their shape and sometimes their color or incrustations in ammonia or $\mathrm{KOH}$; otherwise, they are shown in Congo red. The most relevant spore shapes are illustrated in the Figures, while spore color is better described in writing, due to possible distortions of the digital imagery or to the small number of fully ripe spores.

All species studied and described have clamps and 4-spored basidia, therefore these two features are generally omitted.

\section{Material studied}

Personal collections and duplicates of some of the material received as a gift are deposited in the fungarium of Museo di Storia Naturale di Venezia (The Venice Museum of Natural History, MCVE). All of Smith's types, paratypes and other collections used in this study were on loan from the University of Michigan Fungarium (MICH). When the small size of a type specimen prevented a loan, the collection manager selected for us an available paratype from other collections cited by Smith (1972). Other collections were received on loan from the Royal Botanic Garden at Kew (K), the Naturalis Biodiversity Center (former National Herbarium of Leiden, L), the Fungarium of the New York Botanical Garden (NY), and from private fungaria. Unfortunately, we were not able to obtain the types of $P$. niveobadia, P. phegophila, P. phaseolispora and P. macquariensis. Table 1 reports all samples studied, including the specimens sequenced, the GenBank accession numbers of the sequences generated, host and state of collection, and, when appropriate, the name assigned to them following our revision.

\section{DNA extraction, PCR and sequencing}

DNA was extracted from all dried sporocarps as described by Swo et al. (2004). Briefly, samples were ground to a fine dust using a bead mill, suspended in a CTAB extraction buffer before being frozen using dry ice and then thawed using a heating block set at $70^{\circ} \mathrm{C}$, for three freeze-thaw cycles. Samples were then incubated at $70{ }^{\circ} \mathrm{C}$ for $30 \mathrm{~min}$ before being fully submerged in phenol: chloroform : isoamyl alcohol (25:24:1) and centrifuged for 15 $\min$ at $13000 \mathrm{~g}$. Finally, DNA was purified from the supernatant using the GeneClean Turbo kit (QBiogene, Inc). Samples that failed to amplify using this extraction procedure were extracted using the $\mathrm{NaOH}$ protocol described by Osmundson et al. (2013). Briefly, $200 \mu \mathrm{L}$ of $0.5 \mathrm{~N} \mathrm{NaOH}$ were added to the ground lyophilized tissue. Samples were briefly vortexed, then $5 \mu \mathrm{L}$ were transferred to a new tube containing $495 \mu \mathrm{L}$ of $100 \mathrm{mM}$ Tris, $\mathrm{pH}$ 8.0; $1 \mu \mathrm{L}$ of this mixture was used as template DNA in a $25 \mu \mathrm{L}$ $\mathrm{PCR}$ reaction.

Two genomic loci were selected to conduct the phylogenetic analyses. The markers were the nuclear ribosomal Internal Transcribed Spacer (ITS) and the translation elongation factor 1-alpha $(T e f-1 \alpha)$. Primers used for the amplification and sequencing of ITS were 5'-CTTGGTCATTTAGAGGAAGTAA-3' (ITS1f; forward) and 5'-TCCTCCGCTTATTGATATGC-3' (ITS4; reverse) (Gardes \& Bruns 1993), while those used for Tef-1 $\alpha$ were 5'-GCYCCYGGHCAYCGTGAYTTYAT-3' (983 forward) and 5'-ACHGTRCCRATACCACCRATCTT-3' (1567 reverse) (http:// www2.clarku.edu/faculty/dhibbett/Protocols_Folder/ Primers/Primers.pdf). Amplification reactions were performed in the following $25 \mu \mathrm{L}$ reaction mixture: $5 \times$ buffer, $0.2 \mathrm{mM}$ dNTPs, $1.25 \mathrm{U} / \mu \mathrm{L}$ of GoTaq polymerase (Promega Corp. Madison, WI), $2.0 \mathrm{mM} \mathrm{MgCl}_{2}$ (Invitrogen Corp. Carlsbad, CA, USA), 0.50 uM each non-degenerate primer or 0.64 uM each degenerate primer, and approximately $20 \mathrm{ng}$ of DNA. The PCR program was: $95{ }^{\circ} \mathrm{C}$ for $3 \mathrm{~min}$, followed by 35 cycles of $95{ }^{\circ} \mathrm{C}$ for $40 \mathrm{~s}$, different annealing temperature $\left(53{ }^{\circ} \mathrm{C}\right.$ for ITS, and a touchdown between $66{ }^{\circ} \mathrm{C}$ and $56{ }^{\circ} \mathrm{C}$ with a $1{ }^{\circ} \mathrm{C}$ decrease at each cycle for Tef- $1 \alpha$ ) for $55 \mathrm{~s}, 72^{\circ} \mathrm{C}$ for $55 \mathrm{~s}$, and an extension step at $72{ }^{\circ} \mathrm{C}$ for $7 \mathrm{~min}$. The purified PCR amplicons of ITS and Tef- $1 \alpha$ were Sanger-sequenced in-house at the Forest Pathology and Mycology Laboratory (Berkeley, USA). All amplicons were forward and reverse sequenced with the related primers, and consensus sequences were generated by using the Geneious software, v. 9.0.5 (Biomatters, Ltd). Chromatograms of each sequence were analyzed by using both Geneious and SnapGene ${ }^{\circledR}$ Viewer. The minimum acceptable phred score considered per base was 20 . 


\section{Molecular analyses}

Analyses were performed on the four following datasets: 1 )- the first included 160 ITS sequences, 68 generated by this study, 83 obtained from GenBank and nine from UNITE; 2)- the second included 72 Tef- $1 \alpha$ sequences, 56 generated by this study and 16 selected from GenBank; 3)- the third included both ITS and
Tef- $1 \alpha$ sequences for 52 taxa, 43 generated by this study, and nine selected from GenBank; 4)- the fourth included ITS and Tef$1 \alpha$ sequences for 224 taxa, both sequenced in this study and previously analyzed by Örstadius et al. (2015). The sequences of Bolbitius vitellinus (AFTOL730) and Mythicomyces corneipes (AFTOL972) were selected as outgroups in all of the analyses.

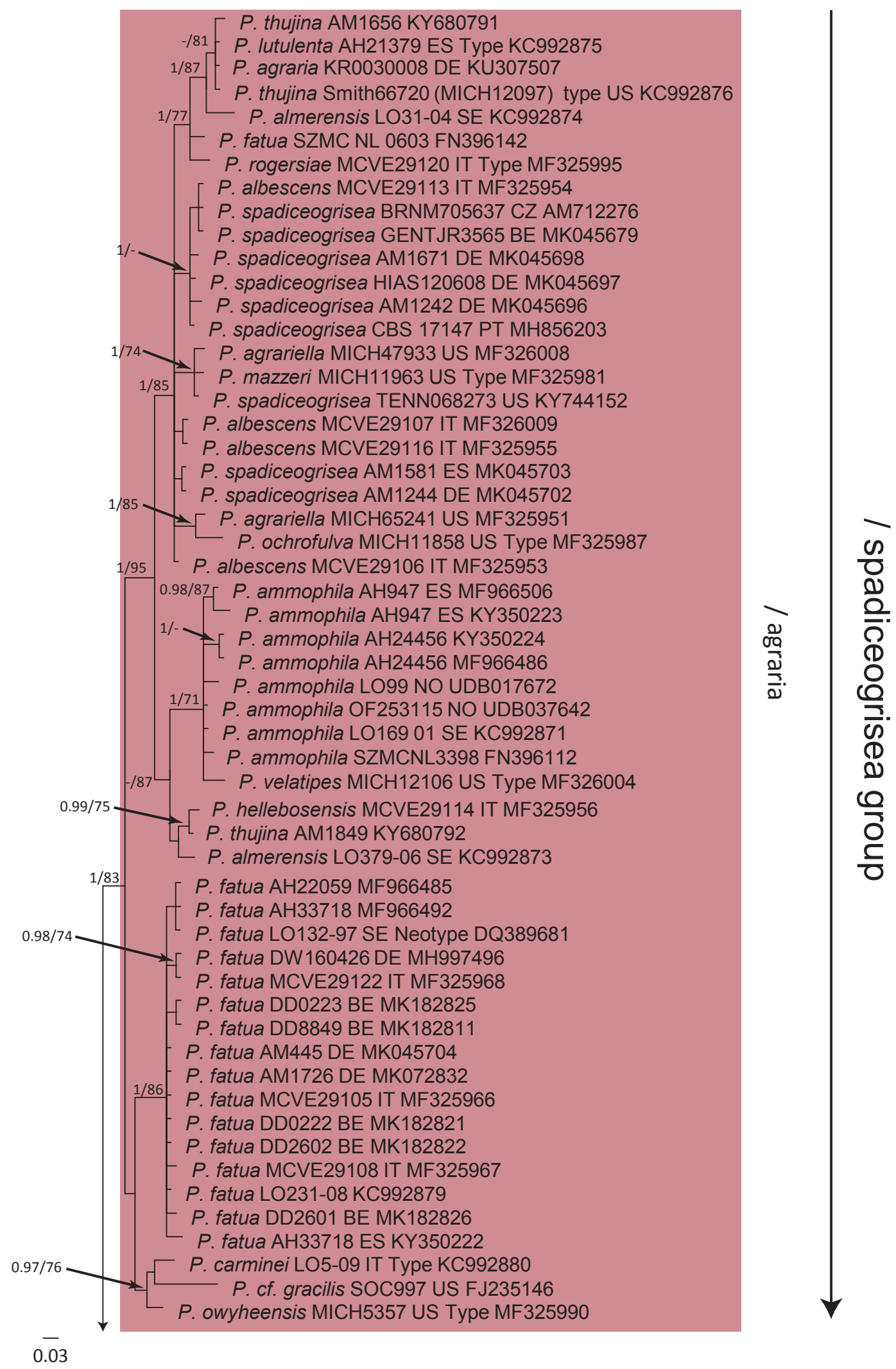

Fig. 1. Bayesian phylogram obtained from the general nrITS sequence alignment of Psathyrella spp. Bolbitius vitellinus was used as outgroup taxon. Only BPP values $\geq 0.95$ and MLB values $\geq 70 \%$ are given above clade branches. 


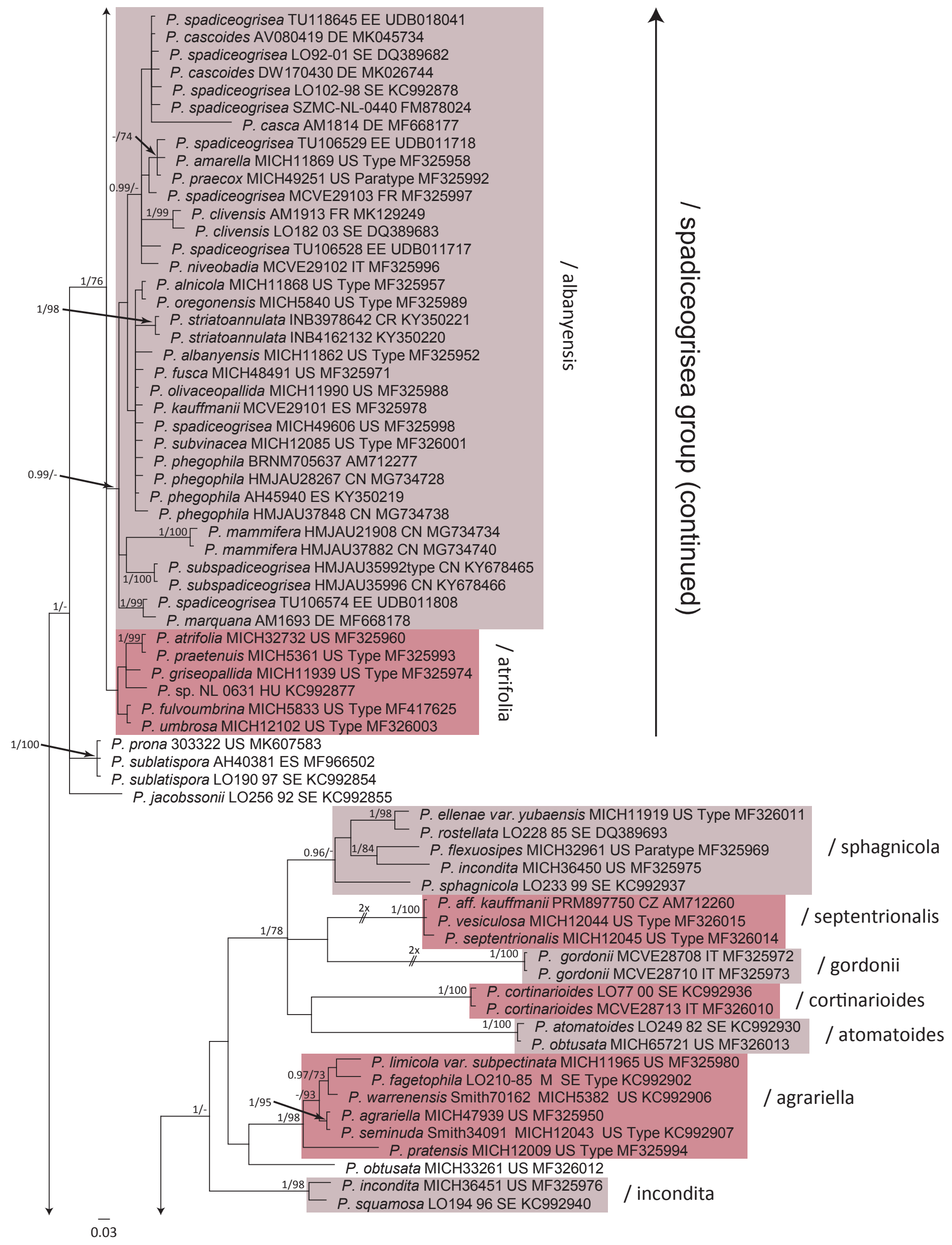

Fig. 1. (Continued). 


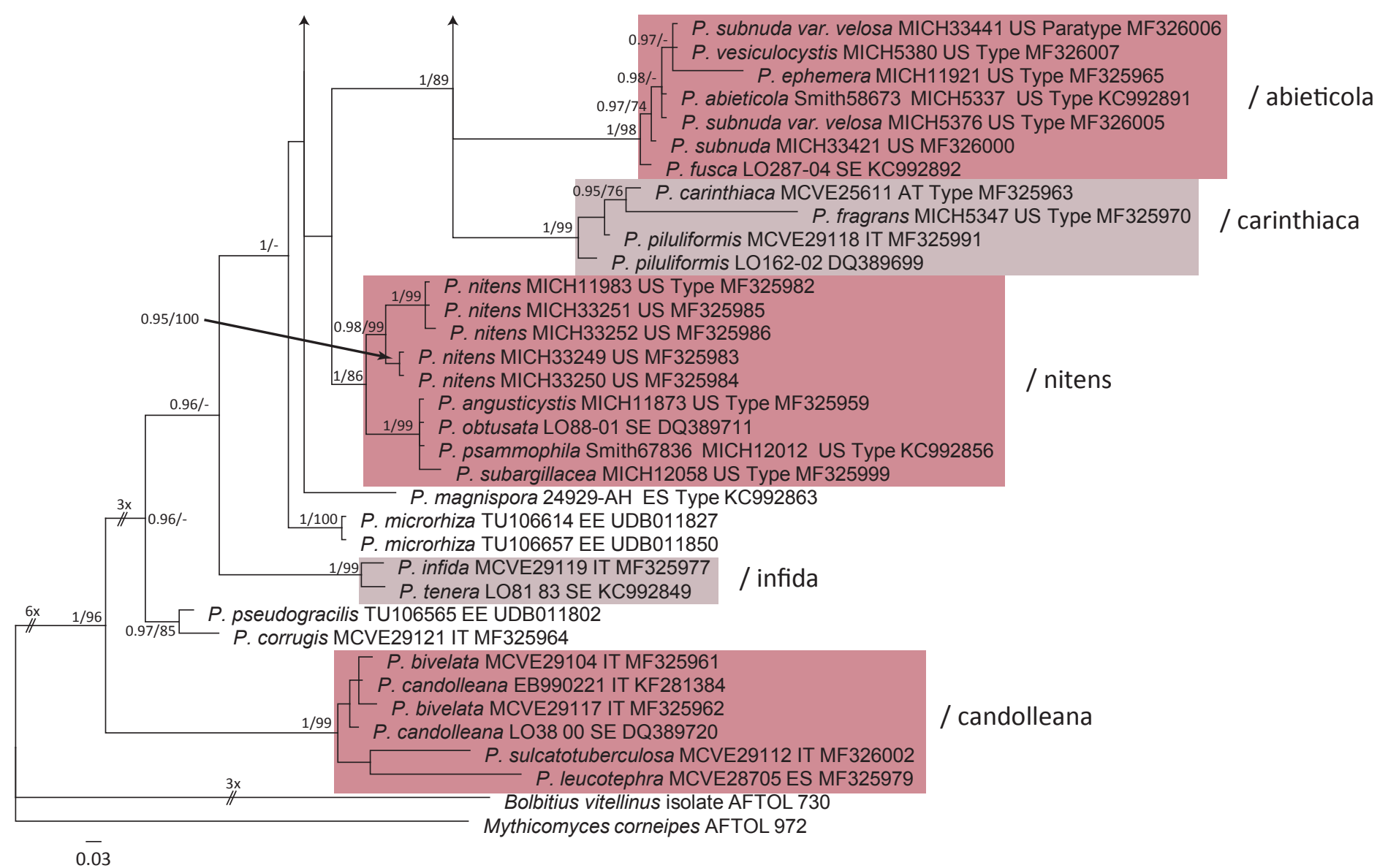

Fig. 1. (Continued).

Sequences of each dataset were first aligned using MAFFT v. 7.017 (Katoh et al. 2002) using default conditions for gap openings and gap extension penalties. Finally, alignments were manually adjusted using Geneious v. R 11.1.4 (https://www.geneious. com, Kearse et al. 2012). The model of sequence evolution GTR +GAMMA+I was selected with the program Modeltest v. 3.7 (Posada \& Crandall 1998). A partition homogeneity test was performed with PAUP v. 4.0a (build 159) (Swofford 2003) to assess character congruence between ITS and Tef- $1 \alpha$ data sets. All datasets were analyzed using Bayesian inference (BI) and maximum likelihood (ML) criteria. The ITS and Tef- $1 \alpha$ data sets were partitioned. BI analysis was performed using MrBayes v. 3.2 (Ronquist et al. 2012) with four incrementally heated simultaneous Monte Carlo Markov Chains (MCMC) run for 10 $M$ generations in datasets $1,2,3$ and for $20 \mathrm{M}$ generations in dataset 4 . Trees were sampled every 1000 generations and the first $25 \%$ trees were discarded as "burn-in" . ML was performed with RAxML v. 7.2.8. (Stamatakis 2006) in Geneious v. R 11.1.4 (Kearse et al. 2012), using a total of 1000 bootstrap replicates (Felsenstein 1985) to assess the relative robustness of the branches of maximum likelihood in RAxML. Only BPP values $\geq 0.95$ and MLB values $\geq 70 \%$ were reported in phylogenetic trees (Figs 1, 2). Pairwise \% identity values of ITS and Tef-1 $\alpha$ sequences were calculated using MEGA v. 10.0.4 (Kumar et al. 2018). BI analyses of the fourth dataset were run on the CIPRES Science Gateway (Miller et al. 2010).

Molecular data were used to contrast or support the extensive morphology-based taxonomy, and to resolve uncertainties that could not be resolved solely based on morphology. Nucleotide homology calculated using BLAST (Altschul et al. 1990) and positioning of sequences on phylogenetic trees were both used to infer presence or absence of molecular conspecificity. When both ITS and Tef- $1 \alpha$ were $>98 \%$ homologous, and the taxa from which both sequences were derived fell as immediate neighbors on a $\mathrm{BI}$ tree, this evidence was regarded as strong support of conspecificity. ITS and/or Tef-1 $\alpha$ homology $<97 \%$ was used to support lack of conspecificity, while $>98 \%$ homology of the ITS only was regarded as inconclusive. If homology levels between two taxa were $97-98 \%$, the phylogenetic positioning of the taxa bearing the sequences was analyzed. Additionally, in these cases, it was analyzed whether heterozygosities or indels were located in introns or exons, and whether they were synonymous or not. Non-synonymous exonic heterozygosities and indels in exons were taken as indication of higher divergence between taxa.

\section{Taxonomy}

1. Psathyrella kauffmanii A.H. Sm., Mem. N. Y. Bot. Gard. 24: 69. 1972. Figs 4, 5.

Molecular heterotypical synonyms and misapplied names proposed here: Psathyrella olivaceopallida A.H. Sm., Mem. N. Y. Bot. Gard. 24: 138. 1972; Psathyrella subvinacea A.H. Sm., Mem. N. Y. Bot. Gard. 24: 124. 1972; Psathyrella fusca sensu A.H. Smith, Mem. N. Y. Bot. Gard. 24: 355. 1972, p.p.; Psathyrella spadiceogrisea sensu A.H. Smith, Mem. N. Y. Bot. Gard. 24: 354. 1972, p.p.

Morphological heterotypical synonyms proposed here: Psathyrella carolinensis A.H. Sm., Mem. N. Y. Bot. Gard. 24: 142. 1972; 


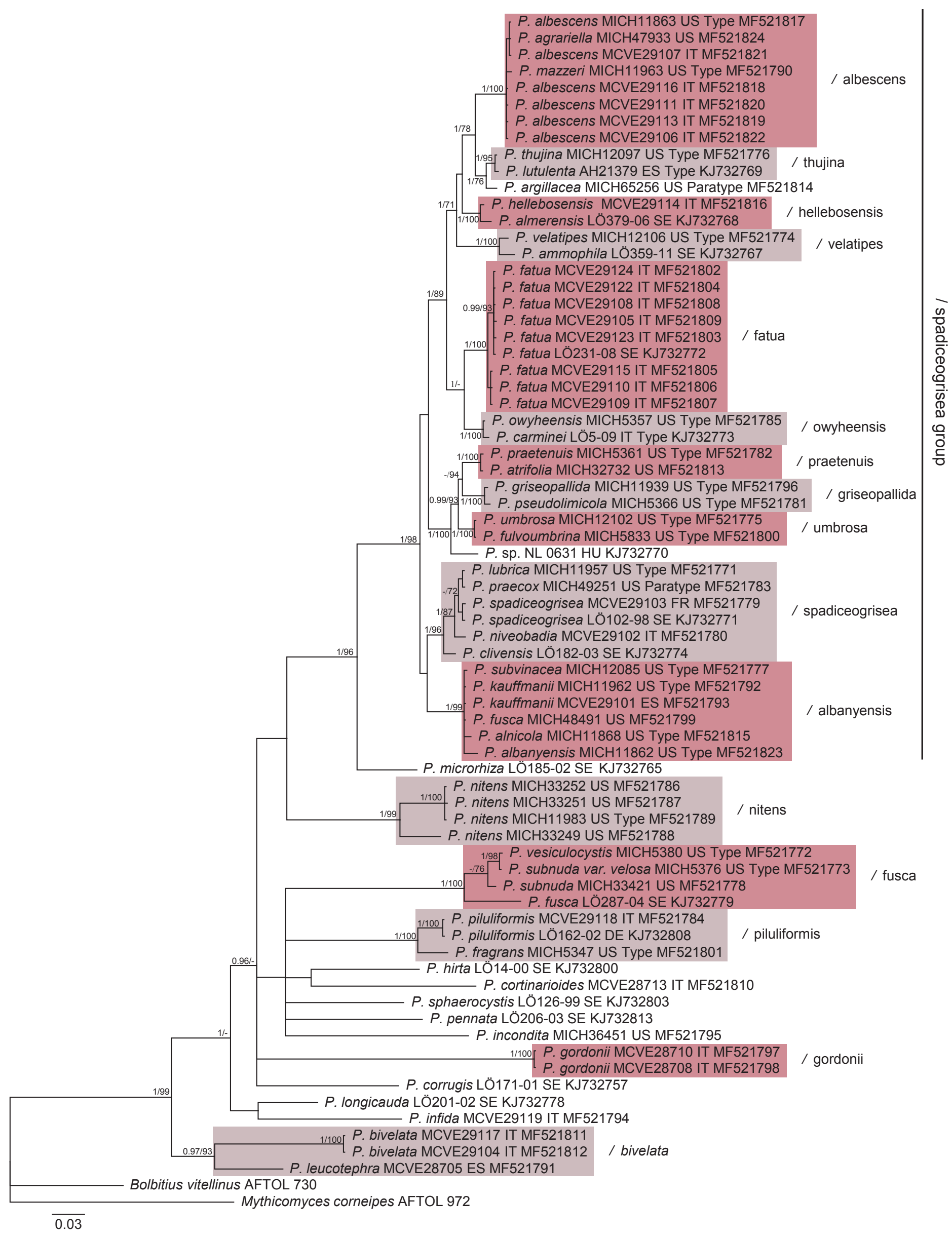

Fig. 2. Bayesian phylogram obtained from the general Tef-1 $\alpha$ sequence alignment of Psathyrella spp. Bolbitius vitellinus was used as outgroup taxon. Only BPP values $\geq 0.95$ and MLB values $\geq 70 \%$ are given above clade branches. 


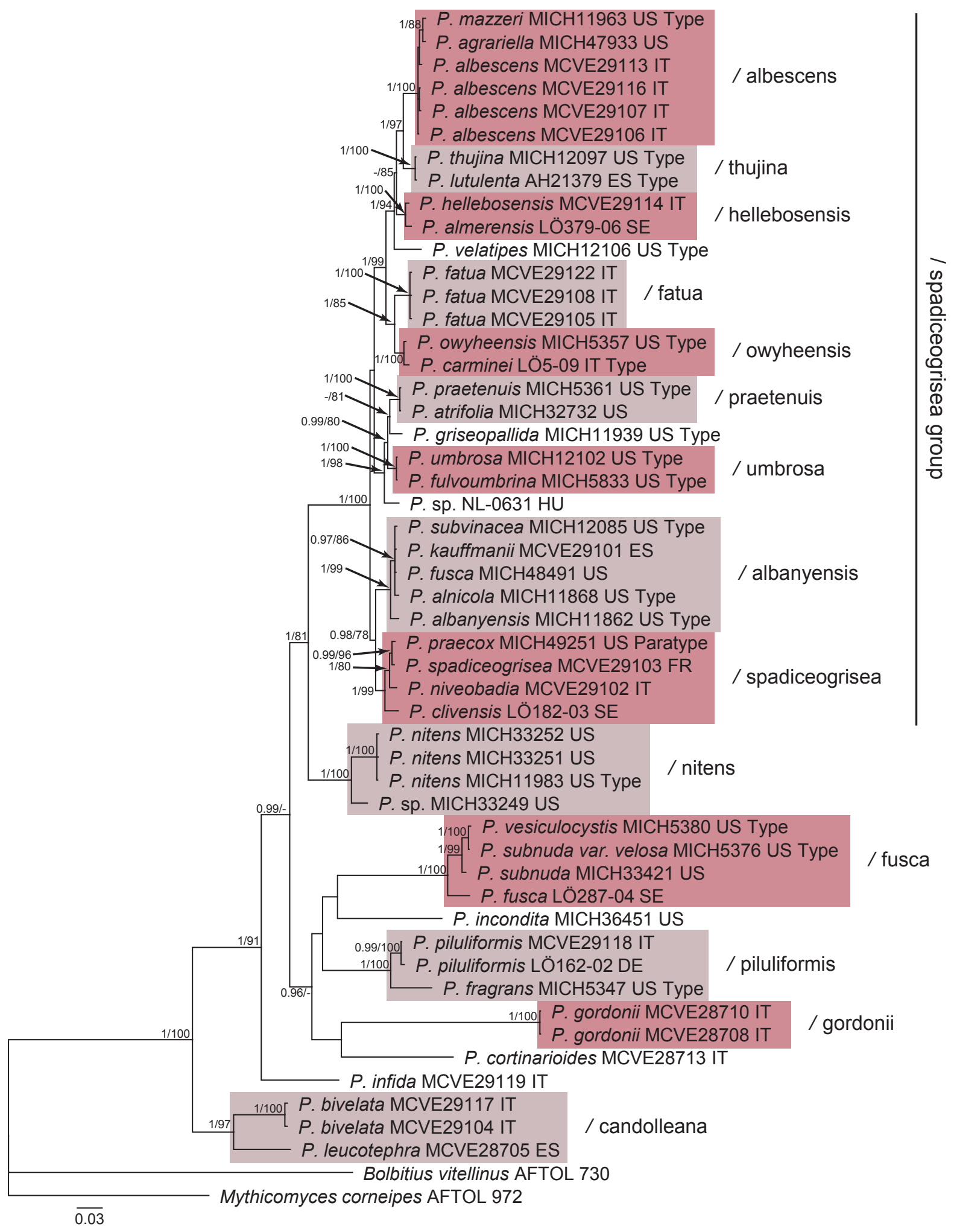

Fig. 3. Bayesian phylogram obtained from combined nrITS and Tef-1 $\alpha$ sequence alignment of Psathyrella spp. Bolbitius vitellinus was used as outgroup taxon. Only BPP values $\geq 0.95$ and MLB values $\geq 70 \%$ are given above clade branches.

Psathyrella kauffmanii var. exannulata A.H. Sm., Mem. N. Y. Bot. Gard. 24: 71. 1972; Psathyrella phegophila Romagn., Persoonia Suppl. vol. 2: 282. 1985.

Pileus $20-80(-90) \mathrm{mm}$ broad, in early stages ovate to obtusely conical, more or less umbonate campanulate, finally expanding through convex to plane and more or less wavy to lobed and rugulose, margin at first inflexed; when young dark, chestnut- brown to cinnamon-brown or honey-brown, possibly with violaceous shades, when mature dark greyish brown to tobaccobrown, hygrophanous, discoloring through warm ochraceous, olivaceous ochraceous, ochraceous brown, ochraceous greybrown, greyish ochre, cinnamon-buff, finally fading to greyish, buff, greyish ochraceous, pale olivaceous ochraceous, sometimes with pinkish to pale violaceous grey tints; faintly translucently striate when moist. Veil white to whitish, when young strongly 
connecting margin of pileus and stipe, when mature leaving usually fugacious fibrils around the margin of pileus and appressed fibrils to floccules on lower half of stipe, also appendiculate at margin, sometimes as a more or less membranous, more or less incomplete annulus with striate upper surface on stipe. Lamellae adnate, sometimes with a decurrent tooth; narrow to moderately broad in age; crowded or moderately crowded; when young whitish to greyish or brownish greyish, finally brownish grey, dark brownish grey to purple-brown or dark reddish brown; edge white fimbriate or not. Stipe 40-120 × (2.5-)3-10(-13) mm, sometimes gradually broadened towards base, extreme base sometimes laterally narrowed to a short pseudorhiza; white, not or little discoloring brownish in age over the basal area; apex pruinose to sometimes striate-sulcate, sometimes fibrillose to flocculose on lower portion. Context fragile, thin at margin to moderately thick at centre in pileus, fragile to firm in stipe, pale to concolorous with surface. Odor indistinctive to mild. Taste mild to slightly bitter. Spore deposit dark purple-brown. Spores (6.2-)6.8-10.3(-11) $\times$ (3.8-)4-5.7(-6) $\mu \mathrm{m}$, on average 7.5-8.9 × 4.5-5.3 $\mu \mathrm{m}, \mathrm{Q}(1.4-)$ 1.5-2(-2.3), avQ 1.6-1.82; in front view elliptic, oval, oblong, sometimes irregularly angular-oval, irregularly angular-oboval, angular-oblong, base truncate to subtriangular, sometimes rounded, in profile adaxially flattened to subamygdaliform or subphaseoliform, sometimes elliptic; dark reddish brown to dark red; germ pore little to moderately distinct, mainly more or less truncate to depressed, 1.4-1.8 $\mu \mathrm{m}$ broad. Basidia 4(2)-spored,

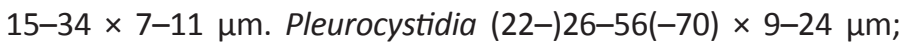
(broadly) utriform to (broadly) ellipsoid or clavate, sometimes lageniform; apex rounded to obtuse, sometimes subobtuse, often capitate to subcapitate, forked or not, incrusted or not; walls sometimes or rarely weakly yellowish; numerous to scattered. Cheilocystidia $19.5-55(-70) \times 7.5-20(-25) \mu \mathrm{m}$, rarely attenuate to subacute, pigment like pleurocystidia, scattered, sometimes moderately numerous or locally numerous. Paracystidia 9-40 $\times$ 4-20 $\mu \mathrm{m}$, sometimes cylindrical-elongate, walls sometimes inconspicuously yellowish pigmented, rarely incrusted, numerous, dominating. Cells below marginal cystidia rarely weakly yellowish pigmented and incrusted. Clamps present.

Habitat: Caespitose to gregarious or scattered, on or connected to wood or woody debris. The host tree of MCVE29101 and the types of $P$. kauffmanii var. exannulata and $P$. phegophila is European beech (Fagus sylvatica). The substrates of the types of $P$. kauffmanii, $P$. olivaceopallida and $P$. subvinacea are indicated only in general terms, as hardwoods and logs; however, habitat where types of these species were collected has a dominance of sugar maples (Acer saccharum), American beeches (Fagus grandifolia), and northern red oaks (Quercus rubra) or other oaks (Quercus spp.). The holotype of $P$. carolinensis was from forest humus at 1220 m. a.s.I. Kits van Waveren (1985) considers Drosophila fusca sensu Malençon \& Bertault 1970 a misinterpretation of P. phegophila, and in this case the host tree is a Quercus ilex in Morocco at an elevation of almost 2000 m. a.s.l.

Collections examined from MICH: Psathyrella kauffmanii A.H. Sm., holotype, Smith 66602; Psathyrella kauffmanii var. exannulata A.H. Sm., holotype, Smith 6285; Psathyrella olivaceopallida A.H. Sm., holotype, Smith 66685; Psathyrella subvinacea A.H. Sm., holotype, Hoseney

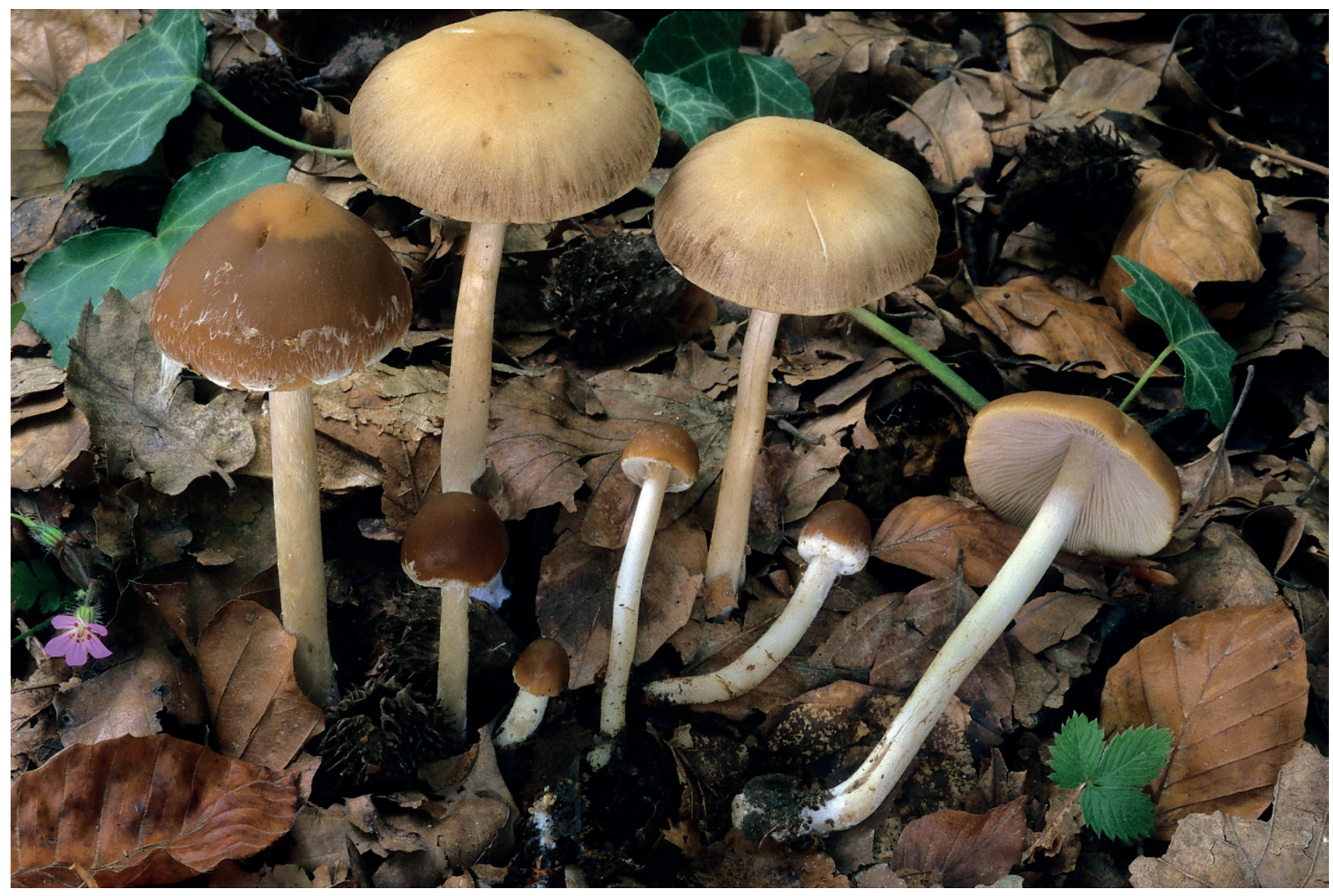

Fig. 4. Psathyrella kauffmanii. MCVE2910. Photo M.À. Pérez-De-Gregorio. 

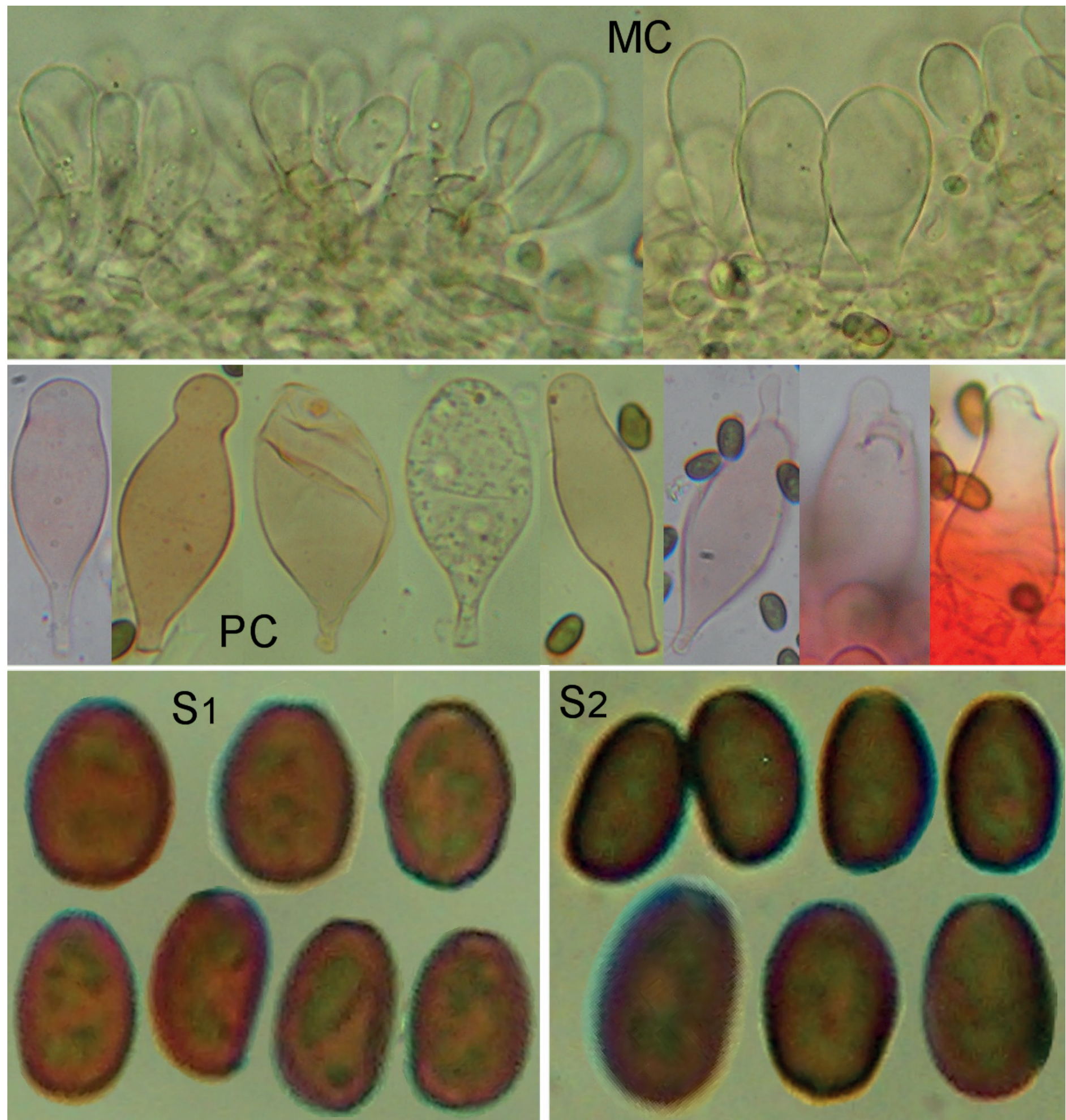

Fig. 5. Psathyrella kauffmanii. A.H. Smith 66602, MICH11962; MC Marginal Cystidia in KOH; PC Pleurocystidia; S1 Spores in water; S2 Spores in KOH.

641; Psathyrella fusca sensu A.H. Smith, Smith 75099; Psathyrella spadiceogrisea sensu A.H. Smith, Smith 74295.

Other material examined: France, Île-de-France, Yvelines, forêt de Saint-Germain, gregarious on woody debris in calcareous beechwood, 16. Nov. 1997, G. Tassi 9776, printed description in Tassi (2010). Spain, Girona, Santa Pau, la Fageda d'en Jordà, 560 m. a.s.l., gregarious in beech leaf litter, 7 Oct. 2000, J. Carbó \& M.À. Pérez-De-Gregorio JC20001007.11 (duplicate MCVE29101), Fig. 4, Tef-1 $\alpha$ MF521793, ITS MF325978, printed description in Pérez de Gregorio et al. (2010).
Notes: In old exsiccata it often happens that only a limited number of dark spores may be found; however, the dark color and not very distinct germ pore of the spores, together with pleurocystidia shape, are diagnostic when comparing this species with the other lignicolous species of the subsection. The sometimes annular veil and the habitat usually represented by Fagus can also be diagnostic. However, the use of host or habitat to corroborate the diagnosis should be done with caution, because Fagus is a known host also for the closely related species $P$. niveobadia. 
Because we could not examine the original material of $P$. phegophila, we have selected a Spanish collection (MCVE29101) that matches it satisfactorily, and that is fully described by both text and pictures of the sporocarps in their natural habitat (Pérez de Gregorio et al. 2010). DNA sequences of the two loci studied and the morphology are a perfect match with sequences and morphology of the holotype of $P$. kauffmanii. Another collection we consider a good European representative of this taxon comes from France and was described and illustrated by Tassi (2000), as voucher 97076 . Thanks to Tassi's courtesy, this sample was loaned to us, but, unfortunately, DNA extraction from this specimen failed. It is to be noted that until now, European reports always lack the annulus, like $P$. kauffmanii var. exannulata, one of the synonyms ascertained in this study.

We could not obtain the holotype of $P$. carolinensis, however, judging from its original description, and considering all the variability observed within $P$. kauffmanii during the course of this study, we consider it to be another synonym of $P$. kauffmanii.

Together with all the taxa regarded as conspecific, $P$. kauffmanii also creates a compact cluster with three other species described below: P. albanyensis, P. alnicola, P. oregonensis.

Psathyrella albanyensis has tridimensional and peculiarly cordiform to pentagonal spores. Psathyrella alnicola is typically associated with alders. Psathyrella oregonensis is characterized by high ITS molecular homology with both P. kauffmanii and P. alnicola (ITS homology was $100 \%$ with P. alnicola and $99 \%$ with all other comparable material of $P$. kauffmanii), however, based on one collection available to us, it can be stated that this species differs from them because it is found in coniferous habitats and because it has broader tridimensional spores. Thus, based on available evidence, we conclude that $P$. oregonensis is an autonomous taxon, maybe to be regarded as an intermediate species between $P$. kauffmanii and $P$. albanyensis. It has been often stated that high homology of ITS sequence among closely related, albeit distinct, taxa is not necessarily indicative of conspecificity, and may be due to interspecific horizontal gene transfer followed by allelic sweeps that effectively eliminate those ITS alleles that were originally present in the "receiver" fungal species (discussed in Bergemann et al. 2009). In order to determine the exact phylogenetic relationships among the above taxa, sequence information from additional loci will be needed.

Psathyrella striatoannulata, recently described from central America, is also strikingly near P. kauffmanii, based both on molecular (approximately $99 \%$ ITS homology) and morphological data. Both taxa share the following: a striate membranous annulus, pleurocystidia often undifferentiated and possibly pigmented and incrusted, the general habit and colors of the basidiomes. However, its authors report that incrustations at the apices of the pleurocystidia distinctively stain reddish brown in $\mathrm{NH}_{4}$, although this feature tends to gradually disappear in old specimens. A further molecular comparison is needed to resolve the relationship between these two species. We believe the descriptions of Psathyrella spec. 3 by Ludwig (2007a) and of P. obtusata var. aberrans sensu Breitenbach \& Kränzlin (1995) may represent $P$. kauffmanii.

1a. Psathyrella kauffmanii A.H. Sm., Mem. N. Y. Bot. Gard. 24: 69. 1972. Fig. 5.

Typus: Psathyrella kauffmanii A.H. Sm. USA, Michigan, Huron Mts. Marquette Co., Big Bay, 16 Jun. 1963, A.H. Smith 66602 (MICH11962), on hardwood debris. Tef-1 $\alpha$ MF521792.
Loan of four sporocarps in good condition and a slice of pileus for micro-morphology investigation.

Spores (6.2-)6.8-8.5(-9.3) × (3.8-)4.3-5.2(-5.7) $\mu \mathrm{m}, \mathrm{Q}$ 1.5-1.7; in front view elliptic to suboval, sometimes (narrowly) oval to angular-oval, base often truncate to subtriangular, in profile adaxially flattened to subphaseoliform; few dark red; germ pore subdistinct, more or less truncate, $\pm 1.5 \mu \mathrm{m}$ broad. Pleurocystidia (22-)33-55 × 13-23 $\mu \mathrm{m}$, utriform to ellipsoid or clavate; apex obtuse, sometimes subobtuse, often capitate, sometimes forked, rarely rostrate, often incrusted; walls sometimes weakly pigmented; moderately numerous. Cheilocystidia 19.5-49 $\times$ 9.5-18 $\mu \mathrm{m}$, scattered. Paracystidia 10-35 × 5-19(-24) $\mu \mathrm{m}$, often cylindrical-elongate, numerous, dominating.

1b. Psathyrella kauffmanii var. exannulata A.H. Sm., Mem. N. Y. Bot. Gard. 24: 71. 1972.

Typus: Psathyrella kauffmanii var. exannulata A.H. Sm. USA, Michigan, Oakland Co., Highland Recreation Area, Haven Hill, 11 Jun. 1937, A.H. Smith 6285 (MICH11961), in a beech wood.

Loan of one sporocarp in good condition and a half pileus for micro-morphology investigation.

Spores 6.9-9.1 × 4.3-5.6(-6), Q 1.4-1.9; in front view elliptic to oval, sometimes oblong, (narrowly) angular-oval, base often truncate to subtriangular, in profile adaxially flattened, sometimes subphaseoliform; mostly orangish to reddish brown, very few dark reddish brown to dark red; germ pore subdistinct, mainly truncate, 1.5-1.8 $\mathrm{mm}$ broad, Pleurocystidia 35-47 $\times$ 12-19 $\mu \mathrm{m}$; utriform, sometimes clavate, often or sometimes irregular in ventral part; apex rounded, subcapitate or not, often or sometimes incrusted; walls sometimes weakly yellowish, numerous. Cheilocystidia 28-42 × 10-18 $\mu \mathrm{m}$, scattered. Paracystidia 9-35 × 5-18 $\mu \mathrm{m}$, walls sometimes yellowish pigmented, numerous, dominating.

Notes: Our attempts to extract and amplify DNA failed, however by morphological comparison we think this material can be viewed as conspecific with $P$. kauffmanii. We note that Smith (1972) reports spores color in $\mathrm{KOH}$ as 'cocoa color and remaining so a long time', therefore not dark; however, we had difficulty in finding dark spores in many old exsiccata of $P$. kauffmanii and conspecific materials.

1c. Psathyrella olivaceopallida A.H. Sm., Mem. N. Y. Bot. Gard. 24: 138. 1972.

Typus: Psathyrella olivaceopallida A.H. Sm. USA, Michigan, Cheboygan Co., Burt Lake, Colonial Point, 20 Jun. 1963, A.H. Smith 66685 (erroneously reported as 4991) (MICH11990), scattered to gregarious on humus in hardwoods. ITS MF325988.

Loan of one sporocarp lacking a slice of pileus for micromorphology investigation.

Spores (7-)7.3-9.2(-10) × 4.1-5(-5.1), Q 1.55-1.9(-2) $\mu \mathrm{m}$; in front view elliptic, oblong to narrowly oval, sometimes oblong- to angular-oval, base often truncate to subtriangular, in profile adaxially flattened, sometimes subphaseoliform; few dark reddish brown; germ pore moderately distinct, often 
more or less truncate, 1.4-1.5 $\mu \mathrm{m}$ broad. Pleurocystidia 29-43 $\times$ 10-22 $\mu \mathrm{m}$; broadly utriform, utriform, ellipsoid, sometimes lageniform, clavate; apex rounded to obtuse, subcapitate or not, often forked, sometimes incrusted; walls sometimes weakly yellowish, numerous. Cheilocystidia 28-43 × 10-20 $\mu \mathrm{m}$, in part (broadly) lageniform with short to elongate neck and subobtuse to subacute apex, pigmented like pleurocystidia, scattered. Paracystidia $-28 \times-15 \mu \mathrm{m}$, often weakly yellowish, numerous, dominating. Cells below marginal cystidia hyaline.

Notes: Although the molecular evidence provided by the ITS sequence alone is inconclusive as stated above, we retain this species a synonym of $P$. kauffmanii. Smith may have found its only collection when the sporocarps were already discolored: the pale olive tint implied by the name and the greyish and pinkish tones on fading reported in Smith's (1972) description belong to the chromatic set of the pileus of $P$. kauffmanii.

\section{1d. Psathyrella subvinacea A.H. Sm., Mem. N. Y. Bot. Gard. 24:} 124. 1972.

Typus: Psathyrella subvinacea A.H. Sm. USA, Michigan, Washtenaw Co., Waterloo State Recreation Area, 31 Aug. 1967, F. Hoseney 641 (MICH12085), on underside of logs on wooded side of sand hill. Tef-1 $\alpha$ MF521777, ITS MF326001.

Loan of three sporocarps in good condition for micro-morphology investigation.

Spores 6.8-9.2(-10.5) × 4.2-5.2(-5.7), Q 1.4-1.8(-2.2); in front view elliptic, oval to oblong-oval, sometimes (narrowly) angularoval, base rounded, truncate to subtriangular, in profile elliptic to subamygdaliform, sometimes subphaseoliform; almost all spores pale to very pale, mostly hyaline to very pale purplish brown, some violaceous orange, very few dark violaceous brown; germ pore indistinct. Pleurocystidia 32-50 × 10-24 $\mu \mathrm{m}$; (broadly) utriform; apex often subcapitate, sometimes forked, sometimes incrusted; walls often weakly yellowish below apex. Cheilocystidia 26-42 × 12-19 $\mu \mathrm{m}$, pigmented like the pleurocystidia, scattered. Paracystidia 9-40 × 6-18 $\mu \mathrm{m}$, walls often weakly yellowish pigmented, numerous, dominating. Cells below marginal cystidia weakly yellowish pigmented, sometimes incrusted.

Notes: Apart from the very pale pigmentation of the spores, which was likely due to delayed maturation, both molecular and morphological characters identify this taxon as conspecific with P. kauffmanii.

\section{1e. Psathyrella spadiceogrisea sensu A.H. Smith p.p.}

Material examined: USA, Michigan, Jackson Co., Munith woods, 13 May 1967, A.H. Smith 74295 (MICH49606), debris. ITS MF325998.

Loan of three full sporocarps and a pileus, in good condition for micro-morphology investigation.

Spores 7.5-10.3(-11) × 4.2-5.3(-5.6) $\mu \mathrm{m}$, on average $8.9 \times 4.7$ $\mu \mathrm{m}, \mathrm{Q}(1.4-) 1.6-2(-2.3)$, avQ 1.73-1.83; in front view oblong, elliptic, narrowly oval, rarely oblong-oval or angular-oval, base rounded, rarely truncate to subtriangular, in profile adaxially flattened to subamygdaliform, sometimes subphaseoliform; reddish brown to dark red; germ pore moderately distinct, mostly more or less truncate to subdepressed, $\pm 1.5 \mu \mathrm{m}$ broad. Pleurocystidia 28-51 × 13-22 $\mu \mathrm{m}$; (broadly) utriform, sometimes ellipsoid; apex rounded, often subcapitate, often forked, sometimes incrusted; walls hyaline; scattered. Cheilocystidia

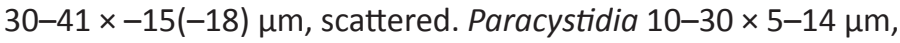
often yellowish, numerous, dominating. Cells below marginal cystidia scarcely yellowish pigmented or incrusted.

Notes: We have attempted to understand Smith's concept of $P$. spadiceogrisea by examining a Smith's collection selected for this purpose by MICH staff. For this material, we have obtained a molecular sequence only for the ITS, which places it in the same subclade as $P$. kauffmanii. Its terete spores exclude conspecificity with $P$. albanyensis and $P$. oregonensis. Nonetheless, we have compared it with $P$. kauffmanii and found a good correspondence between the two. Because the only relevant difference between the two is the slightly greater spore length and, consequently, the slightly greater spore quotient, we retain this collection as a synonym of $P$. kauffmanii. Unfortunately, we could not discover any significant details about the habitat in which these samples were collected. This suggested synonymy does not necessarily apply to the other vouchers Smith deposited in $\mathrm{MICH}$ under this name, which should be considered and evaluated separately.

\section{1f. Psathyrella fusca sensu A.H. Smith p.p.}

Material examined: USA, Michigan, Oakland Co., Proud Lake, 3 Sep. 1967, A.H. Smith 75099 (MICH48491), in wet soil. Tef-1a MF521799, ITS MF325971.

Loan of three sporocarps in good condition and a fragment of pileus for micro-morphology investigation.

Spores 6.9-8.1 × 4.3-5.4 $\mu \mathrm{m}$, in front view oval to elliptic, often angular-oval, base often truncate to subtriangular, in profile adaxially flattened, sometimes subphaseoliform; dark reddish brown to dark red; germ pore moderately distinct, often more or less truncate, 1.4-1.7 $\mu \mathrm{m}$ broad. Pleurocystidia 36-56 × 14$19 \mu \mathrm{m}$; utriform; apex rounded, often subcapitate, sometimes forked, no incrustation seen; walls hyaline; moderately numerous. Cheilocystidia 30-55 × 11-20 $\mu \mathrm{m}$, scattered, sometimes locally numerous. Paracystidia 12-31 × 6-20 $\mu \mathrm{m}$, often weakly yellowish, sometimes incrusted, numerous, dominating.

Notes: We have attempted to understand Smith's concept of $P$. fusca by examining a Smith's collection selected for this purpose by $\mathrm{MICH}$ staff. It has turned out to correspond, both morphologically and molecularly, to P. kauffmanii. This result does not necessarily apply to the other vouchers Smith deposited in $\mathrm{MICH}$ under this name.

2. Psathyrella alnicola A.H. Sm., Mem. N. Y. Bot. Gard. 24: 176. 1972. Fig. 6.

Typus: Psathyrella alnicola A.H. Sm. USA, Idaho, Idaho Co., French Creek Grade, Salmon River, 6 Sep. 1964, A.H. Smith 70222 (coll. K.A. Harrison) (MICH11868), under alder. Tef-1 $\alpha$ MF521815, ITS MF325957.

Loan of one sporocarp in good condition and a half pileus for micro-morphology investigation. 

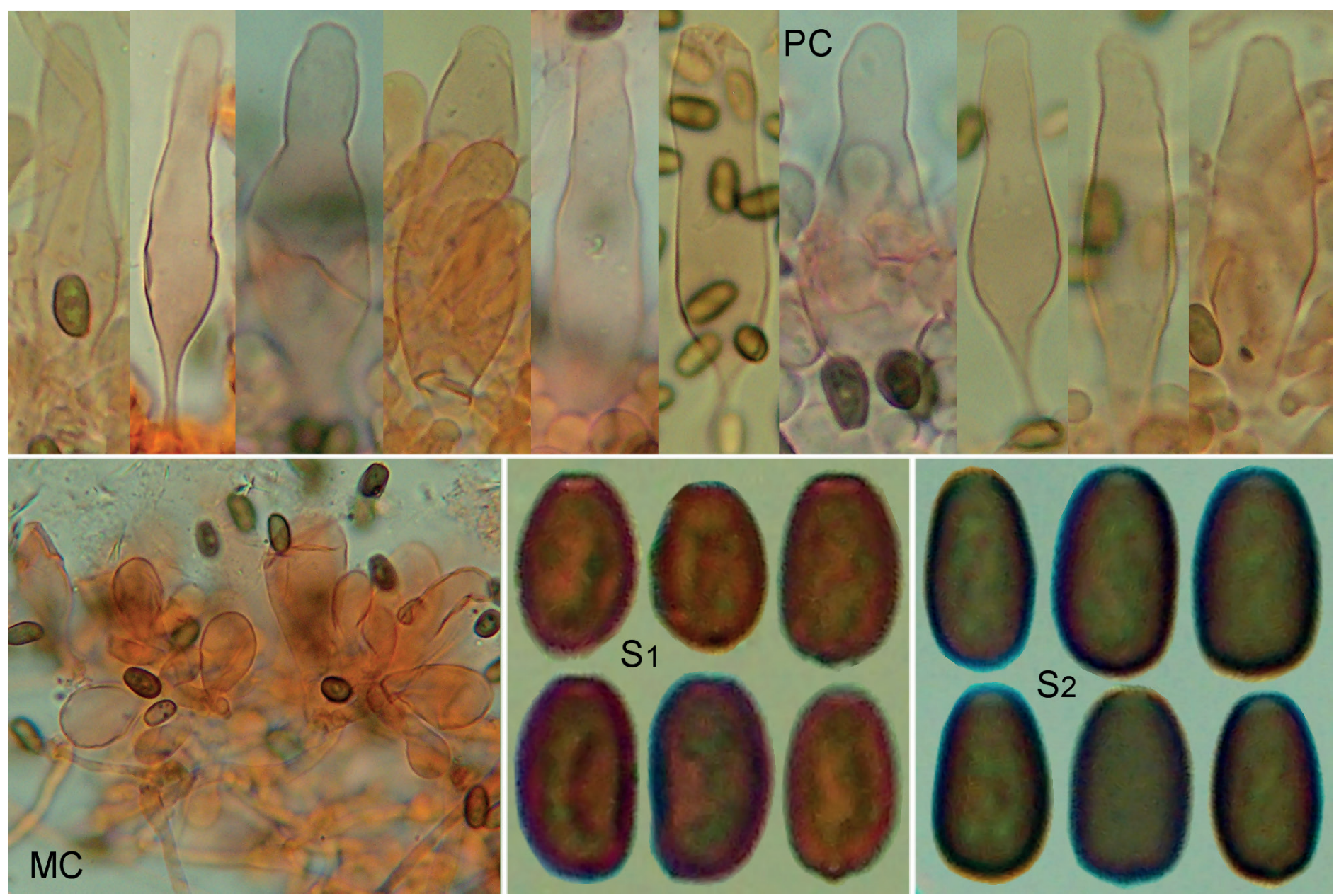

Fig. 6. Psathyrella alnicola. A.H. Smith 70222, MICH11868; PC Pleurocystidia; MC Marginal Cystidia; S1 Spores in water; S2 Spores in KOH.

Spores 7.9-10 × 4.6-5.7(-6.2) $\mu \mathrm{m}(8-11 \times 5-6 \mu \mathrm{m}$ in Smith 1972), Q 1.45-2; in front view elliptic, oval to oblong, sometimes (narrowly) angular-oval, base rounded to truncate, sometimes subtriangular, in profile adaxially flattened, elliptic to subamygdaliform, sometimes subphaseoliform; dark reddish brown to dark red; germ pore subdistinct, more or less truncate, 1.5-1.7 $\mu \mathrm{m}$ broad. Pleurocystidia (37-)45-67(-83) $\times(10-) 13-20(-32) \mu \mathrm{m}$; utriform to conical-lageniform, rarely subcylindrical; apex obtuse to rounded, obscurely subcapitate or not, sometimes forked, sometimes incrusted; walls sometimes weakly pigmented, moderately numerous. Cheilocystidia 35-62 $\times 15-17 \mu \mathrm{m}$, scattered. Paracystidia 8-48 $\times$ 4-25 $\mu \mathrm{m}$, sometimes cylindrical-elongate, sometimes weakly pigmented, rarely incrusted, numerous, dominating.

Notes: The holotype and other five collections determined by Smith are undoubtedly associated with alder (Alnus). Collection of the holotype was made from under a single alder, even if many Ponderosa pines (Pinus ponderosa) and Douglas-firs (Pseudotsuga menziesii) coexisted in the same site. The 99 $\%$ identity of both ITS and Tef- $1 \alpha$ sequences with all other $P$. kauffmanii studied here clearly identifies a very close relationship between the two taxa, however, the hygrophilous Alnus habitat is clearly distinct from the mesophilous habitat characteristic of P. kauffmanii.

3. Psathyrella solheimii McKnight \& A.H. Sm., Mem. N. Y. Bot. Gard. 24: 67. 1972. Fig. 7.
Typus: Psathyrella solheimii McKnight \& A.H. Sm. USA, Wyoming, Albany Co., Laramie Mts., Pole Mountain, Happy Jack Winter Sports Area, 27 Jun. 1944, W.G. Solheim 2178 (MICH12054), on moist soil under aspen, especially around beaver dams.

Loan of two portions of pilei for micro-morphology investigation.

Spores (7.4-)7.5-9.6(-10) × 4.9-5.6 $\mu \mathrm{m}$ (broader, 8-10 × 5-6.2 $\mu \mathrm{m}$, in Smith 1972), Q(1.4-)1.5-1.9, avQ1.66; in front view oblong, elliptic, narrowly to cylindrical- oval, sometimes subangularoval, base broadly rounded, truncate to subtriangular, in profile adaxially flattened to subelliptic, sometimes subamygdaliform, rarely subphaseoliform; dark red-brown; germ pore moderately distinct, truncate to subrounded, 1.1-1.7 $\mu \mathrm{m}$. Pleurocystidia (24-)30-45(-52) × (10-)11.5-21 $\mu \mathrm{m}$, ellipsoid-utriform, fusiform-utriform, utriform, (broadly) clavate, sublageniform, ellipsoid, sometimes ellipsoid mucronate, obconical; apex broadly rounded to obtuse, rarely subacute, sometimes forked, rarely subcapitate, not incrusted; scattered. Cheilocystidia 17$33(-38) \times 7-18 \mu \mathrm{m}$, sometimes lageniform-mucronate, hyaline, scattered to moderately numerous. Paracystidia $10-22(-25) \times$ 5.5-16(-18) $\mu \mathrm{m}$, numerous, dominating; intermediate cells with slightly bulging to submucronate apex, 17-32 × 11.2-17.5 $\mu \mathrm{m}$, scattered to moderately numerous towards the stipe. Marginal cystidia and cells below them hyaline or very pale, not incrusted.

Notes: Unfortunately, DNA extraction of this material failed, but based on the morphological evidence, we consider it to belong to the subsection Spadiceogriseae. Smith (1972) keys it 

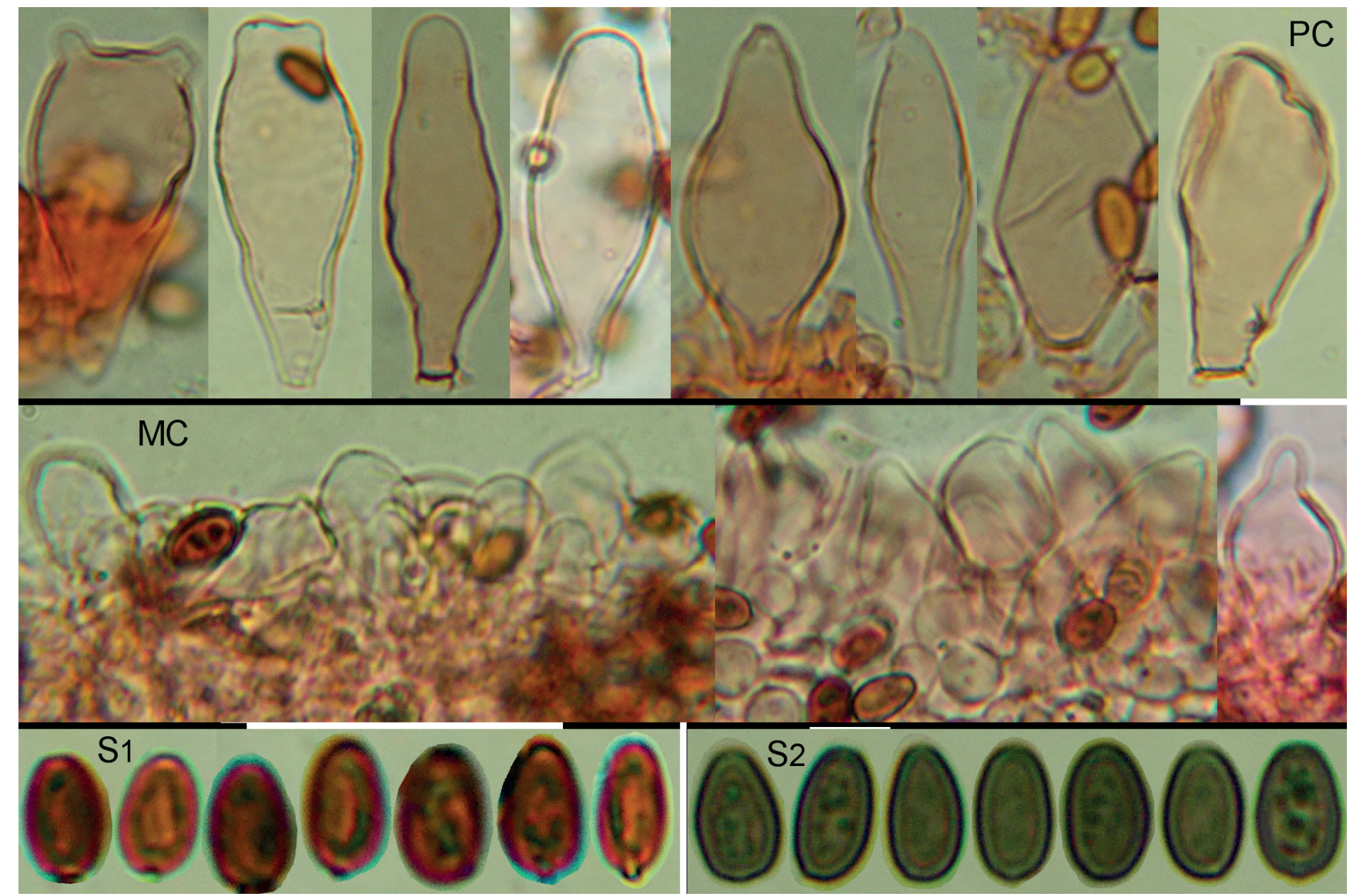

Fig. 7. Psathyrella solheimii. W.G. Solheim 2178, MICH12054; PC Pleurocystidia; MC Marginal Cystidia; S1 Spores in water; S2 Spores in KOH.

just beside $P$. kauffmanii, stating that the latter differs in longer and often forked pleurocystidia, and in slightly larger spores. This was possibly true when comparing $P$. solheimii to Smith's description of $P$. kauffmanii only, but when we take into account all of the materials we have studied identified as $P$. kauffmanii, we see those divergences disappear. A difference we can suggest is that the pleurocystidia apices often tend to have a tapering shape in $P$. solheimii, while in P. kauffmanii they tend to have a more rounded, often capitate, shape. Moreover, the habitat under aspen on moist soil, especially around beaver dams, is in contrast with the mainly dry and beech dominated habitat associated with $P$. kauffmanii. We have also checked $P$. solheimii against $P$. alnicola, given they both share alder as habitat, but their respective pleurocystidia show a marked disparity: on average they are shorter and thicker in $P$. solheimii, while they are longer and slenderer, and often with an elongate apex, in $P$. alnicola. Moreover, gill edge cells are often mucronate in $P$. solheimii and never so in P. alnicola. Until new molecular data are made available, we opted to retain $P$. solheimii as a separate species.

4. Psathyrella sanjuanensis (A.H. Sm.) Voto, Dovana \& Garbel, comb. nov. MycoBank MB831131. Fig. 8.

Basionym: Psathyrella solheimii var. sanjuanensis A.H. Sm., Mem. N. Y. Bot. Gard. 24: 68. 1972. A.H. Smith 51837, MICH12055.

Typus: Psathyrella solheimii var. sanjuanensis A.H. Sm. USA, Colorado, San Miguel Co., Ophir, 4 Aug. 1956, C. Barrows \& A.H. Smith (A.H. Smith 51837) (MICH12055), under aspen.
Loan of two small fragments of pilei for micro-morphology investigation.

Spores (8-)8.2-9.8(-10.7) $\times(5-) 5.2-5.8(-6) \mu \mathrm{m}$, on average $9.3 \times 5.5 \mu \mathrm{m}, \mathrm{Q}(1.4) 1.5-1.9(-2.15)$, avQ 1.7 ; in front view elliptic, sometimes cylindrical, narrowly oval, oblong, base broadly rounded to subtruncate, sometimes obtuse, in profile subamygdaliform to adaxially flattened, rarely subphaseoliform; dark red-brown; germ pore distinct, rounded to subtruncate, sometimes slightly eccentric in profile, 1.3-1.7 $\mu \mathrm{m}$. Pleurocystidia 33-50 × 10-16 $\mu \mathrm{m}$, utriform to lageniform, often elongate in upper part; apex rounded, often subcapitate, rarely capitate, sometimes forked with up to $20 \mu \mathrm{m}$ long protrusions; scattered. Cheilocystidia 24-40(-45) × 7.5-13(-15) $\mu \mathrm{m}$, in part fusiform-lageniform with obtuse apex, apex rarely subcapitate or forked, numerous to abundant and dominating from mid gill towards the stipe, scattered to absent towards the pileus margin. Paracystidia 12-25(-30) × 7-13(-16,5) $\mu \mathrm{m}$, absent or inconspicuous towards the stipe, numerous and dominating towards the pileus margin. Marginal cystidia and cells below them not pigmented, not incrusted.

Notes: The longest strip of gill edge we could examine was 4.5 $\mathrm{mm}$ long. Starting from the pileus margin towards the stipe end, we found that paracystidia went from being numerous and dominating (in $2 \mathrm{~mm}$ long gill segment) to being absent or inconspicuous. Conversely, cheilocystidia showed an inverse trend and went from being absent or rare to being numerous, even abundant, and dominating (in $2.3 \mathrm{~mm}$ long 


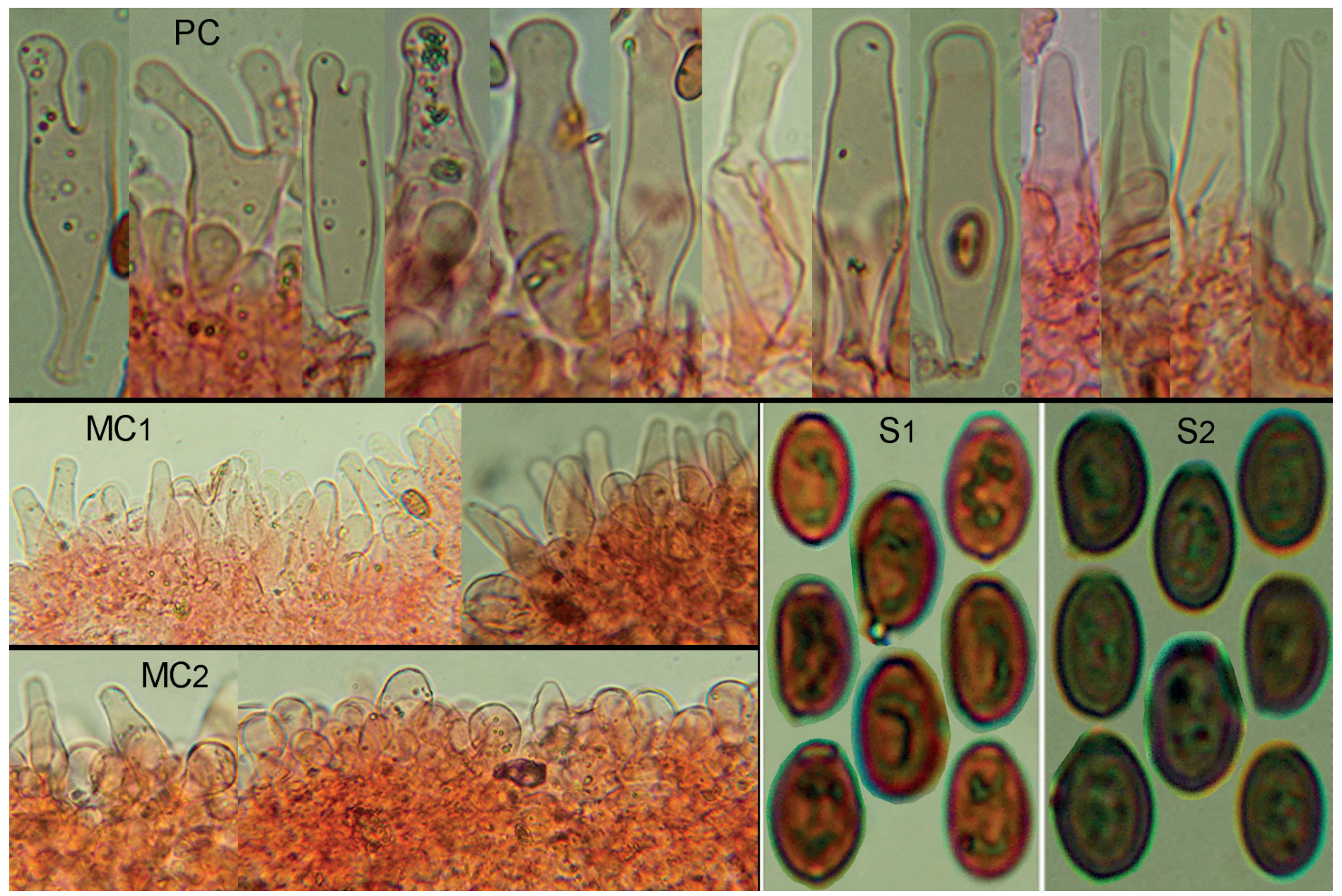

Fig. 8. Psathyrella solheimii var. sanjuanensis. A.H. Smith 51837, MICH12055; PC Pleurocystidia; MC1 Marginal Cystidia towards the pileus margin; MC2 Marginal Cystidia towards the stipe; S1 Spores in water; S2 Spores in $\mathrm{KOH}$.

gill segment). Paracystidia were small and had approximately the same dimensions as basidia [20-31 × 8-12(-15) $\mu \mathrm{m}]$, even where they were dominating. Although we lack the support of molecular evidence, we assume this collection does not belong to the subsection Spadiceogriseae, rather it better fits into the sister subsection Lutenses. Based on such cumulative evidence, we see no reason to maintain its affiliation with $P$. solheimii, and propose to elevate it to the species rank. Interestingly, Smith (1972) too had suggested this taxon could 'eventually deserve recognition as an autonomous species', a statement he made based mainly on the shape of pleurocystidia and on the consistency and colour of the annulus.

\section{Psathyrella oregonensis A.H. Sm., Mem. N. Y. Bot. Gard. 24:} 157. 1972. Fig. 9.

Typus: Psathyrella oregonensis A.H. Sm. USA, Oregon, Clackamas, Beaver Creek, Mt Hood National Forest, 24 Oct. 1947, A. H. Smith 28182 (MICH5840), on conifer wood. ITS MF325989.

Loan of one sporocarp with incomplete pileus for micromorphology investigation.

Spores 7-10(-10.7) × 5-6.7 × 4.4-5.5 $\mu \mathrm{m}$, fQ 1.3-1.7, avQ 1.5, pQ 1.4-1.9, avQ 1.7; in front view oval, elliptic, angularto triangular-oval, base mainly truncate, in profile elliptic, subamygdaliform, subphaseoliform; reddish brown to dark red; germ pore little distinct, 1.4-1.7 $\mu \mathrm{m}$ broad. Pleurocystidia
(31-)37-66(-76) × 11.5-17 $\mu \mathrm{m}$; slenderly utriform, sometimes thickly utriform, sublageniform, subcylindrical, subconical; apex rounded to obtuse, often subcapitate, sometimes forked in Smith's description, sometimes elongate, sometimes incrusted; walls hyaline; numerous. Cheilocystidia 30-43 × 15-20 $\mu \mathrm{m}$, scattered. Paracystidia $-39 \times-21 \mu \mathrm{m}$, sometimes rhomboid, almost hyaline, numerous, dominating.

Notes: Psathyrella latispora is one of the holotypes MICH could not loan, however, based on its description, it belongs to subsection Spadiceogriseae. Its type was collected cespitose from unspecified coarse wood debris, and shares a number of similarities with $P$. oregonensis from which it is mainly differentiated for having terete spores.

6. Psathyrella rugulosa A.H. Sm., Mem. N. Y. Bot. Gard. 24: 158. 1972. Fig. 10.

Typus: Psathyrella rugulosa A.H. Sm. USA, Tennessee, Sevier Co., Great Smoky Mts. National Park, near Clingman's Dome, 24 Jun. 1945, L.R. Hesler 17027 (MICH12040), on a spruce log.

Loan of one sporocarp in good condition for micro-morphology investigation.

Spores (6.2-)7.5-8.8(-9.8) × (4-)4.3-5.2(-5.3) $\mu \mathrm{m}, \mathrm{Q}(1.4-)$ 1.5-1.8(-2.3), avQ 1.7; in front view elliptic to suboval, base mainly obtuse to rounded, in profile adaxially flattened to 


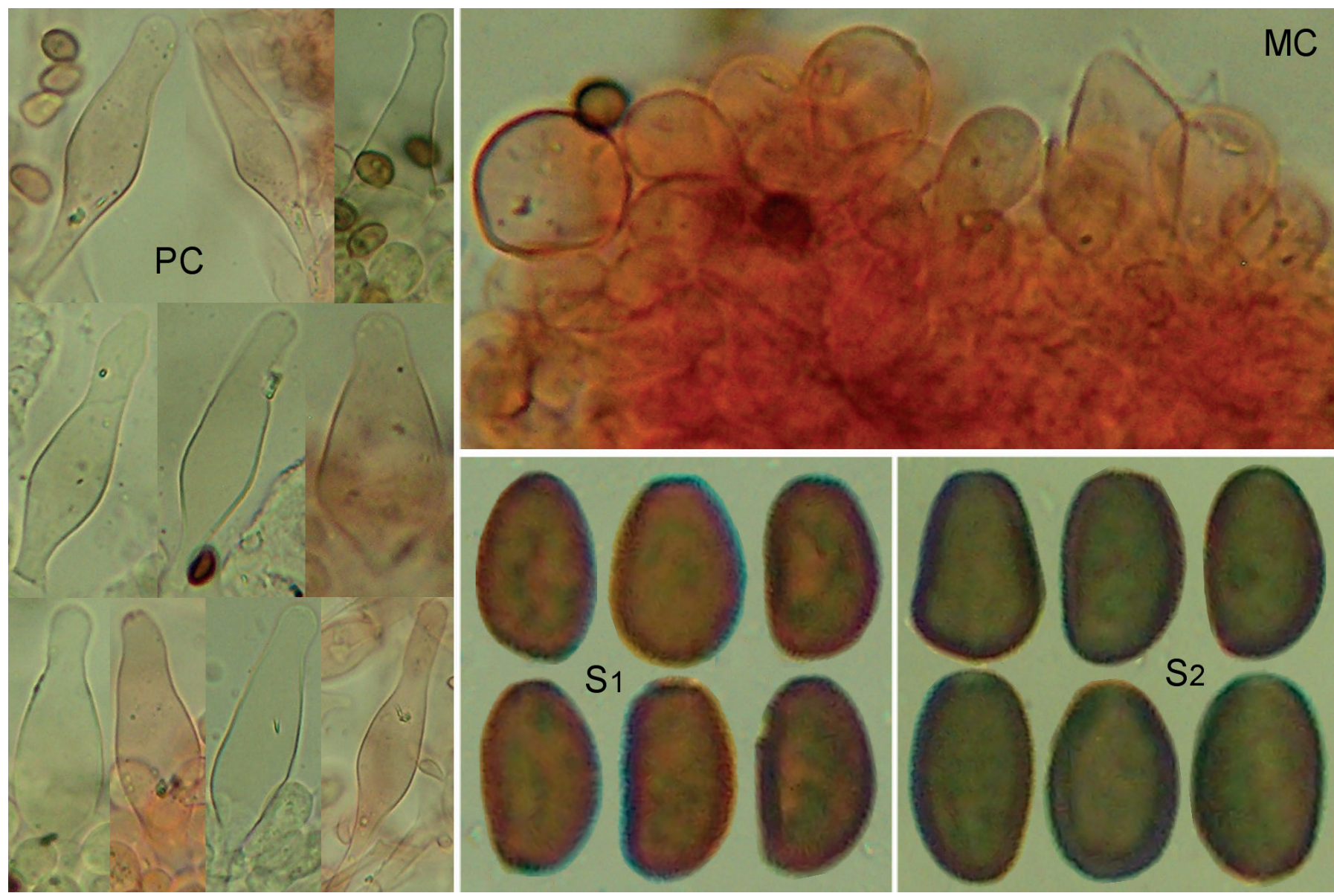

Fig. 9. Psathyrella oregonensis. A.H. Smith 28182, MICH5840; PC Pleurocystidia; MC Marginal Cystidia; S1 Spores in water; S2 Spores in KOH.

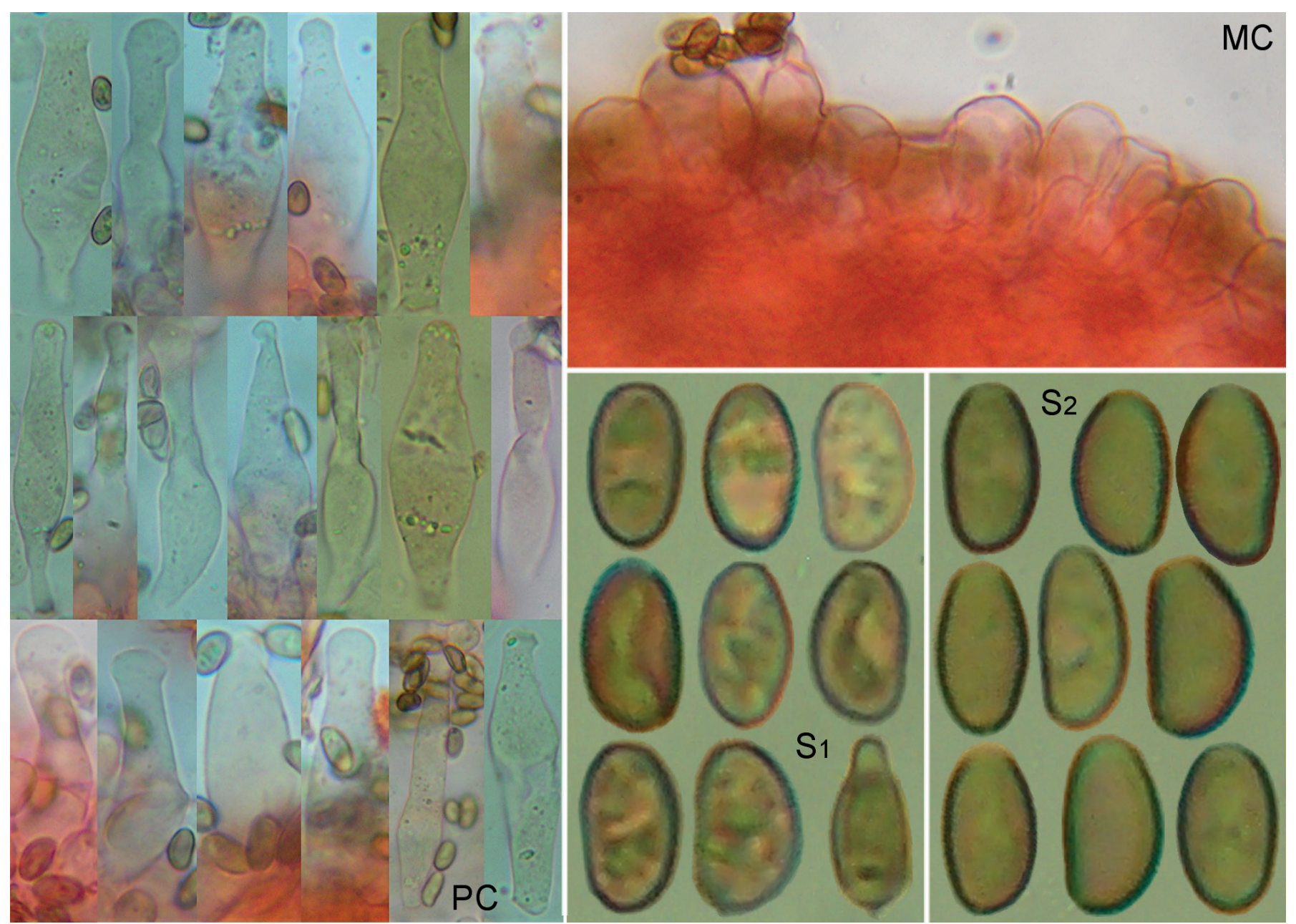

Fig. 10. Psathyrella rugulosa. L. R. Hesler 17027, MICH12040; PC Pleurocystidia; MC Marginal Cystidia; S1 Spores in water; S2 Spores in KOH. 
subphaseoliform, sometimes narrowly subamygdaliform or with a faint suprahilar depression, rarely phaseoliform; pale, few at most dull orangish; germ pore little distinct (callus), mainly subtruncate. Pleurocystidia 38-65 × 9-17 $\mu \mathrm{m}$, utriform to subcylindrical, often with elongate-cylindrical neck, rarely subellipsoid or ventricoseconical; apex (4-)6-10 $\mu \mathrm{m}$ broad, rounded, sometimes obtuse to subacute, often (laterally) subcapitate, rarely forked, sometimes incrusted; numerous. Cheilocystidia up to $60 \times 15 \mu \mathrm{m}$, scattered. Paracystidia $-30 \times-20 \mu \mathrm{m}$, numerous, dominating.

Notes: Smith (1972) reported spores with distinct and narrowly truncate germ pore. Unfortunately, DNA extraction failed on this material; however, general morphological evidence places it into subsection Spadiceogriseae. Due to its pale spores and indistinct germ pore it resembles $P$. clivensis, however, because of its appendiculate veil and conifer habitat, Smith (1972) placed it near $P$. oregonensis, from which it differs because of its pale and terete spores.

7. Psathyrella albanyensis A.H. Sm., Mem. N. Y. Bot. Gard. 24: 140. 1972. Fig. 11.

Morphological heterotypical synonyms proposed here: Psathyrella subcinerascens A.H. Sm., Mem. N. Y. Bot. Gard. 24: 172. 1972.

Typus: Psathyrella albanyensis A.H. Sm. USA, Wyoming, Albany Co., Laramie Mts., drainage at the northeast base of Pole
Mt., 27.V.1956, W.G. \& R. Solheim 4438 (MICH11862), on soil under aspen and conifers at $2438 \mathrm{~m}$ a.s.l. (8 000 feet). Tef-1 $\alpha$ MF521823, ITS MF325952.

Loan of three sporocarps in good condition and a pileus for micro-morphology investigation.

Spores (6.2-)6.7-8.3 ×4.5-6.3 ×4.2-5.2 $\mu \mathrm{m},(7-9 \times 5-6 \times 4-5 \mu \mathrm{m}$ in Smith's description), fQ(1.2-)1.3-1.5(-1.6), pQ1.45-1.7(-2.2); in front view oval, elliptic to subcylindrical, often subtriangular or cordiform to subpentagonal, sometimes subglobose, base often truncate, apex sometimes attenuate and snout-like projected, in profile elliptic, sometimes subamygdaliform; reddish brown to dark red; germ pore indistinct, sometimes distinct but very small, at most $1 \mu \mathrm{m}$. Pleurocystidia 31-45 × 12-17(-19) $\mu \mathrm{m}$; utriform, ellipsoid-rhomboid, sometimes fusiform, subcylindrical, apical part often attenuate to conical or submucronate, apex obtuse to sometimes subobtuse or subrounded, not incrusted, walls hyaline; moderately numerous. Cheilocystidia 19-40 × 1415(-21) $\mu \mathrm{m}$, scattered. Paracystidia 10-33(-36) × 6-16(-23) $\mu \mathrm{m}$, with walls weakly yellowish pigmented and sometimes incrusted, numerous, dominating. Cells below marginal cystidia weakly yellowish pigmented and with incrustations.

Notes: The molecular analysis nests this taxon within the $P$. kauffmanii complex; morphologically it is characterized by often tridimensional, often pentagonal-like spores, both pleuro- and cheilocystidia showing a tendency to an attenuate and conical
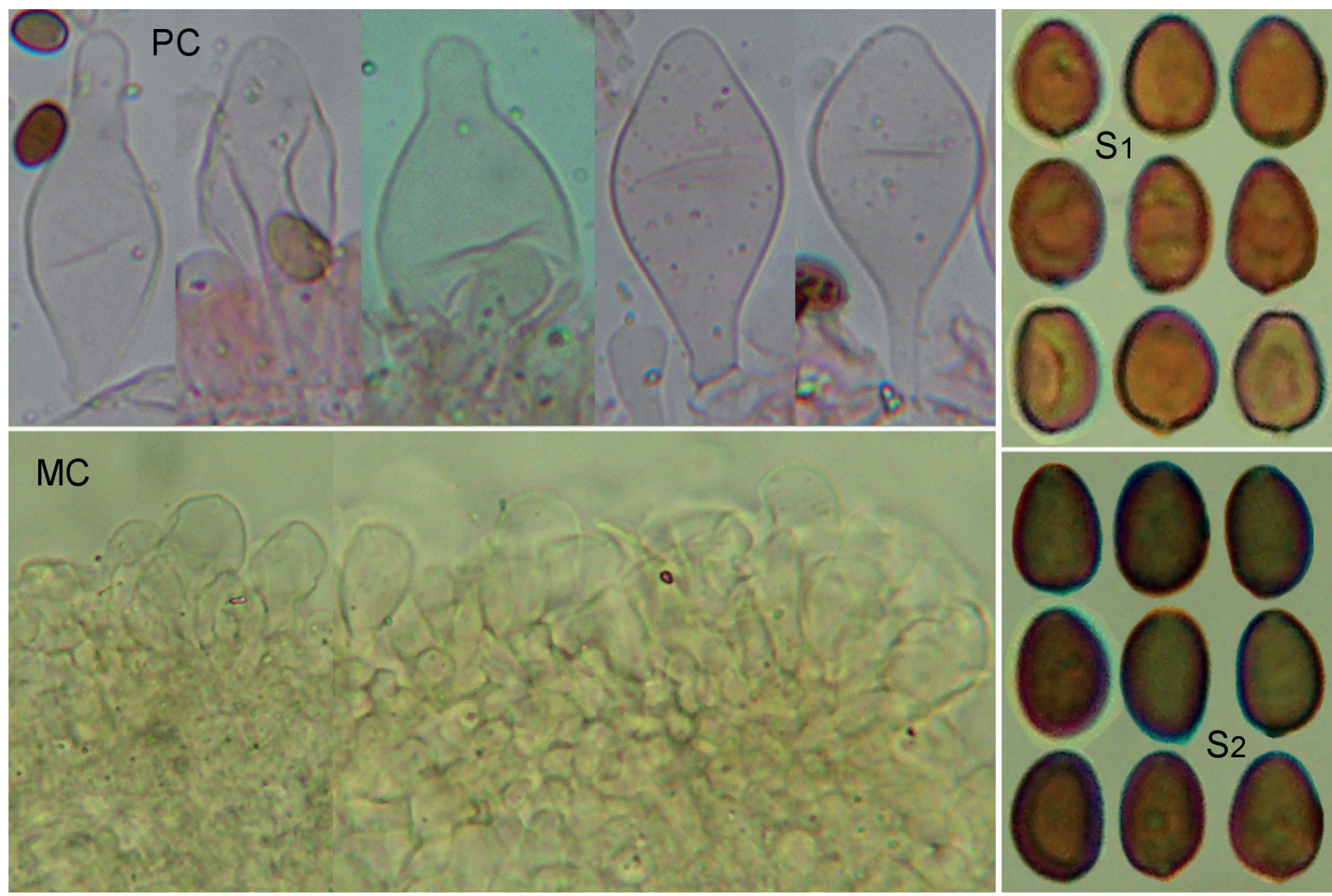

Fig. 11. Psathyrella albanyensis. W.G. \& R. Solheim 4438, MICH11862; PC Pleurocystidia; MC Marginal Cystidia in KOH; S1 Spores in water; S2 Spores in $\mathrm{KOH}$. 
apex, small and slender sporocarps with reddish rusty tints on the pileus. Its habitat occurs at very high elevations (>1500 m a.s.I.), in association with conifers and occasionally with aspen (Populus tremuloides). Psathyrella oregonensis appears to be its closest relative, based on its tridimensional spores and habitat represented by conifers.

Psathyrella subcinerascens is represented only by the holotype, and was one of the Smith's species MICH could not loan because of limited sample size. It was collected on muck near beaver ponds in a mountain setting, thus suggesting that arboreal debris may be a common habitat for this species. We have noticed many morphological similarities with $P$. albanyensis and propose the conspecificity of these two species.

\section{Psathyrella ovaticystis Pegler, Kew Bulletin Additional Series VI: 428. 1977. Fig. 12}

Typus: Psathyrella ovaticystis Pegler. Uganda, Buganda Province, Mengo Distr., Zika Forest, 12 Jun. 1968, D.N. Pegler 1433 (K(M) 196311), among leaf litter.

Loan of one sporocarp lacking a slice of pileus for micromorphology investigation and molecular analysis.

Spores 6.2-8.8(-9.1) × 4.2-5.1 $\mu \mathrm{m}$, on average $7.8 \times 4.9 \mu \mathrm{m}, \mathrm{Q}$ 1.5-1.8, avQ 1.6; in front view oval to cylindrical oval, irregularly to angularly cylindrical-elliptical, irregularly to angularly oboval, base broadly rounded to sometimes truncate, in profile adaxially flattened to subphaseoliform; few spores darkish reddish brown and with little to moderately distinct, mostly truncate, 1.4-1.7 $\mu \mathrm{m}$ broad germ pore. Pleurocystidia 20-32 × (9-)11-16 [apex 8-12.5(-15) $\mu \mathrm{m}$ broad when differentiated], cylindrical-utriform, clavate-utriform, ellipsoid, clavate, ovoid, sometimes utriform; apex rounded to almost truncate, sometimes subcapitate, not forked, not incrusted, often collapsed in exsiccate material; walls not pigmented; moderately numerous to scattered. Cheilocystidia 18-28 × 9-16 $\mu \mathrm{m}$, scattered to locally moderately numerous. Paracystidia 11-25(-30) × 7.5-15(-19) $\mu \mathrm{m}$, dominating.

Notes: Pegler (1977) reports the dimension of the pileus to be $10 \mathrm{~mm}$ and the stipe' s dimension to be $40 \times 1.5 \mathrm{~mm}$, therefore it can be deduced that his collection consists in one only specimen. Some characters of this taxon recall $P$. kauffmanii: color (Pegler 1977: 'fuscobrunneae ... dark fuscous brown' without indication of the liquid of observation) and shape of spores, and shape of cystidia. However, it has distinctly shorter (20-26 × 9-12 $\mu \mathrm{m}$ in Pegler 1977), bulkier on average, oftener undifferentiated pleurocystidia. The carpophore has a reduced, slender habitus and is devoid of veil. Although the DNA analysis failed, the general micro morphological features seem to place it into the subsection Spadiceogriseae, possibly close to the P. kauffmanii complex.

9. Psathyrella spadiceogrisea (Schaeff.) Maire, Mém. Soc. Sci. Nat. Maroc. 45: 113. 1937. Figs 13 (as P. spadiceogrisea), 14 (as P. lubrica), 15 (as P. praecox), 16 (as P. amarella).

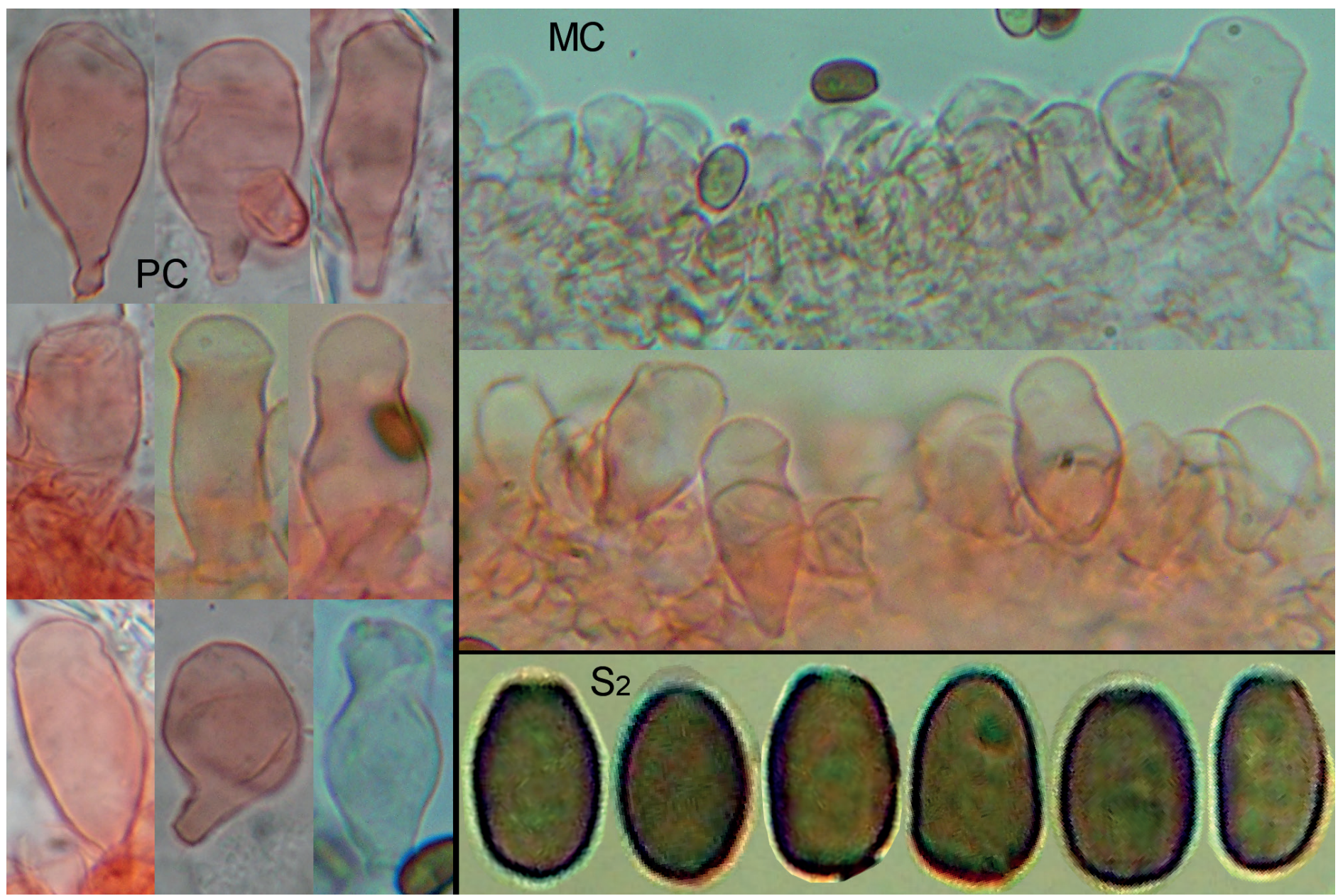

Fig. 12. Psathyrella ovaticystis. D.N. Pegler 1433, K(M) 196311; PC Pleurocystidia; MC Marginal Cystidia; S2 Spores in KOH. 


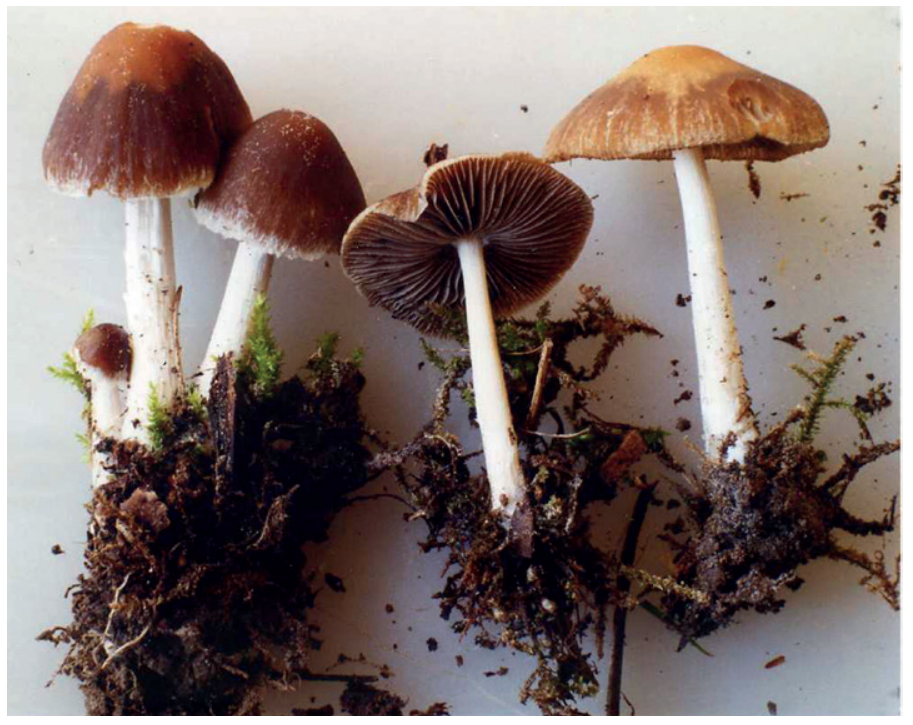

Fig. 13. Psathyrella spadiceogrisea. MCVE29103. Photo G. Tassi.

Molecular heterotypical synonyms proposed here: Psathyrella amarella A.H. Sm., Mem. N. Y. Bot. Gard. 24: 353. 1972; Psathyrella lubrica A.H. Sm., Mem. N. Y. Bot. Gard. 24: 144. 1972; Psathyrella praecox A.H. Sm., Mem. N. Y. Bot. Gard. 24: 352. 1972.

Pileus 15-55 mm broad, in early stages obtusely conical with inflexed margin, finally conical-convex to plane, obtusely umbonate or not, sometimes radially rugulose in old sporocarps; when young dark reddish brown sometimes with a violaceous tinge, discoloring to brown, dark brown, cinnamon brown, rust brown, ochraceous brown, brownish orange, yellow brown, dark yellow brown, grey brown, yellow red, sometimes shiny, hygrophanous, fading cream to alutaceous or whitish, often with greyish tint; translucently striate when moist. Veil white, fugacious, when young on pileus with flocci or fibrils around margin, sometimes fringed at margin, on stipe with appressed fibrils. Lamellae adnate, moderately broad in age, crowded to moderately crowded; when young pale alutaceous to hazelbrown, finally purplish brown; edge white. Stipe 40-80×1.5-8 $\mathrm{mm}$, generally equal; white to whitish; apex pruinose, base sometimes fugaciously felted. Context thick in the centre of pileus and thin towards the margin, fragile to moderately fragile in stipe, pale. Odor indistinctive. Taste mild to bitterish. Spore deposit dark purple-brown. Spores (6-)7-10.1(-10.7) $\times$ (3.5-)3.8-5.5(-5.8) $\mu \mathrm{m}$, on average 7.7-9 × 4.3-5.2 $\mu \mathrm{m}, \mathrm{Q}(1.4-)$ 1.6-2.2, avQ 1.75-2; in front view elliptic, narrowly oval, oblong, subcylindrical, sometimes narrowly angular-oval, base often more or less truncate, in profile subphaseoliform to adaxially flattened, rarely amygdaliform; reddish brown; germ pore distinct, more or less truncate, 1.3-1.7 $\mu \mathrm{m}$ broad. Basidia 4-spored, 18-24(-30) $\times$ 7-9(-10) $\mu \mathrm{m}$. Pleurocystidia 30-64 × 9-20 $\mu \mathrm{m}$, mainly utriform, also fusiform to lageniform, sometimes broadly utriform, subcylindrical, obtusely subconical; apex rounded to subobtuse, rarely acute, rarely subcapitate, sometimes forked, sometimes incrusted; walls sometimes thickened, sometimes yellow brown pigmented; numerous, rarely scattered. Cheilocystidia 25-45 $(-50) \times 10-18 \mu \mathrm{m}$, rare to scattered, rarely absent or rather numerous. Paracystidia 8-33(-42) × 5-17(-20) $\mu \mathrm{m}$, sometimes rhomboid, rarely incrusted; walls sometimes thickened and lightly pigmented (overall towards base); numerous, dominating. Cells below marginal cystidia rarely incrusted, rarely slightly pigmented. Clamps present.
Habitat: gregarious or cespitose; on woody debris, in leaves, on muck; in deciduous woods, in parks, on paths.

Collections examined from MICH: Psathyrella amarella A.H. Sm., Ammirati 2925; Psathyrella lubrica A.H. Sm., holotype, Smith 15019; Psathyrella praecox A.H. Sm., paratype, Potter 4490.

Other material examined: France, Essonne, Mennecy, Parc de Villeroy, ? Apr. 2004, gregarious, on humus, G. Tassi 04005 (duplicate MCVE29103, Tef-1 $\alpha$ MF521779, ITS MF325997), Fig. 13.

Notes: As the holotype material of $P$. spadiceogrisea seems not to be existing anymore we refer, for its molecular concept, to Örstadius et al. (2015) and, for its morphological concept, to the German description of the basionym Agaricus spadiceogriseus by Schäffer (1771) (later followed by a latin description in Schäffer 1774) which includes a color drawing in table 237 (iconotypus). Our morphological concept also matches that by Örstadius et al. (2008) but for some little differences as they, probably, included also $P$. niveobadia in their description.

Schäffer (1800) later authored a reprinted version of its original table displaying a different pileus coloration including distinct violaceous tints, and dirty pinkish for the smallest sporocarps. The first color can also be found in $P$. fatua (see Figs $36,38,40$ ) and $P$. albescens (see Fig. 27) when undergoing the drying process; the distinct pink color, instead, is only known for $P$. fatua (see Figs 37, 39). More comments on Schäffer's table and description are included in the notes about $P$. albescens, but -based on the points above- it is likely that Schäffer's reprinted drawings may also include $P$. fatua collections.

The features of $P$. spadiceogrisea show a range of variability. The initial strong tints of the pileus can linger into the mature stage, until the pileus remains fresh, and may discolor into greyish tints. The pleurocystidia are with or without the following: incrustations, pigmentation or forked apex. Morphological variability and the unrecognized presence in Europe of the American taxon P. albescens (see below), at least until now, have led to misinterpretations, superfluous synonyms, and contradicting interpretations. Many subspecific taxa have been reduced to synonymy: $P$. spadiceogrisea $\mathrm{f}$. mammifera, P. spadiceogrisea f. phaeophylla and Drosophila spadiceogrisea f. russifolia by Ludwig (2007); P. spadiceogrisea f. vernalis both by Ludwig (2007) and by Örstadius (2007). Also Ludwig (2007) synonymized $P$. spadiceogrisea f. exalbicans to $P$. fatua. Some of these synonymies, particularly the last two, may be incorrect as their propounder did not know about the presence of $P$. albescens in Europe; this however would not change the main point that none of them are to be regarded as good species.

The four vouchers we have analyzed in this study display some degree of slight intraspecific variability in their molecular identity too. However ITS sequence homology values were always higher than $98.0 \%$ among the type of $P$. amarella, the paratype of $P$. praecox, and samples LÖ92-01 and MCVE29103 of $P$. spadiceogrisea. Similarly, Tef-1 $\alpha$ sequence homology values were always higher than $99.0 \%$ among the type of $P$. lubrica, the paratype of $P$. praecox, and samples LÖ102-98 and MCVE29103 of $P$. spadiceogrisea.

In MCVE29103 (G. Tassi's voucher 04005), composed of both young and mature specimens, the pilei are date brown, ochraceous in the center, and encircled in the primordial and young stages by a conspicuous band of white veil (see Fig. 13). 
These macro morphological traits are similar to those described for $P$. niveobadia; however the micro-morphological features of this material overlap with those of $P$. spadiceogrisea.

The holotype of $P$. amarella shows some pleurocystidial apex with a thickened and pigmented wall. All of the material examined has shown a sparse presence of little incrustations on pleurocystidia apex, but never a nucous covering.

The lack of strong morphological differences and the similarity of DNA sequences all suggest these collections represent the same species.

Psathyrella marquana and $P$. cascoides are two very recently described species. The former has characters that, although close to those of $P$. spadiceogrisea, are different enough to represent its own species, and it is included in our key. The latter instead, has characters fully consistent with those of $P$. spadiceogrisea, and therefore it has to be regarded as a synonym.

Descriptions of $P$. casca in the literature are mostly misidentifications of $P$. spadiceogrisea or $P$. niveobadia. Kits van Waveren's (1985) interpretation was reported by Örstadius et al. (2008) as synonym to P. spadiceogrisea. Actually, we suspect it, and also $P$. casca sensu Tassi (2000), to represent $P$. niveobadia instead. We consider $P$. casca a dubious name.

For comparison with $P$. niveobadia see below. 9a. Psathyrella lubrica A.H. Sm., Mem. N. Y. Bot. Gard. 24: 144. 1972. Fig. 14.

Typus: Psathyrella lubrica A.H. Sm. USA, Michigan, Oakland Co, Kent Lake, near New Hudson, 28 May 1940, A.H. Smith 15019 (MICH11957), on muck. Tef-1 $\alpha$ MF521771.

Loan of two sporocarps in good condition and a portion of pileus for gross morphology investigation.

Spores 7.5-9 × 3.8-5.5 $\mu \mathrm{m}, \mathrm{Q}(1.46-) 1.61-1.9(-1.93)$, avQ 1.75; in front view elliptic, narrowly oval, subcylindrical, sometimes narrowly angular-oval, base rounded to more or less truncate, in profile adaxially flattened to subphaseoliform; reddish brown; germ pore moderately distinct to distinct, more or less truncate,1.3-1.7 $\mu \mathrm{m}$ broad. Pleurocystidia 45-62 × 10-18 $\mu \mathrm{m}$; utriform to fusiform-utriform or lageniform, sometimes subcylindrical; apex obtuse to subobtuse, sometimes rounded to subacute, rarely subcapitate, sometimes forked, sometimes incrusted; walls hyaline; numerous. Cheilocystidia 25-40 $\times$ 10-15 $\mu \mathrm{m}$, scattered. Paracystidia $-33 \times-13 \mu \mathrm{m}$, sometimes rhomboid, numerous, dominating. Cells below marginal cystidia hyaline, not incrusted.

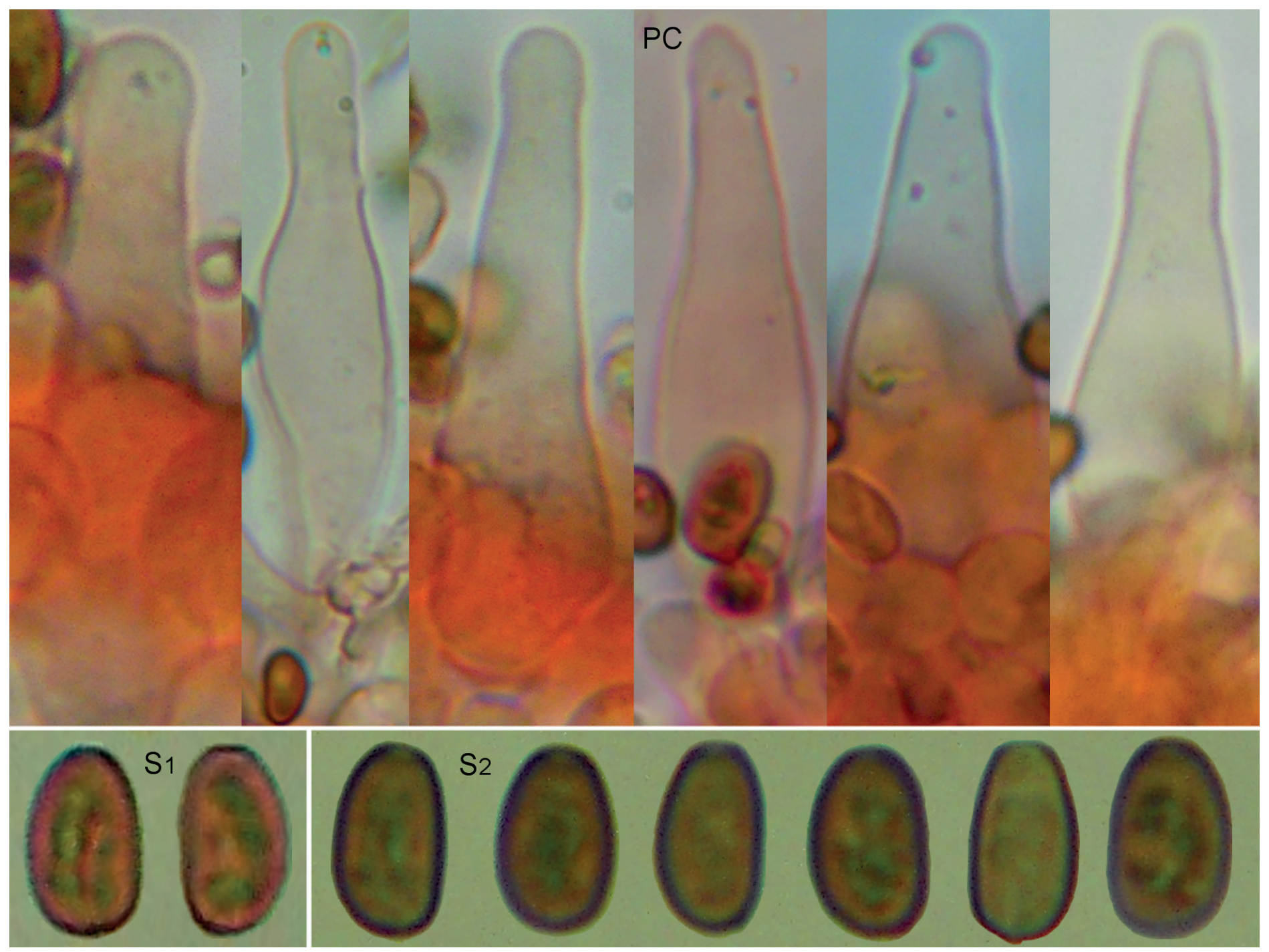

Fig. 14. Psathyrella lubrica. A.H. Smith 15019, MICH11957; PC pleurocystidia; S1 Spores in water; S2 Spores in KOH. 


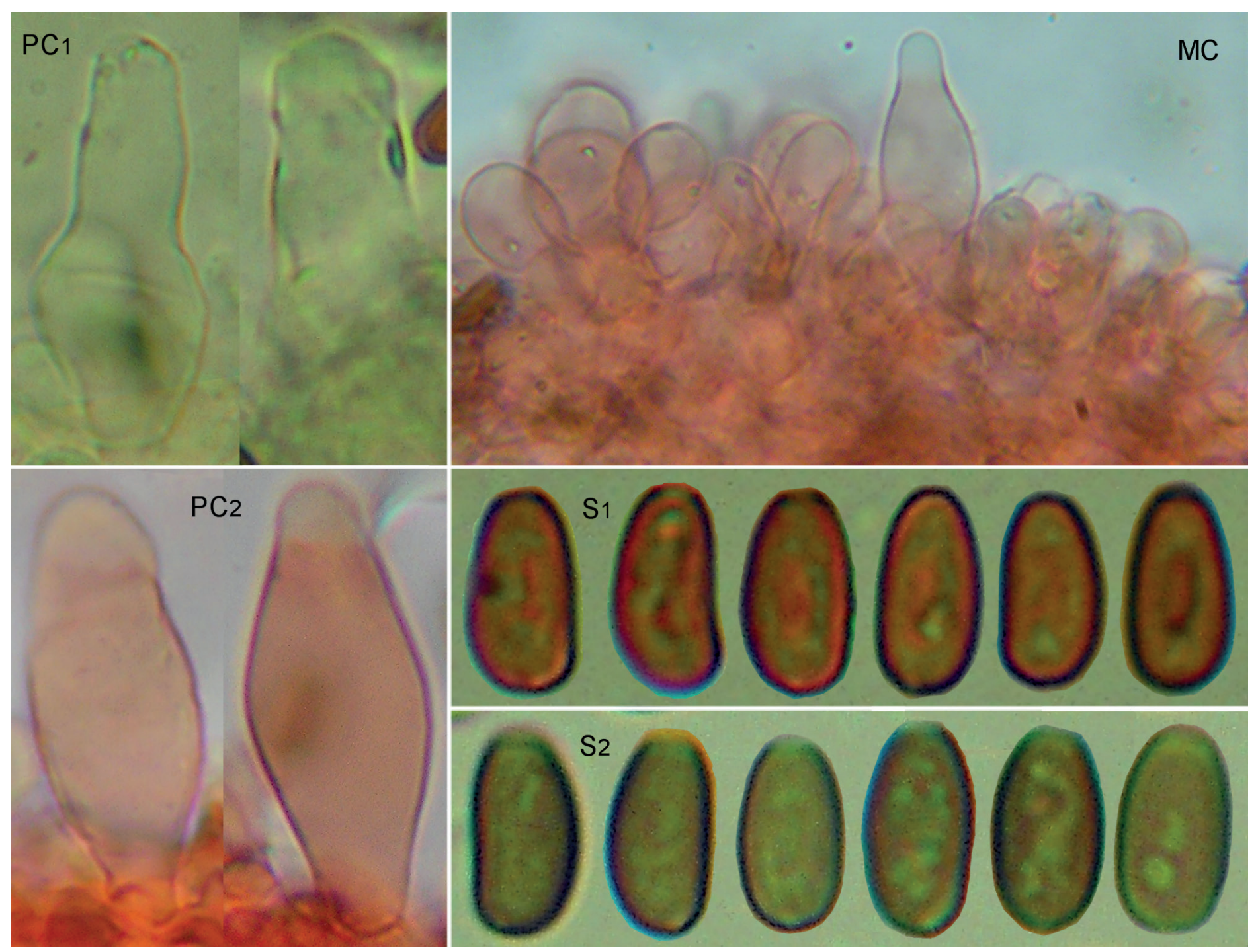

Fig. 15. Psathyrella praecox. V. Potter 4490, MICH49251; PC1 Pleurocystidia in $\mathrm{NH}_{4} \mathrm{OH}$; PC2 Pleurocystidia in Congo red; MC Marginal Cystidia in Congo red; S1 Spores in water; S2 Spores in $\mathrm{KOH}$.

9b. Psathyrella praecox A.H. Sm., Mem. N. Y. Bot. Gard. 24: 352. 1972. Fig. 15.

Paratype: Psathyrella praecox A.H. Sm. USA, Michigan, Gratiot Co., Ithaca, Schovence's woods, 18 May 1948, V. Potter 4490 (MICH49251), on soggy leaf mold near edge of a pond. Tef-1 $\alpha$ MF521783, ITS MF325992.

Loan of various sporocarps in good condition for gross morphology investigation.

Spores 7.5-10.1 × 3.8-5.1 $\mu \mathrm{m}, \mathrm{Q}$ 1.7-2.2, avQ 2; in front view elliptic, cylindrical to oval, sometimes narrowly angular-oval, base often more or less truncate, in profile adaxially flattened to subphaseoliform, sometimes phaseoliform or subamygdaliform; reddish brown; germ pore distinct, often truncate, $\pm 1.6 \mu \mathrm{m}$ broad. Pleurocystidia 32-43 × 10-17 $\mu \mathrm{m}$; utriform, sometimes fusiform-utriform, subcylindrical; apex rounded to obtuse, not subcapitate, sometimes forked, sometimes incrusted; walls sometimes pigmented; numerous. Cheilocystidia 31-36 × 11$12 \mu \mathrm{m}$, rare. Paracystidia 8-31 × 5-17 $\mu \mathrm{m}$, rarely incrusted, walls sometimes thickened and weakly pigmented, numerous, dominating.
Notes: Smith (1972) reports narrower spores, (6-)7-9 × 3.3-3.8 $\mu \mathrm{m}$. Both morphology and DNA reveal that this paratype is a later synonym of $P$. spadiceogrisea. This result does not necessarily apply to the holotype, which could not be obtained due to scarcity of material; however, from the general description of the species we conclude that $P$. praecox is to be considered a synonym of $P$. spadiceogrisea.

9c. Psathyrella amarella A.H. Sm., Mem. N. Y. Bot. Gard. 24: 353. 1972. Fig. 16.

Typus: Psathyrella amarella A.H. Sm. USA, Michigan, Baraga Co., Silver River Area, Dynamite Hill Road, 7 Feb. 1969, J.F. Ammirati 2925 (MICH11869), gregarious on leaf mold in a hardwood forest. ITS MF325958.

Loan of one pileus in good condition for gross morphology investigation.

Spores 7-9.4 × 4-5 $\mu \mathrm{m}, \mathrm{Q}$ 1.6-2.1; in front view elliptic, subcylindrical, (narrowly) oval, base often more or less truncate, in profile subphaseoliform to adaxially flattened; reddish brown; germ pore distinct, subtruncate to rounded, $\pm 1.2-1.6$ $\mu \mathrm{m}$ broad. Pleurocystidia 30-48 × 10-15(-20) $\mu \mathrm{m}$; utriform, 


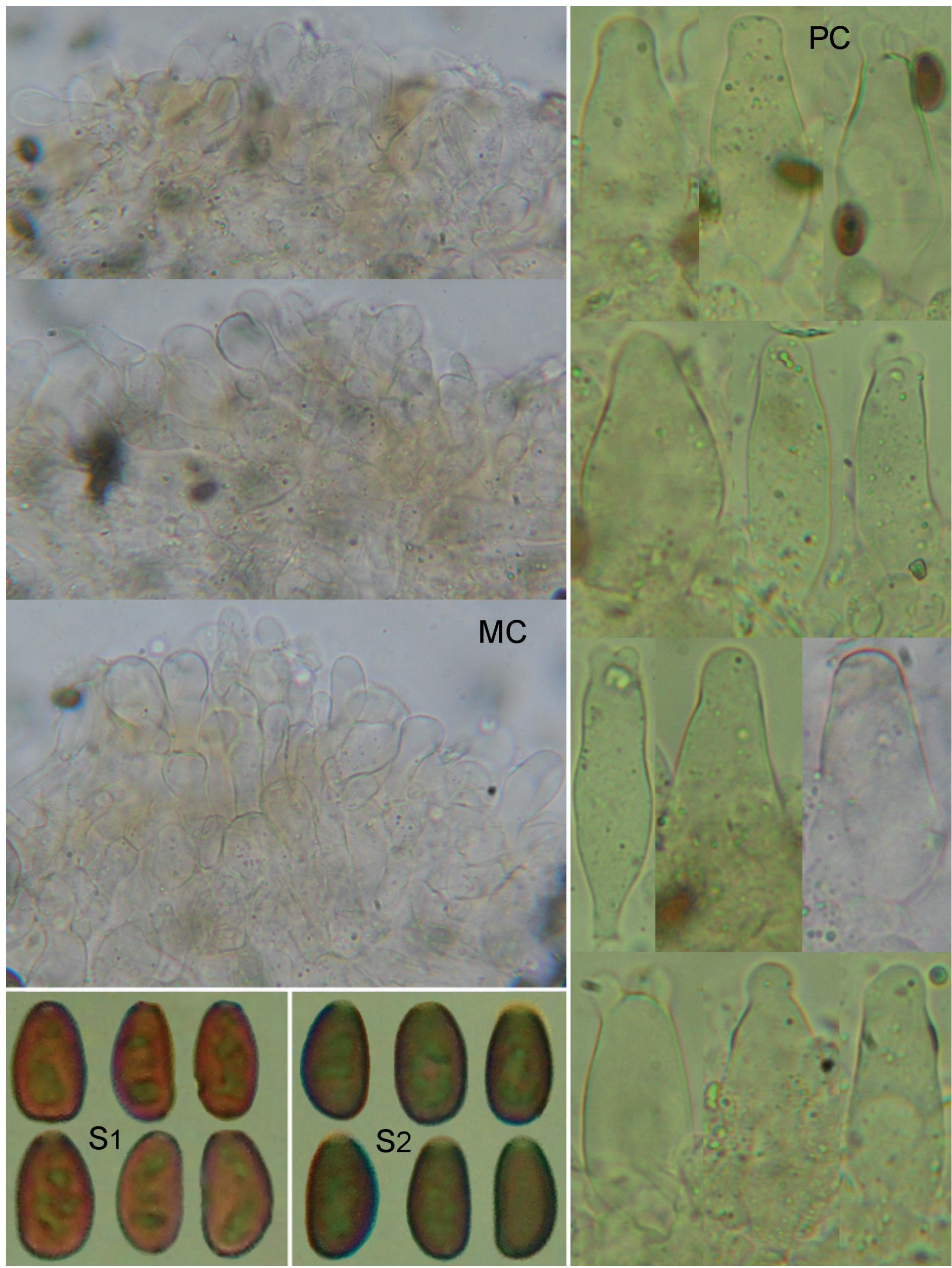

Fig. 16. Psathyrella amarella. J.F. Ammirati 2925, MICH11869; MC Marginal Cystidia in $\mathrm{KOH}$; PC Pleurocystidia in $\mathrm{NH}_{4} \mathrm{OH}$; $\mathrm{S} 1 \mathrm{Spores}$ in water; $\mathrm{S} 2 \mathrm{Spores}$ in $\mathrm{KOH}$. 
ellipsoid-utriform, sometimes clavate-utriform to obtusely fusiform; apex rounded, sometimes subacute, not subcapitate, often forked to irregular, sometimes incrusted; walls sometimes thickened, sometimes reddish brown pigmented; moderately numerous. Cheilocystidia 20-33(-42) × 8-13 $\mu \mathrm{m}$, scattered and visible in mass. Paracystidia 11-31(-40) $\times 5-17(-25) \mu \mathrm{m}$, often cylindrical, walls sometimes thickened and pigmented with a very slightly ochraceous hue (detectable in mass); numerous, dominating. Cells below marginal cystidia slightly pigmented, sometimes incrusted.

Notes: The molecular comparison of this species with the other examined material of $P$. spadiceogrisea shows that the ITS nucleotide homology ranges between $98 \%$ and $99 \%$ identity with 1 to 14 mismatches. Unfortunately, we could not add the evidence of a second locus; however, apart from the bitter taste, we think its morphological traits fit well into the concept of $P$. spadiceogrisea.

10. Psathyrella niveobadia (Romagn.) M.M. Moser, Kleine Kryptogamenflora die Röhrlinge und Blätterpilze (Agaricales) 2b/2: 276. 1978. Figs 17-22.

Pileus 15-72 mm broad, in early stages obtusely conical to paraboloid with inflexed margin, then hemispherical, finally through convex to plane, obtusely umbonate or not, often radially rugulose in old sporocarps; when young dark, violaceous brown to reddish brown or date-brown, possibly still dark when mature, discoloring to ochraceous brown at centre, more brown to greyish brown in periphery, hygrophanous, fading cream to grey-cream or grey-beige, sometimes with olivaceous tints; not translucently striate or only at extreme margin. Veil white, fugacious, when young of fibrils on margin and connecting margin to stipe. Lamellae 3-6 $\mathrm{mm}$ broad, adnate to broadly adnate, crowded to moderately crowded; when young grey brown, finally more or less dark brown; edge white. Stipe 30-130(-200) × 3.5-10 mm, cylindrical, sometimes very broad at apex (up to $17 \mathrm{~mm}$ ) and then tapering downwards, sometimes a little broadening towards the base, often with a short to $10 \mathrm{~cm}$ long rooting base; hollow since when young; white, discoloring pale brownish with age; apex pruinose. Context fairly thick and tenacious in the pileus, distinctly thick and rigid in the stipe cortex, only fragile in the rooting stipe base portion. Odor weak to indistinctive. Spore deposit purplish brown. Spores 6.9-9.5(-10) × (3.9-)4.2-5 $\mu \mathrm{m}$, on average 7.4-8.3 × 4.5-4.7 $\mu \mathrm{m}, \mathrm{Q}(1.5-)$ 1.55-2(-2.25), avQ 1.7-1.8; in front view elliptic to cylindrical or narrowly oval-cylindrical, base truncate to broadly rounded, in profile phaseoliform, subphaseoliform or adaxially flattened, rarely indented above the apiculus; orange-brown to reddish orange brown (darkish reddish brown in $\mathrm{NH}_{4}$ ); germ pore distinct, rounded, 1.0-1.5 $\mathrm{mm}$ broad. Pleurocystidia (26-)35-60(-70) $\times(10-) 14-18(-22) \mu \mathrm{m}$, utriform, lageniform, clavate, clavatemucronate, fusiform or irregularly tapering towards the apex, sometimes cylindrical-utriform, ellipsoid-utriform; apex broadly rounded to narrowly obtuse, sometimes truncate or subacute, subcapitate or not, sometimes distinctly capitate, sometimes forked, sometimes incrusted, often with grossly mucous masses which gradually disappear in exsiccata and, perhaps, also with age of sporocarps; walls often or sometimes slightly thickened especially at apex and yellow brown pigmented; base sometimes with one or two septa; scatter to

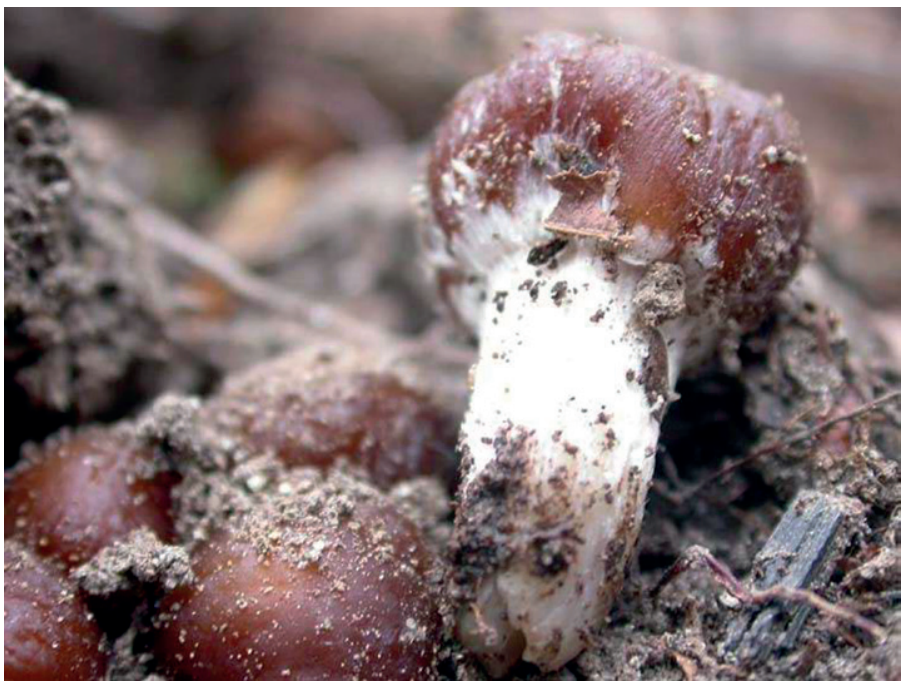

Fig. 17. Psathyrella niveobadia. MCVE29102 Photo B. De Ruvo.

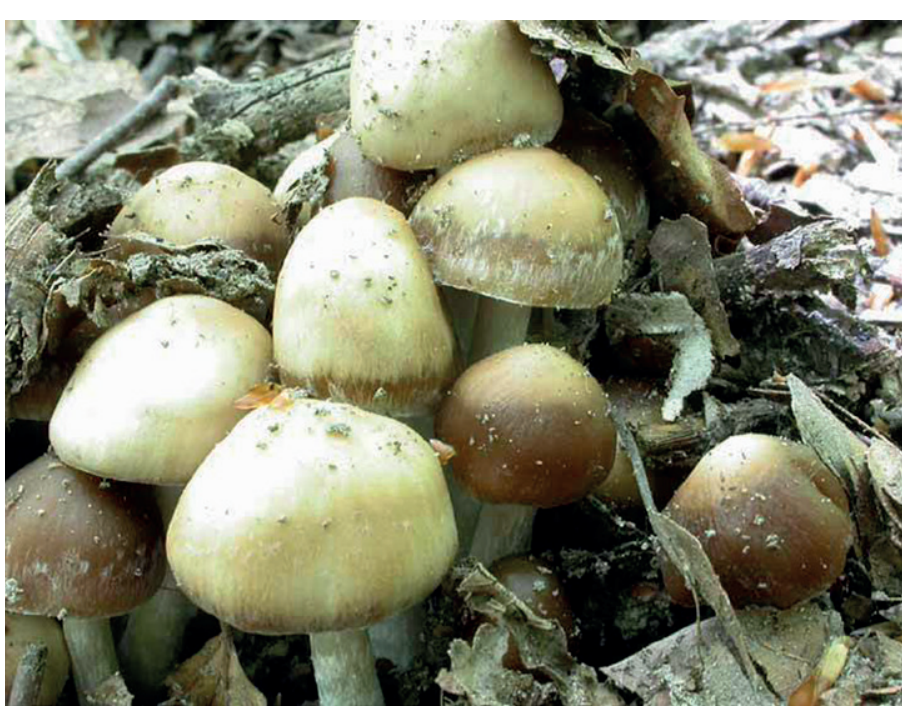

Fig. 18. Psathyrella niveobadia. MCVE29102. Photo B. De Ruvo.

numerous. Cheilocystidia 21-35(-45) × 12-22 $\mu \mathrm{m}$, scattered. Paracystidia $11-30(-40) \times 7-18 \mu \mathrm{m}$; walls sometimes slightly thickened and pale brown; numerous, dominating. Cells below marginal cystidia generally not incrusted and not pigmented.

Habitat: gregarious to caespitose; often growing in spring, lowlands to mountains; on broadleaves woody debris or around stumps, dry to moist.

Material examined: France, Aisne, près de Russy-Bémont, vallée de Russy, forêt de Retz, at the margin of the wood, gregarious on soil and on debris, 14 Feb. 1993, G. Tassi 93014 (9314). Italy, Teramo, Rocca Santa Maria, loc. Ceppo, 1350 m a.s.I., caespitose around stump of Fagus, 4 May 2003, B. de Ruvo, Figs 17, 18, (duplicate MCVE29102, Tef-1 $\alpha$ MF521780, ITS MF325996, more pictures of this collection in http://www.ambmuggia.it/forum/topic/478-psathyrella-fatua/); Pescara, Lettomanoppello, Parco nazionale della Majella, 1300 m a.s.l., gregarious to fasciculate among debris of leaves and needles or around a Fagus stump in a calcareous mixed wood of Fagus, Picea, Abies and Pinus), 13 May 2018, 18 May 2018 and 20 May 2018, A. Micucci, Figs 19-22, (MCVE30076, Tef-1 $\alpha$ MK408675, ITS MK400421). 


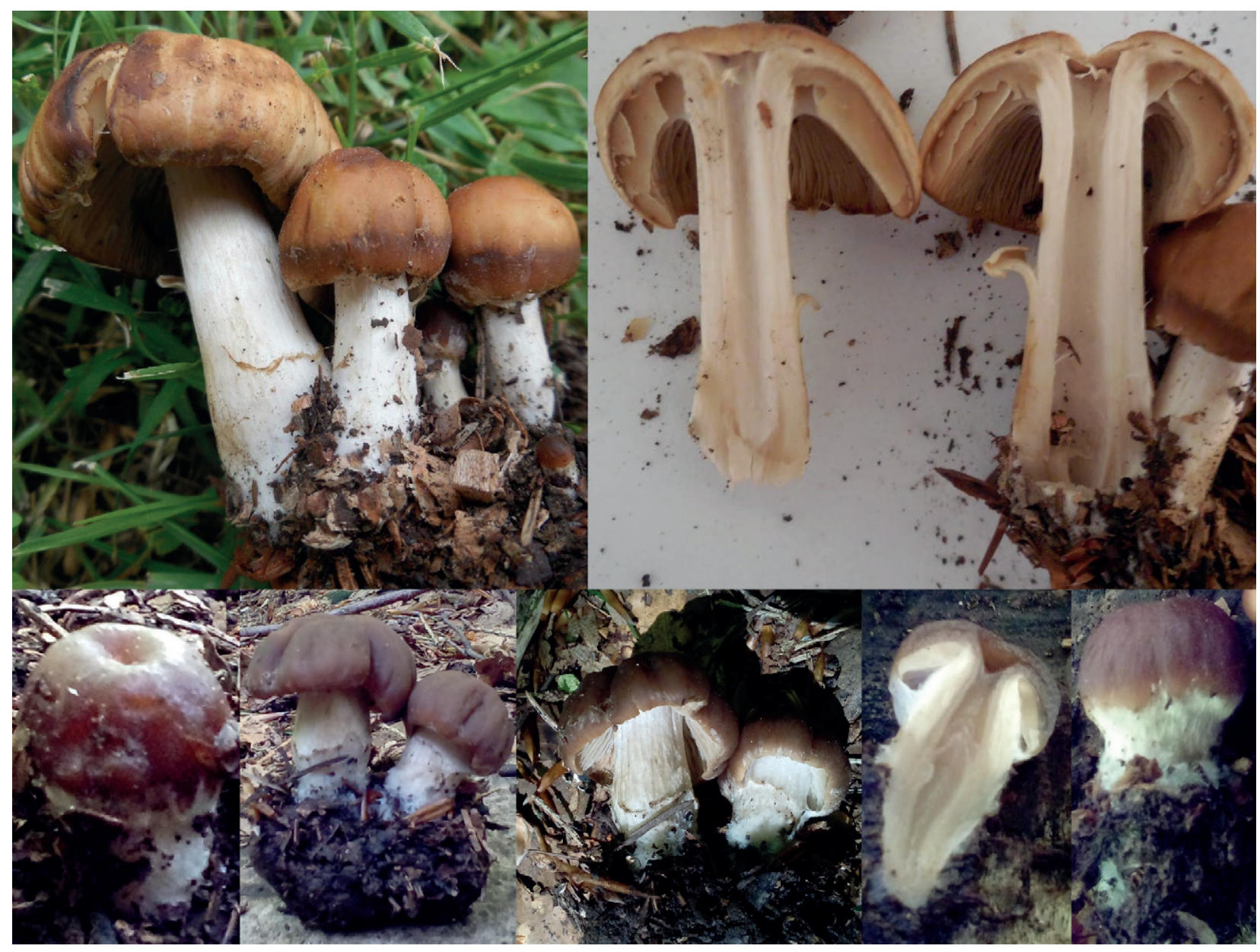

Fig. 19. Psathyrella niveobadia. MCVE30076. Photo A. Micucci.

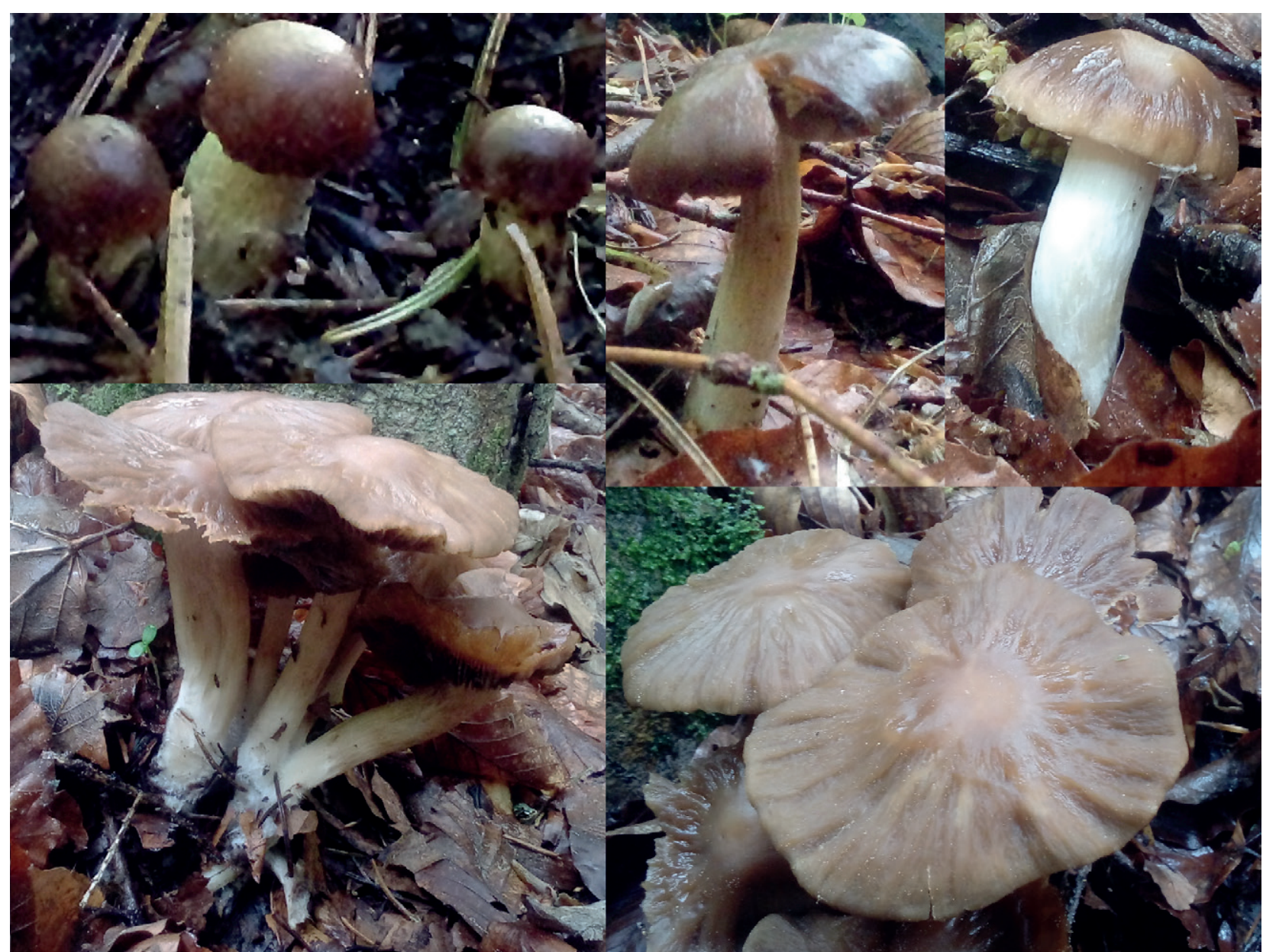

Fig. 20. Psathyrella niveobadia. MCVE3007. Photo A. Micucci. 


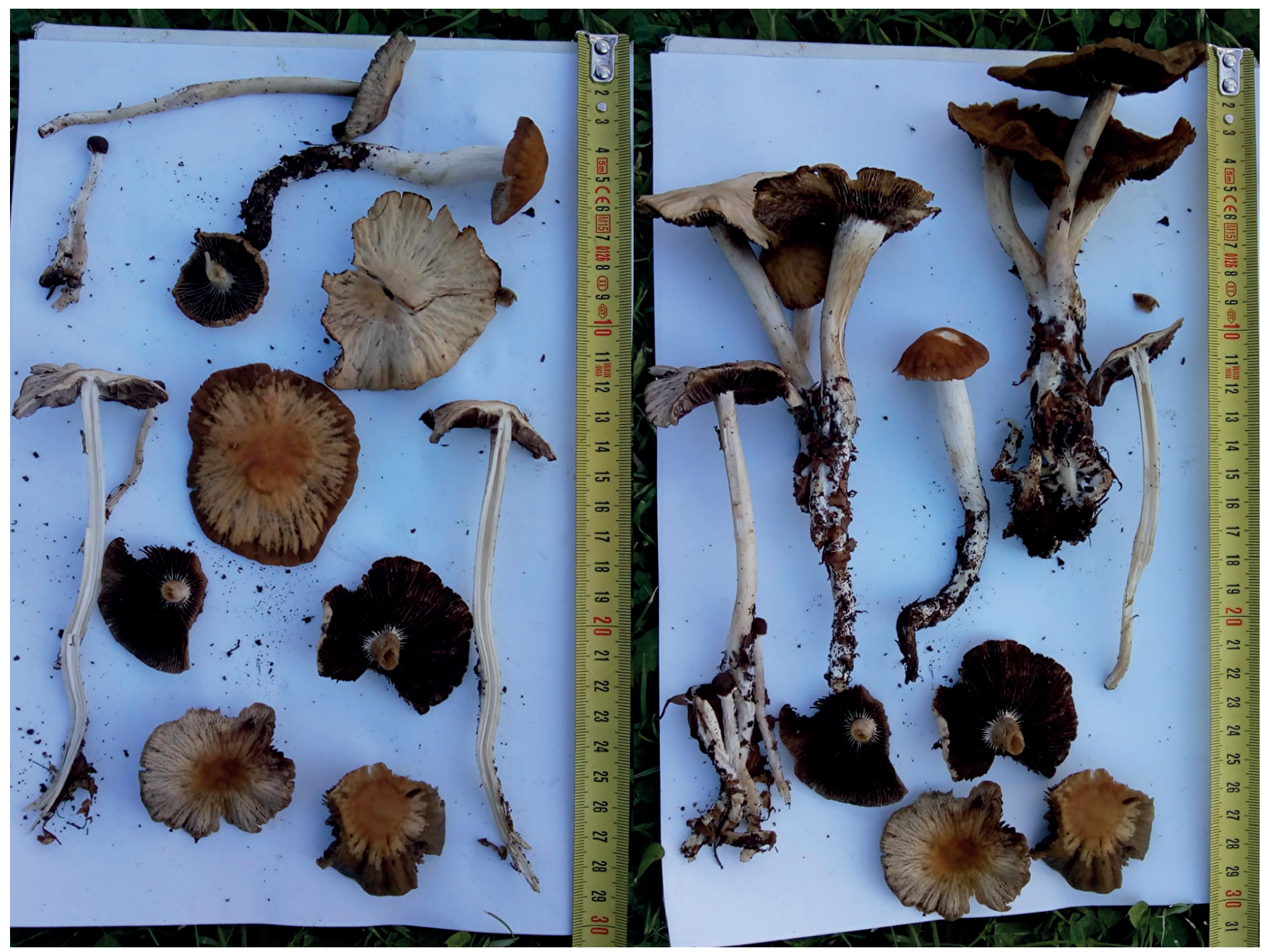

Fig. 21. Psathyrella niveobadia. MCVE30076. Photo A. Micucci.

Notes: The case of $P$. niveobadia remains a little ambiguous. We could not examine the French holotype of its basionym, Drosophila niveobadia, therefore, we have studied two French collections kindly provided to us by G. Tassi. The gross morphology of voucher 04005 (duplicate MCVE29103) recalls that of $P$. niveobadia, but decidedly belongs to $P$. spadiceogrisea (see discussion above). The other voucher, 93014, has microscopical characters in line with those of $P$. niveobadia (shape of pleurocystidia, some pleurocystidia apex thick-walled, dimension and orange-brown color of spores, small germ pore) but, regretfully, DNA extraction failed.

Two other specimens from central Italy (collectors Micucci, MCVE30076, and De Ruvo, MCVE29102), show morphological characters that match perfectly those of $P$. niveobadia described by Kits van Waveren (1985). They possess, and this is particularly true for Micucci's specimen, all the main expected diagnostic features for this species, including: the thickness and rigidity of the stipe cortex and, to a lesser extent, of the pileus, which is scarcely, if at all, striate; the possibly rooting stipe base; the orange-brown spores which are on average 7.4-8.3 $\times$ 4.5-4.7 $\mu \mathrm{m}$ large; the distinctly thickwalled pleurocystidia apex which can be subcapitate or particularly narrow to tapered. From our own observations we can add grossly mucous coverings (in sufficiently fresh specimens at least) of the pleurocystidia apex which is not reported in Kits van Waveren's (1985) description.
We regard other characters in Kits van Waveren's (1985) description as less relevant, not exclusive or unstable; thus, for instance, identifications based mainly on pileus color and veil development, as emphasized in Kits van Waveren's (1985) notes, could actually confuse this species with $P$. spadiceogrisea, while based mainly on rhomboid shape of paracystidia the species in question could actually be $P$. fatua.

Molecular comparisons between the two Italian specimens and the $P$. spadiceogrisea samples included in this paper have produced somewhat ambiguous results, though. Tef-1 $\alpha$ nucleotide homology levels ranged between $98.14 \%$ and 98.67 $\%$, suggesting a possible conspecificity, but ITS nucleotide homology values ranged between $96.77 \%$ and $99.02 \%$, only partially corroborating conspecificity. Because Micucci's sequences were obtained in late 2018, they were not used when constructing the phylogenetic trees, thus their exact placement in the phylogeny of the subsection is unknown. However, taking into consideration the morphological differences listed above and the presence of some, albeit limited, genetic divergence between $P$. spadiceogrisea and $P$. niveobadia in the combined phylogenetic tree (Fig. 3), we have decided to keep the species $P$. niveobadia separate from $P$. spadiceogrisea. Of course, we also acknowledge the specimens belonging to these two species may instead represent extremes of a rather variable single species. 

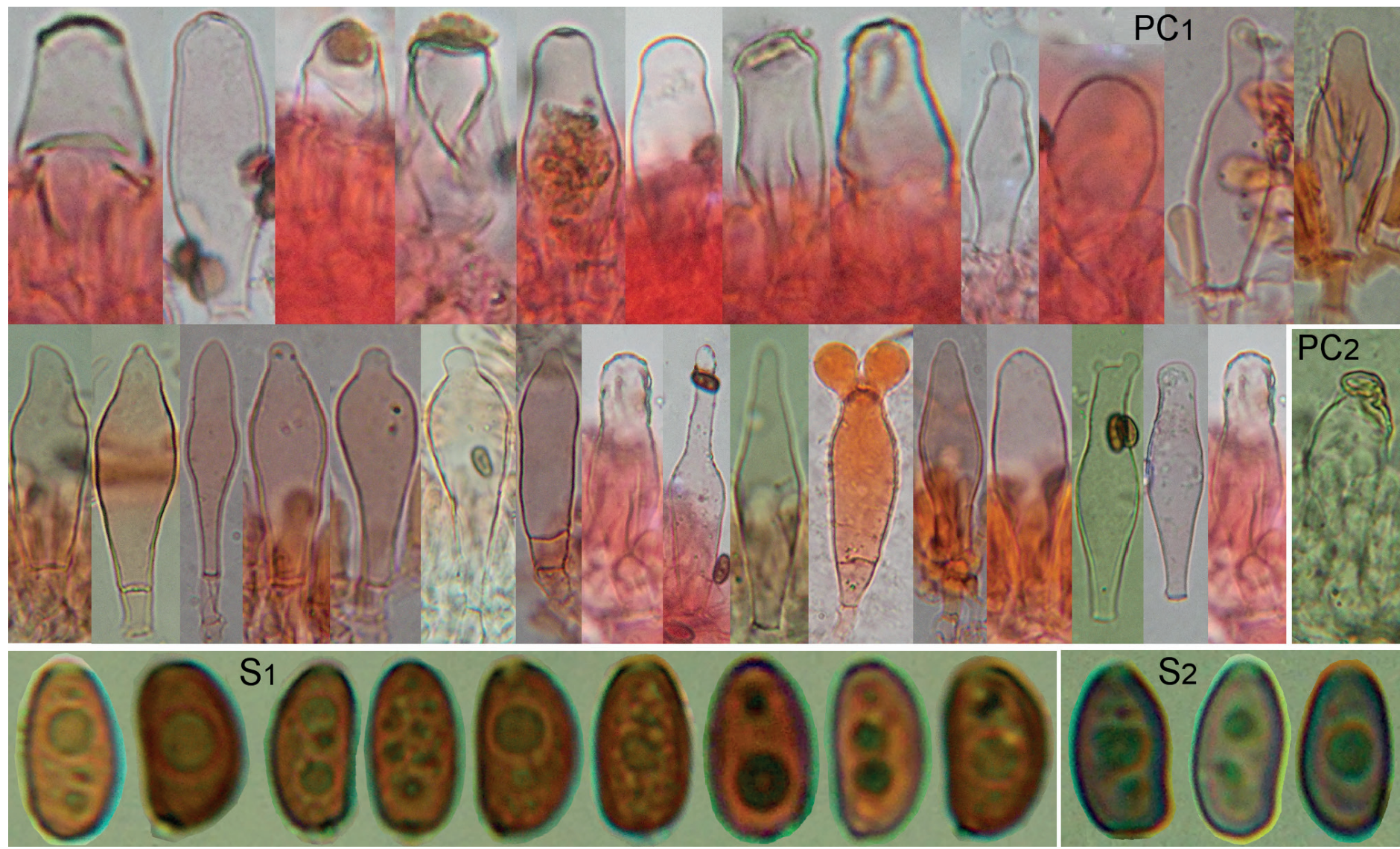

Fig. 22. Psathyrella niveobadia. A. Micucci, MCVE30076; PC1 Pleurocystidia in Congo red; PC2 Pleurocystidium in $\mathrm{NH}_{4} \mathrm{OH}$; $\mathrm{S} 1 \mathrm{Spores}$ in water; $\mathrm{S} 2$ Spores in $\mathrm{KOH}$.

Other images in color drawings are in Tassi (2000: 368, pl. 7) and Ludwig (2007b, pl. 378, figs 98.38A-98.38B).

11. Psathyrella albescens Hesler \& A.H. Sm., Mem. N. Y. Bot. Gard. 24: 133. 1972. Figs 23-32 (as P. albescens), 33 (as $P$. mazzeri).

Molecular heterotypical synonyms proposed here: Psathyrella agrariella sensu A.H. Smith, Mem. N. Y. Bot. Gard. 24: 411. 1972, p.p.; Psathyrella mazzeri A.H. Sm., Mem. N. Y. Bot. Gard. 24: 356. 1972.

Pileus $10-70 \mathrm{~mm}$ broad, in early stages hemispheric to convex, then campanulate to convex, finally convex to plane and rarely slightly depressed at centre, umbonate or not, sometimes radially rugulose, sometimes wavy, margin for some time more or less inflexed, finally straight to sometimes reflexed; when young, dark yellowish brown to cinnamon-brown; when mature, cinnamon-brown, yellowish brown, brownish orange, light to medium Dresden brown, rarely pinkish buff, often moist or shiny, hygrophanous, discoloring to white with ochraceous centre for a time, finally drying from margin to greyish or greyish violaceous; translucently striate when moist. Veil white, when young with fibrils or flocci around the margin of pileus and connecting it to stipe, when mature as fugacious fibrils around the margin of pileus or appendiculate or folded back on the gills, on stipe usually with few appressed fibrils, once as a fragile submembranous annulus. Lamellae (broadly) adnate to slightly decurrent, moderately broad, not or slightly ventricose, crowded; when young whitish to pale pinkish buff or dull brown, finally purplish brown to blackish brown; edge white, fimbriate. Stipe 20-100(-140) × 1.5-6(-12) mm, often broadening towards base or towards both apex and base, extreme base sometimes bent, subrooting or characterized by a short to 50 $\mathrm{mm}$ long pseudorhiza; watery white to whitish, often discoloring brownish; apex pruinose, sometimes subsquamulose or striate, base often felted to subtomentose. Context pale, fragile to rather rigid, in pileus thin. Odor and taste indistinctive to mild. Spore deposit purplish black to blackish brown. Spores (6.3-) 6.7-10.2(-11.7) $\times(3.5-) 3.7-5.4(-5.5) \mu \mathrm{m}$, on average 7.4-9 $\times(4.1-) 4.5-4.9 \mu \mathrm{m}, \mathrm{Q}(1.5-) 1.6-2.4(-2.6)$, avQ (1.70-)1.80$1.90(-2.16)$; in front view oblong to elliptic or oval to narrowly oval, sometimes (sub) angular-oval to cylindrical or irregular, rarely obscurely narrowly oboval or with a median constriction, base broadly rounded to truncate, sometimes triangular, in profile adaxially flattened to subphaseoliform, phaseoliform or indented above the apiculus, sometimes subamygdaliform; orange-brown to orangish reddish brown; germ pore distinct, more or less truncate, 1.3-1.8 $\mu \mathrm{m}$ broad. Basidia 4-spored, $16-24(-29) \times 6-9(-10) \mu \mathrm{m}$. Pleurocystidia $(28-) 32-68(-70) \times$ (8-)10-23(-28) $\mu \mathrm{m}$, utriform to broadly utriform, subcylindrical, fusiform to ellipsoid-rhomboid, rarely lageniform or clavate; apex rounded to obtuse, sometimes subtruncate, rarely subobtuse, subcapitate or not, forked or not, incrusted or not; walls sometimes or often thickened, sometimes brownish pigmented; numerous, sometimes moderately numerous. Cheilocystidia 21-50 (-58) × (7-)10-18(-25) $\mu \mathrm{m}$, similar in incrustations and pigment to the paracystidia, rare to scattered or sometimes locally numerous. Paracystidia 8-48(-56) × 4-28(-30) $\mu \mathrm{m}$, sometimes incrusted, walls sometimes or often thickened and 


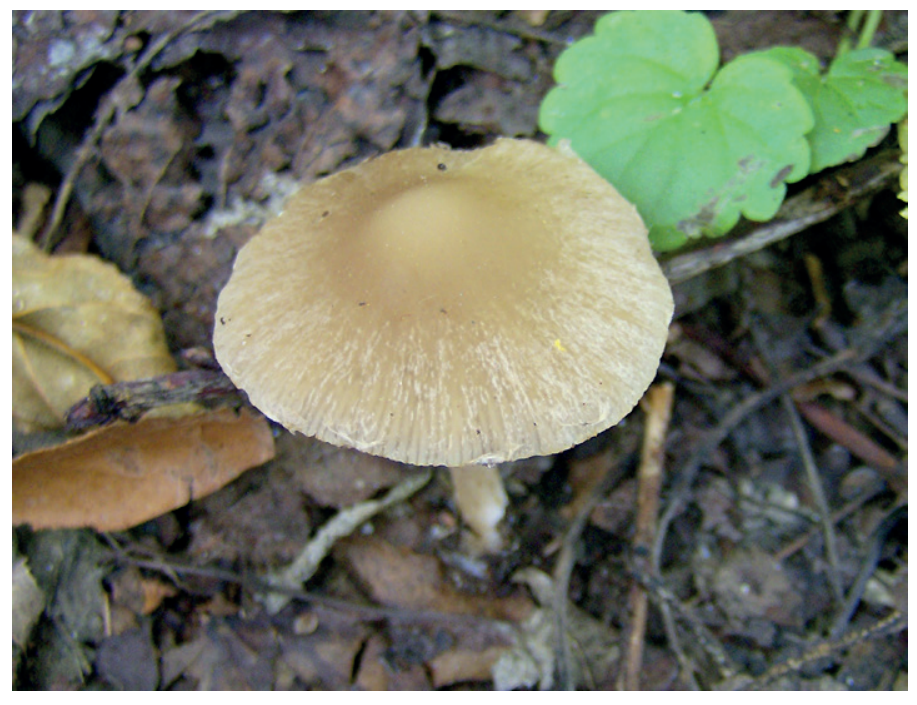

Fig. 23. Psathyrella albescens. MCVE29113. Photo P. Voto.

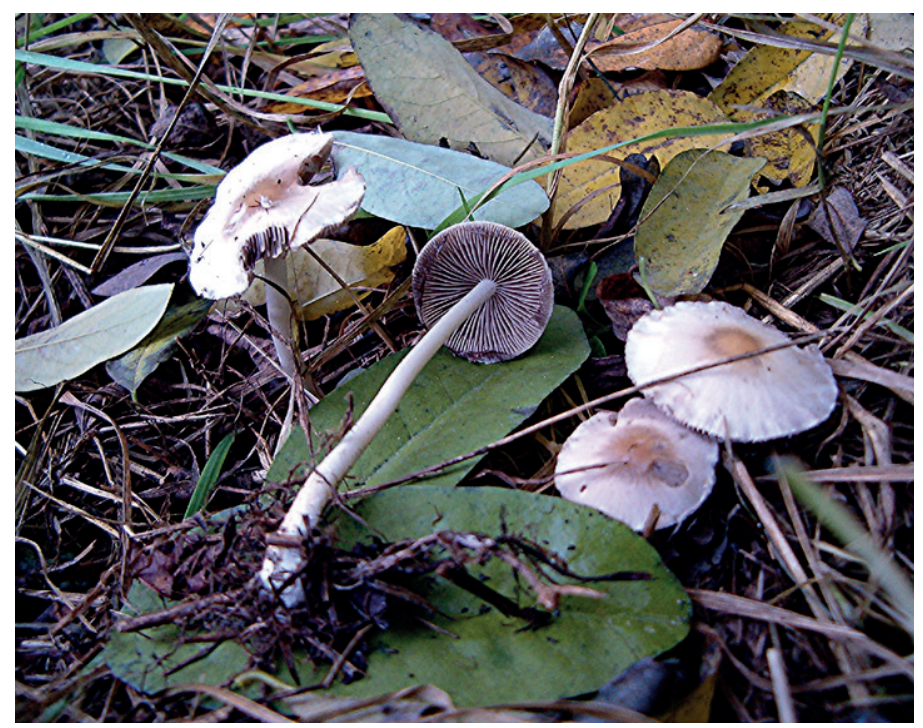

Fig. 25. Psathyrella albescens. MCVE29107. Photo P. Voto.

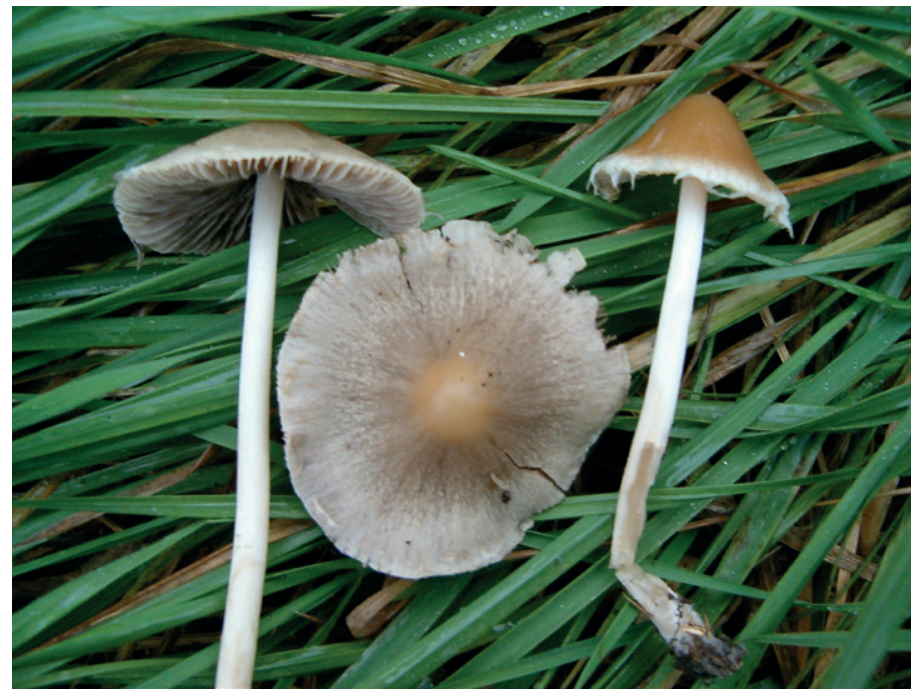

Fig. 27. Psathyrella albescens. MCVE29107. Photo P. Voto.

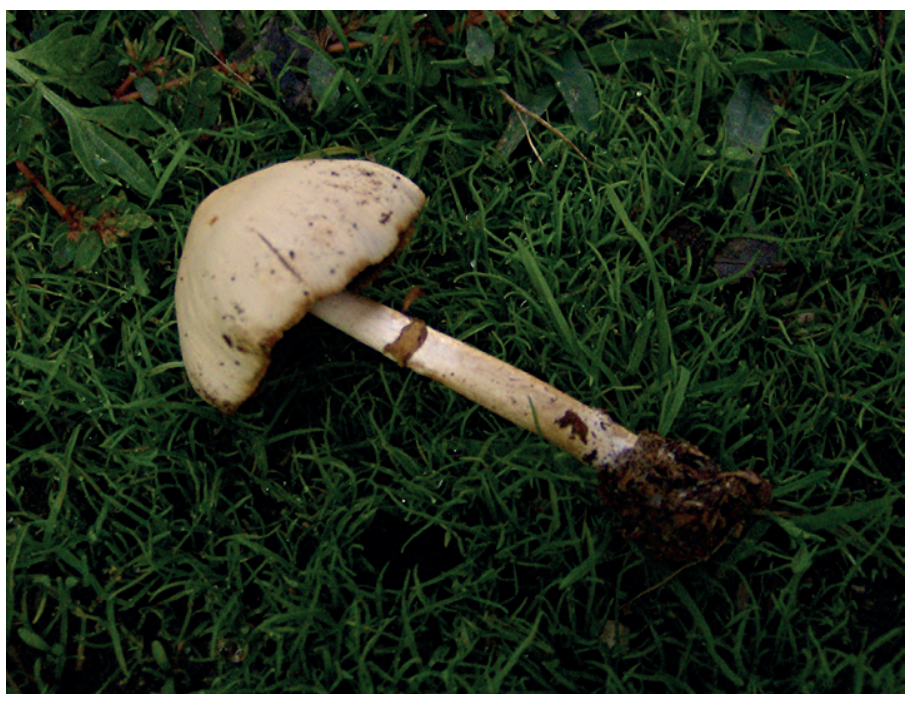

Fig. 24. Psathyrella albescens. MCVE29113. Photo P. Voto.

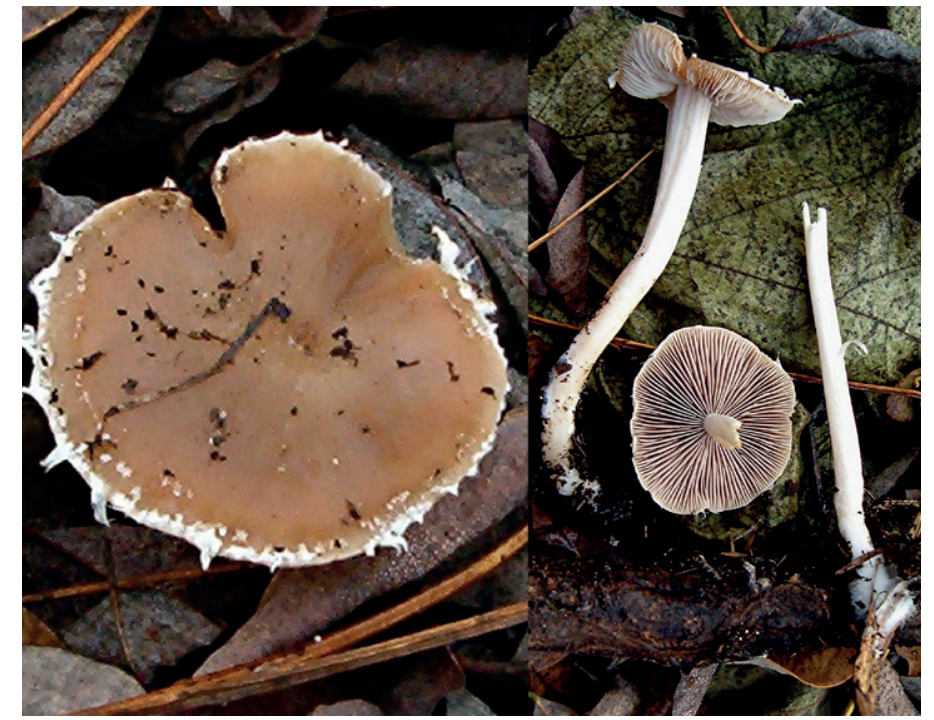

Fig. 26. Psathyrella albescens. MCVE29107. Photo P. Voto.

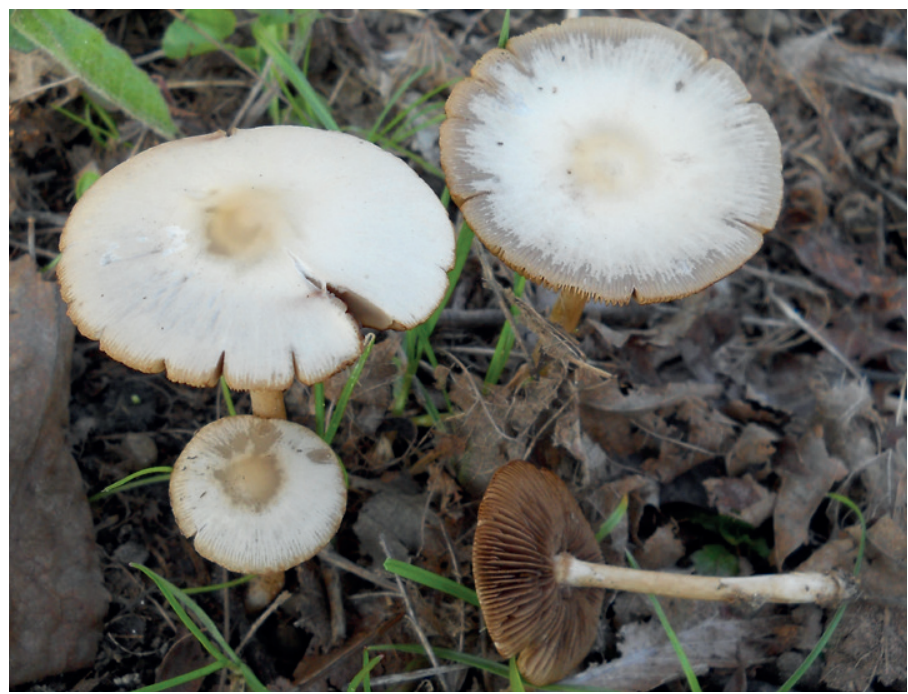

Fig. 28. Psathyrella albescens. Voto 20160313. Photo P. Voto. 


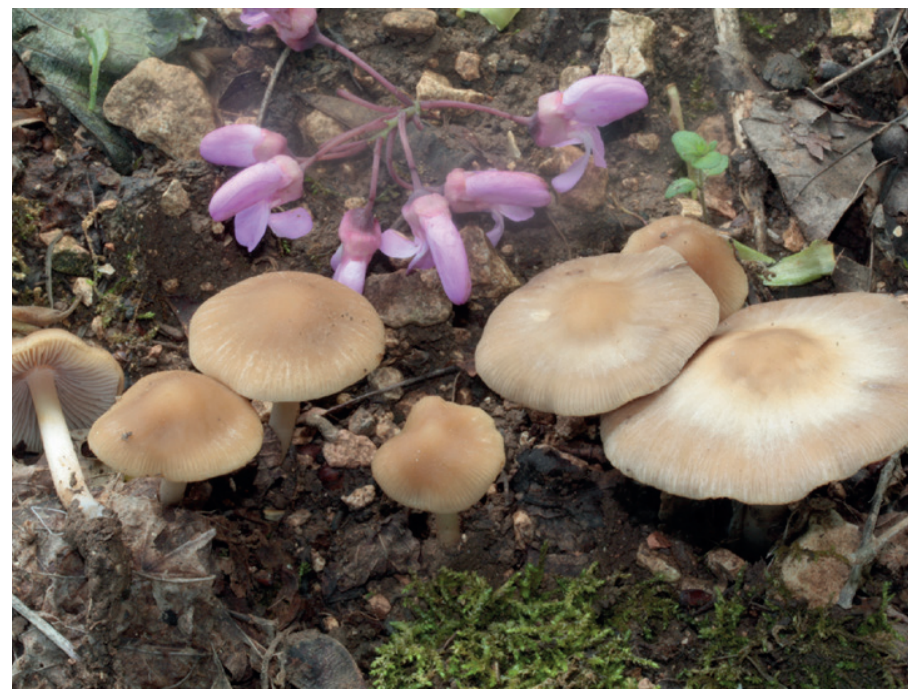

Fig. 29. Psathyrella albescens. MCVE29116. Photo M. Maletti.

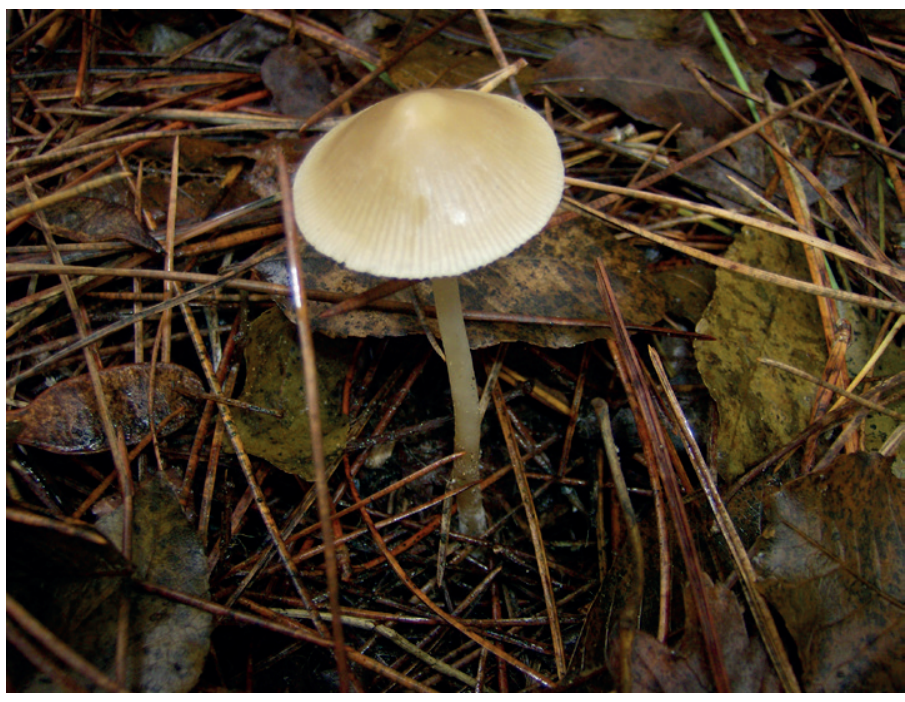

Fig. 30. Psathyrella albescens. MCVE29111. Photo P. Voto.
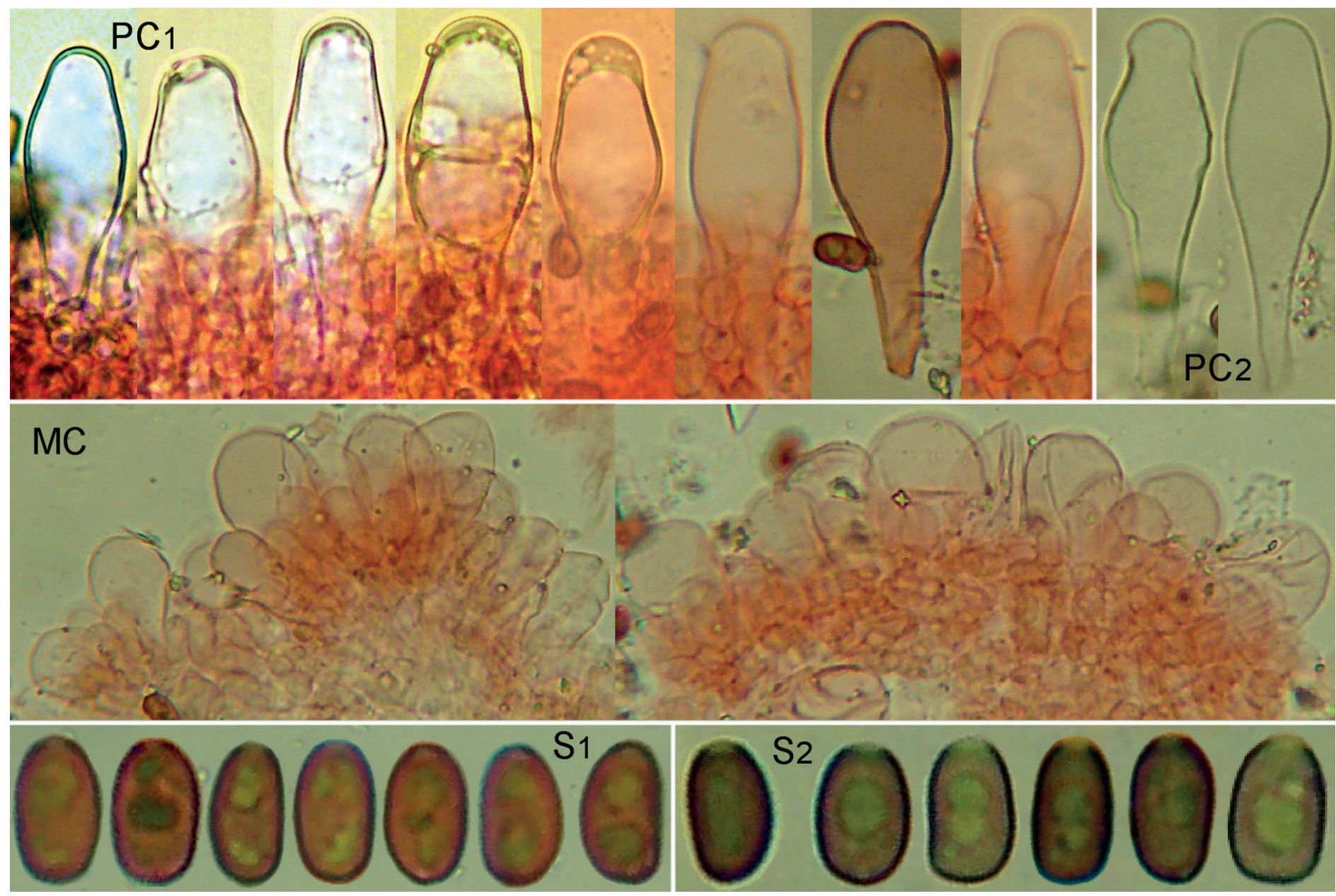

Fig. 31. Psathyrella albescens. P. Voto, MCVE29113; PC1 Pleurocystidia in Congo red; PC2 Pleurocystidia in $\mathrm{NH}_{4} \mathrm{OH}$; MC Marginal Cystidia; S1 Spores in water; $\mathrm{S} 2$ Spores in $\mathrm{KOH}$.

yellowish to brownish pigmented; very numerous, dominating. Cells below marginal cystidia sometimes incrusted, sometimes locally yellowish pigmented. Clamps present.

Habitat: Solitary to gregarious or subcespitose; on woody debris, in leaves, in grass, on sandy humus; in parks, at margin of woods or in wood clearings or in wood paths, in pastures, at roadsides.

Collections examined from MICH: Psathyrella agrariella sensu Smith, Smith 25099 and McKnight F949; Psathyrella albescens Hesler \& A.H. Sm., holotype, Hesler 18895; Psathyrella mazzeri A.H. Sm., holotype, Mazzer 6023. 
Other material examined: Italy, Belluno, Nevegal, about 1000 m a.s.I., gregarious on debris at margin of forest, 24 Sep. 2010, P. Voto, Figs 23, 24, 31 (MCVE29113, Tef-1a MF521819, ITS MF325954); Rovigo, Sant'Apollinare, $6 \mathrm{~m}$ a.s.I., 18 Nov. 2006, gregarious by a roadside among litter of brambles and Robinia pseudoacacia, P. Voto, Figs 25-27 (MCVE29107, Tef-1a MF521821, ITS MF326009); Rovigo, Crespino, 3 $\mathrm{m}$ a.s.I., solitary in a park, 31 Oct. 2006, P. Voto (MCVE29106, Tef-1 $\alpha$ MF521822, ITS MF325953); Rovigo, Villadose, $3 \mathrm{~m}$ a.s.l., gregarious in a park under Tilia platyphyllos, 13 Mar. 2016, P. Voto 20160313, Fig. 28; (Pesaro Urbino, Monti delle Cesane, botanical garden, gregarious among hardwood trees, 29 Apr. 2012, M. Maletti, Fig. 29 (MCVE29116, Tef-1 $\alpha$ MF521818, ITS MF325955 ); Venezia, Chioggia, S. Anna, Nordio forest, 2 m a.s.l., 12 Dec. 2007, solitary on humus of Quercus ilex, P. Voto, Fig. 30 (MCVE29111, Tef-1 $\alpha$ MF521820); at same location, 31 Oct. 2011, gregarious on woody debris, P. Voto 20111031.1; at same location, 5 Nov. 2015, gregarious on woody debris, P. Voto (MCVE29332).

Notes: Psathyrella albescens is difficult to distinguish from $P$. spadiceogrisea based on micro morphological characters. We cite the occurrence of two traits: possibly capitate pleurocystidia that are absent or seldom found in $P$. spadiceogrisea, and spores with a greater tendency to be phaseoliform or indented above the apiculus. More consistent differences can be found in the gross morphology and are listed below. The young pilei of $P$. spadiceogrisea have a reddish brown (in agreement with Schäffer's, 1771 table nr. 237) to dark reddish brown or violaceous brown color, often retained until maturity, while $P$. albescens pilei are at most dark yellowish brown at first, and quickly become discolored to brownish orange, never attaining a dark brown or reddish tint. Furthermore, the discoloring pilei of $P$. spadiceogrisea usually fade to cream or alutaceous tints, while those of $P$. albescens usually fade to white. The veil of $P$. spadiceogrisea is fugacious and conspicuously located on the margin of the pileus where it is usually no longer present in mature sporocarps (in agreement with Schäffer's, 1774 description of 'velo et annulo destitutus'), rarely and exclusively in early stages of development it is in form of appendiculate flocci. Conversely, in favorable climatic conditions, the veil of $P$. albescens can be still appendiculate from the margin of the pileus or folded back on the gills or, rarely, annulate on the stipe in mature sporocarps. Often, $P$. albescens has a stipe base that is more or less swollen and can be subrooting or characterized by a pseudorhiza up to $50 \mathrm{~mm}$ long. Conversely, this trait is not reported by Schäffer (1774) for $P$. spadiceogrisea, which has a stipe base at most slightly attenuated. Finally, $P$. spadiceogrisea is only found on woody material, while $P$. albescens can also be found in grasslands.

The features that can differentiate $P$. albescens from $P$. fatua are slight and often they can do so only partially. The first has a veil at times still appendiculate or folded back on the gills, rarely annular, in mature specimens, while the second has a quickly evanescent veil on the margin. The first species has a discoloring pileus without distinct pinkish shades, at most and rarely pinkish buff, and with a disk never attaining vivid colors: at most it may only have a dull ochraceous tint. The second species has discoloring pilei that may attain pinkish shades on the margin, and vivid yellow tints on the disk. The gill edge is not pigmented in the first species, but it can be red in the second. Pleurocystidia can be brownish, forked, or incrusted in the first, while in the second they are never brownish, and rarely forked or weakly incrusted. Spores of $P$. albescens are orange-brown to orangish reddish brown and often phaseoliform to indented above the apiculus, while those of $P$. fatua are brown to dark red, rarely phaseoliform or indented above the apiculus, sometimes subphaseoliform.
We expect this species to be present in herbaria of European mycologists under the different names $P$. fatua, $P$. pseudocorrugis sensu Kits van Wav., P. niveobadia, and $P$. spadiceogrisea.

Based on our evaluation, at least one voucher determined as $P$. agrariella by Smith is actually $P$. albescens, thus rendering Smith's concept of $P$. agrariella dubious (see descriptions of Smith 25099 and Mc Knight F949 below).

11a. Psathyrella albescens Hesler \& A.H. Sm., Mem. N. Y. Bot. Gard. 24: 133. 1972. Fig. 32.

Typus: Psathyrella albescens Hesler \& A.H. Sm. USA, Tennessee, Knox, Farragut, 20.II.1949, L. R. Hesler 18895 (MICH11863), on decaying chip pile. Tef-1 $\alpha$ MF521817.

Loan of a portion of pileus in good condition for micromorphology investigation.

Spores 6.7-8.5(-10) × 3.7-4.4(-4.9) $\mu \mathrm{m}, \mathrm{Q}(1.4-) 1.6-2(-2.3)$, avQ 1.88; in front view oblong to elliptic, sometimes irregular, sometimes obscurely narrowly oboval or with median constriction, rarely angular-oval, base rounded, sometimes more or less truncate, in profile adaxially flattened to subphaseoliform, sometimes indented above the apiculus; orange-brown to orangish reddish brown; germ pore distinct, mostly more or less truncate, about 1.6-1.7 $\mu \mathrm{m}$ broad. Pleurocystidia 35-52 $\times$ 13-17 $\mu \mathrm{m}$, utriform, sometimes subcylindrical, ellipsoidrhomboid; apex rounded to obtuse, sometimes subcapitate, forked or incrusted; walls sometimes thickened and pigmented; numerous. Cheilocystidia small, scattered. Paracystidia 8-48 $\times 6.5-28 \mu \mathrm{m}$, often with yellowish incrustations, walls often thickened, numerous, dominating. Cells below marginal cystidia conspicuously incrusted.

11b. Psathyrella mazzeri A.H. Sm., Mem. N. Y. Bot. Gard. 24: 356. 1972. Fig. 33.

Typus: Psathyrella mazzeri A.H. Sm. USA, Michigan, Allegan Co., Vivian Baker Farm near Otsego, 16 May 1970, S.J. Mazzer 6023 (MICH11963), scattered to gregarious in open pasture with Phleum pratense and Dactylis glomerata. Tef-1 $\alpha$ MF521790, ITS MF325981.

Loan of two sporocarps in good condition for micro-morphology investigation.

Spores 6.8-9.3(-10) × 3.8-5.2(-5.5) $\mu \mathrm{m}, \mathrm{Q}(1.45-) 1.65-1.9(-$ 2.1), avQ 1.79; in front view elliptic, oblong to narrowly oval, rarely oval to subangular-oval, base rounded, rarely truncate, in profile subphaseoliform to adaxially flattened, sometimes phaseoliform to indented above the apiculus; orange-brown; germ pore distinct, mostly more or less truncate, more or less 1.7-1.8 $\mu \mathrm{m}$ broad. Pleurocystidia 32-51 × 10-16 $\mu \mathrm{m}$; utriform, rarely lageniform; apex rounded, often subcapitate; incrustations and pigment not seen; more or less numerous. Cheilocystidia

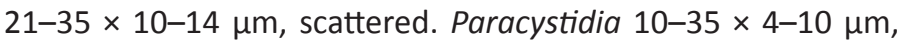
moderately incrusted, walls hyaline, numerous, dominating. Cells below marginal cystidia hyaline, moderately incrusted.

12. Psathyrella agrariella (G.F. Atk.) A.H. Sm., Mem. N. Y. Bot. Gard. 24: 411. 1972. 

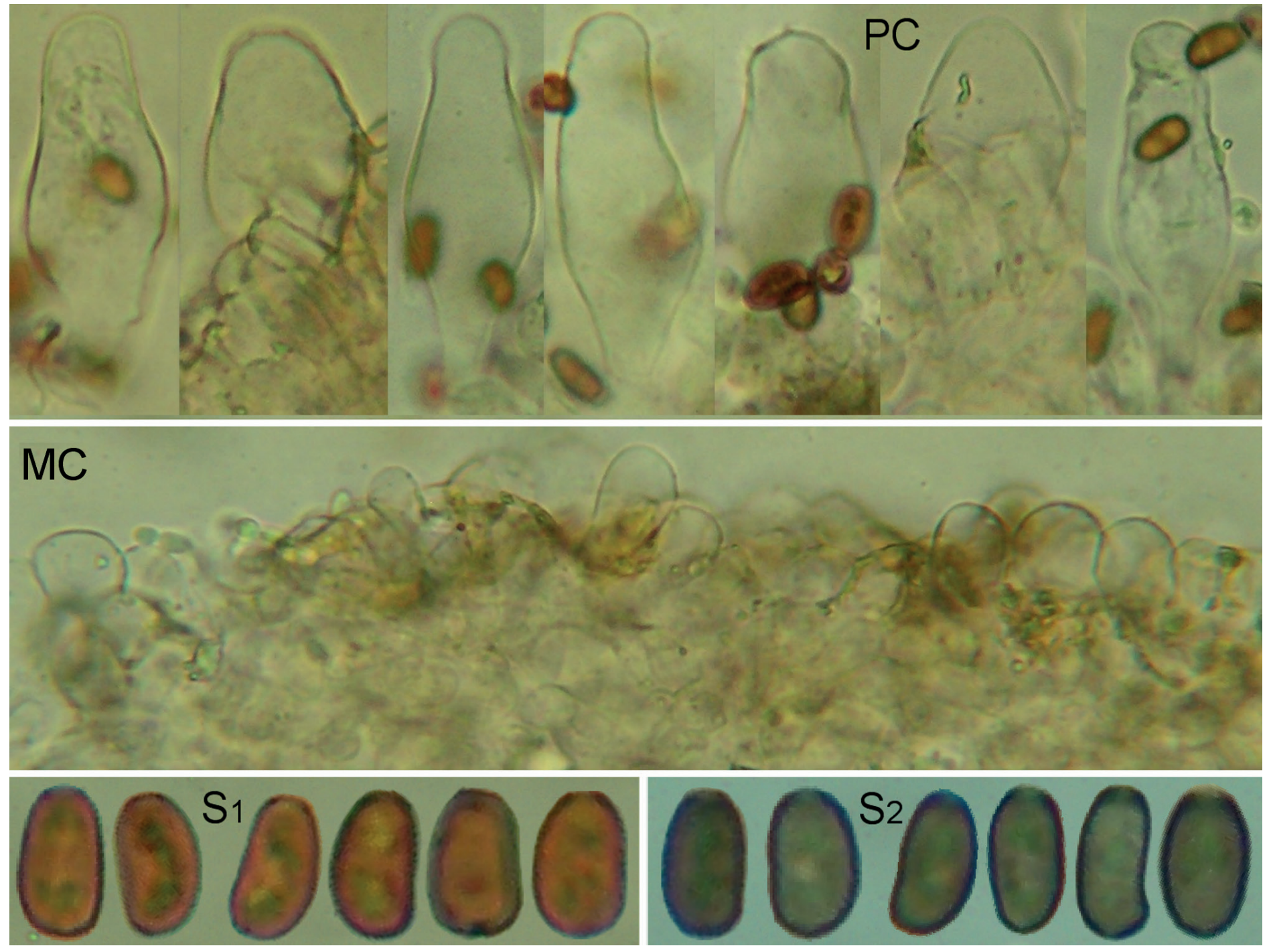

Fig. 32. Psathyrella albescens. L.R. Hesler 18895, MICH11863; MC Marginal Cystidia in $\mathrm{KOH}$; PC Pleurocystidia in $\mathrm{NH}_{4} \mathrm{OH}$; $\mathrm{S} 1 \mathrm{Spores}$ in water; $\mathrm{S} 2 \mathrm{Spores}$ in $\mathrm{KOH}$.

Smith (1972) transferred Psilocybe agrariella to Psathyrella but, apparently, without personally revising the original material; in fact among the material examined he indicated only a number of other collections that he deemed to represent that species. $\mathrm{MICH}$ staff has provided us with three of those vouchers and they have come out to represent at least two different taxa. Smith 28713 has dominating cheilocystidia, and molecularly is close to $P$. seminuda and clearly out of subsection Spadiceogriseae. Smith 25099 has dominating paracystidia and matches $P$. albescens both in morphology and DNA sequence. McKnight F949 also resembles $P$. albescens based on macro and micro-morphology, but the molecular evidence based only on the ITS sequence is inconclusive.

In Atkinson's basionym description of Psilocybe agrariella, the pileus is pale reddish brown to pale rufous, the stipe is concolorous to the pileus at the base, the carpophores dimension is small, and the pleurocystidia are defined lanceolate to subventricose. These parameters above are shared with P. agrariella var. ochrofulva. The cheilocystidia are described as broadly ventricose and shorter than the pleurocystidia, sometimes very broad and bluntly mucronate: therefore it is unclear whether true paracystidia are present or not, although clavate to pyriform cells are reported at stipe apex intermixed with pleurocystidioid cells. We conclude that the true identity of Psilocybe agrariella remains dubious until the holotype is morphologically revised and sequenced. We also suggest that Smith's concept of Psathyrella agrariella should be rejected both because of Smith's vague description of the gill edge cystidia, which are reported as broadly ventricose, mucronate or saccate, without an indication of the ratio between them, and because of the lack of homogeneity in his vouchers.

\section{2a. Smith 25099, MICH47933.}

\section{= Psathyrella albescens Hesler \& A.H. Sm.}

USA, Michigan, Oakland Co., Proud Lake, 26 May 1947, coll. Lange \& Smith, on sandy humus. Tef-1 $\alpha$ MF521824. ITS MF326008.

Loan of a dozen and more sporocarps in good condition for micro-morphology investigation.

Spores 6.3-9.1 × 4-5.2 $\mu \mathrm{m}, \mathrm{Q}$ 1.5-1.8, avQ 1.7; in front view elliptic to oval or angular-oval, sometimes subtriangular, irregular, base generally truncate, in profile subphaseoliform to adaxially flattened; orange-brown, rarely orangish reddish brown; germ pore distinct, $\pm 1.5 \mu \mathrm{m}$ broad. Pleurocystidia $28-50$ $\times 10.5-16.5 \mu \mathrm{m}$; utriform; apex obtuse to rounded, sometimes 


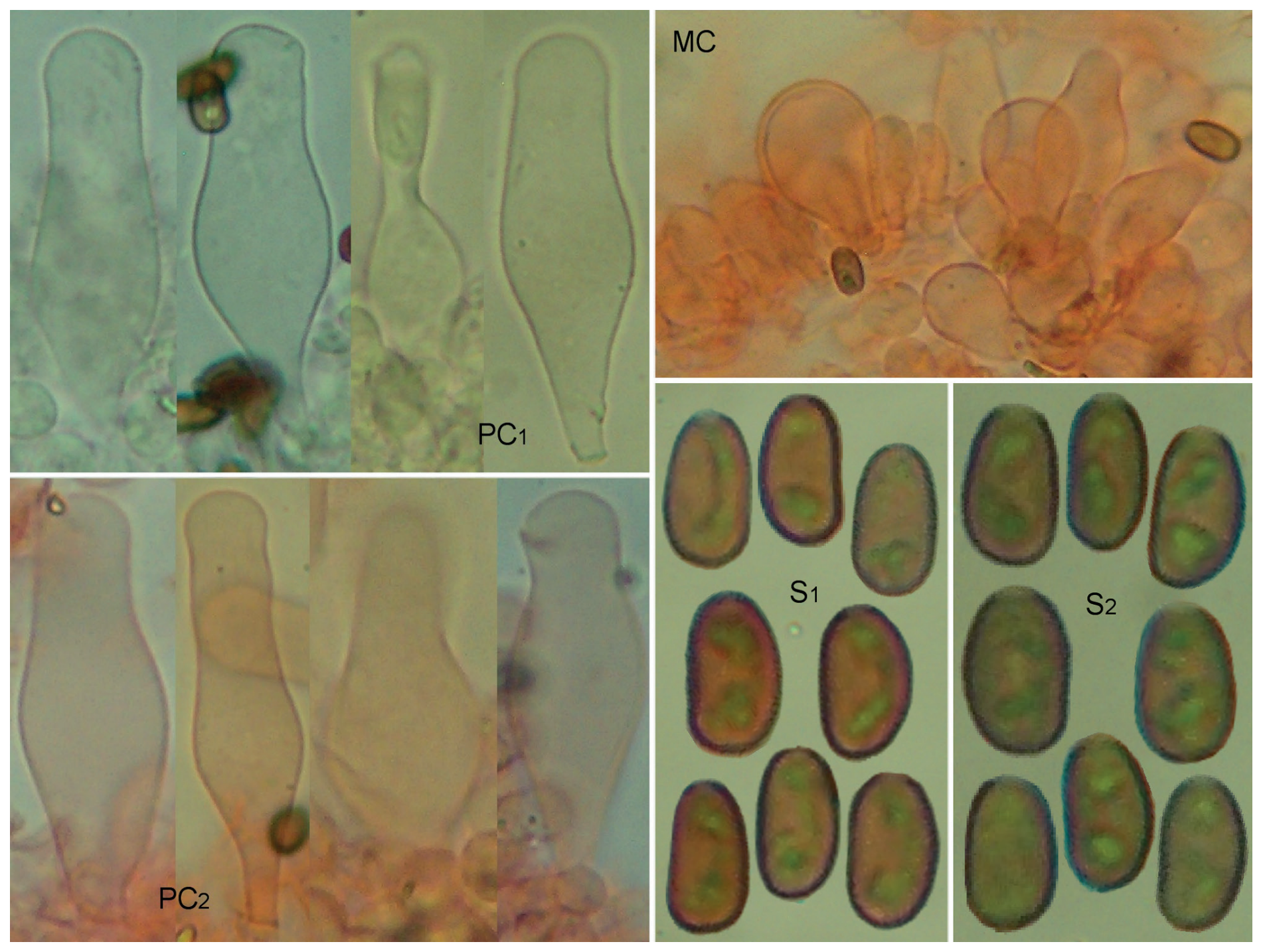

Fig. 33. Psathyrella mazzeri. S.J. Mazzer 6023, MICH11963; PC1 Pleurocystidia in $\mathrm{NH}_{4} \mathrm{OH}$; PC2 Pleurocystidia in Congo red; MC Marginal Cystidia in Congo red; S1 Spores in water; S2 Spores in $\mathrm{KOH}$.

or often subcapitate, sometimes forked, sometimes incrusted, walls hyaline or almost so; moderately numerous. Cheilocystidia 27-37 × 11.5-18 $\mu \mathrm{m}$, moderately numerous. Paracystidia -30 $x-22 \mu \mathrm{m}$, often incrusted, numerous, dominating. Cells below marginal cystidia hyaline or almost so.

Notes: The material received was composed of solitary to clustered sporocarps with stipes progressively slightly broadened towards the base and at that point bent and attached to woody debris; in many pilei the margin had a greyish tint. ITS and Tef-1 $\alpha$ sequences put it in synonymy with $P$. albescens, the morphology is coherent with this result.

\section{2b. Mc Knight F949, MICH65241}

\section{?= Psathyrella albescens Hesler \& A.H. Sm.}

USA, Utah, Duchesne Co., two miles south of Moon Lake, 9 Jul. 1955, coll. K.H. Mc Knight \& R. Duke, in moist soil and moss under Salix. ITS MF325951.

Loan of numerous sporocarps in good condition for micromorphology investigation.
The notes from the collector report the following: pileus 1.5-5.5 $\mathrm{cm}$ across, buffy brown to bistre when moist and a fibrillose annulus; in the exsiccata, we saw long stipes, up to $90 \times 3 \mathrm{~mm}$, and distinct fibrillose veil remains at the stipe apex.

Spores 7-10.1(-12) × 4.4-5.4(-5.7) $\mu \mathrm{m}, \mathrm{Q}$ 1.5-2.1(-2.3), avQ 1.76-1.86; in front view elliptic to oval, sometimes irregular, base rounded to truncate, in profile subphaseoliform to adaxially flattened, sometimes subamygdaliform; orangebrown to orangish reddish brown; germ pore distinct, round to rarely truncate, $1.5-1.8 \mu \mathrm{m}$ broad. Pleurocystidia $34-53 \times$ 7.7-11.5 $\mu \mathrm{m}$; utriform, subcylindrical, sometimes cylindrical, flexuous; apex 6-12 $\mu \mathrm{m}$ broad, rounded to more or less truncate, sometimes or often subcapitate, often forked, often incrusted, walls often slightly thickened, sometimes pigmented; numerous. Cheilocystidia 30-45 × 9.5-11 $\mu \mathrm{m}$, scattered to sometimes somewhat clustered. Paracystidia $-32 \times-17 \mu \mathrm{m}$, often pigmented, hardly incrusted, numerous, dominating. Cells below marginal cystidia locally slightly pigmented.

Notes: The ITS sequence of this voucher has a high homology with sequences of the various $P$. albescens collections, but its homology is even higher with the sequence of $P$. agrariella var. 
ochrofulva. Although we lack here the corroborating evidence of a second locus, the micro morphological traits are very similar to those of $P$. albescens, and the possible presence of an annulus is already demonstrated for that species by our Italian material MCVE29113. Moreover, the bistre color of the fresh pileus corresponds to the dark yellow brown color described for $P$. albescens by Smith.

12c. A.H. Smith 28713, MICH47939.

$=$ ?

USA, Michigan, Washtenaw Co., Dexter, 18.V.1948, on sawdust pile. ITS MF325950.

Loan for micro-morphology investigation of numerous sporocarps in good condition.

Spores (7.2-)7.5-8.7(-9) × 4.2-5 $\mu \mathrm{m}, \mathrm{Q}$ 1.6-2, avQ 1.71.8; in front view elliptic, sometimes oval, base obtuse, in profile adaxially flattened to subamygdaloid, sometimes subphaseoliform; reddish to brownish red; germ pore generally distinct, generally truncate, sometimes eccentric in profile, $\pm 1.5 \mu \mathrm{m}$ broad. Pleurocystidia 27-52 × 9-15 $\mu \mathrm{m}$; utriform, sublageniform, sometimes subcylindrical; apex obtuse to rarely rounded, (4-)5-7(-10) $\mu \mathrm{m}$ broad, rarely subcapitate, rarely forked, often incrusted; numerous. Cheilocystidia (20-)23-34(-
$45) \times 7-11(-13) \mu \mathrm{m}$, numerous, inconspicuously (because small and often recurved to repent) dominating. Paracystidia 11-25($30) \times 6-11(-15) \mu \mathrm{m}$, often incrusted, walls yellowish pigmented, numerous. Cells below marginal cystidia forming a yellowish discontinuous band approximately $25 \mu \mathrm{m}$ broad towards the stipe, becoming pale fulvous and up to approximately $100 \mu \mathrm{m}$ in width towards the pileus margin, generally not incrusted.

Notes: The material received was composed of solitary to clustered sporocarps with most stipes progressively slightly broadened towards base and there attached to woody debris; the pilei had a greyish to greyish violaceous margin; most gills had a purplish edge partly visible by a lens. The phylogenetic evidence places this material very close to $P$. seminuda (DNA nucleotide homology: ITS= $99 \%$ with a single mismatch) but we have found some morphological divergences, such as narrower, terete spores, distinctly smaller pleuro- and cheilocystidia and the presence of numerous, though small, paracystidia not cited for $P$. seminuda. As for the slightly pigmented gill edge it is to be noticed that $P$. seminuda is described with cheilocystidia often rusty brownish colored.

13. Psathyrella ochrofulva (A.H. Sm.) Voto, Dovana \& Garbel, comb. nov. MycoBank MB831128.

Basionym: Psathyrella agrariella var. ochrofulva A.H. Sm., Mem. N. Y. Bot. Gard. 24: 411. 1972. A.H. Smith 33628, MICH11858. Fig. 34.
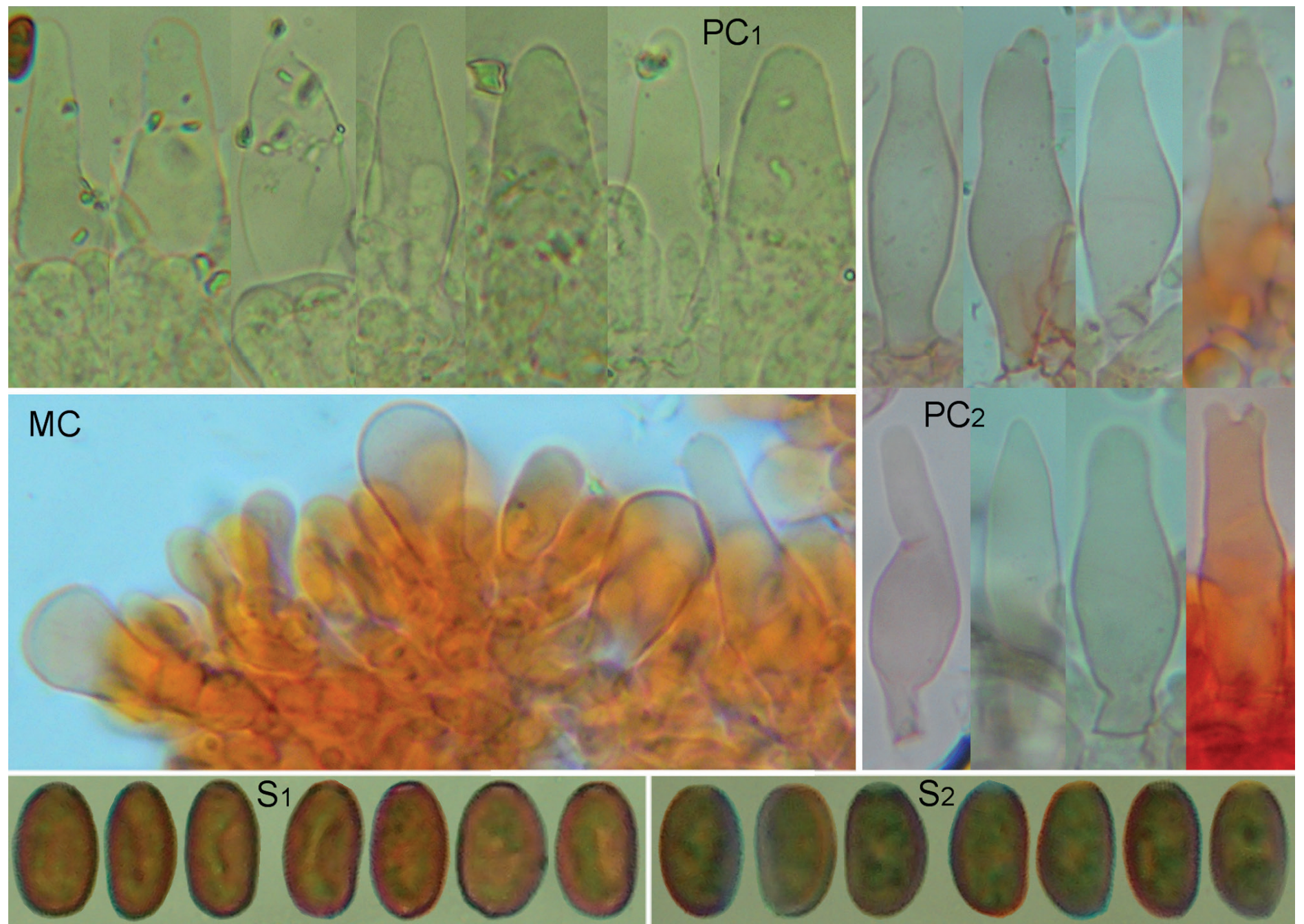

Fig. 34. Psathyrella ochrofulva. A.H. Smith 33628, MICH11858; PC1 Pleurocystidia in $\mathrm{NH}_{4} \mathrm{OH}$; PC2 Pleurocystidia in Congo red; MC Marginal Cystidia in Congo red; S1 Spores in water; S2 Spores in $\mathrm{KOH}$. 
Typus: Psathyrella agrariella var. ochrofulva A.H. Sm. USA, Michigan, Cheboygan Co., Colonial Point Hardwoods near Burt Lake, 13 Sep. 1949, A.H. Smith 33628 (MICH11858), gregarious on sandy humus in cut-over hardwoods. ITS MF325987.

Loan of one pileus in good condition for micro-morphology investigation.

Spores (7.5-)8-10.1 × 4.5-5.6(-6) $\mu \mathrm{m}[7-9(-10) \times 3.8-4.5(-5)$ $\mu \mathrm{m}$ in Smith, 1972], on average $9 \times 5-5.3 \mu \mathrm{m}, \mathrm{Q} 1.4-2.2$, avQ 1.7-1.8; in front view elliptic to oval, sometimes cylindrical, base rounded to truncate, in profile adaxially flattened to subelliptic, sometimes subphaseoliform; reddish brownish; germ pore distinct, rounded to subtruncate, about 1.4-1.8(-2) $\mu \mathrm{m}$ broad. Pleurocystidia 30-50(-53) $\times 11-17 \mu \mathrm{m}$, the smaller ones towards gill edge; utriform, conical, fusiform, lageniform, sometimes ellipsoid, subcylindrical, submucronate; apex obtuse, sometimes rounded or subacute, sometimes forked or truncate, sometimes incrusted, walls sometimes slightly pigmented; moderately numerous. Cheilocystidia 23-36 × 11$13 \mu \mathrm{m}$, inconspicuous, scattered. Paracystidia 9-30 × 4.5-16 $\mu \mathrm{m}$, sometimes incrusted, walls sometimes or often slightly thickened and yellowish pigmented, numerous, dominating. Cells below marginal cystidia with pale pigment, incrusted.

Notes: The ITS sequence places this taxon as an immediate relative of $P$. albescens, but this sample has very variable pleurocystidia, and, in accordance with Smith's description, a relevant number of them are subfusiform, progressively attenuate towards the apex, resulting in an undifferentiated transition between the ventricose and the apical part. This is a pattern not usually found in $P$. albescens. Moreover, differently from $P$. albescens, we have only found some subphaseoliform spores, none distinctly phaseoliform or indented above the apiculus. The pileus is yellowish fulvous when young, and dull reddish cinnamon when mature, but red pigmentation in the pileus of $P$. albescens is currently unknown. Given that we have demonstrated how Smith's concept of $P$. agrariella var. agrariella is not univocal, we believe $P$. ochrofulva stands alone as an autonomous species.

Psathyrella lactobrunnescens, described only from the type collection on hardwood debris, is a species that could not be loaned for scarcity of material. Judging from its description, it belongs to subsection Spadiceogriseae, and, based on a provisional morphological analysis, it resembles $P$. ochrofulva, with whom it shares some peculiar characters such as little differentiated, apically attenuate and never capitate pleurocystidia; small and fragile sporocarps; and pigmented paracystidia. On the contrary, its pilei are described as conical and hardly expanding, while they are obtuse to convex or plane in $P$. ochrofulva. The chromatic evolution of the pileus, initially white and striate, then greyish brown, and finally faded white again, is unusual and may suggest an albino form.

14. Psathyrella fatua (Fr.) Konrad \& Maubl., Encycl. mycol. 14 (Agaricales 1): 125. 1948. Figs 35-43.

Pileus 8-52(-62) mm broad, in early stages broadly conical to paraboloid, then expanding to convex, finally plane, with straight to reflexed margin, subumbonate or not, sometimes rugulose to wavy in old sporocarps; when young reddish brown, when mature already discolored through brown to ochraceous brown,

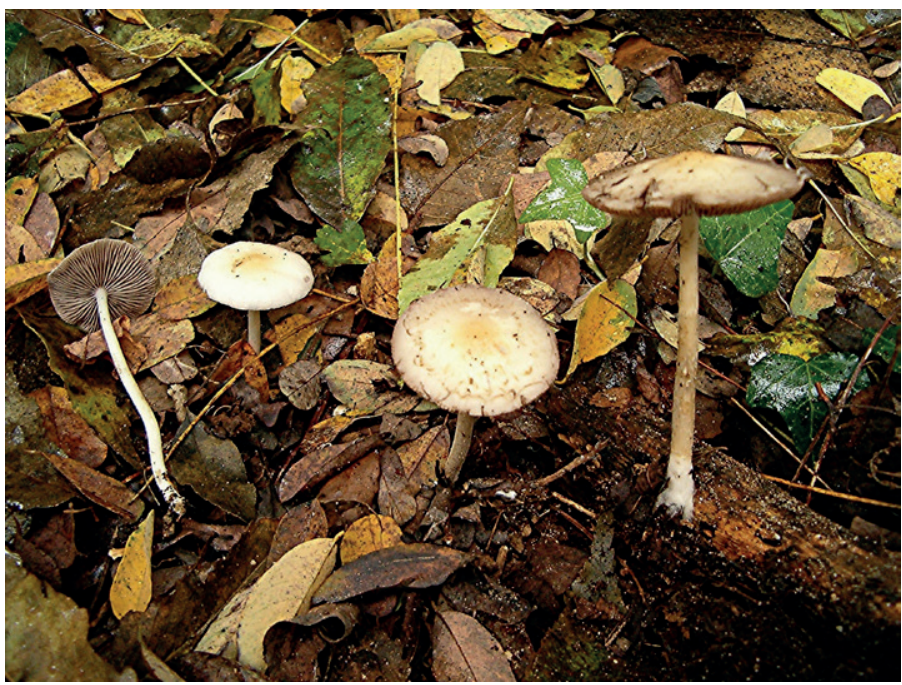

Fig. 35. Psathyrella fatua. MCVE29105. Photo P. Voto.

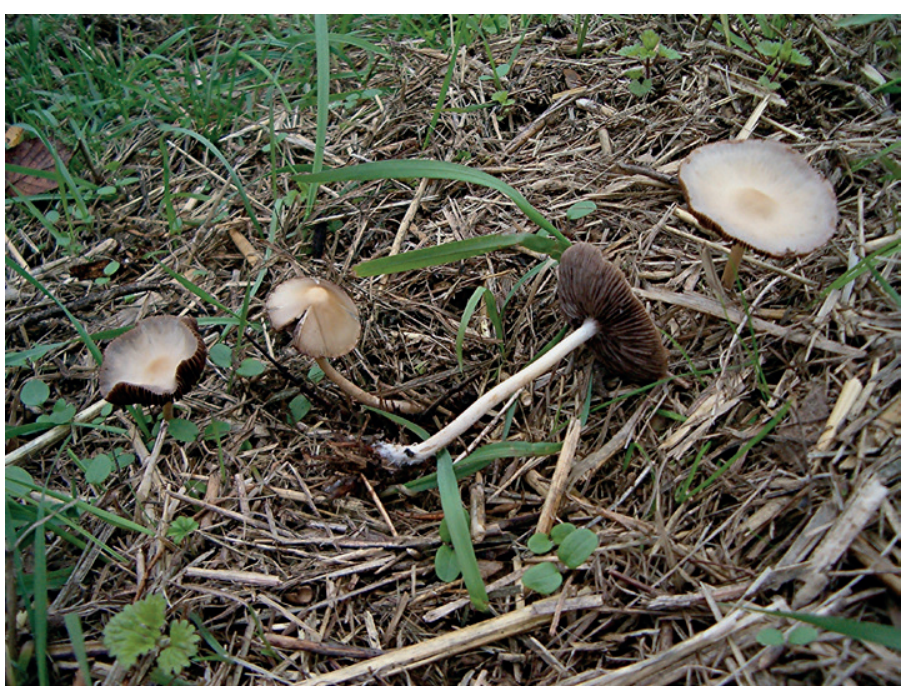

Fig. 36. Psathyrella fatua. MCVE29109. Photo P. Voto.

yellowish brown, brownish orange, pale to medium Dresden brown, pale pinkish chestnut brown, yellow red, sometimes shiny, hygrophanous, quickly fading to whitish, cream, alutaceous, pale to rich pink, pale greyish to pinkish violaceous, with centre pale greyish ochraceous, pale ochraceous, yellowish to vivid yellow, whitish, pale pinkish ochre, finally drying from margin to greyish violaceous; translucently striate when moist. Veil white, quickly evanescent, when young of flocci or fibrils on stipe (mainly on lower half) and on the margin of the pileus or appendiculate from it. Lamellae broadly adnate and usually with a subdecurrent tooth, moderately broad, not or slightly ventricose, crowded to moderately crowded; when young clay to pale brownish grey, then through pinkish clay, lilaceous greybrown or purplish grey to finally dark purplish brown; edge white, sometimes reddish brownish pigmented. Stipe (10-) 20-110(-125) × (1-)2-5.5(-7) mm, straight to flexuous, equal to slightly progressively broadened towards base, sometimes bent towards base, extreme base sometimes attenuate or characterized by a pseudorhiza; white, sometimes discoloring pale brownish; apex pruinose and sometimes striate, base sometimes felted to substrigose. Context rather rigid in the stipe that usually snaps when bent, whitish to pale, sometimes more 


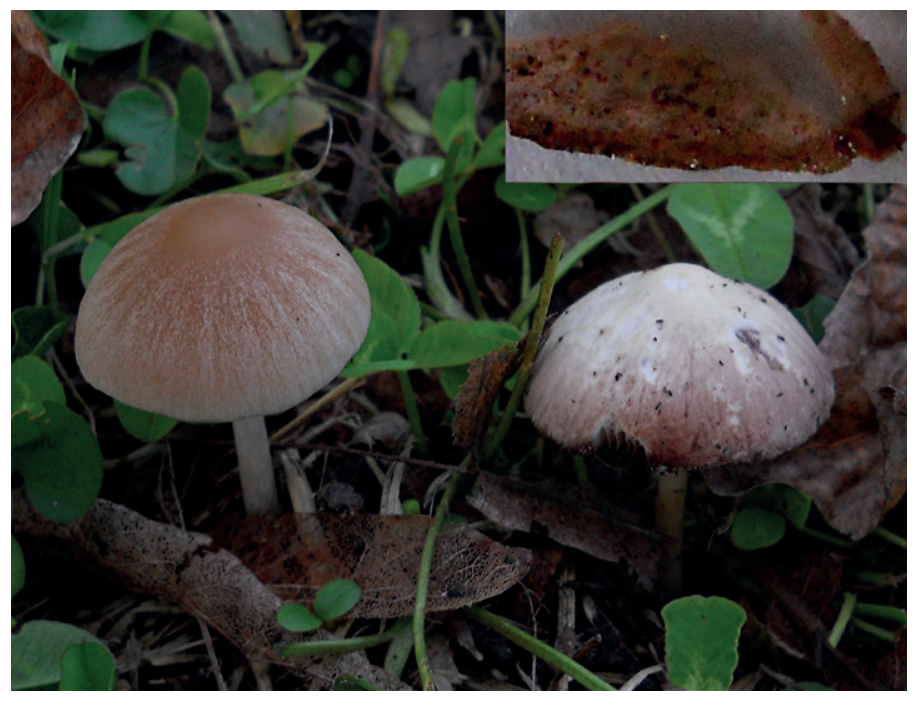

Fig. 37. Psathyrella fatua. MCVE29122. Photo P. Voto.

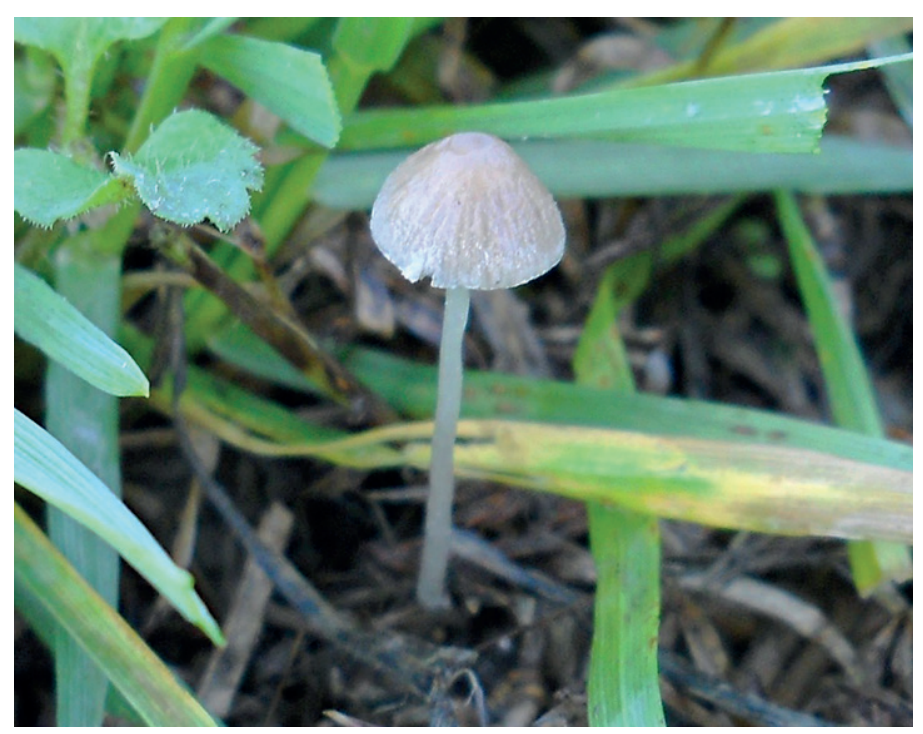

Fig. 39. Psathyrella fatua. MCVE29124. Photo P. Voto.

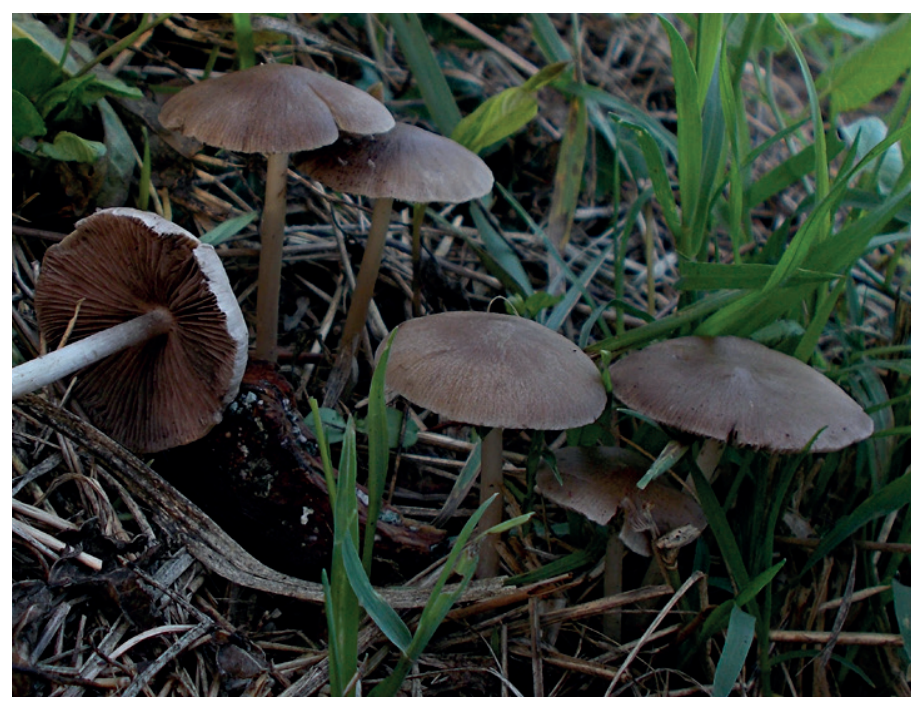

Fig. 41. Psathyrella fatua. Voto 20181105.2. Photo P. Voto.

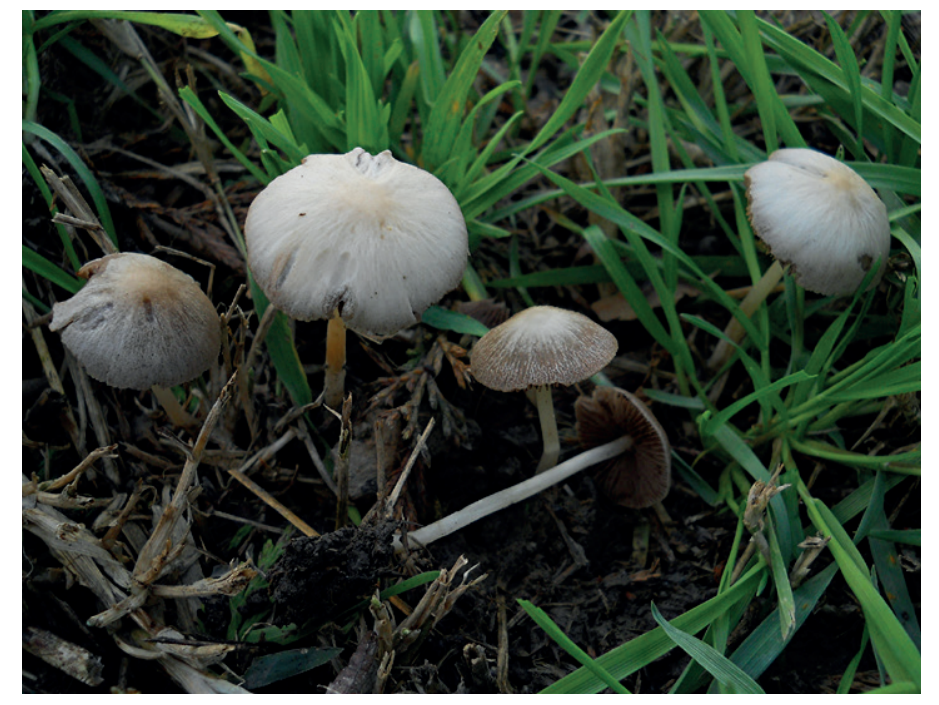

Fig. 38. Psathyrella fatua. MCVE29124. Photo P. Voto.

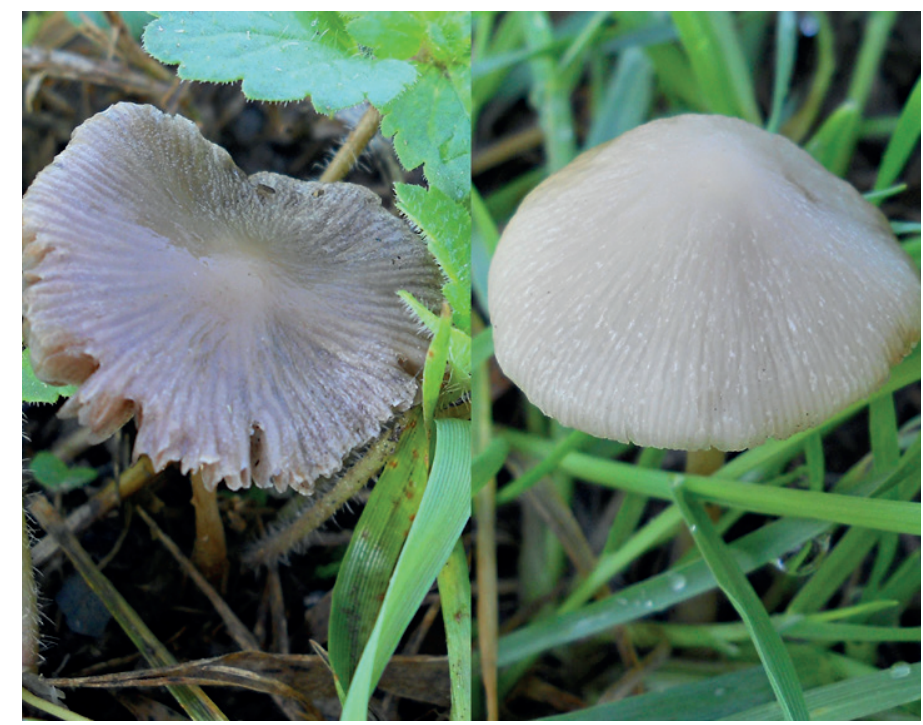

Fig. 40. Psathyrella fatua. MCVE29124. Photo P. Voto.

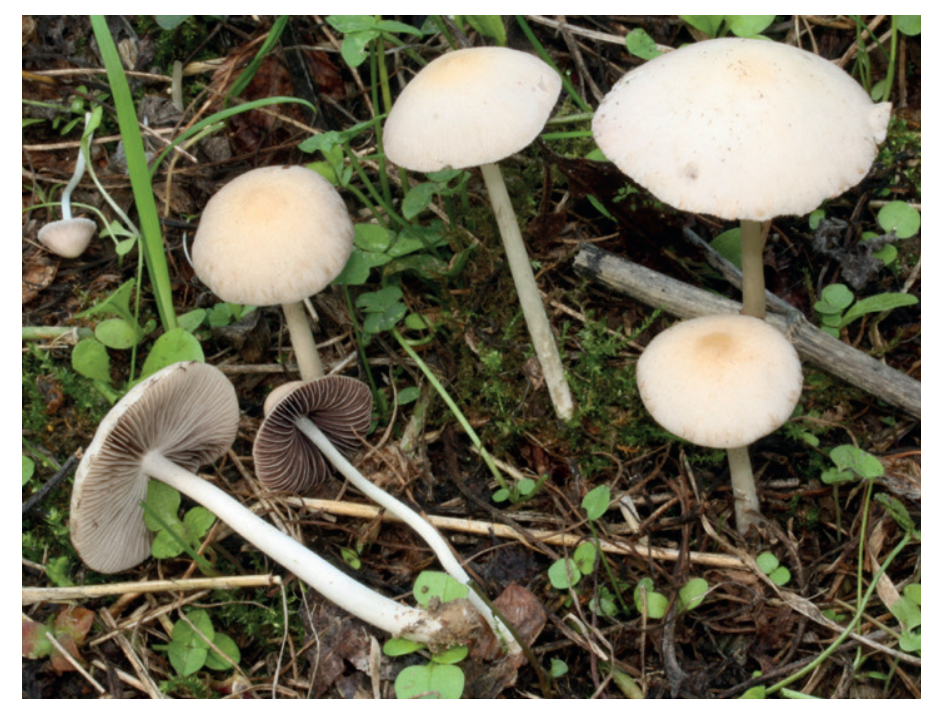

Fig. 42. Psathyrella fatua. MCVE29115. Photo M. Maletti. 


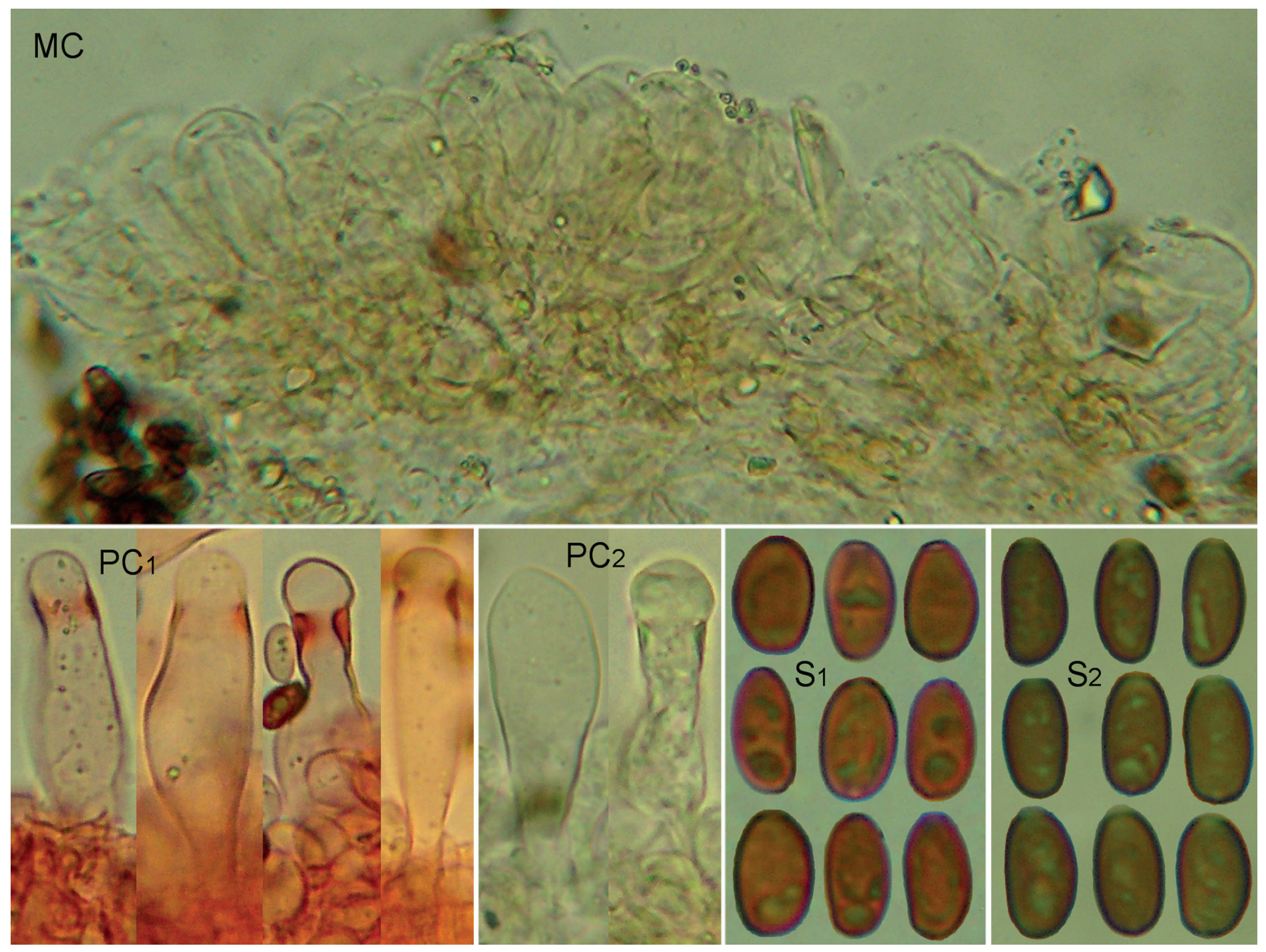

Fig. 43. Psathyrella fatua. Voto, MCVE29109; MC Marginal Cystidia in KOH; PC1 Pleurocystidia in Congo red; PC2 Pleurocystidia in NH${ }_{4} \mathrm{OH}$; $\mathrm{S} 1$ Spores in water; S2 Spores in $\mathrm{KOH}$.

pigmented in stipe base. Odor and taste indistinctive. Spore deposit purplish black. Spores (6.3-)6.8-10.5(-11.7) $\times$ 4-5.6 $\mu \mathrm{m}$, on average 7.7-9 × 4.5-5.2 $\mu \mathrm{m}, \mathrm{Q}(1.4-) 1.5-2.2(-2.3)$, avQ 1.6-2; in front view elliptic, oval, oblong, subcylindrical, sometimes irregular, rarely angular-oval to cylindrical-oboval, base truncate, rounded to obtuse, in profile adaxially flattened to subamygdaliform, rarely or sometimes subphaseoliform, rarely phaseoliform or indented above the apiculus; brown to dark red; germ pore distinct, rounded to truncate, 1.2-2(-2.4) $\mu \mathrm{m}$ broad. Basidia 4-spored, 15-25 × 7.5-10 $\mu \mathrm{m}$. Pleurocystidia (21-)30-60(-65) × 9-19(-21) $\mu \mathrm{m}$, broadly to narrowly utriform, fusiform, conical, lageniform, sometimes submucronate, rarely clavate, ellipsoid, subcylindrical to rhomboid; apex rounded to obtuse, rarely subobtuse, sometimes or often subcapitate, rarely forked or incrusted; walls hyaline or very slightly yellowish but never brownish, sometimes thickened below apex; numerous to scattered. Cheilocystidia 20-45(-60) $\times$ 8-18 $\mu \mathrm{m}$, rare to scattered, sometimes (locally) moderately numerous. Paracystidia 8-40(-45) × 5-23(-35) $\mu \mathrm{m}$, sometimes incrusted; walls often thickened and yellowish to reddish brown pigmented (overall towards base); numerous, dominating. Cells below marginal cystidia often incrusted, pale yellow to yellowish brown with pigment often more concentrated at septa and in discontinuous wall traits. Clamps present.
Habitat: Solitary, gregarious to cespitose; in foliar and on woody debris in broadleaf wood stands, in parks, on paths, in grass; dry; on calcareous and nitrophilous soil.

Material examined: Italy, Venezia, Chioggia, S. Anna, Nordio forest, $2 \mathrm{~m}$ a.s.l., 29 Oct. 2006, gregarious on litter of Quercus ilex, P. Voto, Fig. 35 (MCVE29105, Tef-1 $\alpha$ MF521809, ITS MF325966); at same location, 31 Oct. 2007, gregarious on litter of Quercus ilex, P. Voto (MCVE29110, Tef$1 \alpha$ MF521806); Rovigo, Crespino, 1 m a.s.l., 28 Nov. 2006, gregarious on soil at the top of a ditch bank, P. Voto, Figs 36, 43 (MCVE29109, Tef-1 $\alpha$ MF521807); Rovigo, Villadose, 3 m a.s.l., 19 Nov. 2013, gregarious on dry grassy soil in a wooded park, P. Voto, Fig. 37 (MCVE29122, Tef-1a MF521804, ITS MF325968); at same location, river Adigetto, 16 Nov. 2014, gregarious on often moist grassy ground at the top of the river bank, P. Voto, Figs 38-40 (MCVE29124, Tef-1 $\alpha$ MF521802); at same location on a different spot, 5 Nov. 2018, gregarious, P. Voto 20181105.2, Fig. 41; at same location on a different spot, 16 Nov. 2015, gregarious and subcespitose, P. Voto (MCVE29333); Pesaro Urbino, Fano, loc. Roncosambaccio, gregarious on buried roots, 24 Nov. 2006, M. Maletti 1867 (duplicate MCVE29108, Tef-1 $\alpha$ MF521808, ITS MF325967); Pesaro Urbino, Monte Giano, loc. Rio Secco, 14 Oct. 2011, gregarious among grass on disturbed soil, M. Maletti 3035, Fig. 42 (duplicate MCVE29115, Tef-1 $\alpha$ MF521805). 
Notes: One of our aims was to provide molecular evidence supporting the presence of pilei with pinkish tints and of reddish gills' edges within this species. Ludwig (2007b) was, to our knowledge, the first to report a possible red underlining of the gill edge. A number of collections we have examined show these two parameters can be variously combined, even in materials collected in the same place. Cross comparisons of the sequences originated from various samples show that all of our materials share a minimum homology value of 99.7 $\%$ at the ITS locus and an average $99 \%$ Tef- $1 \alpha$ identity, with the only exception of MCVE29124 which shares a $97 \%$ to 98 $\%$ identity with all others. However molecular evidence does not provide substantial support to split this single voucher from the others. In conclusion, our molecular identification of $P$. fatua includes material with (see Figs $35,37,39$ ) or without a more or less evident pinkish peripheral half of the discoloring pileus, and with (see Fig. 37) or without a pigmented gill edge.

Elements differentiating $P$. fatua from $P$. spadiceogrisea are listed below. Spores are less frequently phaseoliform and rarely indented above the apiculus. Pleurocystidia are never brown, are more varied in shape (utriform, lageniform, fusiform, conical), and sometimes are more or less capitate, rarely forked or incrusted. Gill edges are possibly pigmented. Sporocarps are smaller and with a rapidly discoloring pileus that is never dark colored when mature, while it may be pinkish. For differences between $P$. fatua and $P$. albescens, see notes provided for the latter.
15. Psathyrella tenacipes A.H. Sm., Mem. N. Y. Bot. Gard. 24: 440. 1972. Fig. 44.

Typus: Psathyrella tenacipes A.H. Sm. USA, Michigan, Cheboygan Co., Wolf Bog, 13 Jun. 1948, A.H. Smith 28718 (incorrectly 28717 in original description) (coll. Singer, DiGilio \& Smith) (MICH12091), described as gregarious on muck and small sticks partly burned in protologue, described as gregarious on drying muck in ash swamp in Smith's handwritten field notes.

Loan of various sporocarps in good condition for micromorphology investigation.

Spores 7-9.5(-10.1) × 4.6-5.7 $\mu \mathrm{m}(7-9 \times 4.5-5.5$ in Smith 1972), Q (1.45) 1.6-1.85(-1.9), avQ 1.7; in front view suboval to elliptic, sometimes subangular to suboblong, base rounded to subtruncate, in profile adaxially flattened, sometimes subamygdaliform to subphaseoliform, orangish reddish brown; germ pore distinct, truncate, 1.2-1.7 $\mu \mathrm{m}$ broad. Pleurocystidia 28-50 × 9-14(-16) $\mu \mathrm{m}$, (narrowly) utriform, sometimes lageniform to subcylindrical; apex 4.5-8(-10) $\mu \mathrm{m}$ broad, rounded to obtuse, often or sometimes subcapitate, not incrusted; walls thin, hyaline; moderately numerous. Cheilocystidia 24-30 $\times$ 10-15 $\mu \mathrm{m}$, scattered. Paracystidia $-30 \times-17(-20) \mu \mathrm{m}$; walls thickened and yellowish pigmented in larger ones, numerous, dominating. Cells below marginal cystidia yellowish pigmented.

Unfortunately, DNA extraction failed for this species, which otherwise is remarkable for the presence of some peculiar

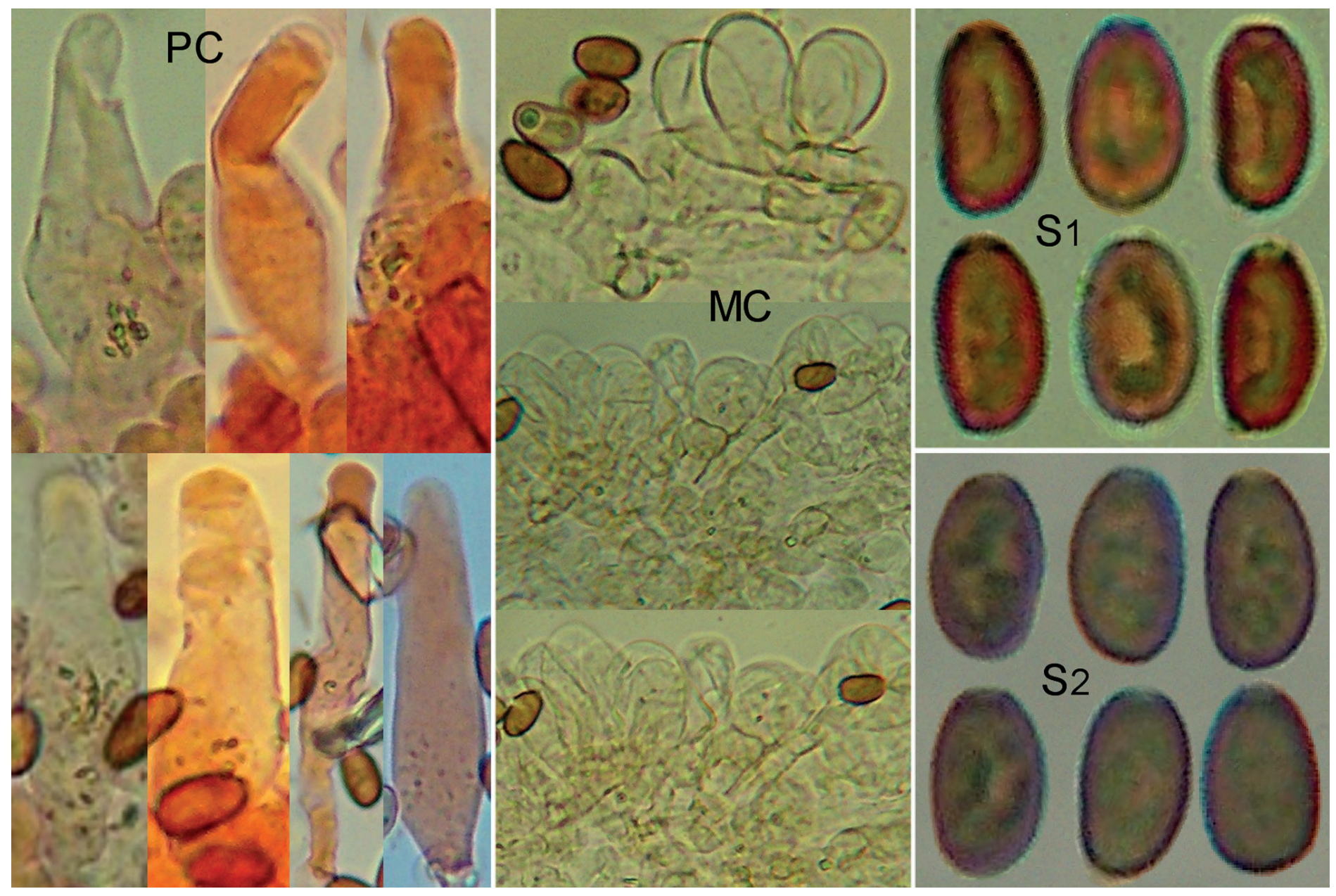

Fig. 44. Psathyrella tenacipes. A.H. Smith 28718, MCVE12091; PC Pleurocystidia; MC Marginal Cystidia in KOH; S1 Spores in water; S2 Spores in KOH. 
characters, such as a scarce and very fugacious veil; a tubular, pliant, fairly tough stipe; pallid brownish gill edges and bistre but soon discoloring pileus color. Based on micro- and gross morphology, we see some similarity between $P$. tenacipes and $P$. fatua, possibly suggesting conspecificity. However, because of the lack of molecular evidence of $P$. fatua from any American collections included in this study, we are not yet ready to recognize this common European species as being present in North America.

16. Psathyrella owyheensis A.H. Sm., Mem. N. Y. Bot. Gard. 24: 174. 1972. Fig. 45.

Molecular heterotypical synonyms proposed here: Psathyrella carminei Örstadius \& E. Larss., Mycol. Prog. 14: 18. 2015.

Typus: Psathyrella owyheensis A.H. Sm. USA, Idaho, Owyhee Co., Sands Basin, 27 Apr. 1969, E. Trueblood 3135 (MICH5357), gregarious in native grass near cow dung. Tef-1 $\alpha$ MF521785, ITS MF325990.

Loan of two sporocarps in good condition for micro-morphology investigation.

Spores (7.5-)8.8-11.1(-12.5) $\times(3.8-) 4.5-5.7(-6.5) \mu \mathrm{m}$, on average $9.4 \times 5.2 \mu \mathrm{m}, \mathrm{Q}(1.4-) 1.6-2(-2.5)$, avQ 1.8-1.9; in front view oval, elliptic, oblong, sometimes subcylindrical, sometimes or often slightly irregular between median portion and base, base obtuse to broadly rounded, in profile subelliptic to subamygdaliform, sometimes subphaseoliform; dull orange; germ pore distinct, often truncate, 1.5-2 $\mu \mathrm{m}$ broad. Pleurocystidia 37-59 × 12-16 $\mu \mathrm{m}$, utriform to lageniform, sometimes subcylindrical; apex obtuse, sometimes subcapitate, rarely forked or incrusted; walls sometimes weakly yellowish pigmented; more or less scattered. Cheilocystidia 22-35 × 9-12 $\mu \mathrm{m}$, scattered. Paracystidia $-23 \times-15 \mu \mathrm{m}$, walls hyaline or almost so, numerous, sometimes incrusted, dominating.

Notes: The molecular sequences of the holotype of $P$. carminei deviates by a few bases from the holotype of $P$. owyheensis (DNA nucleotide homology: ITS = $99 \%$ identity, Tef-1 $\alpha=98 \%$ identity), we consider this to be a good double locus evidence of conspecificity; micro-morphology matches well too. We could not ascertain the exact trophism of the holotype (and only collection) of $P$. owyheensis: it could be the nitrogen-rich soil, due to the nearby dung, or grassy material, we cannot even exclude sagebrush (Artemisia tridentata) debris as this plant is widely distributed in the Sands Basin. Psathyrella carminei is reported on soil in a forest with pines but there are a number of species in subsection Spadiceogriseae growing both with and without association to woody material, e.g. P. fatua, $P$. clivensis and $P$. albescens. Psathyrella carminei is said to smell of fish while $P$. owyheensis has indistinct odor, but we know of other Psathyrella
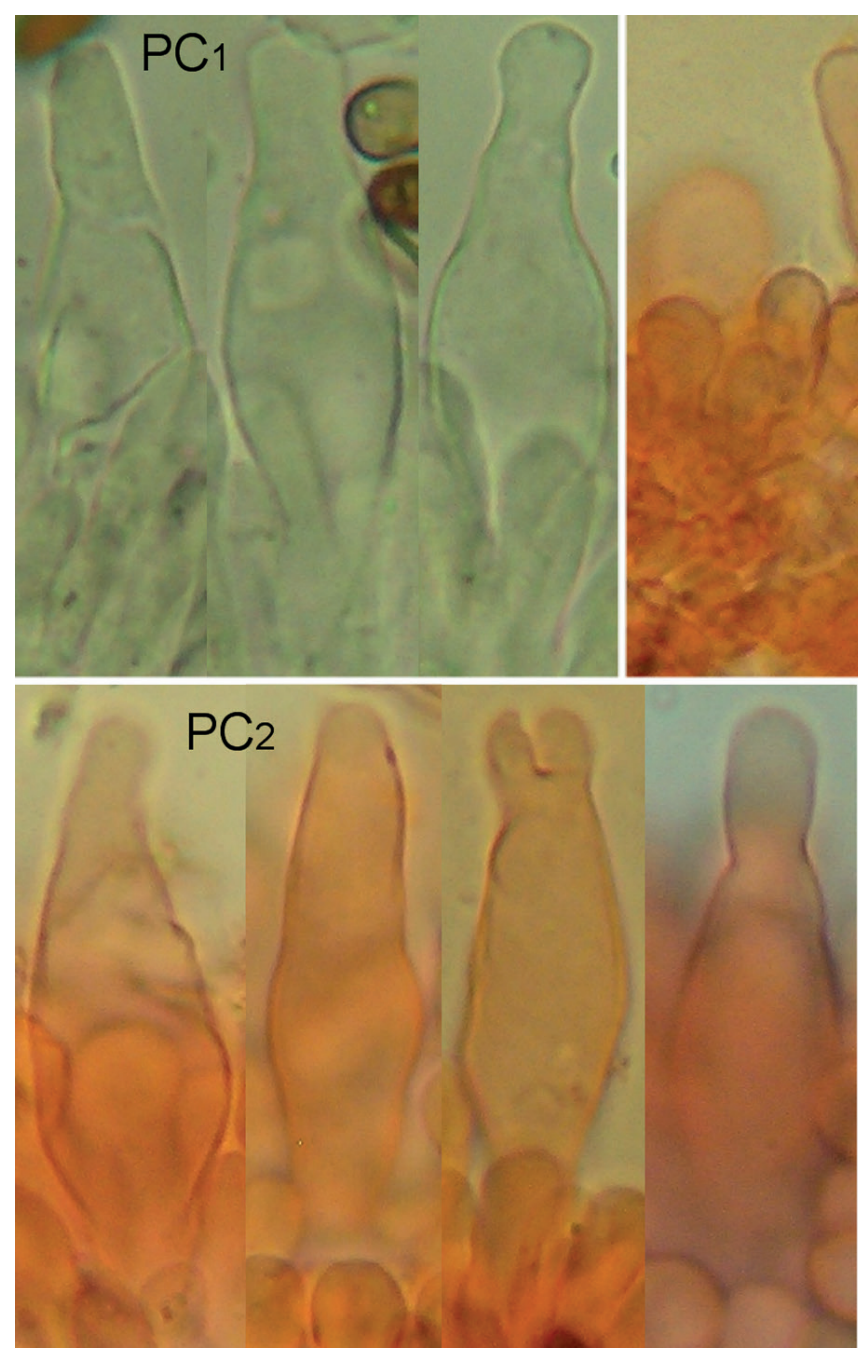
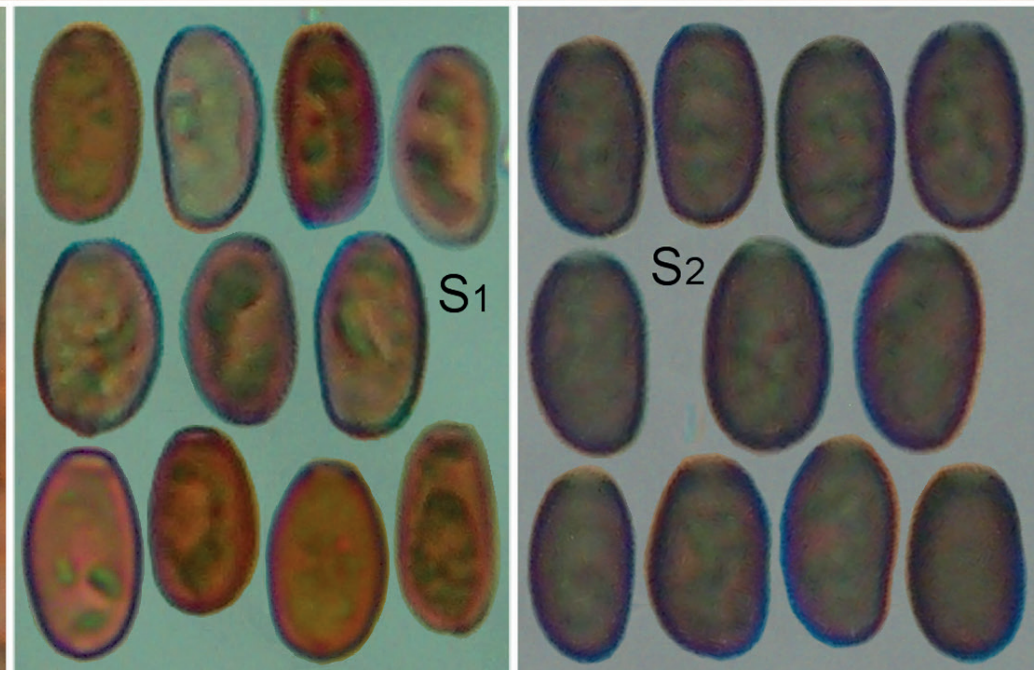

Fig. 45. Psathyrella owyheensis. E. Trueblood 3135, MICH5357; PC1 Pleurocystidia in $\mathrm{NH}_{4} \mathrm{OH}$; PC2 Pleurocystidia in Congo red; MC Marginal Cystidia; S1 Spores in water; S2 Spores in $\mathrm{KOH}$. 
species, e.g. P. bipellis and $P$. saponacea, which may or may not possess a peculiar odor.

17. Psathyrella hellebosensis Deschuyteneer \& Melzer, Bull AMFB 10: 5. 2017. Figs 46, 47.

Spores (6.5-)7-8.5(-11) × 4.7-5.3(-5.6) $\mu \mathrm{m}, \mathrm{Q}(1.4-) 1.5-1.8$, in front view oval to angular-oval, with a base often subtruncate, in profile rarely subphaseoliform, reddish brown, with distinct germ pore. Pleurocystidia, 43-58(-64) × 11-15(-17) $\mu \mathrm{m}$, utriform, often forked to three-lobed. Paracystidia sometimes incrusted and locally weakly yellowish pigmented, dominating.

Material examined: Italy, Pesaro, loc. Villa Ceccolini, near river Foglia, 26 Mar. 2011, M. Maletti 2768 (MCVE29114), gregarious on soil in an unkempt open riparian site. Tef-1 $\alpha$ MF521816, ITS MF325956.

Notes: The colors and habitus of this Italian collection are in perfect agreement with the description of this species. The molecular evidence of the Tef-1 $\alpha$ DNA region clearly isolates this species from neighboring allied taxa, and places it confidently among species of the subsection Spadiceogriseae that are not found in association with woody material.

Two other species should be mentioned here because of their non-lignicolous habitat. Psathyrella agraria (Enderle 1996), reported from mossy soil in a cornfield (Zea mays, Poaceae), shares a $99 \%$ ITS identity with the types of $P$. lutulenta and $P$. thujina, however it has spores mainly and distinctly phaseoliform, and its habitat is not specifically defined wet or moist soil. It remains a dubious European taxon. Psathyrella phaseolispora, whose type could not be studied, is a species described based on a single dilapidated old specimen found in a manured PoaLolietum grassland, and resembles $P$. clivensis but with distinctly phaseoliform and somewhat more pigmented spores, and a somewhat more defined germ pore; it too remains dubious. However, pending more morphological descriptions or convincing molecular evidences, we decided to insert these two species in our key to facilitate their identification from more collections.

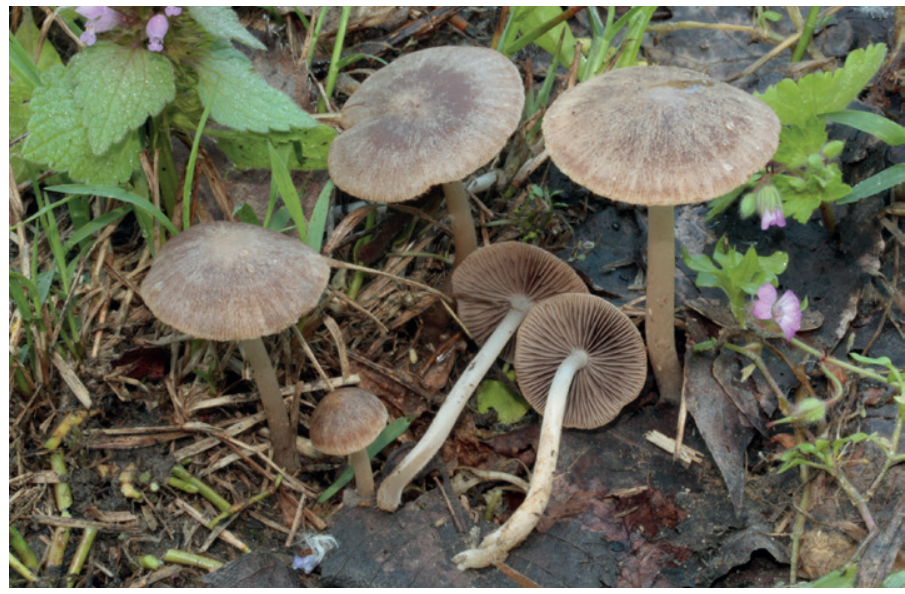

Fig. 46. Psathyrella hellebosensis. MCVE29114. Photo M. Maletti.
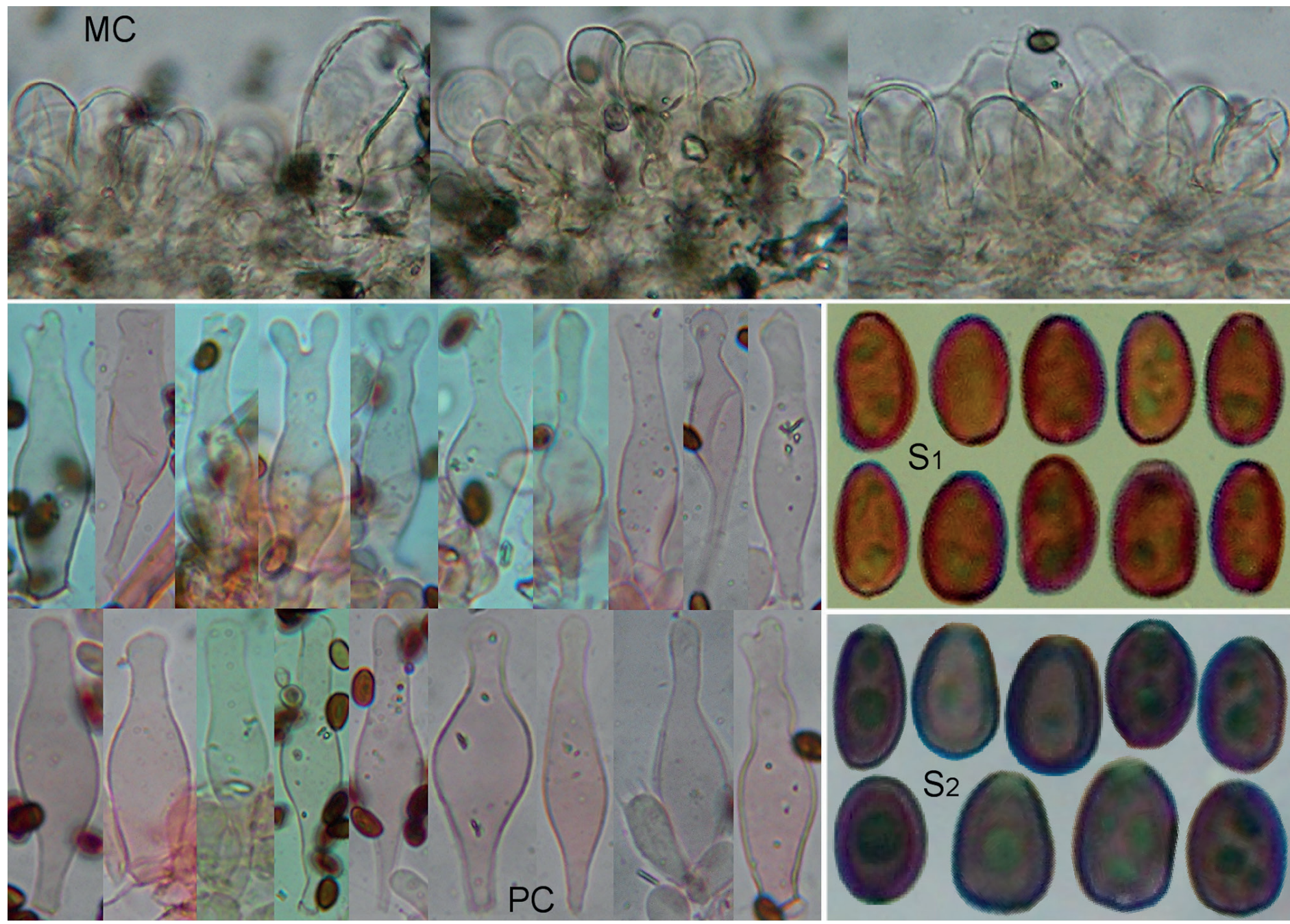

Fig. 47. Psathyrella hellebosensis. P. Voto, MCVE29114; MC Marginal Cystidia in KOH; PC Pleurocystidia; S1 Spores in water; S2 Spores in KOH. 
18. Psathyrella rogersiae Voto, Garbelotto \& Chiarello, sp. nov. MycoBank MB831126. Figs 48, 49.

Etymology. The epithet is a dedication to Patricia Rogers, a collection manager in the University of Michigan Herbarium who helped us navigate the collections at the MICH herbarium.

Typus: Italy, Veneto, Vicenza, Trissino, river Guà, about 100 m a.s.I., 28 Mar. 2013, O. Chiarello (MCVE29120). ITS MF325995.

Pileus 30-40 mm latus, mox convexus sed margine inflexa, per mature leviter undulatus et interdum leviter umbonatus; primo umbrinus vel murinus, per mature brunneus, deinde spadiceus, hygrophanus, in sicco cinereus; humido leviter striatus. Velum album, fibrillosum, pauper, fugax. Lamellae adnatae, modice ventricosae, subdistantes; initio griseae, deinde purpureae, acie alba. Stipes 35-50 ×3.5-6 mm, cylindraceus, albus. Odor ut sapor indistincti. Sporae (6.8-)7.5-10 × 4.6-5.2(-5.5) $\mu \mathrm{m}$, oblongae, ellipsoideae, subovoideae, nonnullae subphaseoliformes, in aqua observatae aurantiacae-brunneae, poro germinativo distinctae. Basidia 4-sporigera. Pleurocystidia 34-54(-59) ×13.3$16.5 \mu \mathrm{m}$, utriformia vel sublageniformia, apice obtusa, interdum vel saepe subcapitata, raro furcata, numerosa. Cheilocystidia 28-45 × 7.5-15 $\mu \mathrm{m}$, pleurocystidiis similia vel fusoidea, dispersa sed modice numerosa ad stipitem. Paracystidia 15-35 × 7.5-21 $\mu \mathrm{m}$, interdum leviter flavida ut crassitunicata, numerosa. Fibulae adsunt. Gregaria in udo prati.
Pileus 30-40 $\mathrm{mm}$ broad, soon convex with inflexed margin, when mature slightly wavy and sometimes slightly umbonate; when young dark brown to dark grey-brown, when mature brown to dark yellowish brown, hygrophanous, fading through various tints of yellowish brown (greyish, dull, medium, bright), finally pale grey; faintly translucently striate when moist. Veil white, as a scarce and fugacious fringe on margin of pileus. Lamellae adnate or with a decurrent tooth; moderately narrow to somewhat ventricose in age; about

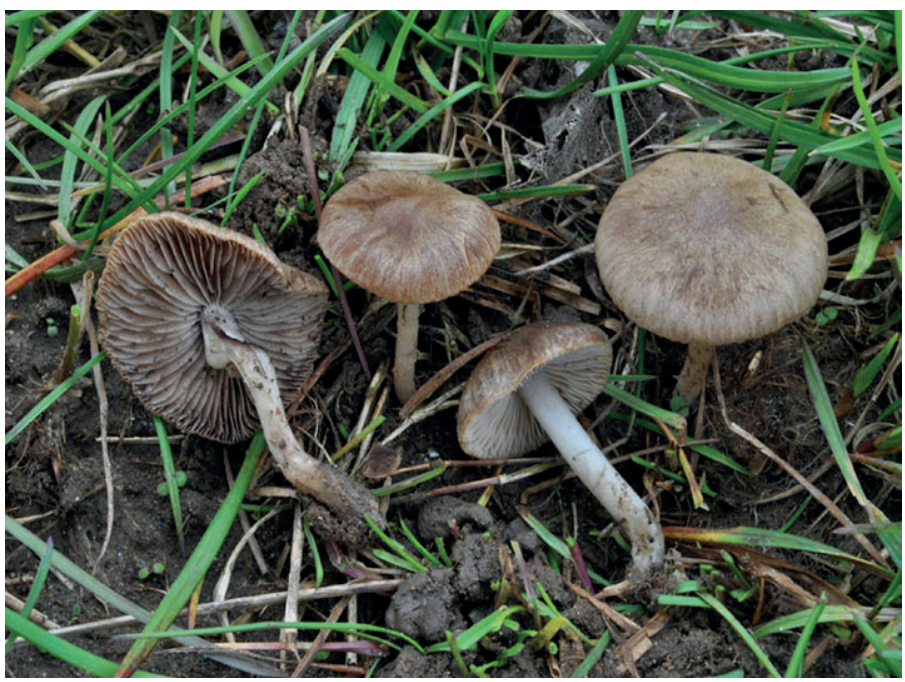

Fig. 48. Psathyrella rogersiae. MCVE29120. Photo O. Chiarello.
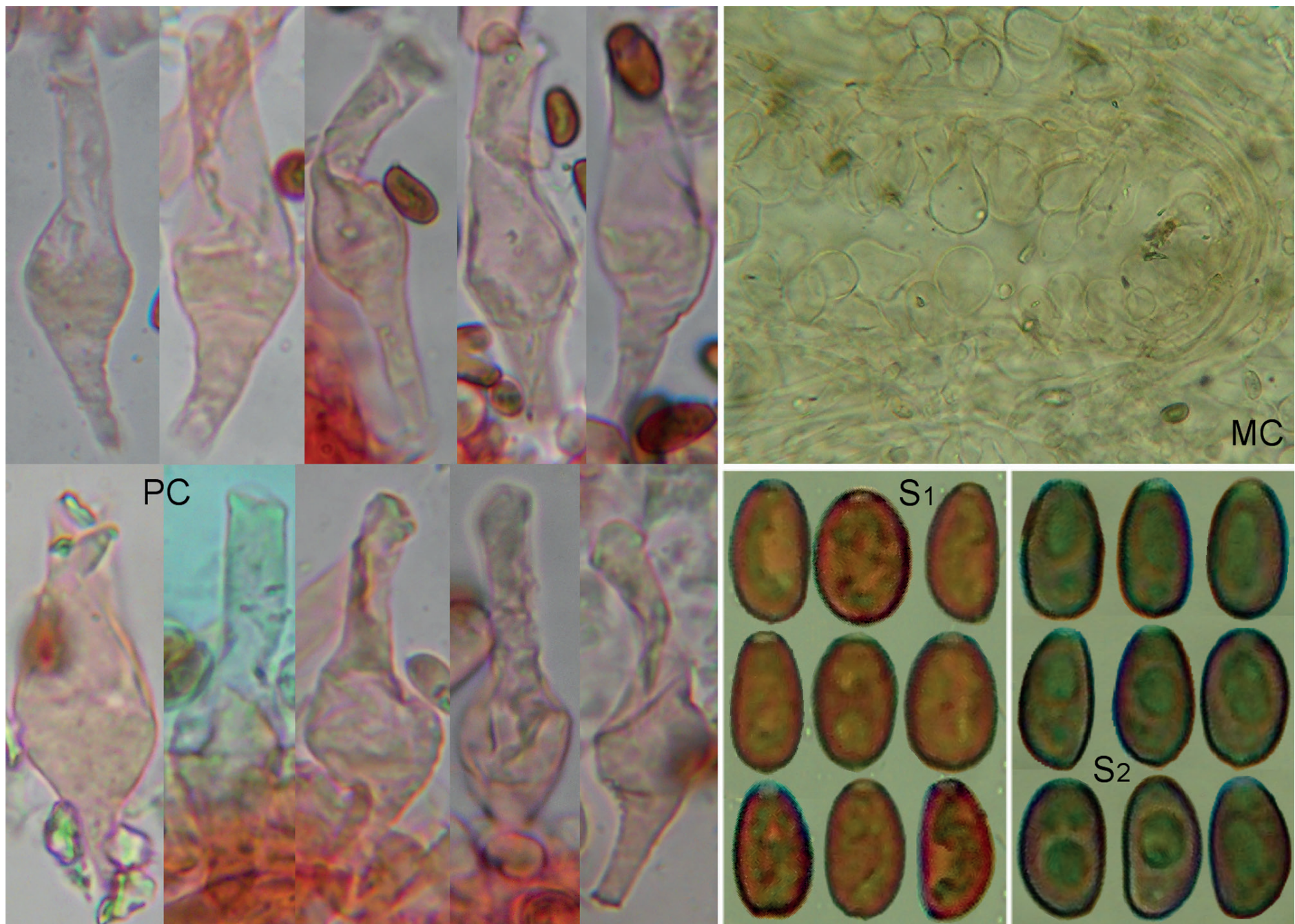

Fig. 49. Psathyrella rogersiae. O. Chiarello, MCVE29120; PC Pleurocystidia; MC Marginal Cystidia in KOH; S1 Spores in water; S2 Spores in KOH. 
28 when mature; when young greyish, finally purplish; edge white. Stipe 35-50 × 3.5-6 mm, cylindrical, occasionally bent towards apex or base; white, a little discoloring brownish over the basal area; apex pruinose, naked or with very scarce velar fibrils. Odor and taste indistinctive. Spores (6.8-)7.5-10 × 4.6$5.2(-5.5) \mu \mathrm{m}$, on average $8.2-9.2 \times 4.8-5 \mu \mathrm{m}, \mathrm{Q}(1.5-) 1.53-$ 1.88 (-1.96), avQ 1.68-1.75; smooth; in front view elliptic to suboval, sometimes sub angular-oval, oblong, base rounded to subtruncate, in profile adaxially flattened, sometimes subphaseoliform, rarely distinctly phaseoliform; dull orange to brownish orangish; germ pore distinct, rounded, 1.3-1.7 $\mu \mathrm{m}$ broad. Basidia 4-spored, 17-28 × 8-11 $\mu \mathrm{m}$. Pleurocystidia $34-54(-59) \times 13.3-16.5 \mu \mathrm{m}$, with quotient $2.7-3.8(-4.2)$, on average 3.42 ; utriform to sublageniform, with often elongate and sometimes eccentric neck, apex rounded to obtuse, often or sometimes subcapitate, rarely forked; numerous. Cheilocystidia 28-45 × 7.5-15 $\mu \mathrm{m}$, sometimes varying to obtusely subfusiform, scattered at margin of pileus to moderately numerous towards stipe. Paracystidia 15-35 × 7.5-21 $\mu \mathrm{m}$, sometimes elongate-ellipsoid, walls sometimes thickened and yellowish pigmented, numerous, dominating. Cells below marginal cystidia incrusted and weakly yellowish pigmented. Pileipellis of clavate to subglobose, 13-30(-40) $\mu \mathrm{m}$ broad cells; underlying hyphae with incrusted pigment. Clamps present.
Habitat: Gregarious; in sandy grassland near a river bank, the area is a moist, often flooded, permeable alluvial plain with Salix alba trees and various hygrophilous plants, such as Carex spp., Phragmites australis, Typha latifolia, Scirpus spp., Ranunculus aquatilis.

Notes: The ITS sequence places this fungus in the subclade $P$. albescens. The differences against $P$. albescens are many and evident, ranging from not thickset utriform pleurocystidia and somewhat less phaseoliform spores to distinctly dark grey brown colors of pileus, scarce veil and hygrophilous habitat; $P$. ochrofulva is a tiny, differently colored species with different pleurocystidia and habitat. Because of its hygrophilous habitat it can be compared to the American taxon P. thujina, which Örstadius et al. (2015) proposed as a prior name for the European $P$. almerensis and $P$. lutulenta, but its smaller spores and slenderer pleurocystidia represent a distinctive combination of characters. It is also comparable to $P$. hellebosensis which differs mainly because of its more pigmented, largely ovoid to angular-ovoid spores.

19. Psathyrella argillacea A.H. Sm., Mem. N. Y. Bot. Gard. 24: 367. 1972. Fig. 50.

Paratype: Psathyrella argillacea A.H. Sm. USA, Wyoming, Albany Co., Laramie River, North Fork River, 27 Jul. 1950, A.H. Smith 35220 (MICH65256). Tef-1 $\alpha$ MF521814.
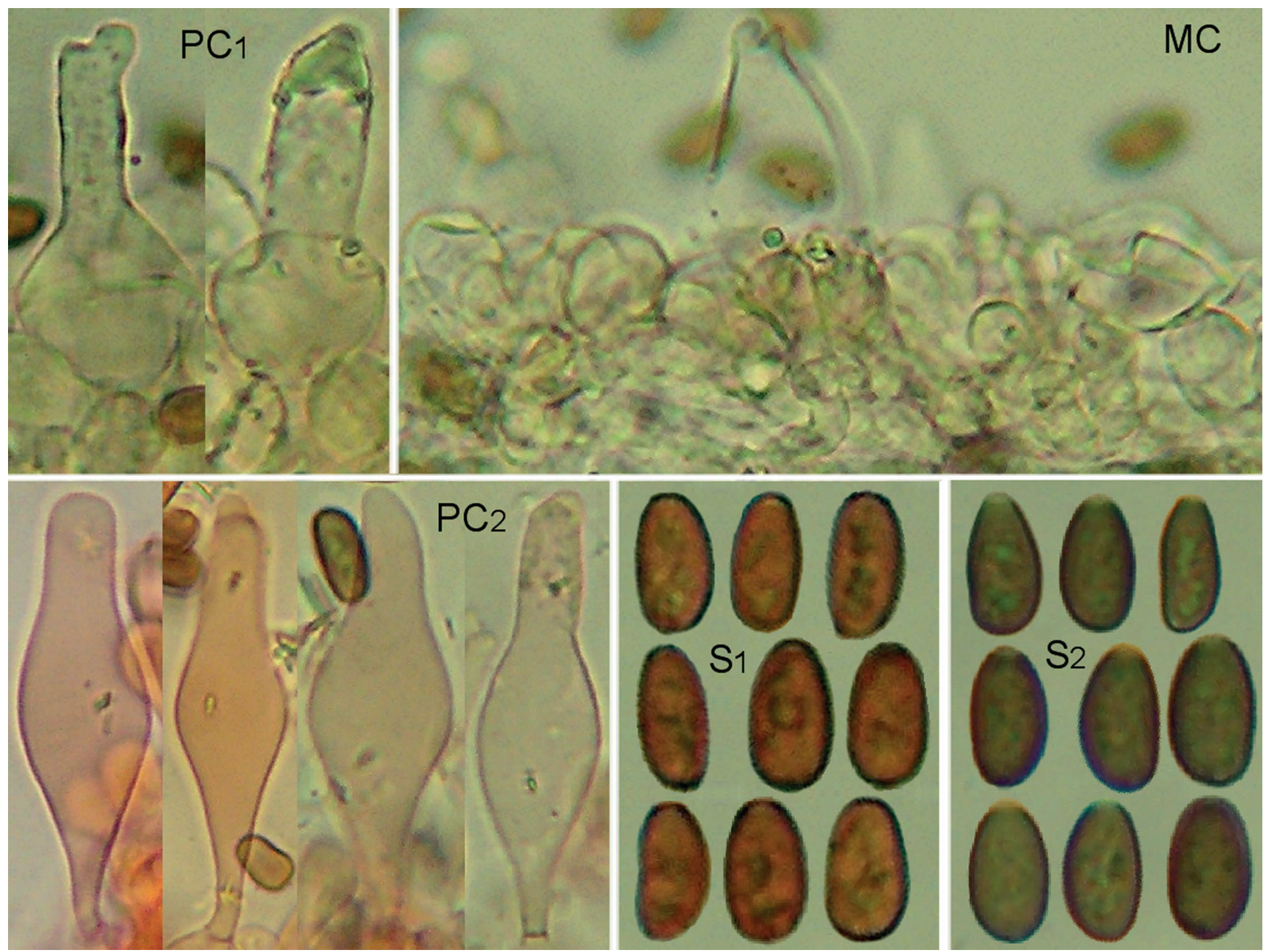

Fig. 50. Psathyrella argillacea. A.H. Smith 35220, MICH65256; PC1 Pleurocystidia in $\mathrm{NH}_{4} \mathrm{OH}$; PC2 Pleurocystidia in Congo red; MC Marginal Cystidia in $\mathrm{KOH}$; S1 Spores in water; S2 Spores in $\mathrm{KOH}$. 
Loan of three pilei and some entire or broken stipes for gross morphology investigation.

Spores 7.3-11 × 4.4-5.6(-6.2) $\mu \mathrm{m}, \mathrm{Q}$ 1.5-2.5, avQ 1.8-2; in front view elliptic to (narrowly) oval, base rounded to subtruncate, in profile adaxially flattened, subcylindrical to subamygdaliform, rarely subphaseoliform; dull orangish brown to brown; germ pore distinct, rounded to subtruncate, about $1.8 \mu \mathrm{m}$ broad. Pleurocystidia 38-55 × 12-15 $\mu \mathrm{m}$; utriform, fusiform-utriform; apex obtuse to rounded, rarely subacute, often forked, often incrusted, walls sometimes brownish pigmented; moderately numerous. Cheilocystidia 25-45 × 12-15 $\mu \mathrm{m}$, scattered. Paracystidia 12-30 × 5-19.5 $\mu \mathrm{m}$, sometimes ellipsoid, often incrusted, walls often thickened and yellowish pigmented, numerous, dominating. Cells below marginal cystidia slightly incrusted and pigmented.

Notes: Best match when blasting the sequence of this material is with the holotype of $P$. lutulenta but with a weak identity that undoubtedly excludes conspecificity. No field notes are attached to this paratype and on careful examination of the whole exsiccata no fragments of non-fungus material could be found for a clue to the habitat; however the holotype, which we could not study for scarcity of material, and all other collections examined by Smith (1972) are reported on hardwood debris and litter, moreover Smith (1972) placed the species in subsection
Lauricolae expressly characterized by lignicolous habitat. The lack of macro characters in the description of this paratype prevents a thorough comparison with $P$. owyheensis, a very similar species based on micro-morphology (see key). Yet, the two are surely different based on DNA evidence.

20. Psathyrella umbrosa A.H. Sm., Mem. N. Y. Bot. Gard. 24: 391. 1972. Fig. 51.

Molecular heterotypical synonyms proposed here: Psathyrella fulvoumbrina A.H. Sm., Mem. N. Y. Bot. Gard. 24: 413. 1972.

Typus: Psathyrella umbrosa A.H. Sm. USA, New Mexico, Rio Arriba Co, Sangre de Cristo Mountains, Aug. 1963, C.A. Barrows, 1416 (MICH12102), densely gregarious on soil filled with rotten wood. Tef-1 $\alpha$ MF521775, ITS MF326003.

Loan of three sporocarps in good condition for micro-morphology investigation.

Spores (6.7-)7.1-9.3 × 4.3-5.7 $\mu \mathrm{m}, \mathrm{Q}$ 1.4-2.1; in front view suboblong to broadly oval, rarely subangular-oval, base mainly broadly rounded, rarely subtruncate, in profile subelliptic to adaxially flattened or subphaseoliform, sometimes subamygdaliform, apex truncate in front view and in profile; orangish to vaguely reddish brown; germ pore distinct, truncate,
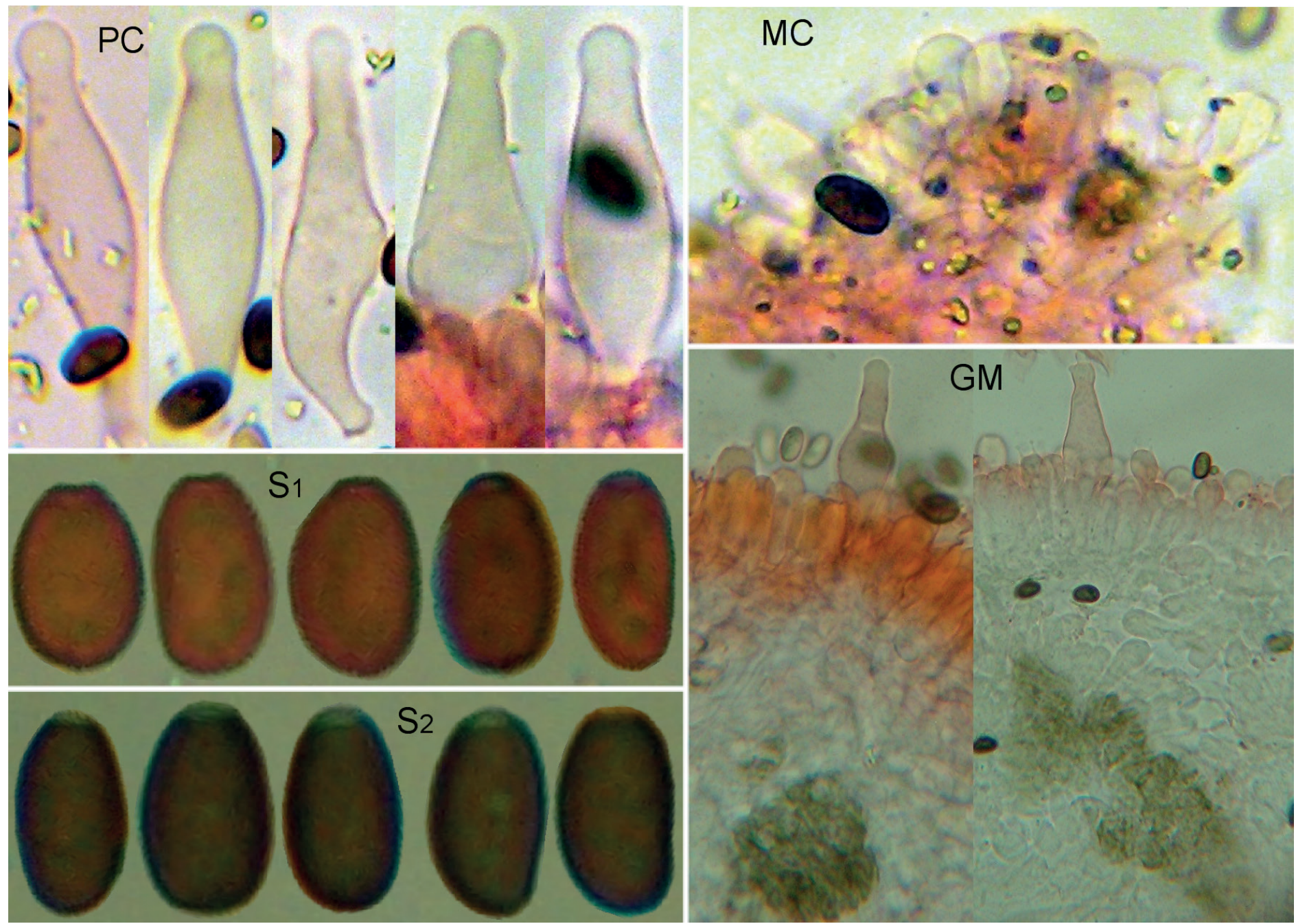

Fig. 51. Psathyrella umbrosa. C.A. Barrows 1416, MICH12102; PC Pleurocystidia; MC Marginal Cystidia; S1 Spores in water; S2 Spores in KOH; GM Greenish masses/incrustations in hymenium. 
1.5-1.8 $\mu \mathrm{m}$ broad. Pleurocystidia 31-51 × 10.5-16 $\mu \mathrm{m}$, utriform to sublageniform or subfusiform, sometimes ventricose-conical; apex obtuse to subcapitate; walls hyaline; moderately numerous. Cheilocystidia 23-40 × 8-14 $\mu \mathrm{m}$, scattered. Paracystidia mainly 9-12 × 5-7 $\mu \mathrm{m}$, some 22-32 × 9-13 $\mu \mathrm{m}$, dominating among numerous basidia and basidiola.

20a. Psathyrella fulvoumbrina A.H. Sm., Mem. N. Y. Bot. Gard. 24: 413. 1972.

Typus: Psathyrella fulvoumbrina A.H. Sm. USA, Idaho, Owyhee Co, Boulder Creek, South Fork, 4 Jun. 1969, E. Trueblood 3167 (MICH5833), gregarious under aspen and fir. Tef- $1 \alpha$ MF521800, ITS MF417625.

Loan for micro-morphology investigation of four sporocarps in good condition.

Spores 7-8.7(-9.5) × 4.4-5.7 $\mu \mathrm{m}, \mathrm{Q}$ 1.3-1.9; in front view elliptic to oval, base broadly rounded, in profile subelliptic to adaxially flattened or subamygdaliform, rarely subphaseoliform; redbrown; germ pore distinct, mostly truncate, 1.5-1.8 $\mu \mathrm{m}$ broad. Pleurocystidia 33-55 × 10-22 $\mu \mathrm{m}$, narrowly utriform, narrowly sublageniform, narrowly fusiform-utriform, broadly ventricose- conical; apex subcapitate or not, sometimes (irregularly) capitate, sometimes subacute, sometimes forked; walls hyaline; moderately numerous. Cheilocystidia 22-27×9-12 $\mu \mathrm{m}$, scattered. Paracystidia mainly small, some 20-30 × 10-13 $\mu \mathrm{m}$, dominating among numerous, up to $10 \mu \mathrm{m}$ broad basidia and basidiola.

Note: There is full correspondence, both molecular and morphological, between $P$. fulvoumbrina and $P$. umbrosa therefore they are synonyms.

21. Psathyrella praetenuis A.H. Sm., Mem. N. Y. Bot. Gard. 24: 110. 1972. Fig. 52.

Molecular heterotypical synonyms proposed here: Psathyrella atrifolia sensu A.H. Smith, Mem. N. Y. Bot. Gard. 24: 146. 1972, p.p.

Typus: Psathyrella praetenuis A.H. Sm. USA, Idaho, Bonner Co., Upper Priest River, 1 Oct. 1968, A.H. Smith 76781 (MICH5361), gregarious on debris under cottonwood trees. Tef-1 $\alpha$ MF521782, ITS MF325993.

Loan of three sporocarps in good condition for micro-morphology investigation.
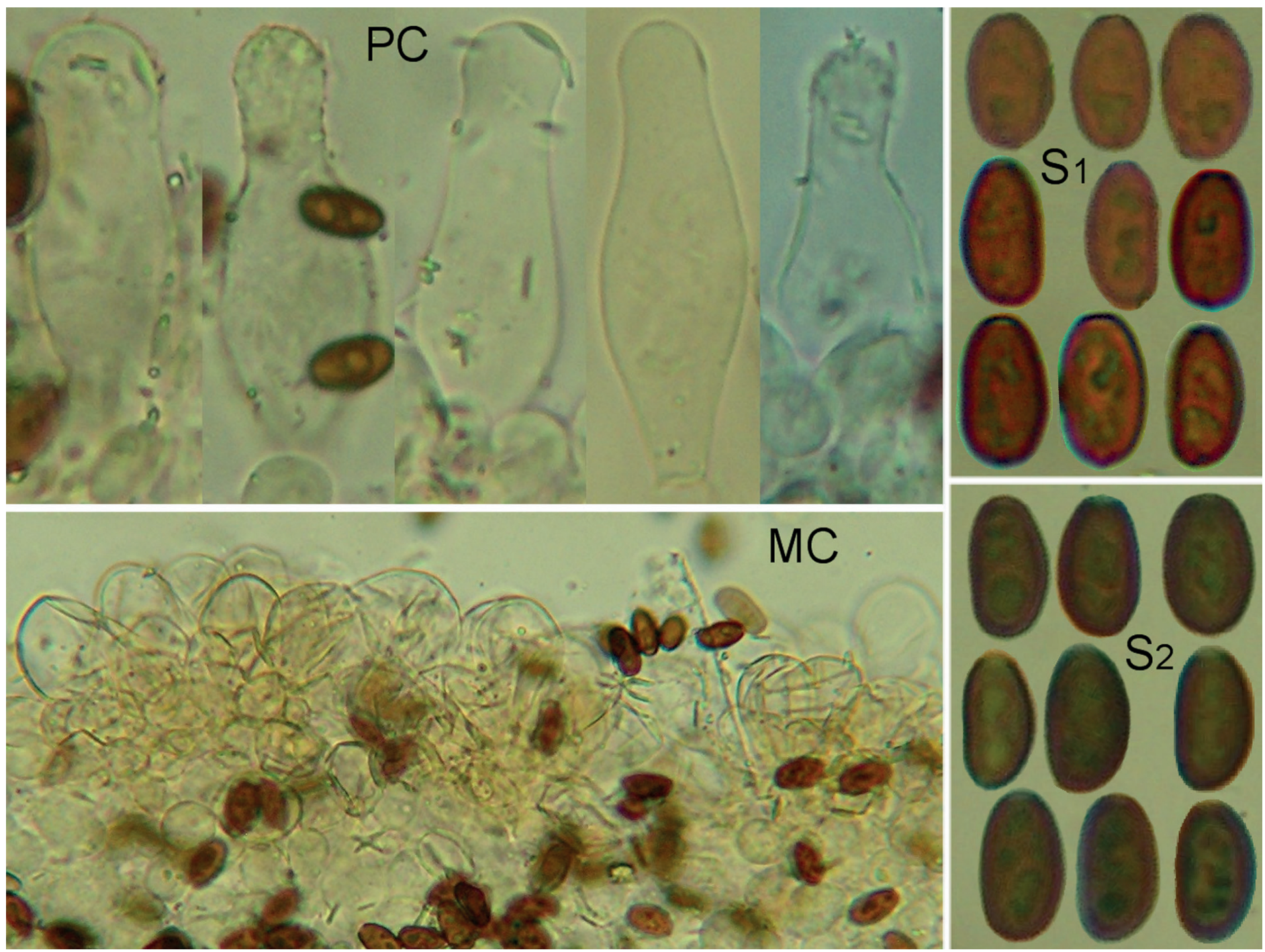

Fig. 52. Psathyrella praetenuis. A.H. Smith 76781, MICH5361; PC Pleurocystidia in $\mathrm{NH}_{4} \mathrm{OH}$; MC Marginal Cystidia in KOH; $\mathrm{S} 1 \mathrm{Spores}$ in water; $\mathrm{S} 2 \mathrm{Spores}$ in $\mathrm{KOH}$. 
Spores (7.5-)8-11(-11.8) × 4.5-6 $\mu \mathrm{m}, \mathrm{Q}(1.5-) 1.7-2.1(-2.2)$, avQ 1.9; in front view elliptic to oblong, sometimes suboval, base rounded, in profile subelliptic to subamygdaliform, sometimes subphaseoliform; sordid brown with a reddish orangish tinge; germ pore distinct, mostly truncate, 1.6-1.7 $\mu \mathrm{m}$ broad. Pleurocystidia 33-55 × 11.5-17 $\mu \mathrm{m}$, utriform, sometimes subcylindrical; apex obtuse, sometimes forked, sometimes (irregularly) subcapitate, often incrusted; walls sometimes brownish pigmented; more or less moderately numerous. Cheilocystidia 22-50 × 11-22 $\mu \mathrm{m}$, scattered. Paracystidia 9-39(49) $\times 7-22 \mu \mathrm{m}$, sometimes submucronate, walls often thickened and pale yellowish pigmented; numerous, dominating. Cells below marginal cystidia faintly yellowish pigmented and incrusted.

Notes: Smith (1972) defines this species as devoid of any trace of veil but places it in subgen. Pannucia, section and subsection Appendiculatae on the assumption that sporocarps may start with an appendiculate veil. For further comments see next species.

Psathyrella atrifolia* (Peck) A.H. Sm., Contr. Univ. Mich. Herb. 5: 38. 1941.

*The original name 'atrofolia' should be correctly spelled 'atrifolia'.

Notes: Smith (1972) has proposed a description of this taxon based on numerous collections but he did not report having revised the holotype of the basionym, Hypholoma atrofolium Peck. We have attempted to understand Smith's concept of $P$. atrifolia by examining three of his collections selected for this purpose by MICH staff. There is a conspicuous correspondence, both molecular (DNA nucleotide homology: ITS= $100 \%$ ) and morphological, between $P$. praetenuis and Smith 73945 (MICH32732) therefore they are conspecific; it is to be noticed that both materials were found among cottonwood tree (Populus deltoides) debris. Smith 87038 (MICH65288), found under aspen (Populus spp.), is likewise morphologically identical but failed to produce a sequence; however, we consider it conspecific too. DNA extraction failed also with Smith 86968 (MICH65287), habitat unknown, but in this case we have found some differences in the spore parameters and it may not be identical to the other vouchers, indeed it recalls $P$. argillacea. Of course these results do not necessarily apply to the other vouchers Smith deposited in $\mathrm{MICH}$ under this name, nor can we be assured of the correct identity between Smith's concept and Peck's basionym as Peck described only, and partially too, the spores among the microscopical characters. Here follows our revision of Smith 73945.

\section{1a. A.H. Smith 73945, MICH32732.}

\section{= Psathyrella praetenuis A.H. Sm.}

Material examined: USA, Idaho, Bonner Co., Priest Lake, Tule Bay, 10 Oct. 1966, in a cottonwood flat. Tef-1 $\alpha$ MF521813, ITS MF325960.

Loan of many sporocarps in good condition for micromorphology investigation.

Spores (7.4-)8.3-9.7(-11.1) ×(3.9-)4.5-5.7(-6.3) $\mu \mathrm{m}$, on average $9 \times 5.1 \mu \mathrm{m}, \mathrm{Q}(1.5-) 1.7-1.9(-2.2)$, avQ 1.85; in front view elliptic, suboval to oblong sometimes angular-oval, base rounded to subtruncate, in profile adaxially flattened to subellipsoid, rarely or sometimes subphaseoliform, sordid brown with a reddish orangish tinge; germ pore distinct, mostly truncate, 1.6-1.8 $\mu \mathrm{m}$ broad. Pleurocystidia 30-54 × 10-20(-21.5) $\mu \mathrm{m}$, utriform; apex obtuse to rounded, rarely subacute, sometimes forked, rarely incrusted; walls hyaline; moderately numerous. Cheilocystidia

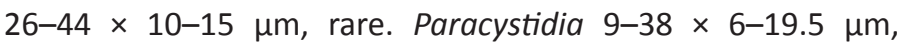
sometimes submucronate, walls often thickened and pale yellowish brownish pigmented, scarcely incrusted; numerous, dominating. Cells below marginal cystidia often pale yellowish brownish pigmented, scarcely incrusted.

22. Psathyrella griseopallida Thiers \& A.H. Sm., Mem. N. Y. Bot. Gard. 24: 417. 1972. Fig. 53.

Typus: Psathyrella griseopallida Thiers \& A.H. Sm. USA, California, San Diego Co, Lake Henshaw, San Luis Rey Campground, 10 Mar. 1970, H.D. Thiers 25079 (MICH11939), Smith's protolog: gregarious on sandy soil near an oak log, Thiers's field note: gregarious in vicinity of dead oak logs. Tef-1 $\alpha$ MF521796, ITS MF325974.

Loan of one entire pileus and a narrow slice of pileus for micromorphology investigation.

Spores (7.3-)8.85-11.9(-13.4) × (4.3-)4.8-5.7(-6.2) $\mu \mathrm{m}(8-10 \times$ 4-5 $\mu \mathrm{m}$ in Smith, 1972), on average $10.2 \times 5.29 \mu \mathrm{m}, \mathrm{Q}(1.6-)$ 1.7-2(-2.2); in front view oblong, oval, subtriangular, base rounded to sometimes truncate, in profile adaxially flattened to faintly subphaseoliform, sometimes subamygdaliform, rarely phaseoliform; red-brown; germ pore distinct, truncate to broadly rounded, 1.7-2 $\mu \mathrm{m}$ broad. Pleurocystidia (28-)32$60 \times 10-19 \mu \mathrm{m}$, utriform, subcylindrical, conical, ventricoseconical, sometimes subellipsoid to sublageniform; apex obtuse to rounded, sometimes or often subcapitate, sometimes incrusted; walls hyaline; (moderately) numerous. Cheilocystidia 22-50 × 10-17 $\mu \mathrm{m}$, mainly lageniform to attenuate, apex mainly obtuse to sometimes subacute, scattered to locally moderately numerous. Paracystidia 8-28(-30) × 5-17 $\mu \mathrm{m}$, apex often incrusted, walls thickened and at most very faintly pigmented in larger ones, otherwise thin and hyaline, numerous, dominating.

Note: Fragments of leaves are clearly recognizable scattered among the exsiccata and connected to some stipe bases, confirming the association with arboreal material.

23. Psathyrella pseudolimicola A.H. Sm., Mem. N. Y. Bot. Gard. 24: 262. 1972. Fig. 54.

Typus: Psathyrella pseudolimicola A.H. Sm. USA, Idaho, Idaho Co, Seven Devil's Mountains, Nezperce National Forest, Papoose Creek, 10 Aug. 1962, A.H. Smith 65850 (MICH5366), gregarious on mud in a cow pasture (mud and manure present). Tef- $1 \alpha$ MF521781.

Loan of three sporocarps in good conditions for micromorphology investigation.

Spores 8.5-10.7(-11.8) × 4.9-5.9(-6.7) $\mu \mathrm{m}$, on average 9-10.5 $\times$ 5-5.5 $\mu \mathrm{m}, \mathrm{Q}(1.6-) 1.7-1.9(-2)$; in front view (narrowly) oval to elliptic-oval, base obtuse to rounded, sometimes 

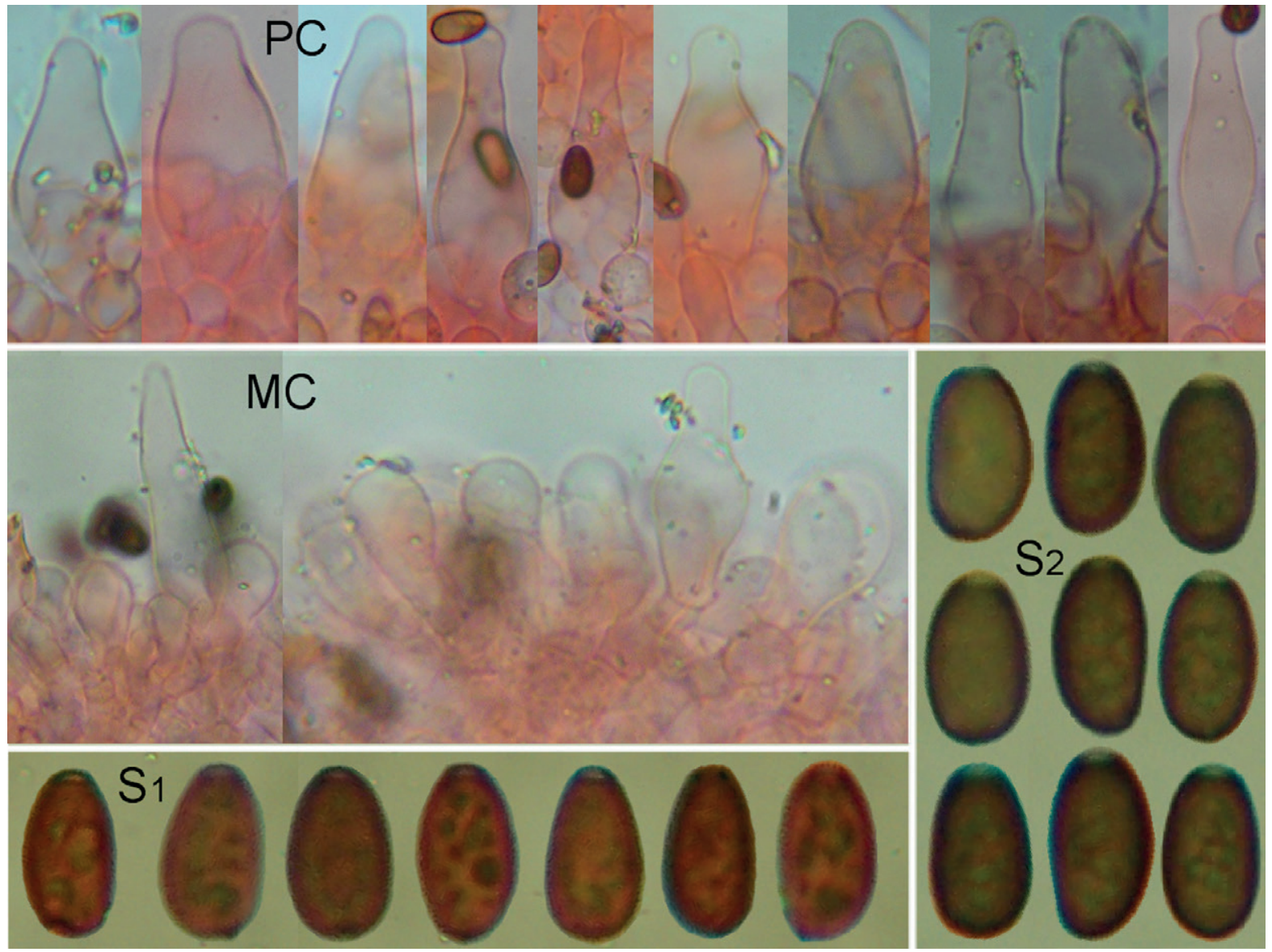

Fig. 53. Psathyrella griseopallida. H. D. Thiers 25079, MICH11939; PC Pleurocystidia; MC Marginal Cystidia; S1 Spores in water; S2 Spores in $\mathrm{KOH}$.
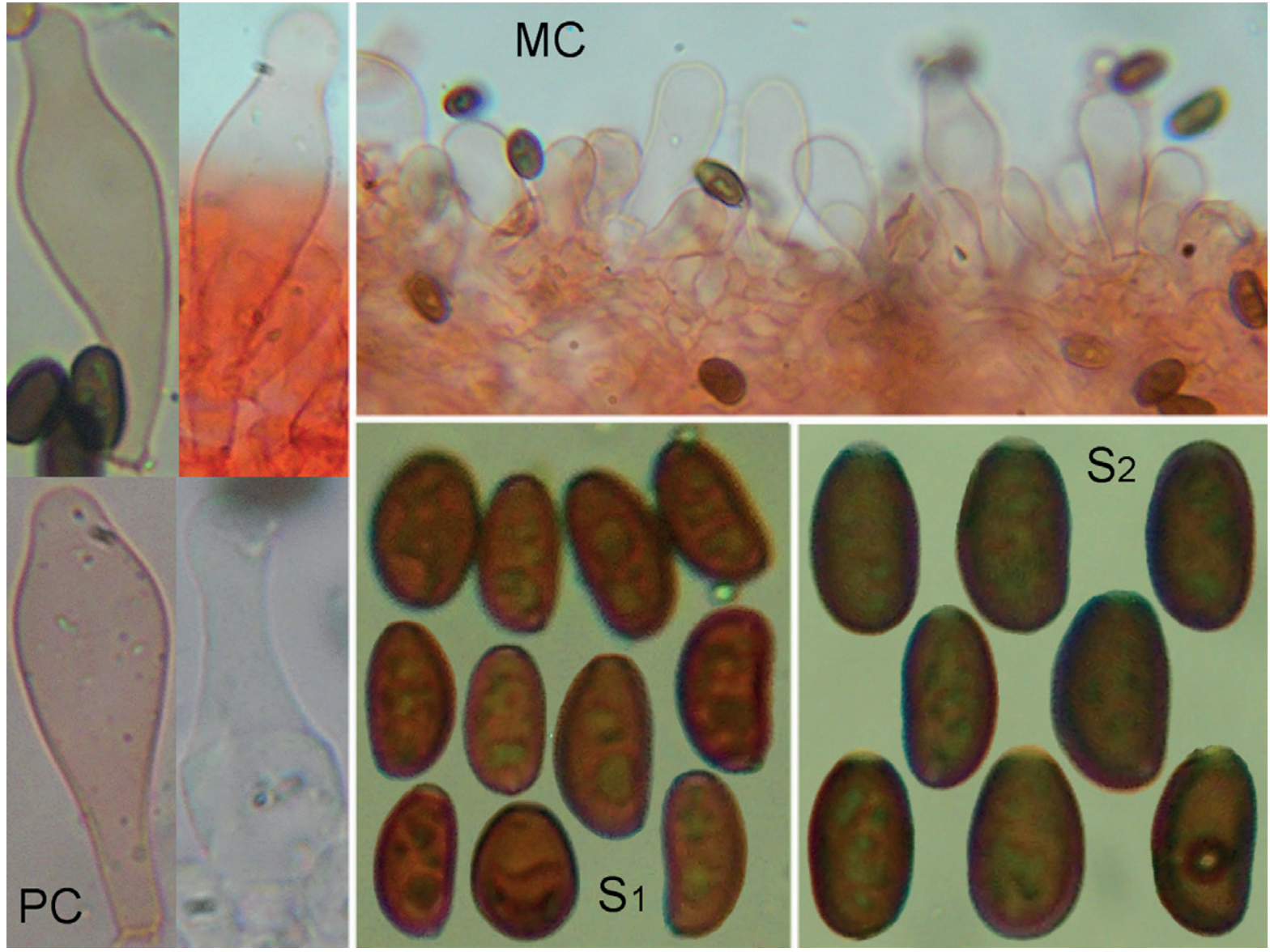

Fig. 54. Psathyrella pseudolimicola. A.H. Smith 65850, MICH5366; PC Pleurocystidia; MC Marginal Cystidia; S1 Spores in water; S2 Spores in $\mathrm{KOH}$. 
truncate, in profile (narrowly) adaxially flattened-ellipsoid to subphaseoliform, sometimes phaseoliform; reddish brown; germ pore distinct, rounded to subtruncate, 1.5-1.9 $\mu \mathrm{m}$ broad. Pleurocystidia 33-53 × 10-16(-19) $\mu \mathrm{m}$, utriform, sometimes ellipsoid-utriform, lageniform; apex rounded to obtuse, subcapitate or not; walls sometimes faintly pigmented; scattered to moderately numerous. Cheilocystidia $25-43 \times 12-13 \mu \mathrm{m}$, often (broadly) lageniform, sometimes cylindrical-utriform (recalling the broadly cylindrical-utriform pleurocystidium sketched by Smith 1972), scattered. Paracystidia up to $35 \times 15 \mu \mathrm{m}$, hyaline, numerous, dominating. Cells below gill edge hyaline.

Notes: Smith (1972) reports the spores 8.5-11 × 4.5-5 (up to $12 \times$ 6) $\mu \mathrm{m}$ as if he had found only a few broader spores. The molecular evidence places it beside the previous species, $P$. griseopallida, but at a consistent distance (DNA nucleotide homology: Tef-1 $\alpha=$ $95 \%)$. Smith (1972) commented having a doubt as to whether this species is coprophilous or not as 'it was not found on cow dung though ample opportunity was at hand'; on examination of the exsiccata multiple loosen dried leaves and a small amount of crumbled unidentifiable plant material were found in the box with the dried fungi but none attached at stipe bases. We presume the habitat to be either herbicolous or on nitrogen-rich soil.

24. Psathyrella velatipes A.H. Sm., Mem. N. Y. Bot. Gard. 24: 442. 1972. Fig. 55.

= Psathyrella ammophila (Durieu \& Lév.) P.D. Orton
Typus: Psathyrella velatipes A.H. Sm. USA, Michigan, Washtenaw Co., Ann Arbor, Liberty St., 30 Sep. 1971, A.H. Smith 80623 (MICH12106), gregarious-cespitose in a parking strip. Tef-1 $\alpha$ MF521774, ITS MF326004.

Loan for gross morphology investigation of four sporocarps, some of which broken.

Spores (8.2-)8.7-10.5(-12) ×5-5.8 $\mu \mathrm{m}$, on average $9.9 \times 5.5 \mu \mathrm{m}$, $\mathrm{Q}$ (1.5-)1.7-2.1(-2.2), avQ 1.8; in front view cylindrical-oblong to elliptic, base obtuse, in profile subamygdaliform, sometimes subphaseoliform, base often with a suprahilar depression; reddish brown; germ pore distinct, sometimes eccentric in profile, 1.8-2(-2.5) $\mu \mathrm{m}$ broad. Pleurocystidia 28-40 × 11-15 $\mu \mathrm{m}$; narrowly utriform, lageniform, sometimes fusiform-conical to flexuous, rarely ovoid-utriform to thickly utriform, often emerging for only $10 \mu \mathrm{m}$ length or less, neck often elongate; apex obtuse to rounded, sometimes subcapitate, rarely forked; scattered. Cheilocystidia 28-55 × 10-15 $\mu \mathrm{m}$, sometimes submucronate, pigment as in the paracystidia, rare to scattered towards margin of pileus, moderately numerous towards stipe. Paracystidia $-37 \times-21 \mu \mathrm{m}$, often incrusted, walls often thickened and yellowish pigmented moreover towards base, numerous, dominating. Cells below marginal cystidia often incrusted and yellowish pigmented.
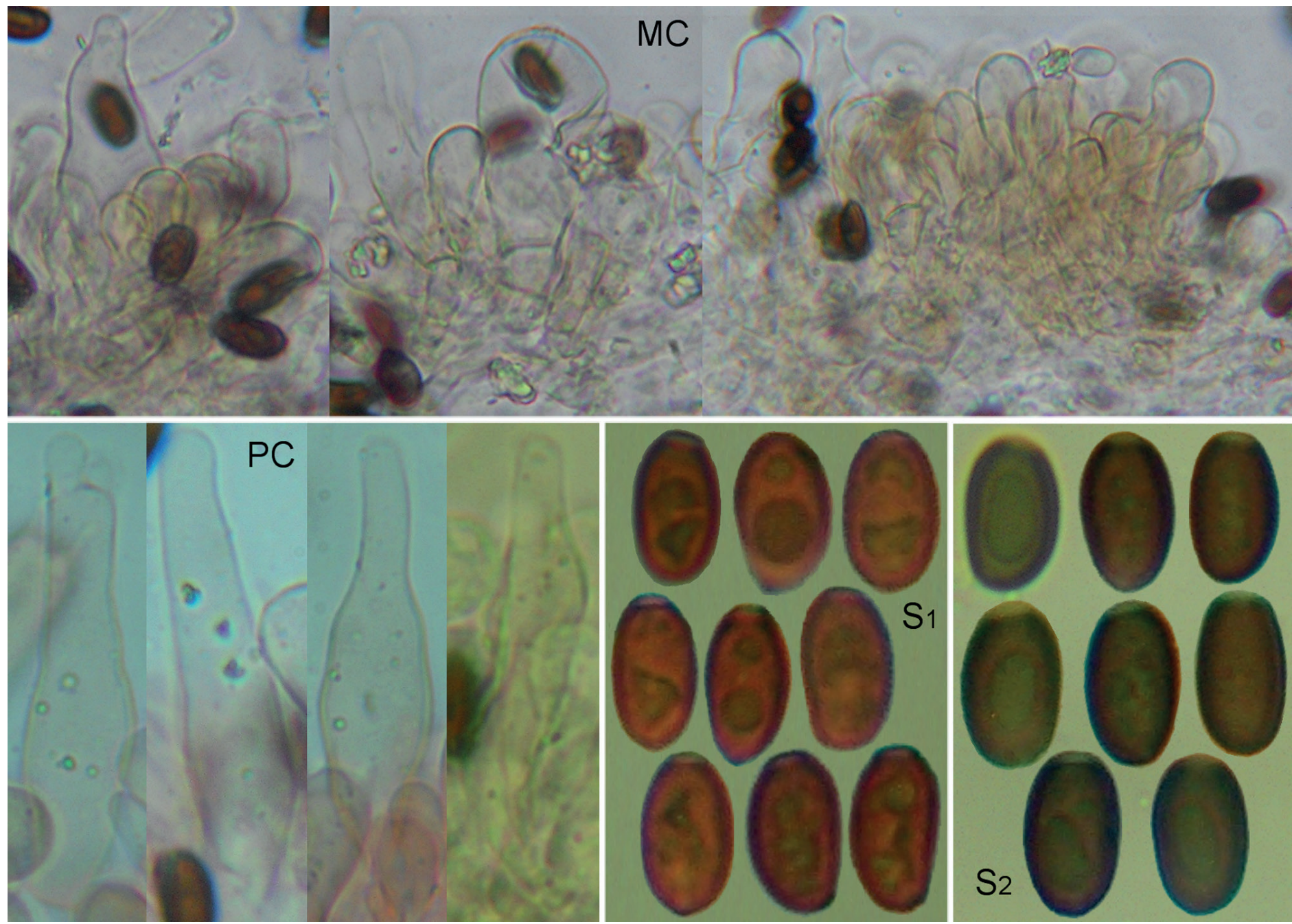

Fig. 55. Psathyrella velatipes. A.H. Smith 80623, MICH12106; MC Marginal Cystidia in KOH; PC Pleurocystidia; S1 Spores in water; S2 Spores in KOH. 
Notes: There is morphological and molecular evidence that this species corresponds to $P$. ammophila. The distinctly pigmented marginal cells recall the description of $P$. ammophila f. marginata by Bon (1988). Smith (1972) was particularly impressed by the 'distinct fibrillose scurfy' covering of the stipe, but we know that $P$. ammophila has initially a dense velar coating possibly leaving wooly layers on the stipe too. The habitat in Ann Arbor town, far away from the sea shore and sand dunes, is not an obstacle for recognition of this species as sand from river or lakeshore caves is often used in making the foundation of urban green areas; moreover coarse soil, probably including grains of sand, was found attached to the stipe base. The spores of $P$. ammophila are usually described as larger by European mycologists, but Heykoop et al. (2017) report collections with smaller spores, similar in size to those of $P$. velatipes. Actually this species spores have a very wide range, both in dimension and in quotient: (7.5-)8.5-14 × (4.7-) 5-8.5 $\mu \mathrm{m}$, avQ 1.5-1.9.

Smith (1972) considered $P$. arenulina the American counterpart of $P$. ammophila and Kits van Waveren (1985) treated it as a synonym. We have not studied this material but, basing on Smith's (1972) description, it shares almost all characters, including scarcity of pleurocystidia, indeed none reported ('normally very scarce and easily overlooked' in Kits van Waveren, 1972 for P. ammophila). Only the pileus is unusually 'widely and irregularly striate' while the spores in $\mathrm{KOH}$ are 'cocoa-color slowly becoming darker' which, as we explain further, generally corresponds to a medium, not dark, color in water. Overall we accept this synonymy.

Psathyrella dunarum, created on the base of a solitary sporocarp found on a mossy coastal sand dune, has a strongly striate pileus, scarce subobtusely lageniform pleurocystidia and orange-brown, 8-9 $\times$ 4.5-5.5 $\mu \mathrm{m}$, on average $8.7 \times 5.4 \mu \mathrm{m}$, spores. We see a strong correspondence between $P$. dunarum and $P$. ammophila therefore, unless molecular evidence should demonstrate convincingly the existence of an autonomous species, we consider them synonyms.

25. Psathyrella neotropica A.H. Sm., Mem. N. Y. Bot. Gard. 24: 108. 1972. Fig. 56.

Basionym: Drosophila pallidispora Murrill, Mycologia 10(2): 64 (1918). Typus: Cuba, Herradura, 17 Aug. 1907, F.S. Earle 572 (NY 00649148), in soil in a garden.

Loan for gross morphology investigation of fragments of pilei and stipes.

Spores (7-)8-12.2(-13.8) × 5-7.5(-8.5) $\mathrm{mm}[9-12(-13) \times 5-6.5$ $\mu \mathrm{m}$ in revision of Smith, 1972], on average $10.25 \times 6.4 \mu \mathrm{m}, \mathrm{Q}$ 1.3-1.9(-2.05), avQ 1.6; wall often irregular in shape or with protrusions, swellings or discontinuities, in front view suboval to elliptic, sometimes cylindrical, base rounded to truncate, in profile adaxially flattened, amygdaliform, subamygdaliform, elliptical, phaseoliform to subphaseoliform; yellowish; germ

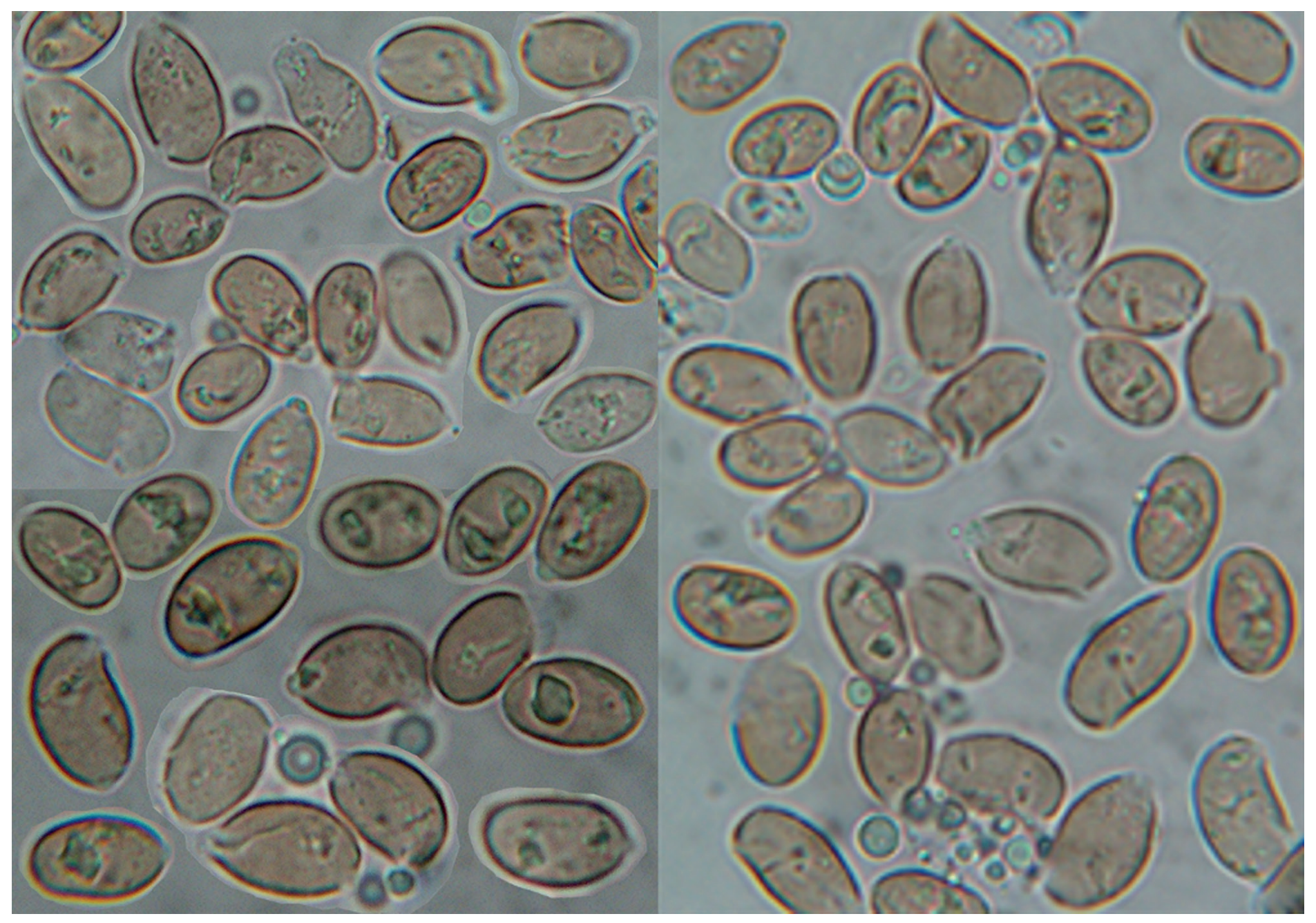

Fig. 56. Psathyrella neotropica. F. S. Earle 572, NY 00649148; Spores in $\mathrm{NH}_{4} \mathrm{OH}$. 
pore generally absent to indistinct (callus), sometimes as a protruding bubble in alkali, rounded, 1.5-1.8 $\mu \mathrm{m}$ broad when discernible. Hymenial cystidia, basidia and clamps could not be observed because the material revived very badly.

Notes: Unfortunately, DNA sequencing failed because of contamination and likewise our morphological revision too was strongly hampered by poor rehydration of the sample. However we are able to report an unpublished private revision, included in the holotype box, Pegler made in 1986 in which he reported spores 8.5-12×5.5-7 $\mu \mathrm{m}$, on average 9.5-10.5 × 5.7-6.3 $\mu \mathrm{m}, \mathrm{Q}$ 1.4 , very pale, pleurocystidia ventricose-fusoid, cheilocystidia spheropedunculate. Pegler's notes seem to clearly implicate that paracystidia are dominating on the gill edge; this and the description by Smith (1972) of broadly rounded apex of pleurocystidia confidently places this taxon into subsection Spadiceogriseae. Beyond the anomalous characteristics of the spore outline, which we tend to view as a casual sufferance and not as a taxonomical attribute, we can remark on the short pleurocystidia, 28-37 × 10-14 $\mu$ m, as reported by Smith (1972). Although we cannot know its phylogenetic position, for some traits this material is reminiscent of the European $P$. clivensis which we have not found in any of the American materials studied.

26. Psathyrella septentrionalis A.H. Sm., Mem. N. Y. Bot. Gard. 24: 134. 1972. Fig. 57.

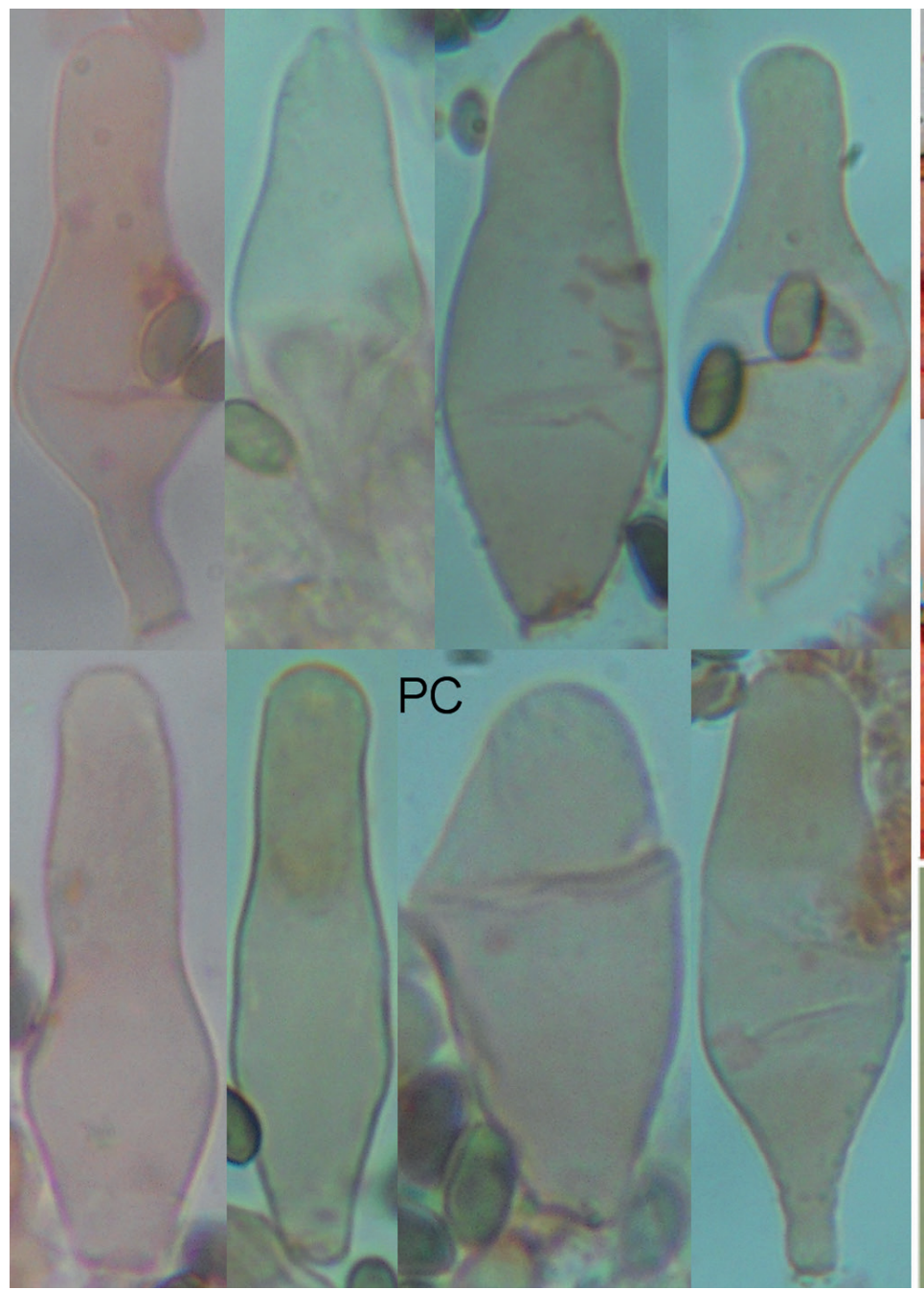

Typus: Psathyrella septentrionalis A.H. Sm. USA, Michigan, Chippewa Co., Tahquamenon Falls State Park, near Paradise, 2 Jul. 1951, D. Palmer 36553 (MICH12045), on hardwood. ITS MF326014.

Loan of two sporocarps and a pileus in good condition for micromorphology investigation.

Spores (7-)7.3-8.7(-9) × 4.1-5(-5.2) $\mu \mathrm{m}, \mathrm{Q}$ 1.6-2(-2.1); in front view elliptic to narrowly oval, base obtuse, sometimes rounded, in profile adaxially flattened to subphaseoliform, sometimes distinctly phaseoliform; orangish to reddish brown; germ pore distinct, 1-1.5(-1.7) $\mu \mathrm{m}$ broad. Pleurocystidia 35-53 $\times(7-) 9.5-20(-22) \mu \mathrm{m}$, utriform to obtusely ventricose-conical, sometimes cylindrical-ellipsoid, conical to sublageniform; apex obtuse to rounded, rarely subacute, sometimes subcapitate or somewhat irregular, rarely capitate, rarely incrusted; moderately numerous to numerous. Cheilocystidia 24-50 × 13$22(-25) \mu \mathrm{m}$, numerous to abundant, dominating. Paracystidia 8-15 × 6-10 $\mu \mathrm{m}$ and numerous, $15-20 \times 10-15$ and moderately numerous.

Notes: This is one of those species where we could not know, by means of Smith's (1972) vague description only, whether or not it had the attributes of subsection Spadiceogriseae; molecular evidence and abundant, dominating cheilocystidia clearly exclude it.

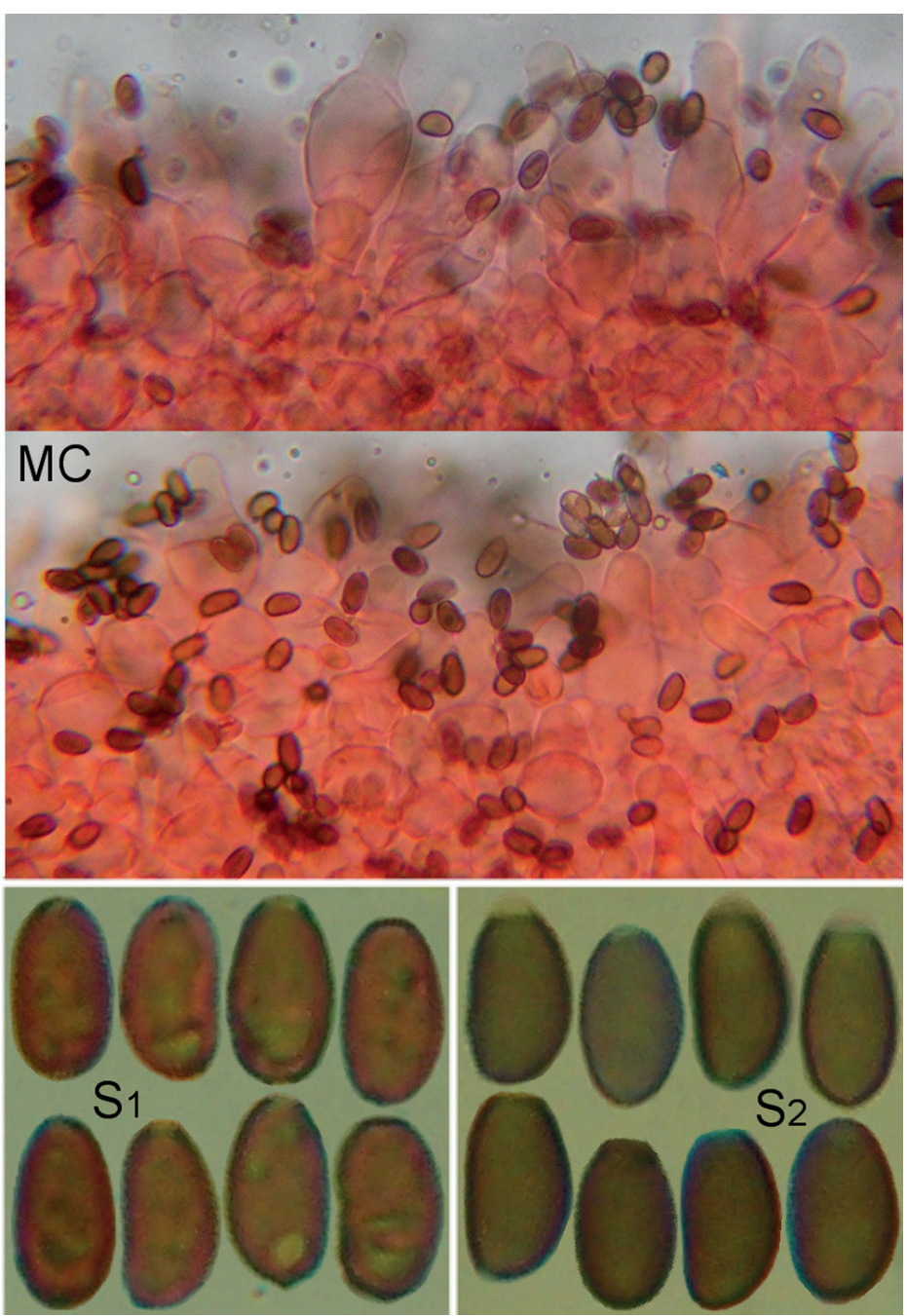

Fig. 57. Psathyrella septentrionalis. D. Palmer 36553, MICH12045; PC Pleurocystidia; MC Marginal Cystidia; S1 Spores in water; S2 Spores in KOH. 


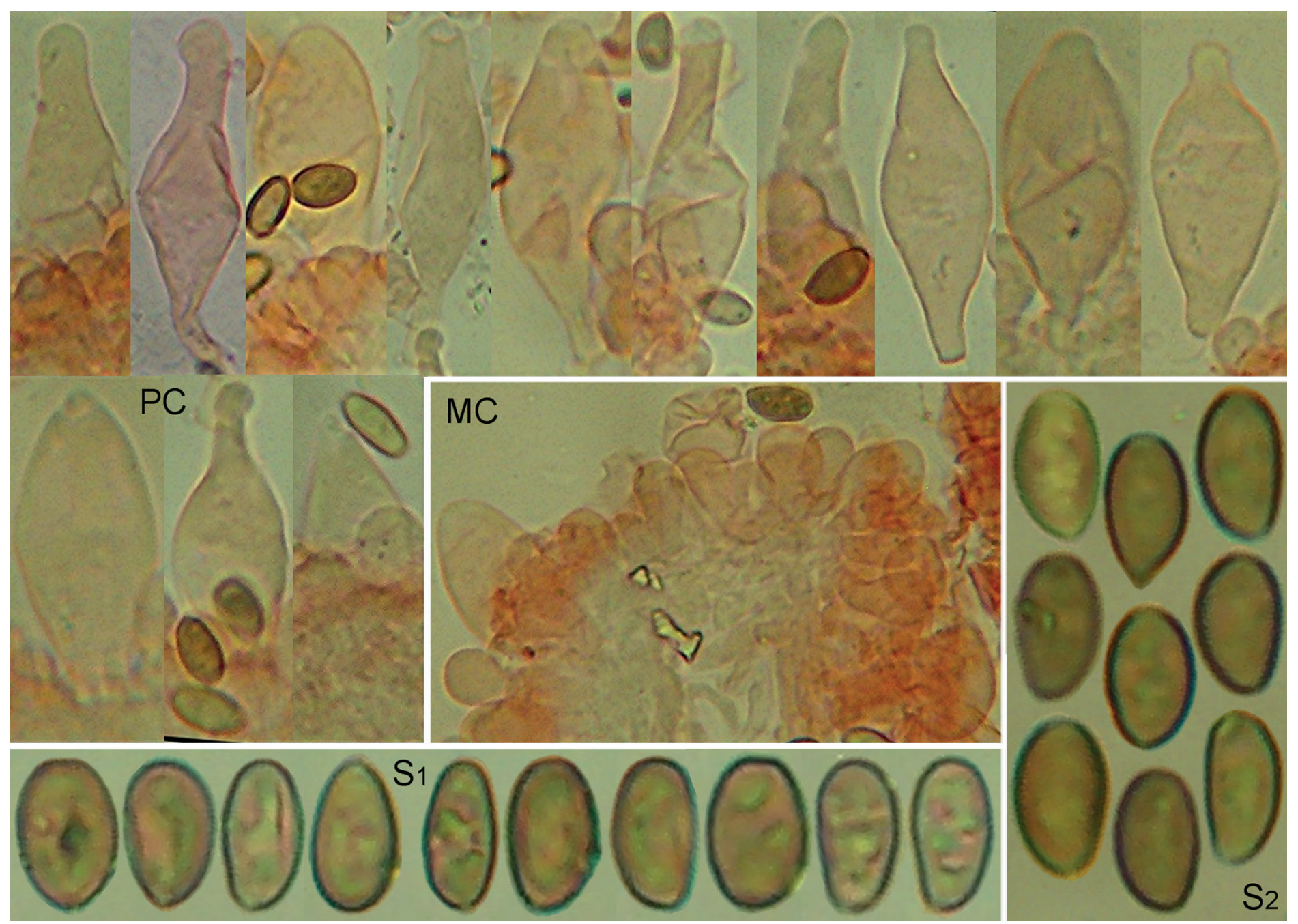

Fig. 58. Psathyrella vesiculosa. A.H. Smith 63485, MICH12044; PC Pleurocystidia; MC Marginal Cystidia; S1 Spores in water; S2 Spores in KOH.

27. Psathyrella vesiculosa (A.H. Sm.) Voto, Dovana \& Garbel, comb. nov. MycoBank MB831130. Fig. 58.

Basionym: Psathyrella septentrionalis var. vesiculosa A.H. Sm., Mem. N. Y. Bot. Gard. 24: 136. 1972. A.H. Smith 63485, $\mathrm{MICH} 12044$.

Typus: Psathyrella septentrionalis var. vesiculosa A.H. Sm., USA, Michigan, Chippewa Co, Tahquamenon River, White House Landing, 30 Jun. 1961, A.H. Smith 63485 (MICH12044), cespitose on hardwood logs. ITS MF326015.

Loan of two sporocarps and a pileus in good condition for micromorphology investigation.

Spores 6.9-9.9(-10.6) × 3.5-5.5 $\mu \mathrm{m}, \mathrm{Q}$ 1.4-2.1(-2.6), avQ 1.8-1.9; in front view oblong to elliptic, base obtuse to attenuate, in profile adaxially flattened or with a faint suprahilar depression, sometimes amygdaliform, subamygdaliform to subphaseoliform; pale orange-brown, pale dull orange; germ pore indistinct (callus), $\pm 1,5-1,7 \mu \mathrm{m}$ broad. Pleurocystidia 29-50 $\times(10-) 13-17 \mu \mathrm{m}$, utriform, fusiform, conical, clavate-mucronate to lageniform, sometimes ellipsoid; apex obtuse to subacute, sometimes subcapitate; very numerous. Cheilocystidia 30-45 $\times$ 9-15 $\mu \mathrm{m}$, apex often subacute, scattered. Paracystidia 7-37 $\times 4-20 \mu \mathrm{m}$, apex sometimes obscurely mucronate to obscurely acutely papillate, hyaline, numerous, dominating.
Notes: Smith (1972) described the spores of $P$. septentrionalis var. vesiculosa as 'in $\mathrm{KOH}$ chocolate color, gradually fading and with an ochraceous tinge (in about three hours)' and with a distinct germ pore, but we found them distinctly pale immediately and the germ pore indistinct; he also detected longer pleurocystidia, up to $60 \mu \mathrm{m}$. Psathyrella septentrionalis and $P$. vesiculosa show a molecular proximity (DNA nucleotide homology: ITS = $99 \%$ with five mismatches) but there are a number of micro morphological elements that distinguish $P$. vesiculosa, such as the spores (distinctly paler, somewhat slenderer, often attenuate at base, scarcely subphaseoliform), the gill edge dominated by the paracystidia, and partly the pleurocystidia which are somewhat slenderer and less rounded at apex. In macro morphology, we also notice that the pileus of $P$. septentrionalis is described as obtuse to convex, expanding from broadly convex to plane (Smith's plates $43 \mathrm{~b}, 46 \mathrm{a}$ and $46 \mathrm{~b}$ clearly confirm this), while the pileus of $P$. vesiculosa is described as obtusely conical becoming campanulate. Predominance of paracystidia and, partly, shape of pleurocystidia may induce to consider $P$. vesiculosa a possible member of subsection Spadiceogriseae, but it has a colored veil and, as we anticipated in the introduction, this parameter has to be given a relevant discriminating importance. This is one of those species evidencing that dominating paracystidia alone are not exclusive of subsection Spadiceogriseae. 
28. Psathyrella velibrunnescens A.H. Sm., Mem. N. Y. Bot. Gard. 24: 128. 1972. Fig. 59.

Typus: Psathyrella velibrunnescens A.H. Sm. USA, Washington, Jefferson Co., Bottom, Clearwater River, 9 May 1939, A.H. Smith 13240 (MICH12107), on Alnus debris.

Loan of a slice of a pileus for micro-morphology investigation.

Spores 7.7-9.5(-10) × 4.5-5.1(-5.4) $\mu \mathrm{m}, \mathrm{Q}$ 1.6-2.1(-2.2), avQ 1.8; in front view oblong to elliptic, sometimes oval, base mainly obtuse, in profile adaxially flattened to subphaseoliform; dull orangish or paler; germ pore indistinct (callus). Pleurocystidia 40-79 $\times$ 9-17 $\mu \mathrm{m}$, utriform to subcylindrical, often elongatecylindrical in upper part; apex mainly rounded, sometimes or often (irregularly) subcapitate; very numerous. Cheilocystidia 27-51 × 9-12(-19) $\mu \mathrm{m}$, scattered. Paracystidia 9-41×5-23 $\mu \mathrm{m}$, numerous, dominating. No pigment or incrustation seen on any type of cystidia.

Notes: Unfortunately DNA extraction failed on this material, but, based on morphological evidence, we consider $P$. velibrunnescens to pertain to the $P$. septentrionalis complex. We note that Kits van Waveren (1985), on the contrary, regards it as an American subspecies of $P$. chondroderma ( $=P$. pertinax). For further comment see notes to the following species.
29. Psathyrella aff. kauffmanii, Czech Republic, Bohemia, Volary, Černý Kř́žz, Mount Šumava, Jelení vrch area, 870 m. a.s.I., 13 Jul. 2000, J. Holec 61/2000 (PRM897750, erroneously registered in GenBank as BRNM:705626), gregarious on very rotten trunk of Fagus sylvatica in a mixed forest with also Picea abies and Abies alba. ITS AM712260.

\section{?= Psathyrella velibrunnescens $\mathrm{A} . \mathrm{H}$. Sm.}

(Description produced from data and images received from Vašutová).

Pileus 15-40 mm, campanulate, red-brown, hygrophanous, distinctly radially rugulose. Veil yellowish whitish at margin of pileus. Lamellae pale violet-brown. Stipe 40-70 × 7-9 mm, cylindrical, whitish, brownish towards the base, innately white marbled. Smell rubber-like. Spores 7.5-9 × 4-5 $\mu \mathrm{m}, \mathrm{Q} \pm 1.7-2.1$, avQ \pm 1.8 , in front view elliptic, in profile subphaseoliform, rarely subamygdaliform to adaxially flattened, light to medium brown, germ pore little distinct (callus). Pleurocystidia (40-) 46-60 $(-72) \times 12-14 \mu \mathrm{m}$, utriform to sublageniform, with apex obtuse to rounded, rarely subacute. Cheilocystidia 30-40 × 11$15 \mu \mathrm{m}$, scattered. Paracystidia 20-34 × 9-13 $\mu \mathrm{m}$, numerous, dominating.

Notes: When blasting the ITS sequences of $P$. septentrionalis and $P$. vesiculosa in GenBank we have discovered that they allied with $P$. aff. kauffmanii from Europe synthetically
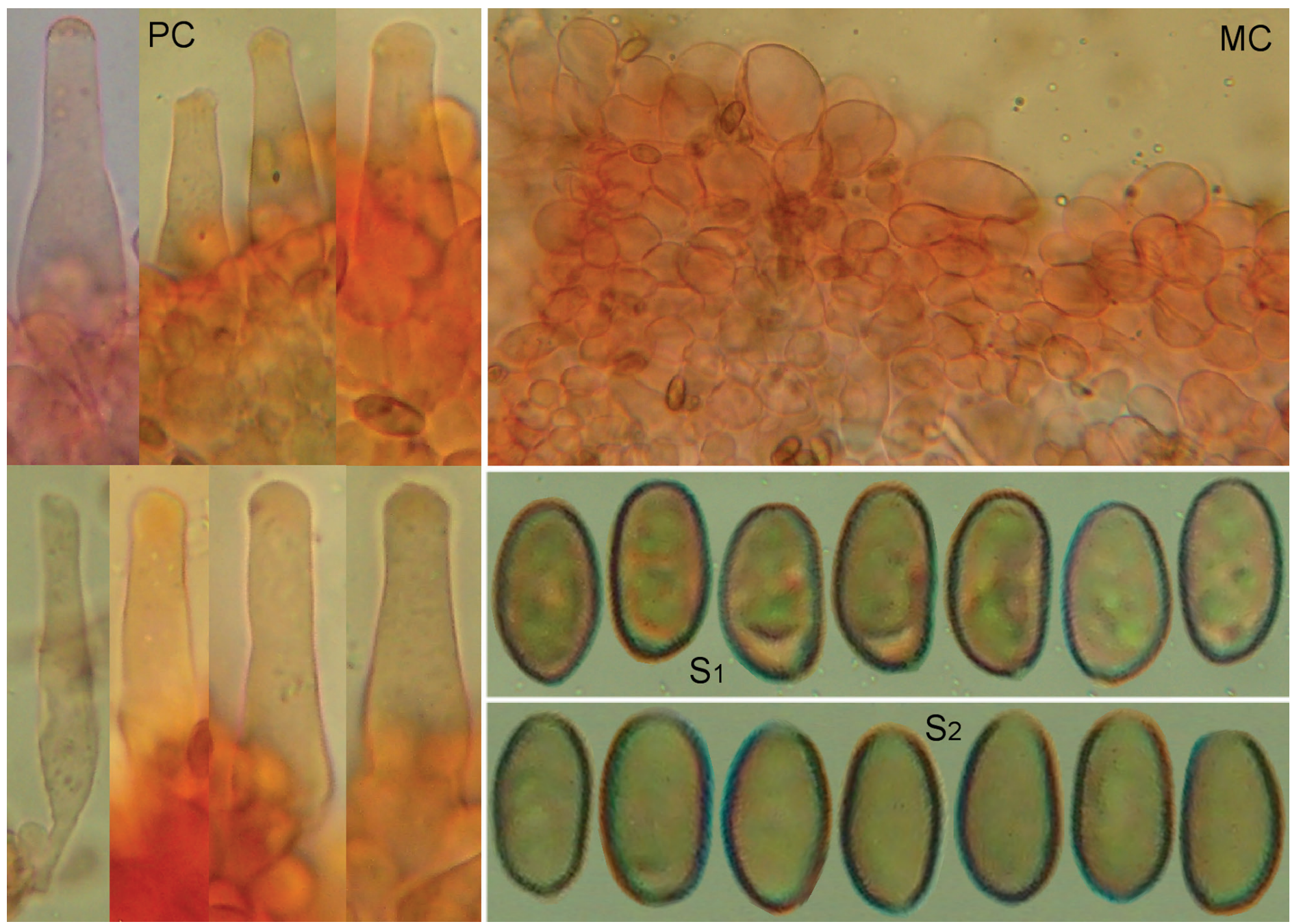

Fig. 59. Psathyrella velibrunnescens. A.H. Smith 13240, MICH12107; PC Pleurocystidia; MC Marginal Cystidia; S1 Spores in water; S2 Spores in KOH. 
described in Vašutová et al. (2008). Upon our request, Vašutová has provided us with a more detailed description, has shown us some images of microscopical characters, and has discussed with us the molecular outcome. Various characters link $P$. aff. kauffmanii to $P$. vesiculosa: the gill edge dominated by paracystidia, the pale spores, the little distinct germ pore, the slender pleurocystidia, the yellowish veil at the margin of a campanulate pileus; on the contrary the often phaseoliform spores with rounded, not attenuate base seem to differentiate them; moreover P. aff. kauffmanii has very thickset, 7-9 $\mathrm{mm}$ broad, stipes, while $P$. vesiculosa has slender, $1.5-5 \mathrm{~mm}$ broad stipes. A more interesting comparison, though not based on phylogenetic data, can be made with the unsequenced $P$. velibrunnescens. A very strong correspondence can be noticed between the two, both in gross and micro characters as well as in the lignicolous habitat and, but for the lack of molecular support, we would suggest their conspecificity. However, while we wish Vašutová to find and describe it again in more detail, surely $P$. aff. kauffmanii has been shown to be a European species on its own right. It only remains to understand whether it may be autonomous from or conspecific with any of the American species of the phylogenetic cluster to which it belongs.

Psathyrella conica, recently described from China, shares many morphological characters with the last three species here described, namely $P$. vesiculosa, $P$. velibrunnescens and $P$. aff. kauffmanii. Like them, it has paracystidia dominating, utriform pleurocystidia, pale spores with an indistinct or absent germ pore, campanulate to conical pilei and a lignicolous habitat. Moreover, like them it is molecularly outside of spadiceogrisea clade and has a veil which its authors have noticed not to be merely white ('white to dirty white'). We strongly suspect that, just as $P$. aff. kauffmanii is a European representative of $P$. vesiculosa group, $P$. conica could be instead an Asian member of the same group.

30. Psathyrella obtusata (Fr.) A.H. Sm., Contr. Univ. Mich. Herb. 5: 55. 1941, sensu Smith, Mem. N. Y. Bot. Gard. 24: 385. 1972.

We have attempted to understand Smith's (1972) concept of $P$. obtusata by examining three Smith vouchers, Ammirati 2811, Harrison 8023 and Smith 73998, selected for this purpose by $\mathrm{MICH}$ staff. Our revision of these materials has revealed that they represent three different species: Harrison 8023 has the gill edge dominated by the cheilocystidia, Ammirati 2811 and Smith 73998 have the gill edge lined with numerous paracystidia often mucronate to attenuate at the apex.

30a. J.F. Ammirati 2811, MICH49136.

= Psathyrella obtusata (Fr.) A.H. Sm.

Material examined: USA, Michigan, Baraga Co., Huron River, Skanee Road, 25 Jun. 1969, on hardwood log.

Loan of two sporocarps in good condition for micro-morphology investigation.

The original gross description by the collector reports pilei color ranging from watery sayal brown to dark brown, fading to clay color at centre and tan at margin; stipe more or less up to 6 $\mathrm{mm}$ broad at apex, white fibrillose, sordid brownish in age; odor slight, taste slightly raphanoid. Spores (5.5-)6.7-8.3(-9.1) × 4.35.6(-6) $\mu \mathrm{m}, \mathrm{Q}$ 1.4-1.7; in front view elliptic to oval, sometimes somewhat irregular, base generally rounded, in profile adaxially flattened to subphaseoliform; dull orangish to reddish orangish; germ pore little distinct, small. Pleurocystidia (35-)40-63 $\times$ (7.5-)8-16(-17.5) $\mu \mathrm{m}$; narrowly utriform, narrowly fusiform, (flexuously) conical, sometimes sublageniform; apex obtuse, sometimes subacute, rarely subcapitate to submucronate, often incrusted; walls sometimes slightly thickened and pale yellowish below apex; numerous. Cheilocystidia 28-43 × 8.5-15.5 $\mu \mathrm{m}$, locally scattered to numerous, locally dominating. Paracystidia 13-40 × 9.5-20(-27) $\mu \mathrm{m}$, often mucronate to attenuate, yellowish, often incrusted towards base, numerous, locally dominating. Cells below marginal cystidia yellowish pigmented and incrusted.

Note: We failed to sequence this material but it has the typical characters of $P$. obtusata.

30b. K.A. Harrison 8023, MICH65721. Fig. 60.

= Psathyrella atomatoides (Peck) A.H. Sm.

Material examined: Canada, Nova Scotia, Victoria Co., Forks Baddeck, 22 Sep. 1968, densely cespitose on sawdust pile. K.A. Harrison 8023, MICH65721. ITS MF326013.

Loan of numerous sporocarps in good condition for micromorphology investigation.

The original gross description by the collector reports pilei up to $3.6 \mathrm{~cm}$ broad, slightly conic to subumbonate, sometimes expanding to nearly convex, hygrophanous, when young dark brown, when dried tan, radially striate, veil connecting pileus and stipe when young then fibrillose on margin; gills up to 2 $\mathrm{mm}$ broad, close, dark smoky brown; stipe 30-35 × 3-4 mm, covered by fibrils. Spores 6.8-8.5(-9.1) × 3.8-4.8 $\mu \mathrm{m}, \mathrm{Q} 1.5-$ 1.9(-2.1); in front view oblong, elliptic to oval, base generally obtuse, in profile amygdaliform, subamygdaliform to adaxially flattened, sometimes subphaseoliform to narrowly elliptic or subfusiform; strong orange-brown to red-orange; germ pore indistinct to little distinct, small. Pleurocystidia 45-65 × 10-15(17) $\mu \mathrm{m}$; lageniform to conical, sometimes subutriform, fusiform, irregularly cylindrical-mucronate; apex subobtuse to subacute, rarely subcapitate, often incrusted; walls often thickened and yellowish to yellowish brownish below apex; numerous to moderately numerous. Cheilocystidia 32-60 × 10-12 $\mathrm{mm}$, more often fusiform-conical, scattered near pileus margin, numerous elsewhere, dominating. Paracystidia 22-28 × 9-10 $\mu \mathrm{m}$, often incrusted, more or less scattered, numerous near pileus margin. Cells below marginal cystidia pigmented near pileus margin, hyaline elsewhere.

Notes: This material is in good molecular concordance, though with evidence provided by only one locus (DNA nucleotide homology: ITS= $99 \%$ with 1 mismatch), with $P$. atomatoides; morphology too is very similar except for the distinct reddish pigmentation of the gill edge in a short, $3 \mathrm{~mm}$ long, segment near the pileus margin, in correspondence with the dominance zone of the paracystidia. 

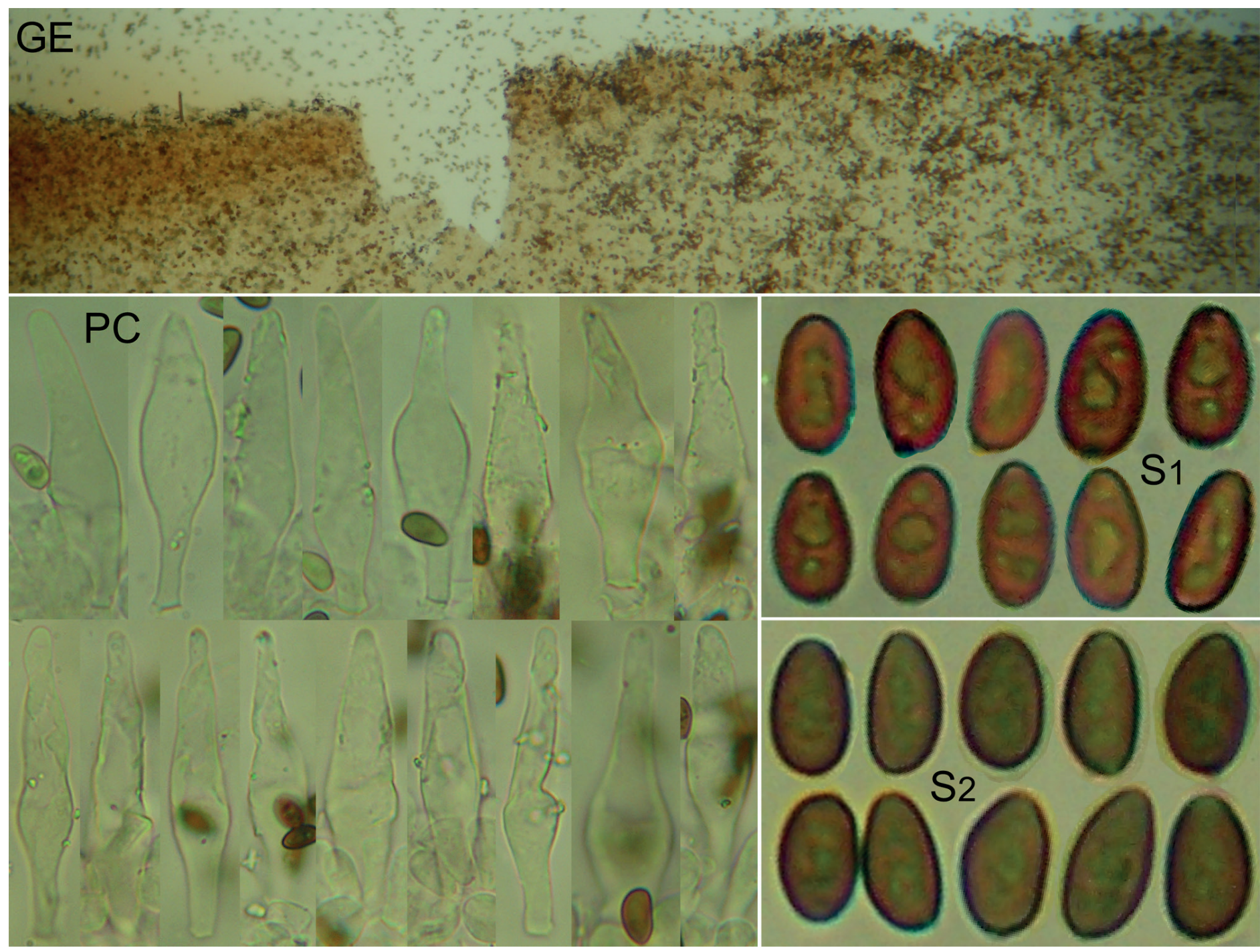

Fig. 60. Psathyrella obtusata. K. A. Harrison 8023, MICH65721; GE Gill edge at pileus margin; PC Pleurocystidia in $\mathrm{NH}_{4} \mathrm{OH}$; $\mathrm{S} 1 \mathrm{Spores}$ in water; $\mathrm{S} 2$ Spores in $\mathrm{KOH}$.

30c. A.H. Smith 73998, MICH33261. Fig. 61.

$=?$

Material examined: USA, Idaho, Bonner co., Priest River, Priest River Experimental Forest, 6 Oct. 1966, on debris of cedar slash, A.H. Smith 73998, MICH33261. ITS MF326012.

Loan of five, entire or broken, sporocarps in good condition for micro-morphology investigation.

The original gross description by the collector reports pilei watery tawny when moist, striate half way; veil of white particles at margin; gills broad, adnate, when young brownish, when mature near hair brown; stipe pallid, soon honey below, thinly fibrillose. Spores 7-8.5(-9.2) × 4.2-5 $\mu \mathrm{m}$, on average $7.9 \times 4.55 \mu \mathrm{m}, \mathrm{Q} 1.5-$ 2 , avQ 1.7; in front view elliptic to oval, base rounded to obtuse, in profile amygdaliform, subamygdaliform to somewhat adaxially flattened, sometimes subphaseoliform; reddish brown; germ pore distinct, rounded to truncate, 1.4-1.7 $\mu \mathrm{m}$ broad. Pleurocystidia 29-45(-52) × 10-16 $\mathrm{mm}$; variable, ellipsoid, fusiform, conical, lageniform, sometimes narrowly utriform, sublageniform, flexuous; apex subacute to obtuse, sometimes acute, rarely minutely rounded subcapitate, sometimes incrusted; numerous to moderately numerous. Cheilocystidia $21-33 \times 8.5-12(-14) \mu \mathrm{m}$, moderately numerous to locally rare. Paracystidia $14-23(-26) \times$ 8-12.5 $\mu \mathrm{m}$, often mucronate to subpapillate, hyaline, numerous. Cells below marginal cystidia hyaline.

Notes: This voucher corresponds neither to any European species, nor to any American material sequenced in this work; however phylogenetic analysis, though based on one locus only, clearly places it outside subsection Spadiceogriseae. Smith (1972) has described some species with Pennatae-type pleurocystidia and a conspicuous presence of paracystidia on the gill edge so it should be placed among, and compared with, them, which is outside this paper's purpose.

31. Psathyrella limicola var. subpectinata A.H. Sm., Mem. N. Y. Bot. Gard. 24: 416. 1972.

Typus: Psathyrella limicola var. subpectinata A.H. Sm. USA, Wyoming, Carbon Co., Lower French Creek, Medicine Bow Mountains, 30 Jun. 1950, A.H. Smith 34407 (MICH11965), gregarious on wet soil along stream. ITS MF325980.

Loan for gross morphology investigation of three sporocarps in good condition. 


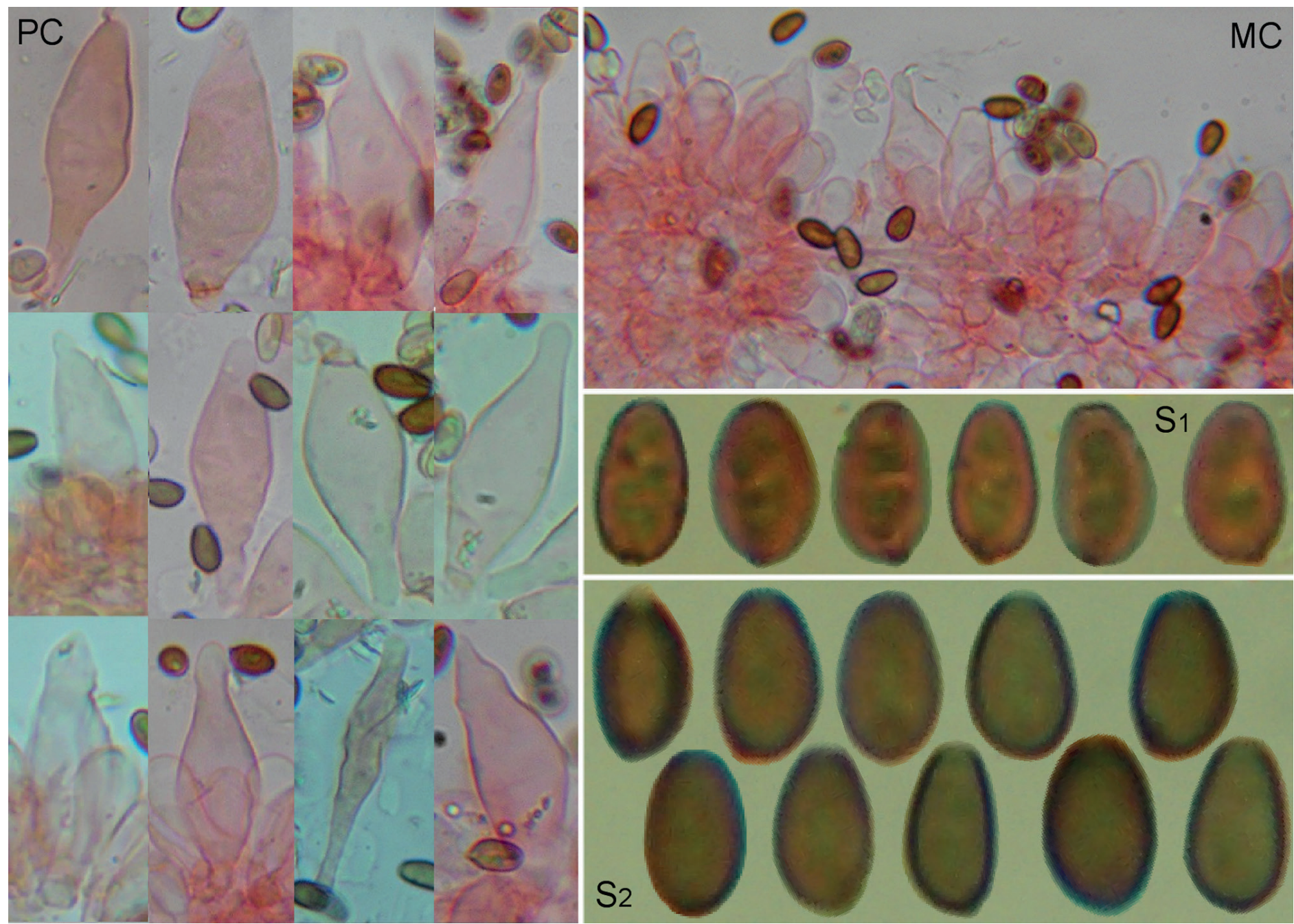

Fig. 61. Psathyrella obtusata. A.H. Smith 73998, MICH33261; PC Pleurocystidia; MC Marginal Cystidia; S1 Spores in water; S2 Spores in KOH.

Spores 6.8-9.3 × 3.8-5 $\mu \mathrm{m}, \mathrm{Q}(1.6-) 1.8-2.1(-2.3)$, avQ 1.9; in front view (narrowly) oval to elliptic, base rounded, in profile subamygdaliform to subphaseoliform, sometimes adaxially flattened; reddish brown; germ pore indistinct to moderately distinct, sometimes distinct, rounded to truncate, 1.2-1.6 $\mu \mathrm{m}$ broad. Pleurocystidia 29-41 × 10-13 $\mu \mathrm{m}$; utriform to fusiform-utriform; apex subrounded, sometimes subcapitate, sometimes weakly incrusted, walls slightly pigmented; moderately numerous. Cheilocystidia 20-30(-37) × 8-10 $\mu \mathrm{m}$, walls sometimes thickened and weakly pigmented in lower half, generally numerous, generally dominating. Paracystidia $8-20(-28) \times 6-13 \mu \mathrm{m}$, sometimes irregular, walls in larger ones sometimes thickened and weakly pigmented, numerous, locally dominating where larger ones are crowded. Cells below marginal cystidia sometimes with thickened and weakly pigmented walls.

Notes: This material has a $99 \%$ ITS nucleotide homology with a number of species outside of subsection Spadiceogriseae: $P$. warrenensis, P. seminuda, P. fagetophila, and Smith 28713, one of the Smith vouchers under the name of $P$. agrariella.

32. Psathyrella affinis A.H. Sm., Mem. N. Y. Bot. Gard. 24: 232. 1972. Fig. 62.

Paratype: Psathyrella affinis A.H. Sm. USA, Michigan, Oakland Co., Highland Lake, 14 Jun. 1945, A.H. Smith 20414 (MICH11857), gregarious to scattered on wet leaves in swamp.
Loan for gross morphology investigation of two pilei.

Spores (6.8-)8-10.4(-12.5) × (4.6-)5.4-6.2(-6.8) بm, Q (1.4-)1.51.6(-2.1); in front view (broadly) oval, sometimes subtriangular to elliptic, base often subtruncate, in profile adaxially flattened, elliptic, subphaseoliform; orange-brown; germ pore distinct to indistinct, sometimes eccentric in profile, rounded, 1.3-1.6 $\mu \mathrm{m}$ broad. Basidia 8-13 $\mu \mathrm{m}$ broad, some 2-spored. Pleurocystidia 25$40 \times 10-17(-20) \mu \mathrm{m}$; ventricose-lageniform, sometimes utriform to lageniform; apex 4.5-6(-7.5) $\mu \mathrm{m}$ broad, obtuse, sometimes subobtuse to subrounded, sometimes subforked; more or less moderately numerous. Cheilocystidia 27-38 ×11-15 $\mu \mathrm{m}$, more or less scattered to locally absent. Paracystidia 7.5-31(-36) × 7-17(22.5) $\mu \mathrm{m}$, often incrusted towards base, walls sometimes faintly pigmented, numerous, dominating.

Notes: Unfortunately we failed to sequence this material, so we have no molecular information about its phylogenetic position. The pleurocystidial shape is particular: the obtuse, never rounded nor acute to subacute, apex is somewhat ambiguous but the neck is much slenderer than the ventricose portion, looking on the whole unfit for section Spadiceogriseae.

\section{Psathyrella nitens A.H. Sm.}

Because of scarcity of material, the holotype could be obtained for DNA sequence only. The MICH staff has selected four other 


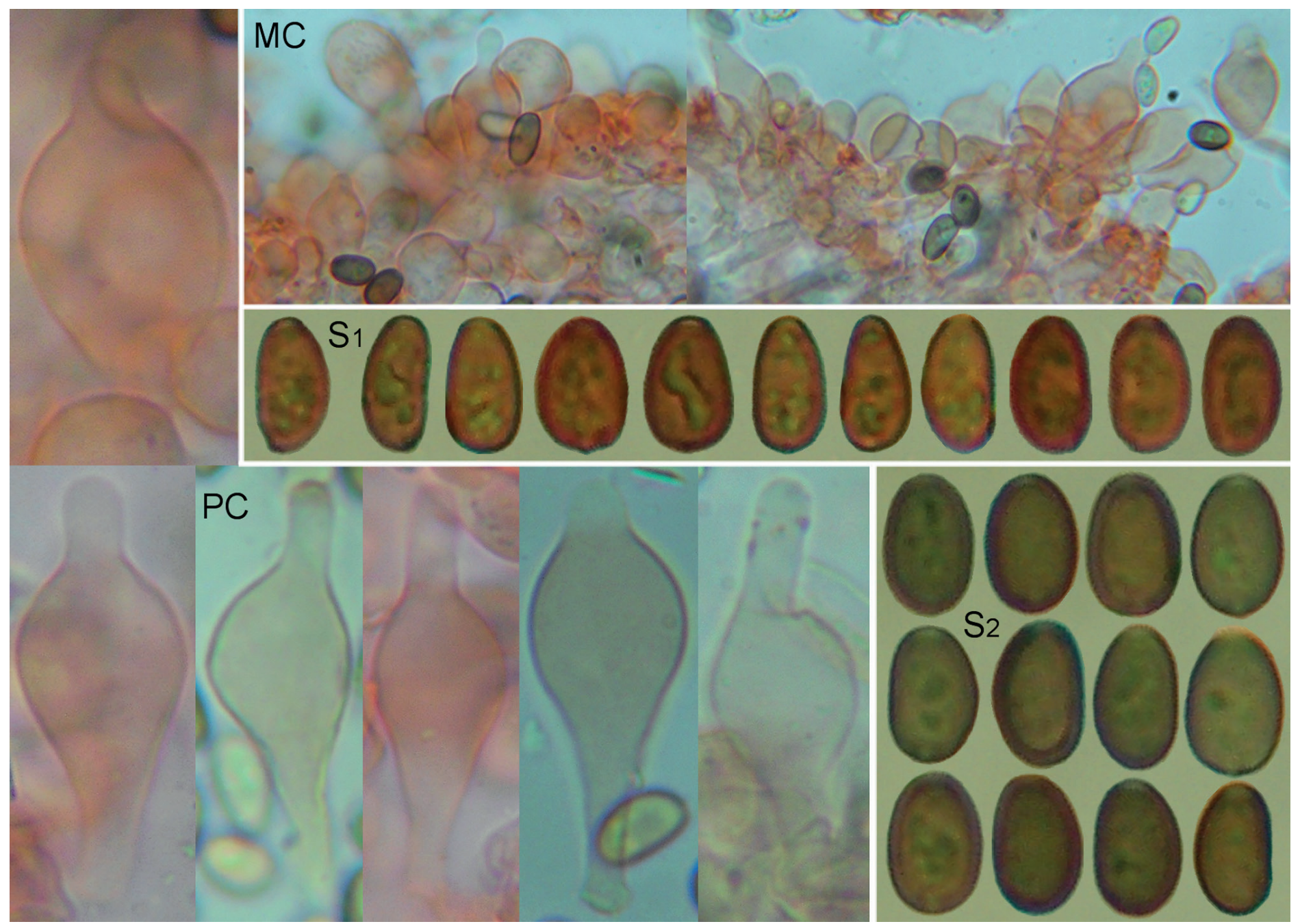

Fig. 62. Psathyrella affinis. A.H. Smith 20414, MICH11857; PC Pleurocystidia; MC Marginal Cystidia; S1 Spores in water; S2 Spores in KOH.

collections from the same site by Smith and deposited under the same name for micro-morphology investigation. Two of them, Smith 30241 and Smith 30239, correspond molecularly to the holotype and morphologically to the description given by Smith (1972) therefore they are confidently assigned to the typical P. nitens. Smith 29642 deviates significantly from the holotype (DNA nucleotide homology: ITS= $99 \%$, Tef-1 $\alpha=94 \%$ ) and we have found that the spores are appreciably smaller, the pleurocystidia and paracystidia are somewhat smaller and the apex of the pleurocystidia are more obtuse. Smith 30175 is distinctly closer to Smith 29642 (DNA nucleotide homology: ITS= $99 \%$ with 1 mismatch) than to the other three vouchers (DNA nucleotide homology: ITS= $99 \%$ with 8 to 9 mismatches) and it too displays the same differences exactly as found in Smith 29642 therefore they are conspecific; we consider them a separate taxon from $P$. nitens and report their morphological revision in a unified description. All these vouchers fall outside of subsection Spadiceogriseae and nest beside P. obtusata; their pleurocystidia are never thickly utriform and the apex is sometimes more or less acute but never rounded, the gill edge has often intermediate, mucronate to rhomboid, cells.

33a. Psathyrella nitens A.H. Sm., Mem. N. Y. Bot. Gard. 24: 320. 1972.

Typus: Psathyrella nitens A.H. Sm. USA, Washington, Pierce Co., Mt. Rainier National Park, Lower Tahoma Creek, 21 Aug.
1948, A.H. Smith, 30388 (coll. D.E. Stuntz) (MICH11983), on debris; only for molecular sequence. Tef-1 $\alpha$ MF521789, ITS MF325982.

Loans for micro-morphology investigation: USA, Washington, Pierce Co., Mt. Rainier National Park, Lower Nisqually, 18 Aug. 1948, A.H. Smith 30239 (MICH33251), on debris, Tef-1 $\alpha$ MF521787, ITS MF325985; USA, Washington, Pierce Co., Mt. Rainier National Park, Lower Tahoma, 18 Aug. 1948, A.H. Smith 30241 (MICH33252), on alder debris, Tef-1 $\alpha$ MF521786, ITS MF325986.

Spores 8.3-11.2(-12) × 5-6.5(-6.8) $\mathrm{mm}, \mathrm{Q}$ 1.4-1.7(-1.9); in front view oval to elliptic, base obtuse to broadly rounded, in profile suboval, amygdaliform to subamygdaliform, sometimes subphaseoliform; reddish brownish; germ pore distinct, mainly truncate to subtruncate, 1-1.7 $\mu \mathrm{m}$ broad. Pleurocystidia 4275(-87) × 11-17.5 $\mu \mathrm{m}$; lageniform, conical, subutriform, usually with elongate neck; apex acute to subobtuse, sometimes subcapitate or forked, incrusted or not; moderately numerous. Cheilocystidia 25-45(-49) × 11-12.5(-16) $\mu \mathrm{m}$, mainly with neck very short, looking mucronate, to medium long (2-10 $\mu \mathrm{m})$, locally numerous and in tufts. Paracystidia 16-36 × 8-14 $\mu \mathrm{m}$, walls sometimes or often thickened, yellowish pigmented, numerous, dominating. Cells below marginal cystidia with yellowish pigment. 
33b. A.H. Smith 29642, MICH33249; A.H. Smith 30175; MICH33250. Fig. 63.

$=$ ?

Loans for micro-morphology investigation: USA, Washington, Pierce Co., Mt. Rainier National Park, Lower Tahoma, 30 Jul.

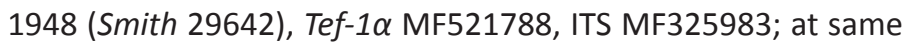
location, 16 Aug. 1948, coll. D.E. Stuntz \& B. Knowles, on humus (Smith 30175), ITS MF325984.

No description was attached to either voucher by the collectors.

Spores (7.5-)8.1-9.6(-10.5) × (4.5-)5-5.6(-5.8) $\mu \mathrm{m}$, on average $8.9 \times 5.2 \mu \mathrm{m}, \mathrm{Q}(1.44) 1.52-1.88(-2)$, avQ 1.70; in front view elliptic, sometimes suboval, base rounded, in profile adaxially flattened, sometimes amygdaliform to subamygdaliform; reddish brownish; germ pore distinct, mainly truncate, 1.1-1.5 $\mu \mathrm{m}$ broad. Pleurocystidia 40-60 × 8.8-16 $\mu \mathrm{m}$; narrowly utriform to lageniform, sometimes fusiform to conical, sometimes flexuous, neck variably long; apex obtuse, rarely subacute, sometimes incrusted; moderately numerous to numerous. Cheilocystidia (18-)31-45 $\times$ 7-15 $\mu \mathrm{m}$, apex sometimes incrusted, scattered to numerous. Paracystidia 11-24(-38) × 6-12(-17) $\mu \mathrm{m}$, walls sometimes or often thickened and slightly yellowish pigmented towards base, moderately numerous to numerous and intermixed with many basidia and basidiola. Cells below marginal cystidia mostly or only locally with yellowish pigment, sometimes incrusted.

34. Psathyrella psammophila A.H. Sm., Mem. N. Y. Bot. Gard. 24: 357. 1972.

Molecular heterotypical synonyms proposed here: Psathyrella angusticystis A.H. Sm., Mem. N. Y. Bot. Gard. 24: 383. 1972; Psathyrella subargillacea A.H. Sm., Mem. N. Y. Bot. Gard. 24: 386. 1972.

Typus: Psathyrella psammophila A.H. Sm. USA, Michigan, Washtenaw Co., Pinckney Recreation Area, 7 May 1964, A.H. Smith, 67836 (MICH12012), on sandy soil. ITS KC992856.

Loan for micro-morphology investigation of a slice of a pileus in good condition.

Spores 7.5-9.3(-11) × (4.4-)4.7-5.5(-5.7) $\mu \mathrm{m}$, on average 8.2 $\times 5 \mu \mathrm{m}, \mathrm{Q} 1.5-1.7(-2)$, avQ 1.6; in front view broadly oval to elliptic, base rounded, in profile subphaseoliform to adaxially flattened, sometimes distinctly phaseoliform; brownish orange, sometimes with a vague reddish shade; germ pore mainly indistinct and small. Pleurocystidia 40-60 × 10-16(-18) $\mu \mathrm{m}$; utriform, rarely cylindrical-ellipsoid to clavate; apex obtuse, sometimes rounded, sometimes mucronate to subcapitate,
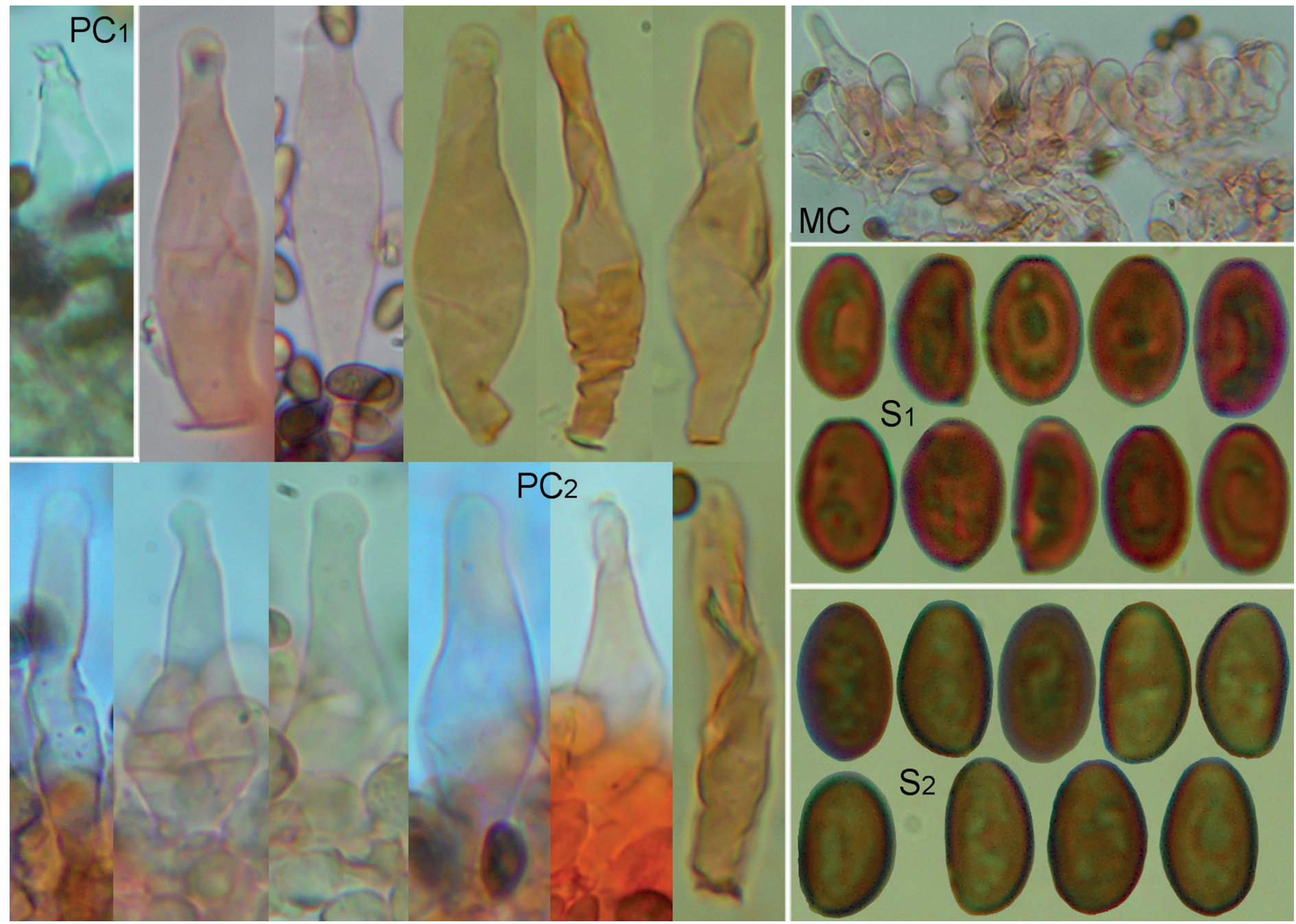

Fig. 63. Psathyrella nitens. A.H. Smith 29642, MICH33249; PC1 Pleurocystidium in $\mathrm{NH}_{4} \mathrm{OH}$; PC2 Pleurocystidia in Congo red; MC Marginal Cystidia; S1 Spores in water; S2 Spores in $\mathrm{KOH}$. 
rarely forked, often incrusted; walls often weakly thickened and yellowish pigmented; numerous. Cheilocystidia 25-40(-50) $\times$ 8-15 $\mu \mathrm{m}$, sometimes subacute, moderately numerous to scattered. Paracystidia $-20 \times-15 \mu \mathrm{m}$, sometimes mucronate, often incrusted, numerous.

Notes: On accurate observation of the holotype material it can be noticed that some debris of little twigs or grass stems are attached at the stipe base. We have found the ITS sequence in GenBank, unfortunately we have failed to add the Tef- $1 \alpha$ region sequence.

Psathyrella psammophila is very close to the two following species, $P$. subargillacea and $P$. angusticystis (DNA nucleotide homology: ITS = $99 \%$ with 4 and 1 mismatches respectively). A number of characters join these three taxa together such as small sporocarps, rudimentary veil, fragile context, pale colored and campanulate to broadly conical, never expanded, mature pileus, moderately crowded to distant (not distinctly crowded) gills, spore parameters in general including the little distinct germ pore, cheilocystidia generally sparse, paracystidia numerous but generally small, general feature of pleurocystidia. In all three cases we lack a second locus evidence; however, as we have found no relevant morphological difference, we consider both taxa conspecific with P. psammophila, the slightly paler spores of $P$. angusticystis being the only different element we could possibly point out in objection.

34a. Psathyrella subargillacea A.H. Sm., Mem. N. Y. Bot. Gard. 24: 386. 1972.

Typus: Psathyrella subargillacea A.H. Sm. USA, Michigan, Luce Co., Tahquamenon Falls State Park, near Paradise, 23 Jun. 1963, A.H. Smith, 66717 (coll. A.H. Smith \& S. Brough) (MICH12058), on rotten wood. ITS MF325999.

Loan for micro-morphology investigation of one almost entire pileus in good condition.

Spores (7.2-)7.5-9.5(-11.2) × 4.3-5.3(-6.2) $\mu \mathrm{m}$, on average $8.5 \times 4.9 \mu \mathrm{m}, \mathrm{Q}(1.55-) 1.65-1.95(-2.15)$, avQ 1.75; in front view oval to elliptic, base subtruncate, rounded to obtuse (tapered in Smith's sketches), in profile adaxially flattened to subphaseoliform, sometimes subamygdaliform to phaseoliform; brownish to reddish orange; germ pore small and indistinct (callus). Pleurocystidia (30-)46-68 × (8-)10-17 $\mu \mathrm{m}$; conical, subcylindrical, fusiform, sometimes ellipsoid, ellipsoidmucronate, narrowly utriform, lageniform; apex 4-8 $\mu \mathrm{m}$ broad, obtuse, sometimes rounded, rarely subacute, sometimes subcapitate, rarely forked, sometimes weakly incrusted; walls sometimes weakly thickened below apex; moderately numerous. Cheilocystidia 25-48 $\times$ 7.5-17 $\mu \mathrm{m}$, scattered to moderately numerous. Paracystidia $-23 \times-20 \mu \mathrm{m}$, sometimes rhomboid to mucronate, walls often pigmented and thickened, numerous. Cells below marginal cystidia weakly pigmented.

34b. Psathyrella angusticystis A.H. Sm., Mem. N. Y. Bot. Gard. 24: 383. 1972.

Typus: Psathyrella angusticystis A.H. Sm. USA, Michigan, Emmet Co., Wilderness Point, Wilderness State Park, 24 Sep. 1953, A.H. Smith, 43146 (MICH11873), gregarious on debris in a clearing. ITS MF325959.
Loan for micro-morphology investigation of one sporocarp and a half cut lengthwise, both in good condition.

Spores (7.3-)7.7-9.3(-10) ×4.4-5.5(-6.2) $\mu \mathrm{m}, \mathrm{Q}(1.45-) 1.6-1.9(-$ 2.05), avQ 1,74; in front view oval to elliptic, sometimes irregular, base rounded, in profile subphaseoliform to subamygdaliform; pale dull orangish; germ pore indistinct (callus). Pleurocystidia (30-)38-63 × 7-17 $\mu \mathrm{m}$; narrowly utriform, fusiform, conical, sometimes cylindrical to ellipsoid, rarely thickly utriform; apex obtuse to subacute, rounded, rarely acute, often subcapitate, sometimes forked, rarely rostrate; often incrusted; walls sometimes weakly pigmented; numerous. Cheilocystidia 25-55 $\times$ 8-17 $\mu \mathrm{m}$, often with subacute apex, incrustations not seen, scattered, towards margin of pileus numerous. Paracystidia 10$28 \times 6-20 \mu \mathrm{m}$, incrusted, numerous, often dominating.

35. Psathyrella incondita A.H. Sm., Mem. N. Y. Bot. Gard. 24: 405. 1972.

Since the holotype could not be obtained because of its scarcity, the MICH staff has selected two other collections Smith determined and deposited under this name. Our revision has evidenced they are unequivocally two different taxa: Harrison 10471 comes molecularly near $P$. flexuosipes and could represent the true $P$. incondita, Hoseney 1728 is distant from it. Both materials fall outside of section Spadiceogriseae.

35a. K.A. Harrison 10471, MICH36450.

\section{?= Psathyrella incondita A.H. Sm.}

Material examined: USA, Michigan, Marquette Co., Ives Lake, Loop Rd., 21 Jul. 1971, det. Smith, gregarious on elm wood, K.A. Harrison 10471, MICH36450. ITS MF325975.

Loan for micro-morphology investigation of two sporocarps and some fragments of pileus.

Spores (6.2-)7-8.7 × 3.3-4.4 $\mu \mathrm{m}, \mathrm{Q}$ 1.8-2.45(-2.6), avQ 2-2.1; in front view cylindrical to oblong, sometimes irregular, base obtuse, in profile mainly subamygdaliform to subphaseoliform; pale reddish brown to brownish orangish; germ pore distinct, mainly truncate, $\pm 1.5 \mu \mathrm{m}$ broad. Pleurocystidia 33-64 × 10$16.5 \mu \mathrm{m}$; lageniform, ventricose-fusiform, conical, utriform, ellipsoid; apex 3.5-6.5 $\mathrm{mm}$ broad, subacute to obtuse, sometimes irregular to bent, often incrusted; numerous. Cheilocystidia (25-)35-50(-52) × 9-15 $\mu \mathrm{m}$, often incrusted, moderately numerous, dominating. Paracystidia $-25(-31) \times$ $-11 \mu \mathrm{m}$, more or less numerous. Cells below marginal cystidia hyaline.

35b. F.V. Hoseney 1728, MICH36451. Fig. 64.

$=$ ?

Material examined: USA, Michigan, Livingston Co., Hell, Fralick's Tree Farm, 28 Oct. 1970, det. Smith, under pines, F.V. Hoseney 1728, MICH36451. Tef-1 $\alpha$ MF521795, ITS MF325976.

Loan of various sporocarps entire and in fragments for micromorphology investigation. 


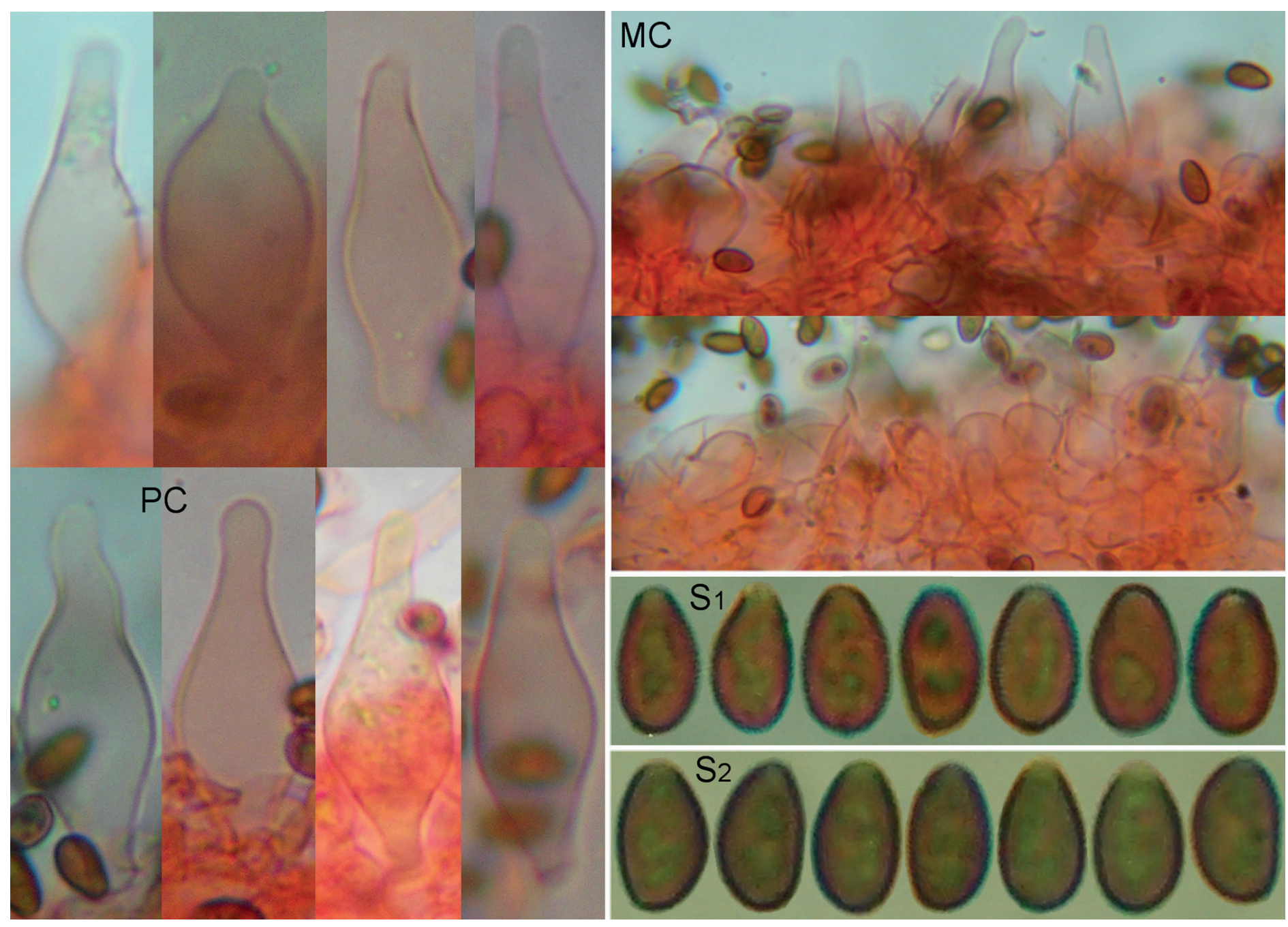

Fig. 64. Psathyrella incondita. F. V. Hoseney 1728, MICH36451; PC Pleurocystidia; MC Marginal Cystidia at centre of gill; S1 Spores in water; S2 Spores in $\mathrm{KOH}$.

The notes of gross morphology by the collector report pileus 4.7 $\mathrm{cm}$ broad and stipe up to $5 \mathrm{~mm}$ thick at apex.

Spores (6.1-)6.8-8.1(-9.5) $\times(3.7-) 4-4.8(-5.7) \mu \mathrm{m}$, on average $7.7 \times 4.4 \mu \mathrm{m}, \mathrm{Q} 1.5-1.9(-2.05)$, avQ 1.7; in front view oval, sometimes oval-sublimoniform to triangular, base rounded, in profile subelliptic to adaxially flattened, amygdaliform to sublimoniform, sometimes oval; orange-brown; germ pore moderately distinct to indistinct, 1-1.2 $\mu \mathrm{m}$ broad. Pleurocystidia (23-)25-40 × (8-)10-15 $\mu \mathrm{m}$; lageniform to broadly ventricoselageniform, sometimes subutriform, sometimes flexuous towards apex; apex obtuse, sometimes subacute, submucronate, subcapitate, often incrusted; walls sometimes sub hyaline; scattered. Cheilocystidia 22-39 × (7.5-)9-15 $\mu \mathrm{m}$, moderately numerous at centre of gill edge, more scattered elsewhere. Paracystidia $-27 \times-16 \mu \mathrm{m}$, sometimes rhomboid, hyaline, moderately numerous at centre of gill edge, inconspicuous elsewhere. Gill edge at centre with equal dominance of both types of cells or with locally alternate predominance. Cells below marginal cystidia hyaline.

Notes: The best reliable match when blasting the ITS region is with L0194-96 and LO164-96, two vouchers representing $P$. squamosa, with $99 \%$ identity; when blasting the Tef- $1 \alpha$ region none is above $90 \%$ identity but it must be noticed that Tef$1 \alpha$ regions of the two aforesaid vouchers are not sequenced.
However micro morphological characters do not fully correspond to those of $P$. squamosa.

36. Psathyrella flexuosipes A.H. Sm., Mem. N. Y. Bot. Gard. 24: 145. 1972.

Paratype: Psathyrella flexuosipes A.H. Sm. USA, Oregon, Douglas Co., Lake Tahkenitch, 21 Nov. 1935, A.H. Smith 3578 (MICH32961), on debris. ITS MF325969.

Loan for gross morphology investigation of one sporocarp with a broken pileus.

Spores 7-9(-10) × 4.1-5.3 $\mu \mathrm{m}, \mathrm{Q}(1.3-) 1.5-2.1$, avQ 1.7; in front view oval to elliptic, base rounded, in profile adaxially flattened, subamygdaliform, subphaseoliform; bright reddish; germ pore distinct, truncate to subrounded, 1.5-1.8 $\mu \mathrm{m}$ broad. Pleurocystidia 38-60 × 9-17 $\mu \mathrm{m}$; fusiform-utriform, fusiform, ventricose-fusiform to ventricose-conical, sometimes (slenderly) utriform; apex obtuse, never acute or broadly rounded, often (grossly) incrusted; numerous to moderately numerous. Cheilocystidia 30-60 × 7.5-16 $\mu \mathrm{m}$, sometimes minutely incrusted, numerous and generally dominating. Paracystidia 9-35 × 7-18 $\mu \mathrm{m}$, sometimes submucronate, sometimes incrusted, walls sometimes or often thickened and yellowish pigmented, numerous and locally dominating. 
Notes: We wanted to study this species because Smith (1972) did not specify the ratio between cheilocystidia and paracystidia but, unfortunately, $\mathrm{MICH}$ could not loan the holotype for scarcity of material. However, this paratype does not belong to subsection Spadiceogriseae and has no closely resembling counterpart in Europe.

37. Psathyrella abieticola A.H. Sm., Mem. N. Y. Bot. Gard. 24: 348. 1972. Figs 65-66A (as P. subnuda var. velosa), 66B (as $P$. vesiculocystis).

Molecular heterotypical synonyms and misapplied names proposed here: Psathyrella subnuda sensu A.H. Smith, Mem. N. Y. Bot. Gard. 24: 138. 1972, p.p.; Psathyrella subnuda var. velosa A.H. Sm., Mem. N. Y. Bot. Gard. 24: 139. 1972; Psathyrella vesiculocystis A.H. Sm., Mem. N. Y. Bot. Gard. 24: 349. 1972.

Pileus 15-40 mm broad, in early stages obtusely conical to convex with straight margin, expanding broadly conic to broadly convex or sub plane, moist or not; dark cinnamon-brown, rusty cinnamon, Mars brown, buckthorn brown, hygrophanous, fading to dull clay color, dingy tan, cinnamon buff, somewhat pale cinnamon-drab, brownish grey; translucently striate when moist. Veil white, quickly evanescent, when young with few thin patches of fibrils along the margin appendiculate fragments, thin and fibrillose on stipe. Lamellae adnate to ascending-adnate; narrow to moderately broad; moderately crowded; when young brownish to dingy cocoa-color, finally violaceous fuscous to dark vinaceous brown; edge white. Stipe 30-110 × 1-6 mm, equal or nearly so; white, watery white to pallid, not discoloring; apex pruinose. Context (very) fragile, thin in pileus, concolorous to surface. Odor and taste indistinctive. Spore deposit fuscous black. Spores (7-)7.7-10(-11.2) × (5-)5.5-7.2 × (4-)4.4-5.5 $\mu \mathrm{m}$, fQ 1.3-1.6, pQ 1.5-2; in front view broadly oval, often or sometimes (irregularly) angular-oval, sometimes broadly elliptic, rarely subglobose, triangular, oboval or mitriform, base obtuse to broadly rounded, sometimes truncate, apex often attenuate to sometimes snout-like projected, in profile subelliptic to adaxially flattened, rarely subamygdaliform, oval or subphaseoliform; dusky brown with a reddish to orangered shade; germ pore distinct, mainly truncate, sometimes somewhat oblique in profile, $1.6-2(-2.5) \mu \mathrm{m}$ broad. Basidia 4-spored, 17-25 × 6-11(-11.8) $\mu \mathrm{m}$. Pleurocystidia 33-60(-65) $\times$ 9-20 $\mu \mathrm{m}$, broadly utriform to subcylindrical, often or sometimes ellipsoid-saccate to subclavate, sometimes sublageniform; apex broadly rounded to obtuse, rarely subcapitate, rarely incrusted; walls hyaline, sometimes thickened below apex; moderately numerous, rarely numerous. Gill edge cystidia $8-33(-48) \times$ 4.5-19(-25) $\mu \mathrm{m}$, a mixture of three types of cystidia: distinctly utriform to sometimes sublageniform, 25-33 × 12-13 $\mu \mathrm{m}$, usually scattered; ellipsoid to rhomboid, 21-29 × 10-17 $\mu \mathrm{m}$, numerous; saccate to clavate, $9.5-30 \times 6-17 \mu \mathrm{m}$, numerous. Caulocystidia up to $140 \times 20 \mu \mathrm{m}$, utriform to clavate. Clamps present.

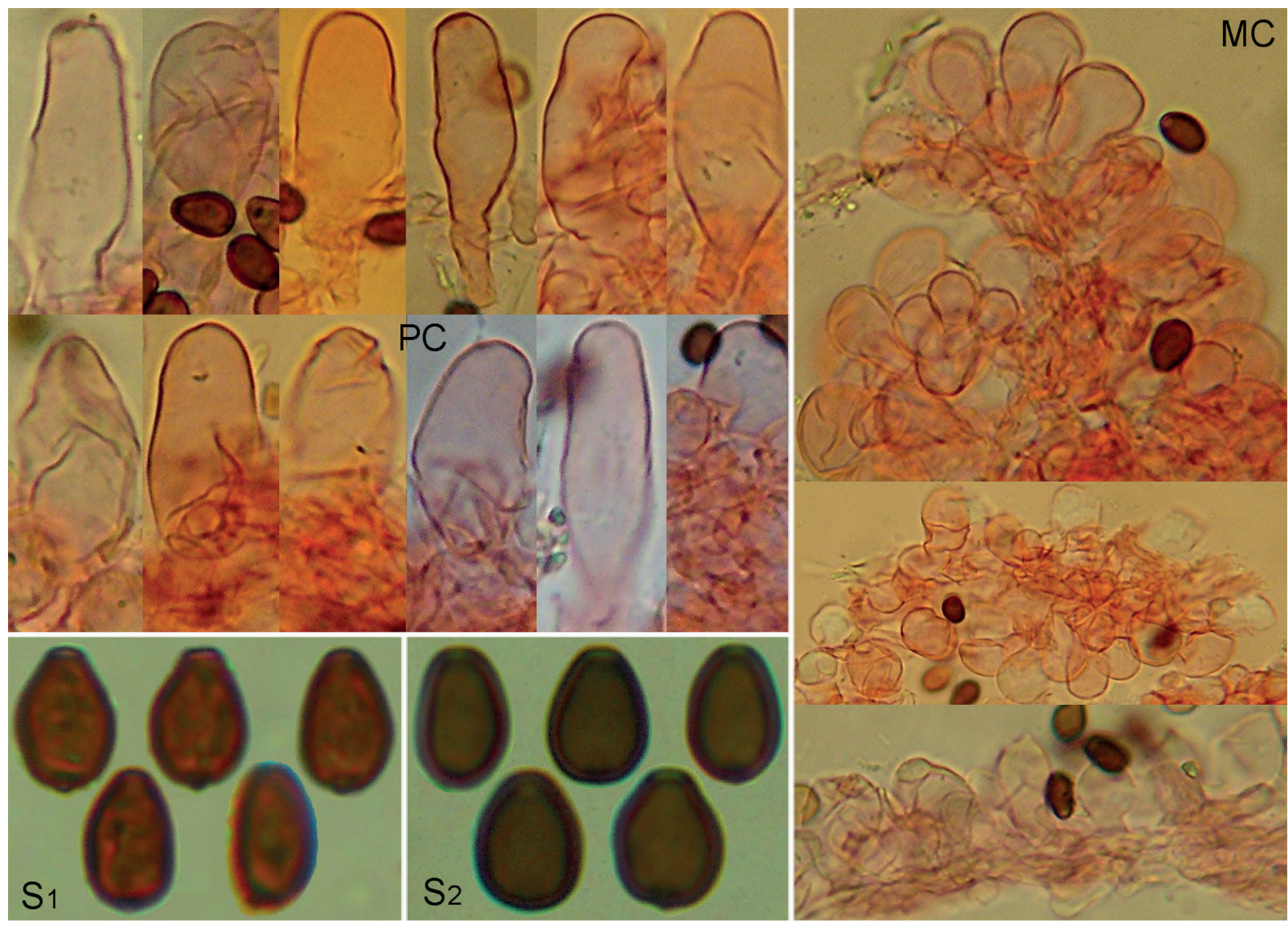

Fig. 65. Psathyrella subnuda var. velosa. F. P. Sipe, 1100, MICH33441; PC Pleurocystidia; MC Marginal Cystidia; S1 Spores in water; S2 Spores in KOH. 

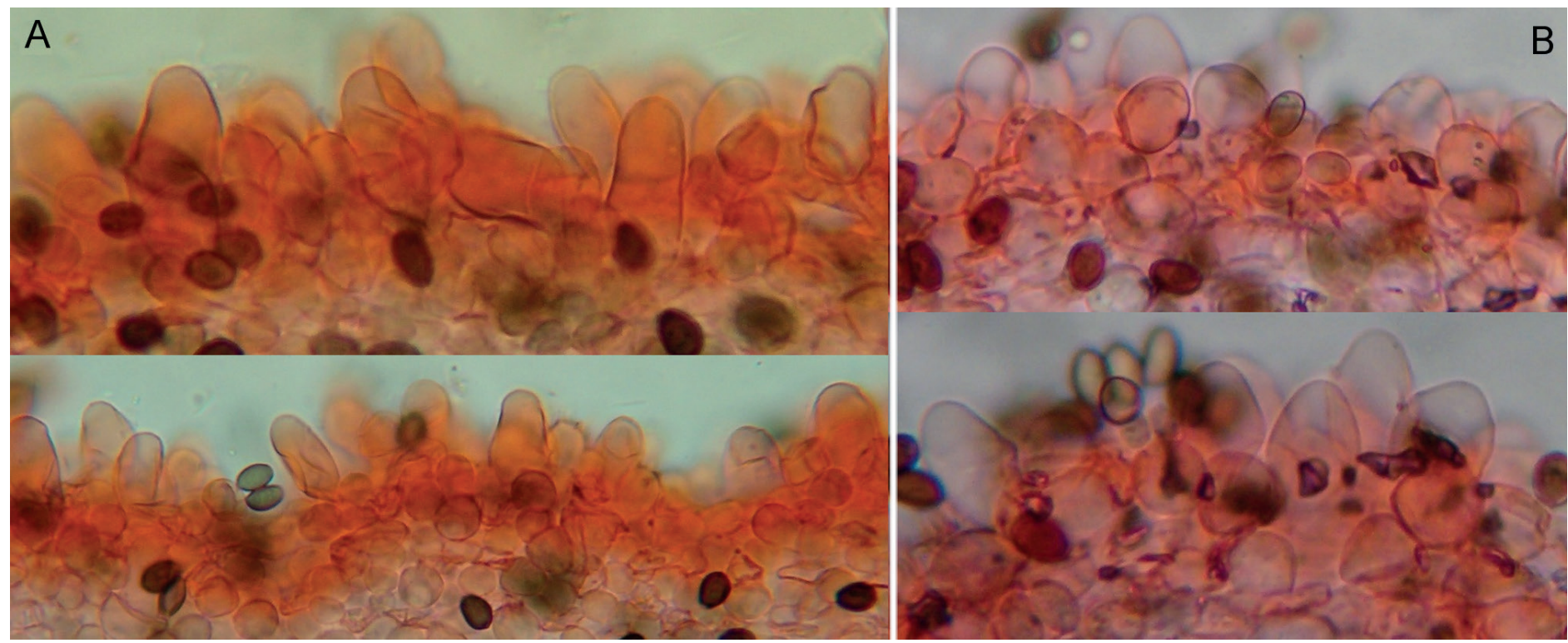

Fig. 66. A. Psathyrella vesiculocystis. A.H. Smith \& H. D. Thiers 70089, MICH5380; Marginal Cystidia. B. Psathyrella subnuda. A.H. Smith 56936, MICH33421; Marginal Cystidia.

Habitat: Gregarious or scattered; on humus of cottonwood or conifer, once on burned soil.

Collections examined from MICH: Psathyrella subnuda sensu A.H. Smith, Smith 56936; Psathyrella subnuda var. velosa A.H. Sm., holotype, Smith 73947; Psathyrella vesiculocystis A.H. Sm., Smith \& Thiers 70089.

Notes: The full description above comprises our revision and Smith's (1972) description of all taxa we acknowledge as conspecific, with exclusion of Smith's (1972) description of $P$. subnuda. The presence of many pleurocystidia not distinctly utriform but subcylindrical, ellipsoid-saccate to subclavate makes the gill edge cystidial pattern highly composite and a neat distinction between cheilocystidia and paracystidia hardly applicable. Sometimes the intermediate marginal cells are very small and can be ambiguously confused with the surrounding paracystidia, making these latter seem dominating.

We have not examined material of $P$. abieticola, but we have found strong molecular correspondence between $P$. vesiculocystis, $P$. subnuda var. velosa, and the holotype of $P$. abieticola present in GenBank (accession nr. KC992891). According to Smith's (1972) description, we see a good overlap of the morphological data, including the tridimensional, strongly oval to angular-oval spores with truncate base and attenuate to snout-like projected apex. For comments on $P$. subnuda sensu Smith see below.

Psathyrella fusca is a common, relatively similar European species but it is clearly not conspecific based on strong molecular evidence and very different spores.

37a. Psathyrella subnuda var. velosa A.H. Sm., Mem. N. Y. Bot. Gard. 24: 139. 1972. Fig. 65.

Typus: Psathyrella subnuda var. velosa A.H. Sm. USA, Idaho, Bonner Co, Tule Bay, Priest Lake, 5 May 1966, A.H. Smith 73947 (MICH5376), on debris in cottonwood flat; only for molecular sequence. Tef- $1 \alpha$ MF521773, ITS MF326005.

Paratype studied: Psathyrella subnuda var. velosa A.H. Sm. USA, Oregon, Pruetts place, 20 Nov. 1949, F.P. Sipe, 1100 (det. Smith) (MICH33441), habitat not reported. ITS MF326006.
Loan for micro-morphology investigation of very tiny fragments, the largest measuring $2 \mathrm{~mm}$.

The notes from the collector report a pileus $3-4 \mathrm{~cm}$ broad, conical, smooth, light cinnamon drab, expanded when older, without surface structures; stipe white, fragile gills drab with white edge; spores up to $10 \times 7 \mu \mathrm{m}$, reddish, dark with violet tints in deposit. Spores 8.2-10(-10.7) × 6-7.1 × 4.8-5.5 $\mu \mathrm{m}$, fQ 1.3-1.5, pQ 1.6-2; in front view oval, triangular, angularoval to mitriform, base truncate to broadly rounded, apex often attenuate to sometimes snout-like projected, in profile subelliptic to adaxially flattened, dusky brown with an orangered shade; germ pore distinct, mostly truncate, sometimes somewhat oblique in profile, 1.6-2 $\mu \mathrm{m}$ broad. Pleurocystidia 33-55 × 12-20 $\mu \mathrm{m}$, broadly to cylindrical utriform or ellipsoidsaccate, apex broadly rounded, sometimes obtuse; walls hyaline, sometimes thickened; moderately numerous. Gill edge cystidia 10-33 × 7-16(-19) $\mu \mathrm{m}$, a mixture of scattered distinctly utriform cells, scattered obtusely fusoid cells and numerous, small to large, saccate to clavate cells.

Notes: We could only observe scattered little traits of gill edge and we believe that most utriform and, overall, fusoid marginal cells must have collapsed, at least in their apical part, given the badly fragmented state of the material received.

37b. Psathyrella vesiculocystis A.H. Sm., Mem. N. Y. Bot. Gard. 24: 349. 1972. Fig. 66A.

Typus: Psathyrella vesiculocystis A.H. Sm. USA, Idaho, Idaho co, French Creek Grade, Salmon river near Burgdorf, 4 Sep. 1964, A.H. Smith \& H.D. Thiers 70089 (MICH5380), gregarious on conifer duff. Tef-1 $\alpha$ MF521772, ITS MF326007.

Loan of one sporocarp and one pileus in good condition for micro-morphology investigation.

Spores 7.8-9.8 × (5-)5.5-6.5(-7) × (4-)4.5-5.5 $\mu \mathrm{m}, \mathrm{fQ}$ 1.3-1.55, pQ 1.6-2; in front view oval to subangular-oval, base obtuse to broadly rounded, sometimes truncate, apex often attenuate 
to snout-like projected, in profile adaxially flattened; dusky brown with an orange-red shade; germ pore distinct, mainly truncate, sometimes somewhat oblique in profile, 1.6-1.8 $\mu \mathrm{m}$ broad. Pleurocystidia 37-60 × 12-20 $\mu \mathrm{m}$, broadly utriform, subcylindrical to subclavate, apex broadly rounded; walls hyaline; moderately numerous. Gill edge cystidia 8-48 × 4.5-18 $\mu \mathrm{m}$, a mixture of some distinctly utriform cells and numerous, dominating, small to large, saccate, clavate and subellipsoid cells in variable number.

Notes: Smith (1972) detected some broader cheilocystidia, up to $25 \mu \mathrm{m}$ broad, and reported occasional subechinulate protrusions near the apex of pleurocystidia. These last however are only the deceptive optical result of inwardly collapsed thin-walled apices sometimes leaving a rugged or spiked crater; this occurrence has been observed also in the following collection, Smith 56936 ( $P$. subnuda sensu A.H. Smith).

37c. Psathyrella subnuda (P. Karst.) A.H. Sm., Contr. Univ. Mich. Herb. 5: 61. 1941.

We have attempted to understand Smith's (1972) concept of $P$. subnuda by examining the voucher Smith 56936 selected for this purpose by $\mathrm{MICH}$ staff. We have found a sufficiently good correspondence, both morphological and molecular, with $P$. abieticola. This result does not necessarily apply to the other vouchers Smith deposited in $\mathrm{MICH}$ under this name. The basionymous name Psathyra subnuda P. Karst. sensu auct. Eur. is generally associated to P. spadiceogrisea. Kits van Waveren (1985), and Romagnesi, in personal communication to him, considered it extremely dubious.

Smith 56936, MICH33421. Fig. 66(b).

\section{= Psathyrella abieticola}

Material examined: USA, California, Humboldt Co., Trinidad, 22 Dec. 1956, on burned soil, Smith 56936, MICH33421. Tef-1 $\alpha$ MF521778, ITS MF326000.

Loan of one sporocarp in good condition with pileus and stipe separated for micro-morphology investigation.

The notes of gross morphology by the collector report pileus mars brown, veil absent, stipe dull white and not darkening. Spores (7.2-)7.7-10(-11.2) × 5.2-7.2 × 4.4-5.5 $\mu \mathrm{m}$, fQ 1.3-1.6, av. fQ 1.45, pQ 1.5-1.8 (1.9), av. pQ 1.6; in front view oval, broadly elliptic, sometimes (irregularly) angular-oval, rarely oboval, base obtuse to rounded, rarely subtruncate, apex attenuate or not, rarely snout-like projected, in profile adaxially flattened, rarely subphaseoliform; dusky reddish brown; germ pore distinct, mainly truncate, sometimes somewhat oblique in profile, 1.6-2(-2.5) $\mu \mathrm{m}$ broad. Pleurocystidia 33-55 × 11-17 $\mu \mathrm{m}$; utriform to subcylindrical, sometimes sublageniform; apex rounded, sometimes subcapitate; walls hyaline, sometimes thickened; moderately numerous. Gill edge cystidia 9.5-33 × 6-17 $\mu \mathrm{m}$, a mixture of three types of cells: distinctly utriform to sublageniform, $25-33 \times 12-13 \mu \mathrm{m}$, scattered; ellipsoid to rhomboid and 21-29 × 10-17 $\mu \mathrm{m}$, numerous; saccate to clavate and $9.5-30 \times 6-17 \mu \mathrm{m}$, numerous.
38. Psathyrella infida Quél., Bull. Soc. bot. Fr. 23: 329. 1877. Figs 67-69.

Pileus $10-20 \mathrm{~mm}$ broad, in early stages conical-campanulate and umbonate with inflexed margin, finally convex and subumbonate or not, radially rugulose in old sporocarps; when young dark to blackish brown, hygrophanous, discoloring reddish to ochraceous brown, at centre remaining for a time so then fading to ochre, in periphery fading to white, at margin keeping for a time an ochre-brown color often with a pinkish tint; translucently striate when moist. Veil white, already reduced to scarce or absent on most pilei but still present as small to large flocks on some young pilei (see Fig. 62, at the centre) and as small tufts on lower half stipe. Lamellae adnate, broad, not or little ventricose, distant (about 16-18); greyish then purplish grey or with brownish tinge; edge pale, reddish towards margin of pileus. Stipe $18-40(-55) \times 1.8-2.5$ $\mathrm{mm}$, cylindrical, often flexuous; concolorous with pileus, hygrophanous, discoloring white to translucent-hyaline in upper half, pale to subconcolorous with pileus in lower half; apex apparently not pruinose, base sometimes with appressed mycelium. Spores (10.5-)11-13.7(-15) × (5.2-)6.2-7(-8) $\mu \mathrm{m}$, on average 12-12.5 × 6.4-6.6 $\mu \mathrm{m}, \mathrm{Q}(1.7-) 1.75-2(-2.2)$, avQ 1.85-1.9; in front view elliptic, base obtuse, in profile elliptic to subamygdaliform, sometimes adaxially flattened to narrowly limoniform, apex sometimes snout-like projected; dark brown; germ pore distinct, truncate, 1.5-2 $\mu \mathrm{m}$ broad. Basidia 4-spored, 11.5-12.5 $\mu \mathrm{m}$ broad. Pleurocystidia 23-63 × 11.5-16(-22) $\mu \mathrm{m}$, fusiform to lageniform, rarely utriform or conical; neck short and more or less rostrate to long, sometimes flexuous; apex subacute, rarely obtuse; moderately numerous. Cheilocystidia $-50 \times 11-15 \mu \mathrm{m}$, scattered to locally moderately numerous. Paracystidia 15-40 × 9-20(-29) $\mu \mathrm{m}$; walls often thickened, hyaline to slightly pigmented towards base; numerous and dominating. Cells below marginal cystidia yellow-brown to pale yellow-brown pigmented. Clamps present.

Habitat: Gregarious to cespitose; among moist grass of alluvial plain near river bank with Salix alba trees and various hygrophilous plants.

Collection examined: Italy, Vicenza, Trissino, near the river Guà, on moist soil with deciduous trees, 28 Mar. 2013, O. Chiarello (det. P. Voto), MCVE29119. Tef-1 $\alpha$ MF521794, ITS MF325977.

Notes: We base our concept of $P$. infida on Romagnesi as he studied French material and is presumably the most reliable in understanding Quélet's short diagnosis. Therefore we refer to Kits van Waveren's (1985) description as he reports a full description received from Romagnesi and adds one's own microscopical observations of an exsiccatum received by the same French mycologist.

Kits van Waveren (1985) cites a description by Einhellinger (1973) but that German material is reported as having larger spores and 2(1)-spored basidia thus suggesting it may represent P. prona.

The above description of our collection fits well with that by Kits van Waveren (1985). The main features of this species are large dark spores, fusiform to lageniform pleurocystidia, small sporocarps, distant and broadly adnate to triangular gills, strongly developed but evanescent flocculose veil, pileus possibly drying with pinkish shades at margin, gill edge possibly 


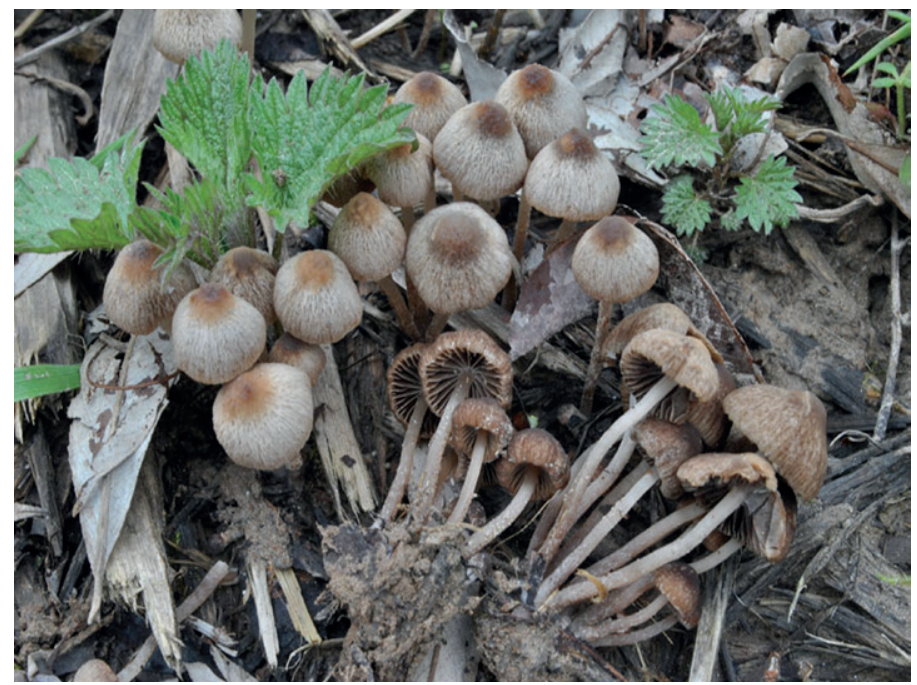

Fig. 67. Psathyrella infida. MCVE29119. Photo O. Chiarello.

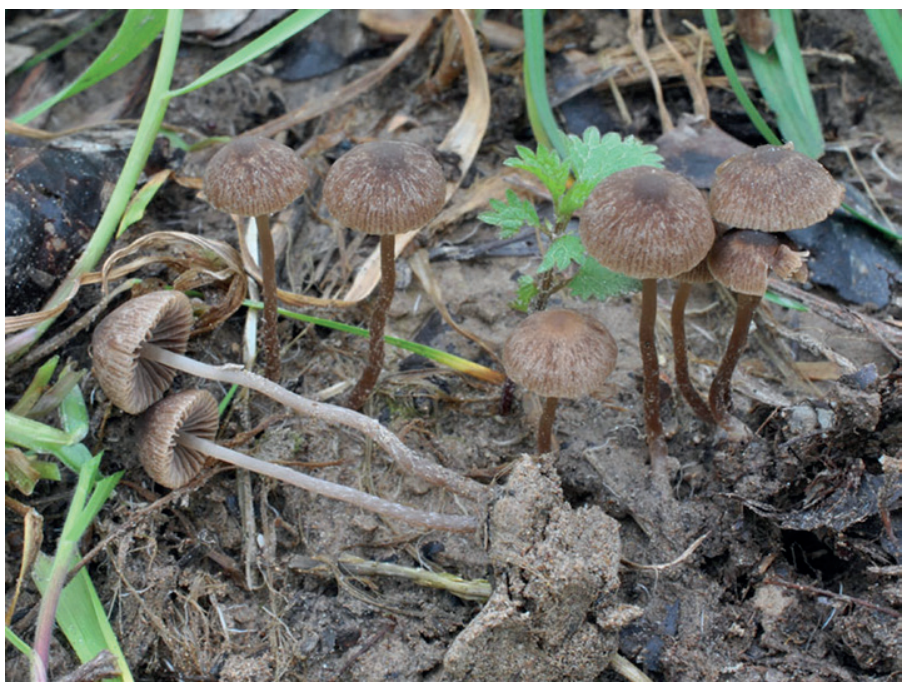

Fig. 68. Psathyrella infida. MCVE29119. Photo O. Chiarello.

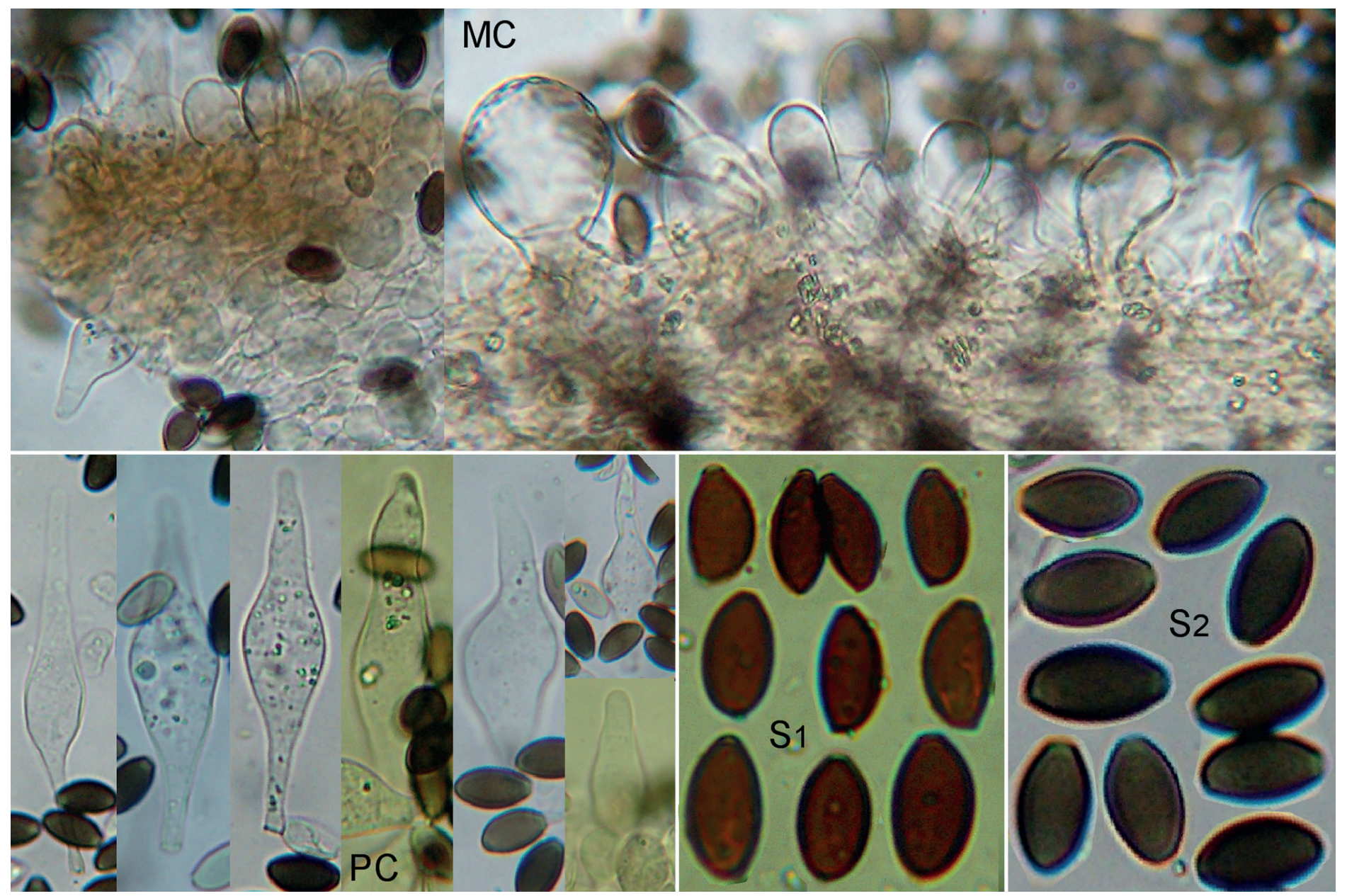

Fig. 69. Psathyrella infida. O. Chiarello, MCVE29119; MC Marginal Cystidia in KOH; PC Pleurocystidia; S1 Spores in water; S2 Spores in KOH.

reddish pigmented, habitat associated to deciduous trees in moist to dry soil.

From a morphological perspective, various species are very similar, the closer allies among them are $P$. romagnesii, which has more distant gills and smaller sporocarps, $P$. orbicularis, which has the gill edge dominated by cheilocystidia, P. orbitarum, which has smaller spores on average.

The ITS sequence of our sample is very similar to that of $P$. tenera found in GenBank (DNA nucleotide homology: ITS = $99 \%$ with 7 mismatches). It shares the moist habitat and many morphological characters (for micro-characters of $P$. tenera we refer to Smith 1972, and to Örstadius et al. 2015 who both have revised Peck's type). However, there are two relevant elements of differentiation given by the spores which are distinctly shorter and have consequently a lower quotient and by the gill edge which is markedly dominated by small to large paracystidia intermixed with generally scattered cheilocystidia. Unfortunately only the ITS region sequence is available in GenBank for $P$. tenera; however, until a second locus contradicting evidence should emerge, we consider this collection a consistent representative of $P$. infida and a good species in its own right. 
39. Psathyrella bivelata Contu., Bull. Soc. Mycol. Fr. 107: 86. 1991. Figs 70-73.

This species is very close to $P$. candolleana from which it differs for having larger spores, (6.5-)7.5-12.5(-15) $\times(4.2-)$ 4.5-6.7(-7.5) $\mu \mathrm{m}$, on average 9-9.5 × 5-5.5 $\mu \mathrm{m}$, of a medium to somewhat pale reddish brown color and with presence of some 2-spored basidia. The habitat of $P$. bivelata is, at least as up to now ascertained, herbicolous and possibly associated to nitrogen-rich soil but we cannot exclude it could also be detriticolous on woody humus outside of woods. However, two peculiar characters bond both species together: the presence of a strong stripped incrustation on the pileal general veil cells and the broadly ellipsoid to globose shape of a number of the same cells, this last character possibly more emphasized in $P$. bivelata. In gross morphology these two characters produce a tendency of the general veil to turn brownish, or even to be so already in young specimens, and to reduce itself to little flocks.

After its original collection in Sardinia, Italy, in 1989 a long period of oblivion followed, until it was found for a second time in 2006, again in Italy, precisely in Veneto. Since then, we have identified this species in other collections from the same region. The first Veneto collection including images was fully described by Voto (2007), although images of the type were not included in the protologue. Due to the fact that CAG, where the type is hosted, does not loan any material, we have now provided a reference sequence for that collection and we have re-deposited it as MCVE29104. More illustrations are in Voto (2013) (under the name of P. candolleana, voucher D030208, now MCVE29117) and Voto (2011). More images from the Veneto collections are in this paper, including two additional illustrations of MCVE29104.

Materials examined: Italy, Veneto, Rovigo, Villadose, $3 \mathrm{~m}$ a.s.l., gregarious in grass in garden, 10 Nov. 2005, P. Voto, Fig. 70, 71 (MCVE29104, Tef-1 $\alpha$ MF521812, ITS MF325961); at same location, 6 May 2006; at same location, 28 May 2006, at same location, 6 Jun. 2006; Rosolina Mare, 0-1 m a.s.l., gregarious in grass in garden, 10 Nov. 2007, P. Voto, Figs 72, 73 (MCVE29330); Vicenza, $39 \mathrm{~m}$ a.s.l., caespitose in grass in urban flower bed near a Platanus, 27 May 2012, E. Zanella (MCVE29117, former Voto D030208, Tef-1 $\alpha$ MF521811, ITS MF325962).

40. Psathyrella yaoundeana Mossebo \& Pegler, Kew Bulletin 53: 1001. 1998. Fig. 74.

Typus: Psathyrella yaoundeana Mossebo \& Pegler. Cameroon, Yaoundé, Cité-Verte, 30 Oct. 1996, D.C. Mossebo 42B (K(M)55648), among grass.

Loan of two entire sporocarps somewhat mouldy for micromorphology investigation.

The authors described this taxon as provided with frequent, obtusely ventricose-lageniform to broadly fusoid pleurocystidia (utriform with rounded to obtuse apex by their sketched illustration and following our terminology) and with a mixture, without frequency ratio, of obtusely clavate, utriform to sublageniform cells on the gill edge. These data made it an eligible species of subsection Spadiceogriseae and the authors themselves commented that it most closely approached $P$. spadiceogrisea. In our revision we could find no pleurocystidia but we noticed that various cheilocystidia, dislodged by pressure

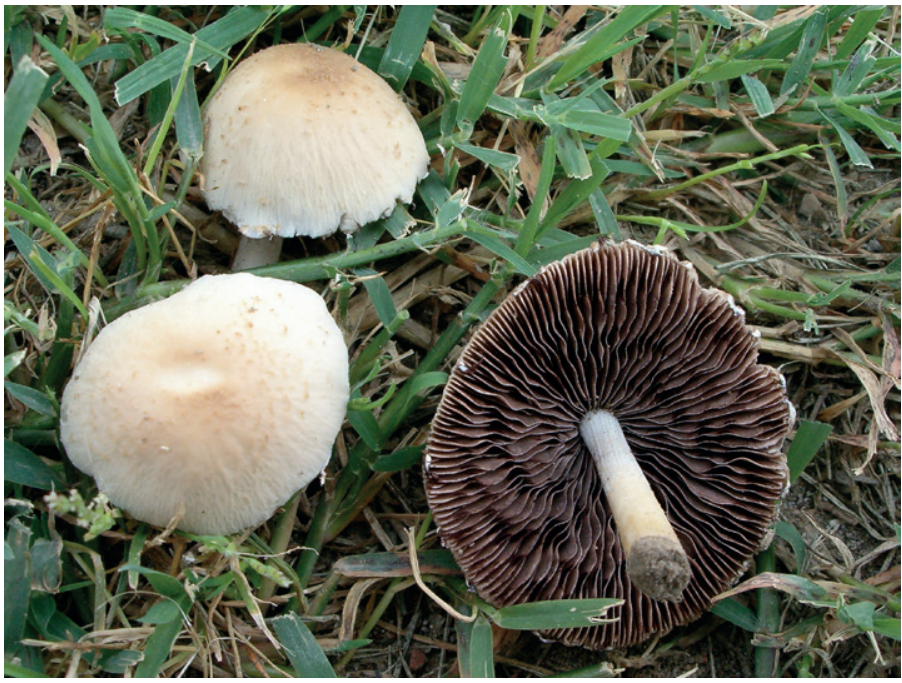

Fig. 70. Psathyrella bivelata. MCVE29104. Photo P. Voto.

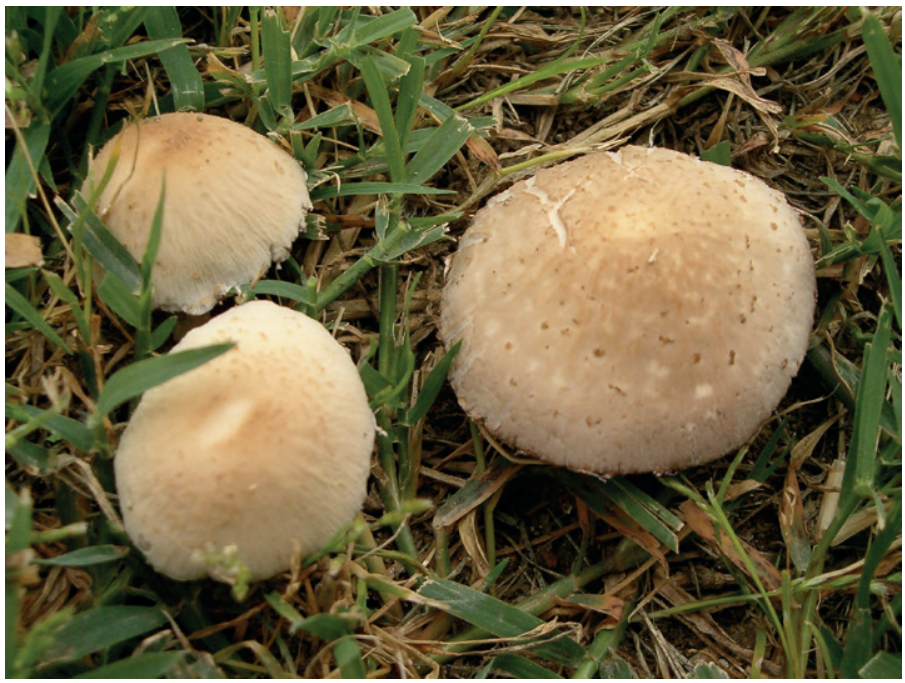

Fig. 71. Psathyrella bivelata. MCVE29104. Photo P. Voto.

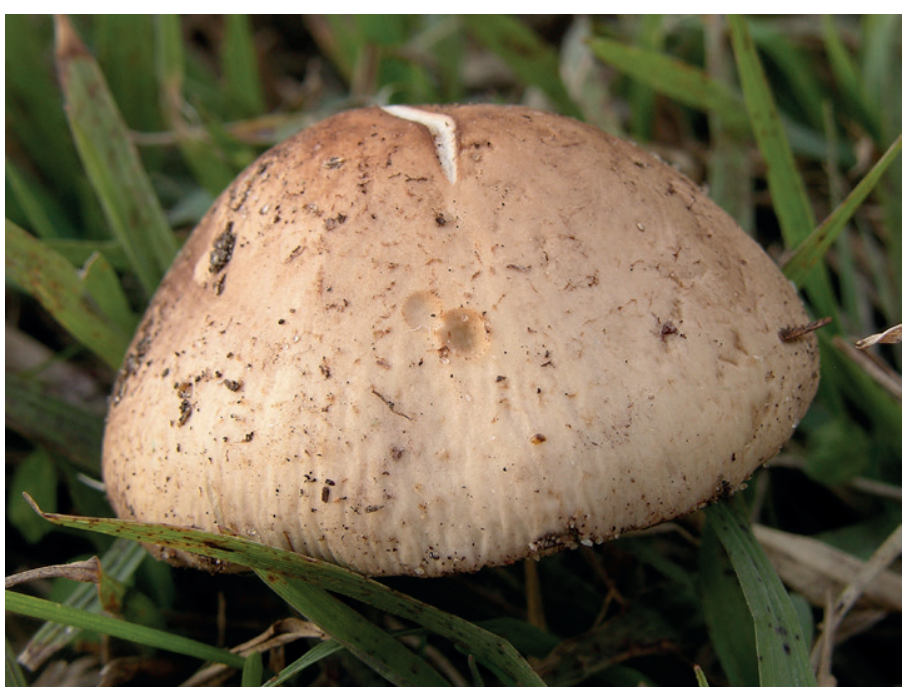

Fig. 72. Psathyrella bivelata. Voto20071109.2. Photo P. Voto.

on the coverslip, floated and casually anchored themselves on the gill sides. Cheilocystidia are about $21-37 \times 12-17(-22) \mu \mathrm{m}$ large, the gill edge has the typical pattern of that of $P$. candolleana with absent to very inconspicuous paracystidia. Spores (6.2-) 6.5-8.5(-9.8) × (3.7-)4.2-5(-5.5) $\mu \mathrm{m}, \mathrm{Q}(1.4-) 1.6-2$, avQ 1.7 


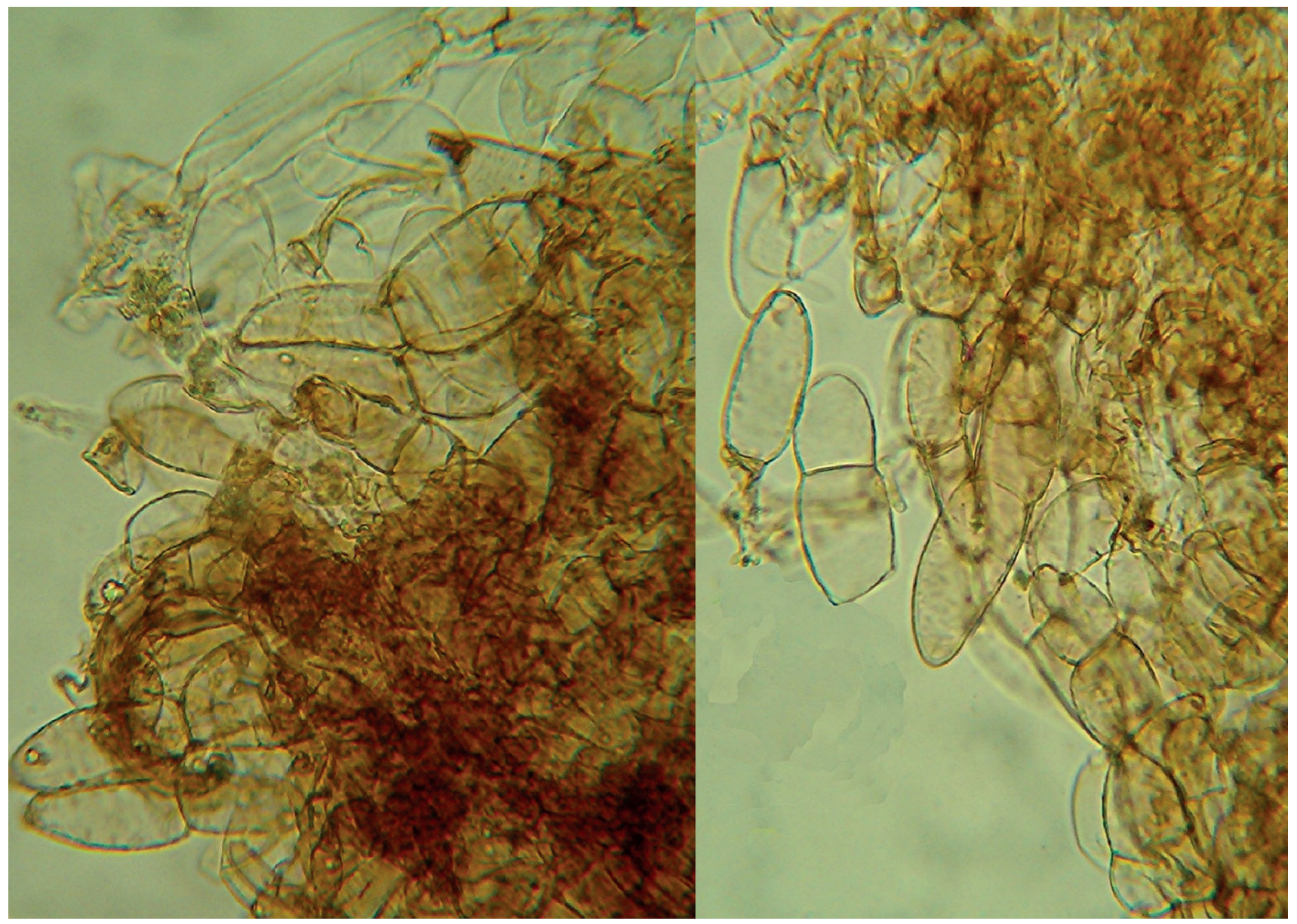

Fig. 73. Psathyrella bivelata. Voto20071109.2; Cells of general veil on pileus in Congo red.

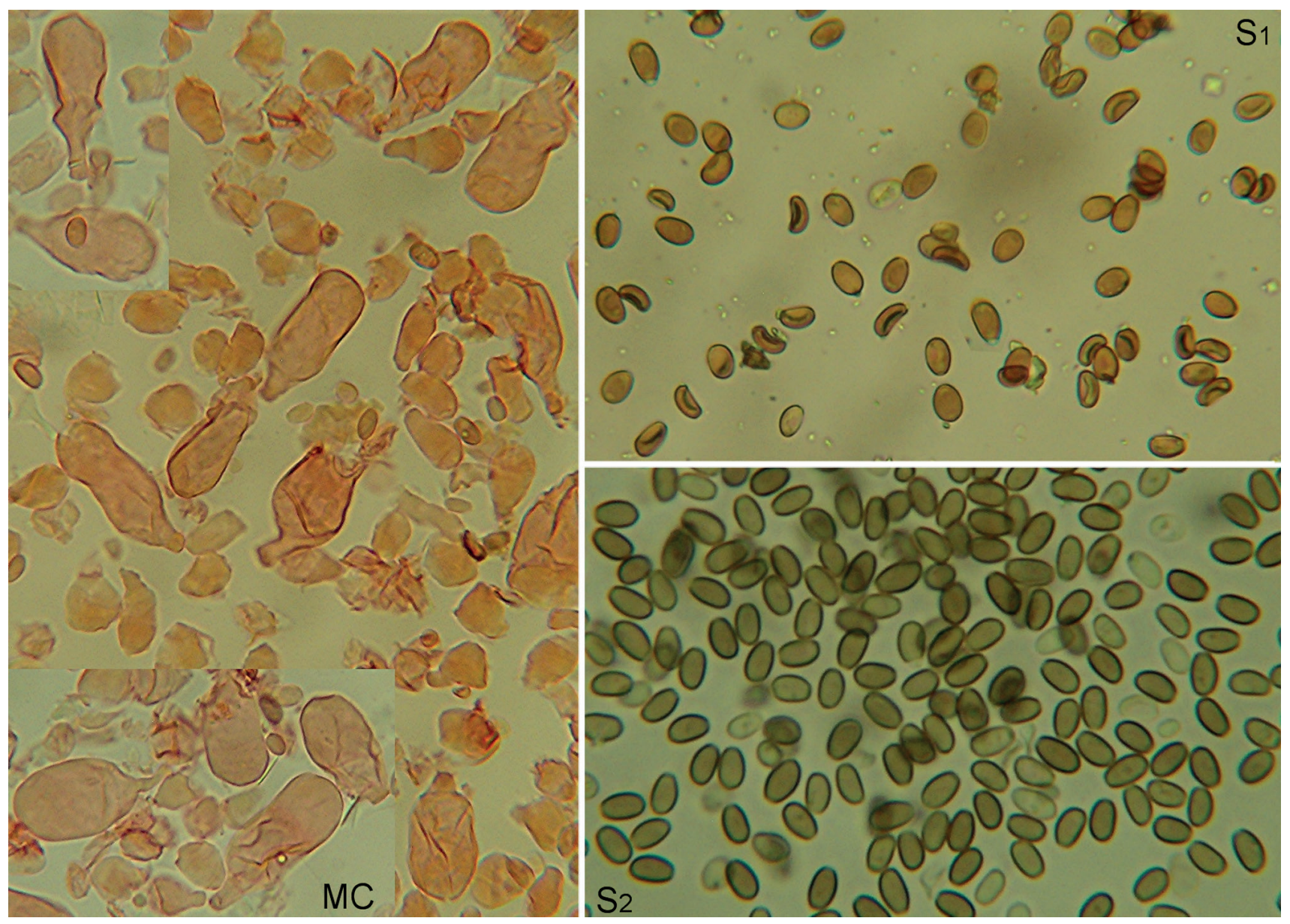

Fig. 74. Psathyrella yaoundeana. Mossebo 42B, K(M)55648; MC Marginal Cystidia; S1 Spores in water; S2 Spores in KOH. 
[we have also found a number of broader spores, up to 5.7(-6.3) $\mu \mathrm{m}$ with $\mathrm{Q}$ 1.3-1.5], in front view elliptic to oval, base rounded, in profile mainly adaxially flattened to subphaseoliform, sometimes phaseoliform to elliptic; pale brown with a vague reddish shade; germ pore distinct, rounded, 1-1.7 $\mu \mathrm{m}$ broad.

We failed to obtain the ITS sequence and only obtained a dirty unusable sequence of the Tef- $1 \alpha$ region from this sample; however, on the whole, we are convinced this material belongs to section Spintrigerae.

\section{Phylogeny}

The ITS alignment included 673 characters, and contained 380 (56.5\%) variable sites; the Tef- $1 \alpha$ alignment included 607 characters, and contained 335 (55.2\%) variable sites; the concatenated ITS and Tef- $1 \alpha$ alignment included 1281 characters, and contained $679(52.0 \%)$ variable sites. The partition of homogeneity tests found no conflicts between the ITS and the Tef- $1 \alpha$ alignments. Both Maximum Likelihood and Bayesian analyses produced the same tree topologies. Only the Bayesian trees with posterior probability and bootstrap values are shown. The most significant differences between the ITS (Fig. 1) and the Tef-1 $\alpha$ (Fig. 2) trees were mostly due to variation in the list of taxa covered by each, due to failed sequencing of one of the loci for some samples. The concatenated ITS-Tef$1 \alpha$ tree was characterized by higher statistical support of its branches, and can be used to infer the overall phylogenetic relationships among the Psathyrella samples analyzed. In the concatenated tree, Psathyrella samples were all placed in a monophyletic group containing several statistically supported clades, including a clade representative of the subsection Spadiceogriseae. The nitens clade is placed as the closest relative to the spadiceogrisea clade, while the candeollana clade appears as the most distantly related to the spadiceogrisea group, at least among the taxa include in this analysis. Refer to the tree in the Supplementary Fig. 1 for a better coverage of species to identify the closest relatives to the spadiceogrisea group. In an intermediate position between the nitens and the candeollana clade, the analysis identified a clade including the three subclades fusca, piluliformis, and gordonii and the two taxa $P$. incondita and $P$. cortinarioides. Psathyrella infida was a solitary taxon outside all of the clades and subclades identified by this analysis.

The spadiceogrisea group was further subdivided in nine strongly supported groups, identified in Fig. 3 by the following subclades: albescens, thuijna, hellebosensis, fatua, owyheensis, praetenuis, umbrosa, albanyensis, spadiceogrisea. These nine subclades provide a strong and exhaustive framework to understand the evolution of species within the section Spadiceogriseae, and to differentiate between potential gross misidentifications (taxa falling in different subclades), and nomenclature issues caused by the close relatedness of sister taxa (taxa falling within the same subclade) possibly due to the lack of distinctive morphological traits. Besides the limited morphological variation when comparing closely related taxa, the composition of taxa within each subclade may be associated with geographic range and/or with habitat.

Pairwise genetic distances within clades were in general

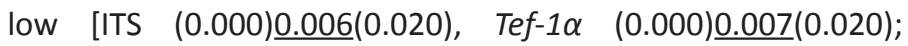
(min)average(max)], even for morphologically distinct species, and five clades included both North American and European species suggesting either a recent evolutionary divergence, or a dynamic phylogeographic history resulting in the intercontinental movement of species. No distinctive morphological trait was associated with clades, except for the albanyensis clade characterized by dark, often tridimensional spores, and with a little to moderately distinct germ pore. Clades though did differ in habitat association as follows. Clades spadiceogrisea and albanyensis were found in association with woody substrates, even in the case of $P$. clivensis, which apparently grows in grasslands but is also associated with woody debris. Clades umbrosa and praetenuis appeared to be intermediate and include both lignicolous and non-lignicolous species. All remaining clades seemed to be distinctively more detached from woody substrates and included species growing in grasslands or in "specialized" habitats such as wetlands populated by hygrophilous plants (e.g. P. thuijna), and sandy substrates ( $P$. ammophila).

In spite of the fact that the bulk of the sequences of the largest dataset came from the published study by Örstadius et al. (2015), the concatenation of Tef-1 $\alpha$ and ITS failed to meet the requirements of the partition of homogeneity tests. Nonetheless, we opted to provide the phylogenetic tree resulting from this larger dataset in the supplementary materials (Supplementary Fig. 1). The resulting tree has in fact the convenience of being directly comparable with that of Örstadius et al. (2015), of including a larger number of taxa within and outside the section Spadiceogriseae, and of allowing for a relative placement of the group within the genus. Once again, the spadiceogrisea group results as monophyletic and includes nine well supported clades. Three species, namely $P$. sublatispora, $P$. prona and $P$. jacobssonii, made up an additional clade that - based on ITS analysis - could be regarded either as part of the same group, or as a sister clade to the subsection (Fig. 1).

Based on morphology and molecular analyses combined, this study describes a new species ( $P$. rogersiae), renames three species ( $P$. vesiculosa, $P$. ochrofulva, $P$. sanjuanensis), identifies as present in Europe two taxa previously described only in North America ( $P$. albescens, $P$. kauffmanii), resolving the related nomenclature issues, and suggests the possible presence in Europe of a third American species (see notes about $P$. velibrunnescens and $P$. aff. kauffmanii). Five species of uncertain status were fully validated ( $P$. bivelata, $P$. carinthiaca, $P$. fragrans, $P$. infida, $P$. aff. kauffmanii).

The analysis of the holotypes of $P$. fusca, $P$. spadiceogrisea, $P$. agrariella, $P$. atrifolia and $P$. subnuda is still missing, however the combined DNA and morphological analysis of non-typical vouchers (Smith 1972) reveals that Smith may have had an ambiguous concept of these species. In particular, the last three species remain dubious. Likewise, the analysis of the holotypes is still missing for $P$. niveobadia, $P$. phaseolispora and $P$. agraria ad int., three European taxa Smith never studied; the latter two species remain dubious while we propose a provisional solution for the first.

Finally, in this study we have identified 13 heterotypical synonyms (see Table 1). All of the specific taxonomic contributions of this paper are listed in Table 1 . We have previously discussed our approach with regards to how DNA sequence information was used to confirm or contest species boundaries, especially when morphology was insufficient to make that call. In brief, while DNA homology < $97 \%$ was used with confidence to identify distinct taxa, highly homologous sequences (> $98 \%$ ) cannot be used by themselves to exhaustively determine conspecificity, because of possible transfer of alleles between 
species, especially if closely related. High DNA homology at one locus can though be used to support conspecificity if such conspecificity is further suggested by homology at another locus, morphology, habitat, and geographic range. We have regarded homology levels of $97 \%$ and $98 \%$ as border-line, and looked for non-synonymous polymorphisms in exonic regions (DNA variation resulting in a variation in aminoacids transcribed) or for indels (insertion or deletions) in intronic regions to suggest the evolutionary significance of this relatively small variation in DNA sequences. Individual species description drew on such DNA-based comparisons when needed.

\section{DISCUSSION}

A first clue of monophyly of the subsection Spadiceogriseae supported by molecular evidence was provided in Vašutová et al. (2008), though based only on three vouchers. The parsimonious tree in Örstadius et al. (2015) show that such monophyly is confirmed when applied to a wider European range of species. The results obtained through the present work confirm the monophyly of a joint clade spadiceogrisea in Europe and America, with four cases that need be discussed in detail.

a) P. umbrosa has paracystidia which, although dominating the gill edge, are mainly unusually small and intermixed with numerous basidia and basidiola;

b) Psathyrella sp. (NL-0631) is described as having scattered cheilocystidia and very scattered paracystidia;

c) P. ochrofulva (and P. lactobrunnescens, if indeed it belongs to the clade spadiceogrisea) has often fusiform to conical pleurocystidia equipped with highly variable, mainly obtuse, apex, which is unusual in comparison to usually utriform to lageniform cystidia with mainly rounded apex;

d) $P$. aff. kauffmanii and $P$. vesiculosa are outside of the clade spadiceogrisea but are morphologically associated to the subsection Spadiceogriseae. However, it can be noted that they, together with the unsequenced $P$. velibrunnescens, are characterized by a distinctly pigmented veil, which is otherwise unknown in this group. From this last cited case we infer that a white veil must be included among the morphological parameters defining the subsection Spadiceogriseae.

Based on morphological analysis and on sequence data from both ITS and Tef-1 $\alpha$, nine statistically well-supported clades comprise the subsection Spadiceogriseae. ITS data alone identified an additional clade including $P$. prona, $P$. sublatispora, and $P$. jacobssoni that, although rather distantly related to the other clades, could be regarded as being included in the subsection. However, these three taxa were not included in this study, and therefore no direct comparative morphological data or Tef-1 $\alpha$ sequence information is available to confirm their taxonomic placement. Due to the distinct positioning of this clade within an expanded - yet still monophyletic - P. spadiceogriseae subsection, morphology-based taxonomic positioning may also be more ambiguous than for the other taxa beloging to a more narrowly defined subsection.

The paramount character of the subsection Spadiceogriseae, i.e. the dominance of paracystidia on the gill edge, can be present also in other subdivisions of the genus and, therefore, this character must have originated independently multiple times in the evolution of Psathyrella. Yet, the set of characters that together define the subsection Spadiceogriseae is morphologically unambiguous.

The revision, based on both morphological and molecular data, of a number of samples and holotypes, has resolved some problematic taxonomic situations, the more relevant of which are listed immediately below.

The European P. phegophila has been shown to be a solid species with a transcontinental range, though its correct and prior name has to be the Smith epithet $P$. kauffmanii; this result is only morphology-based as we lack the type sequence and morphological revision of $P$. phegophila, however the European collection we selected as a reference point is perfectly adherent to its concept.

Previously unknown in Europe, the American species $P$. albescens is discovered and documented in the old continent; this taxon was until now repeatedly misidentified in Europe.

Although our conclusions were not based on the sequencing of the type, nor on its morphological examination, we propose to accept the autonomy of the European species $P$. niveobadia, after analyses of some collections fully matched its morphological concept. We were also able to describe the differences with its closest relative, i.e. P. spadiceogrisea. Our molecular comparisons revealed there is some evolutionary divergence between the two species, however, because this divergence is modest and ambiguous when comparing results from the two loci, we expect future analyses based on multiple loci will be necessary to definitely confirm or discard our decision.

Based on the examination of some samples with pigmented gill edge and pinkish pileus margin, we propose, with molecular corroboration, that the taxon described with the informal name of $P$. pseudocorrugis sensu Kits van Waveren (1985) should be considered an intraspecific variation of $P$. fatua. The correct, original interpretation, P. pseudocorrugis sensu Romagnesi, on the contrary, is a species outside subsection Spadiceogriseae because of its gill edge dominated by cheilocystidia (Örstadius \& Knudsen 2008).

The little-known Czech material present in GenBank under the provisional name of $P$. aff. kauffmanii is more completely described here, and we show that it nests within a small complex of American species.

A critical examination of the clade spadiceogrisea in the Tef- $1 \alpha$ tree indicates that species within this clade may not be distributed randomly within subclades, but there may be trophism-based grouping. In subclades spadiceogrisea and albanyensis, all species grow strictly associated with arboreal material and humus, with the only partial exception of $P$. clivensis growing usually in grassland but also found directly attached to (buried) sticks (Tassi 2000). A second group, containing Psathyrella sp. NL-0631 and subclades umbrosa and praetenuis, has an intermediate situation with three lignicolous species and two others not associated with arboreal material. The subclades albescens, thujina, hellebosensis, fatua, owyheensis and the species $P$. ammophila, on the contrary, only include one species, $P$. argillacea, collected consistently in association with arboreal material. All other fungi of this last grouping are generally found in open fields, grasslands, pastures, etc. with the partial exceptions of $P$. fatua, $P$. albescens and $P$. owyheensis which extend their trophism to both kinds of habitat. Some species in this complex have developed strict associations with specialized habitats, such as the association 
with hygrophilous plants in moist to wet soil reported for $P$. thujina and allied taxa, or the association with sandy habitats reported for $P$. ammophila.

Spore color in the subsection Spadiceogriseae is broadly assignable to two categories: (a) brown, pale reddish, orange or paler, and, (b) red-brown or darker. Generally, and using Smith's terminology, spores of the first group in $\mathrm{KOH}$ have a cocoa color or paler tones possibly turning slowly to chocolate color. Those in the second group are from the beginning, or rapidly turn into, a chocolate or a darker color when in $\mathrm{KOH}$. Of course, intermediate situations can occur. Because Smith (1972) described spore color only in $\mathrm{KOH}$, this observation can offer a possible clue for deducing spore color in water of Psathyrella species described by Smith and not yet revised.

Some species outside of subsection Spadiceogriseae have been studied here as well. The holotypes of $P$. fragrans and $P$. carinthiaca were sequenced and, based on their molecular and morphological characters, they can be confirmed as close to, but autonomous from, $P$. piluliformis. Collections of the littleknown European species $P$. infida and $P$. bivelata are respectively described and commented upon and their phylogenetic sequences have been generated to offer a molecular reference point. Finally, MCVE28713 represents an interesting rare albinistic occurrence of $P$. cortinarioides, and was also sequenced.

\section{Key to subsection Spadiceogriseae}

At the conclusion of this study, we provide an intercontinental key of the subsection Spadiceogriseae. Note that besides all the species previously discussed in this paper, the key also includes an additional taxon, identified in GenBank as Psathyrella sp., voucher NL-0631, and belonging to the $P$. umbrosa complex.

Psathyrella affinis, P. basii, P. cortinarioides, P. dunensis, Kauffmania larga (formerly $P$. larga), P. obtusata, P. pertinax, $P$. psammophila and $P$. sanjuanensis though not belonging to the clade spadiceogrisea, are included in the key because they have, or occasionally may have, the gill edge lined by numerous paracystidia and/or they may have utriform pleurocystidia. The users of this key should take into consideration the limited knowledge of variability in morphology and habitat for the species described with few or only one collection. After each species name, the continent where its occurrence is ascertained is reported in brackets; in the most recurrent cases of America and Europe the initial letters $A$ and $E$ respectively are affixed instead.

A document by Voto, containing a key to all European species of Psathyrella and a list of the principal synonyms with reference to their first propounders, is also published online in the website of The Associazione Micologica ed Ecologica Romana - A.M.E.R. (www.ameronlus.it/chiavi_micologia.php).

1. Germ pore absent to indistinct; spores pale to orangish (light to medium brown in P. aff. kauffmanii,

(pale) yellow-brown in P. subspadiceogrisea)

1. Germ pore distinct and/or spores distinctly pigmented

2. Spores 4.5-6.5 $\mu \mathrm{m}$ broad or more

2. Spores $6.5-10 \times 3.5-5.5 \mu \mathrm{m}$

3. Pileus 30-140 mm; pleurocystidia 40-90 × 10-24; associated to woody debris see Kauffmania larga (A, E)

3. Pileus within $40 \mathrm{~mm}$ broad

4

4. Pleurocystidia $28-37 \times 10-14 \mu \mathrm{m}$; found on soil in garden

P. neotropica (A)

4. Pleurocystidia $35-60 \times 10-18 \mu \mathrm{m}$; associated or not to woody debris P. clivensis $(\mathrm{E})$

5. Veil yellow to brown colored; pileus conical to campanulate; lignicolous see $P$. vesiculosa (A), P. velibrunnescens (A), P. aff. kauffmanii (E), P. conica (Asia)

Veil white

6. Spores on average $7-8 \mu \mathrm{m}$ long

6. Spores on average longer

7. Pleurocystidia often yellow below the apex; spores not triangular, often phaseoliform; veil flocculose, extending to halfway or centre of the pileus; smell indistinct ................................................... see P. cortinarioides (E)

7. Pleurocystidia not pigmented; spores partly subtriangular, not or sometimes phaseoliform; veil scanty

8. Pileus $-75 \mathrm{~mm}$ broad; stipe $30-90 \times 5-12 \mathrm{~mm}$; smell sometimes sweetish

8. Pileus $-23 \mathrm{~mm}$ broad, at start brown with darker centre; stipe 30-50 × 2.5-3 mm; smell indistinct; spores (pale) yellow-brown see $P$. pertinax $(\mathrm{E})$

P. subspadiceogrisea (Asia)

9. Pleurocystidia utriform to subcylindrical, often with elongate-cylindrical neck, rarely subellipsoid or ventricose-conical; apex (4-)6-10 $\mu \mathrm{m}$ broad, mainly rounded, sometimes obtuse to subacute; paracystidia never mucronate

10. Growing in open fields, grasslands, pastures, on herbaceous debris, among hygrophilous plants, in nitrogen rich soil, arenicolous, on dry to wet soil 
11. Spores on average less than $9.3 \mu \mathrm{m}$ long and $5.1 \mu \mathrm{m}$ broad 12

12. Spores often distinctly ovoid to angular-ovoid, reddish brown; pleurocystidia often capitate to forked; on moist soil

13. Pileus usually still distinctly greyish brown when mature, not pink at margin; gill edge not pigmented; spores rarely or sometimes phaseoliform; pleurocystidia not or rarely incrusted, forked or brownish

Pileus quickly discoloring, usually to brownish orange shades, sometimes with pinkish tints, fading to white, drying greyish violaceous; gill edge sometimes pigmented; stipe at the base sometimes bent, swollen, or equipped with a pseudorhiza [If pleurocystidia fusiform with apex in part mucous or subcapitate, see $P$. dunensis (E)]

14. Spores reddish brown; in moist, often flooded, permeable alluvial plain with Salix and hygrophilous plants

14. Spores orangish; in open pastured ground or in forest soil

15. Pleurocystidia (narrowly) utriform, sometimes fusiform, rarely lageniform or clavate, capitate or not, forked or not, incrusted or not, sometimes brownish; spores often \pm phaseoliform, to \pm indented above the apiculus, orangish brown to orangish reddish brown; veil mature sometimes still appendiculate at the margin of the pileus, folded back on the gills or, rarely, annular on the stipe; gill edge rarely weakly pigmented; pileus at most and rarely pinkish buff

P. albescens $(\mathrm{A}, \mathrm{E})$

Pleurocystidia utriform, lageniform, fusiform, conical, rarely clavate, capitate or not, rarely incrusted or forked, never brownish; spores rarely phaseoliform or indented above the apiculus, sometimes subphaseoliform, brown to dark red; veil fugacious; gill edge sometimes red; pileus sometimes discoloring with distinct to weak pinkish tints

Habitat arenicolous on coastal dunes or inland, not associated to moist soil or hygrophilous plants; spores (7.5-)8.5-14 × (4.7-)5-8.5 $\mu \mathrm{m}$, avQ 1.5-1.9

Growing in wet to moist soil among hygrophilous plants (e.g. Typha, Phragmites, Cirsium, Epilobium); sometimes clampless

[If pleurocystidia (ventricose-) lageniform to obconical, see P. basii (E)]

Habitat different, on mud in a cow pasture (it is dubious whether this species is coprophilous/nitrophilous or not)

Spores tridimensional or broader than $5.5 \mu \mathrm{m}$ in front view, strongly pigmented; germ pore little distinct; stipe without a ring [if pleurocystidia mainly ventricose-lageniform with obtuse apex, see $P$. affinis (A)]

Spores on average $<5.5 \mu \mathrm{m}$ broad, not or inconspicuously tridimensional; some species with a moderately distinct germ pore [If spores (8-)8.2-9.8(-10.7) $\times(5-) 5.2-5.8(-6) \mu \mathrm{m}$, dark, germ pore distinct, on moist soil under aspen, see $P$. sanjuanensis $(\mathrm{A})]$

23. Spores often cordiform to pentagonal, 7-9 $\times 4.5-6.3 \times 4-5 \mu \mathrm{m}$, fQ 1.3-1.5; on soil in a mixture of aspen and conifers at about $2438 \mathrm{~m}$ a.s.l. (8 000 feet) 
25. Pleurocystidia 20-32 × (9-)11-16 $\mu \mathrm{m}$ long, with mainly undifferentiated apex; veil absent or scarce; pileus $10 \mathrm{~mm}$; stipe $40 \times 1.5 \mathrm{~mm}$; spores dark, oval, cylindrical oval, oboval, sometimes irregular or angular, with broadly rounded to subtruncate base; germ pore little to moderately distinct

26. Pleurocystidia in $\mathrm{NH}_{4}$ often with reddish brown mucoid to granular coverings and granular contents, utriform to clavate or cylindrical, sometimes slightly thick-walled and pigmented, 45-52 × 14-21 $\mu \mathrm{m}$; stipe with a striate, membranous ring; spores 7.5-9.5(-10) $\times 4-5.5 \mu \mathrm{m}$

Spores dark, often with a truncate to subtriangular base, sometimes (irregularly) angular-oval or angular-oblong; germ pore moderately to little distinct; veil when mature often still distinct with floccules at the margin or appendiculate or as a membranous ring; pleurocystidia forked or not, incrusted or not, sometimes or rarely weakly pigmented

Different combination of characters; without a ring (occasionally in $P$. albescens); if spores dark then germ pore distinct (see P. fatua)

Pleurocystidia mainly slender, (37-)45-67(-83) × (10-)13-20(-32) $\mu \mathrm{m}$, never clavate, often with a tapering and elongate upper portion, scarcely subcapitate; gill edge cystidia never mucronate; in association with Alnus

28. Pleurocystidia shorter, $(22-) 26-56(-70) \times 9-24 \mu \mathrm{m}$, sometimes clavate, with an apex often broad, tapering or not in the upper portion; gill edge cystidia sometimes or often mucronate; mainly in association with Alnus or Fagus

29. In mesophilous habitat, mostly with Fagus; cheilocystidia rarely attenuate to subacute at the apex; pleurocystidia utriform to ellipsoid or clavate, sometimes lageniform, with an often capitate to subcapitate apex, (22-)26-56(-70) × 9-24 $\mu \mathrm{m}$

In moist habitat under Alnus; cheilocystidia often mucronate; pleurocystidia more varying: utriform, clavate, sublageniform, mucronate, obconical, with a rarely subcapitate apex, (24-)30-45(-52) × (10-)11.5-21; spores (7.4-)7.5-9.6(-10) × 4.9-5.6 $\mu \mathrm{m}$

31. Spores reddish orangish to dull orange; pileus sometimes fading to pinkish buff

32. Pleurocystidia utriform to lageniform, sometimes subcylindrical, apex rarely forked or incrusted; paracystidia (sub) hyaline; spores in front view sometimes oblong to subcylindrical or slightly irregular; context rigid; odor sometimes of fish

Pleurocystidia utriform, apex often forked or incrusted; paracystidia often yellowish; spores not so; context fragile

33. Pileus clay color turning to greyish tints, $1-3 \mathrm{~cm}$; stipe $20-30 \times 2-4 \mathrm{~mm}$, equal; spores medium reddish brown; on oak debris

Pileus discoloring to cinnamon buff with a slightly redder centre, fading pale date brown, 3-5 cm; stipe 60-120 × 3-6 mm, subclavate; spores sordid reddish brown; often on Populus debris

34. Paracystidia mainly 9-12 $\times 5-7 \mu \mathrm{m}$, some $-32 \times-13 \mu \mathrm{m}$, hyaline, among numerous basidia and basidiola; pleurocystidia rarely to sometimes forked, hyaline, never incrusted or pigmented; pileus pale dingy cinnamon brown turning dark brown when mature, fading to pallid, $1-3 \mathrm{~cm}$ broad; stipe 20-50 × 1-3 mm; spores sometimes or rarely subphaseoliform, (6.7-)7-9.3(-9.5) × 4.3-5.7 $\mu \mathrm{m}$

35. Pleurocystidia sometimes brownish, forked or capitate, apex often with pigmented thickwalled traits or covered with grossly mucous masses disappearing in old exsiccata; pileus not or scarcely striate, when young with dark tones of violaceous brown to reddish brown, possibly still dark when mature, 15-72 mm; stipe 30-130(-200) × 3.5-10 mm, base often attenuate to strongly rooting; spores on average $7.4-8.3 \times 4.5-4.9 \mu \mathrm{m}$, orange-brown to reddish orange brown (darkish reddish brown in $\mathrm{NH}_{4}$ ), often phaseoliform; context of pileus and especially of stipe cortex thick, rigid, tenacious 
35. Pleurocystidia apex not mucous; stipe base at most subrooting or equipped with a pseudorhiza;

spores brown, reddish brown, dark red (see $P$. albescens and $P$. tenacipes with orangish reddish brown spores);

context not distinctly thick and rigid (but species with somewhat rigid stipe cortex can occur,

e.g. P. fatua, P. albescens, P. tenacipes)

36. Pleurocystidia often little differentiated between ventricose and apical part, sometimes or often subcapitate, not forked, not incrusted, not pigmented; paracystidia yellow and gill edge pallid brownish; pileus becoming distinctly rugulose, not discoloring pinkish, 10-40 mm; spores orangish reddish brown, 7-9.5(-10.1) × 4.6-5.7 $\mu \mathrm{m}$, sometimes subphaseoliform; stipe rather stringy, fibrous, cartilaginous-pliant, 30-60 × 2-3.5 mm; in moist to wet habitat (on muck and small sticks partly burned in the protologue, on drying muck in ash swamp in the field notes)

36. Different combination of characters; in dry habitat 37

37. Pileus $-20 \mathrm{~mm}$ broad, striate; pleurocystidia often little differentiated, apex mainly obtuse or subacute, rarely rounded, never capitate; stipe $-30 \times-2.5 \mathrm{~mm}$; paracystidia sometimes or often with a pale pigment (gill edge possibly pigmented?) [If pileus usually drying with pinkish tints, pleurocystidia apex in part mucous or subcapitate, see $P$. dunensis (E)]

37. Larger sporocarps or else different combination of characters

38. Pileus yellowish fulvous to reddish cinnamon, mature broadly convex to plane; pleurocystidia conical, utriform-conical, fusiform, ellipsoid, also utriform, subcylindrical, lageniform, slightly pigmented, apex sometimes mucronate, forked, truncate, incrusted; spores orange-brown (in KOH bright cocoa slowly turning chocolate in Smith 1972) P. ochrofulva (A)

38. Pileus white turning greyish brown when mature and fading white, obtusely conical and hardly expanding; veil apparently absent; pleurocystidia mainly subfusoid to subutriform, not pigmented, not mucronate, not forked, not incrusted; spores in $\mathrm{KOH}$ dark cocoa brown slowly turning darker in Smith (1972)

P. lactobrunnescens (A)

39. Pileus not striate, hardly expanding, 25-30 mm broad, bronze brown, then gray- to clay-brown or pale ochre to cream; stipe 50-70 × 3-4 mm; spores rarely subphaseoliform, reddish brown, 8-10.5 × 4.5-5 $\mu \mathrm{m}$; germ pore small; pleurocystidia utriform to subutriform, scarcely subcapitate, rarely yellowish brown incrusted

P. marquana (E)

39. Pileus striate when fresh, usually expanding; sporocarps of the same dimension or larger; different combination of characters

40. Pleurocystidia sometimes capitate, rarely incrusted or forked, never brownish; spores brown to dark red, rarely phaseoliform, sometimes subphaseoliform; pileus reddish brown, quickly discolouring through brown to brownish orange or paler, sometimes with distinct to weak pink tints, 8-50 (60) mm broad; gill edge sometimes red; stipe (10-)20-110 × 1-5.5(-7) mm, base sometimes attenuate or with a pseudorhiza

40. Pleurocystidia sometimes brownish, incrusted, forked; spores not dark red; gill edge generally not pigmented; spores on average 7.4-9 $\mu \mathrm{m}$ long, usually often \pm phaseoliform to \pm indented above the base; pileus rarely with vague pinkish shades (P. albescens)

41. Pileus when young dark yellowish brown to cinnamon-brown, discolouring through shades of brownish orange (rarely pinkish buff) to finally white, 10-70 mm; stipe 20-100(-140) × 1.5-6(-12) mm, base often attenuate, subrooting or equipped with a pseudorhiza; veil mature sometimes still appendiculate or folded back on the gills, rarely annulate; spores orangish brown to orangish reddish brown; pleurocystidia subcapitate or not

P. albescens $(\mathrm{A}, \mathrm{E})$

Pileus dark (violaceous) reddish brown, when mature sometimes often still strongly pigmented, usually not fading completely white, $15-55 \mathrm{~mm}$; stipe $40-80 \times 1.5-8 \mathrm{~mm}$, base at most sub attenuate; veil mature fugacious; spores reddish brown; pleurocystidia rarely capitate

P. spadiceogrisea (A, E)

\section{ACKNOWLEDGEMENTS}

We are grateful to the curators of the following herbaria: $\mathrm{K}, \mathrm{MICH}, \mathrm{NY}$, and particularly wish to express our gratitude to the MICH's Collection Manager and correspondent, Patricia Rogers, for her collaboration in answering our many questions about the $\mathrm{MICH}$ specimens studied. We wish to thank Kathy Richmond, of the Southern Idaho Mycological Association (SIMA), who verified a collection site in Idaho, Joaquim
Carbó, Ottorino Chiarello, Alessio Micucci, Miquel À. Pérez-De-Gregorio, Bruno de Ruvo, Marco Maletti, Gerard Tassi, Renato Tizzoni, Evelina Zanella and Marino Zugna who supplied us with gifts of collections and pictures; thanks are also due to Giovanni Robich of the herbarium MCVE who for a time assisted us in communicating with the herbaria. Also, we are grateful to L. Örstadius and L. Nagy for providing to us details about their Psathyrella sp. NL-0631, and to M. Vašutová for the collaboration on $P$. aff. kauffmanii. The key also includes an additional 
taxon, identified in GenBank as Psathyrella sp., voucher NL-0631, which belongs to the $P$. umbrosa complex. This was possible thanks to courtesy of L. Nagy, who collected it together with Z.S. Gorliczai, and to L. Örstadius, who examined it microscopically.

\section{REFERENCES}

Altschul SF, Gish W, Miller W, et al. (1990). Basic local alignment search tool. Journal of Molecular Biology 215: 403-410.

Bergemann S, Smith A, Parrent J, et al. (2009). Genetic population structure and distribution of a fungal polypore, Datronia caperata in mangrove forests of Central America. Journal of Biogeography 36: 266-279.

Bon M (1988). Flore Mycologique du Littoral. Documents Mycologiques 19: 62-64.

Breitenbach J, Kränzlin F (1995). Champignons de Suisse. Contribution à la connaissance de la flore fongique de Suisse. Tome IV. Champignons à lames 2ème partie. Mykologia, Luzern.

Einhellinger A (1973). Die Pilze der Pflanzengesellschaften des Auwaldgebiets der Isarzwischen München und Grüneck. Berichte der Bayerischen Botanischen Gesellschaft zur Erforschung der heimischen Flora 44: 5-100.

Enderle M (1996). Studien in der Gattung Psathyrella. IV. Beitrage zur Kenntnis der Pilze Mitteleuropas 10: 35-58.

Felsenstein J (1985). Confidence limits on phylogenies: an approach using the bootstrap. Evolution 39: 783-791.

Gardes M, Bruns TD (1993). ITS primers with enhanced specificity for Basidiomycetes application to the identification of mycorrhizae and rusts. Molecular Ecology 2: 113-118.

Heykoop M, Moreno G, Alvarado P, et al. (2017). El género Psathyrella (Fr.) Quél. s.I. en España. VI. Especies nuevas o raras y reevaluación de otras. Boletín de la Sociedad Micológica de Madrid 41: 71-98.

Huijsman HSC (1955). Observations on Agarics. Fungus 25: 18-43.

Ivors KL, Hayden KJ, Bonants PJM, et al. (2004). AFLP and phylogenetic analyses of North America and European populations of Phytophthora ramorum. Mycological Research 108: 378-392.

Katoh K, Misawa K, Kuma K, et al. (2002). MAFFT: a novel method for rapid multiple sequence alignment based on fast Fourier transform. Nucleic Acids Research 30: 3059-3066.

Kearse M, Moir R, Wilson A, et al. (2012). Geneious Basic: an integrated and extendable desktop software platform for the organization and analysis of sequence data. Bioinformatics 28: 1647-1649.

Kits van Waveren E (1985). The Dutch, French and British species of Psathyrella. Persoonia Supplement 2: 1-300.

Kumar S, Stecher G, Li M, Knyaz C, et al. (2018). MEGA X: Molecular Evolutionary Genetics Analysis across computing platforms. Molecular Biology and Evolution 35: 1547-1549.

Ludwig E (2007a). Pilzkompendium Band 2, Beschreibungen. Die gröBeren Gattungen der Agaricales mit farbigem Sporenpulver (ausgenommen Cortinariaceae). Fungicon-Verlag, Berlin.

Ludwig E (2007b). Pilzkompendium Band 2, Abbildungen. Die gröBeren Gattungen der Agaricales mit farbigem Sporenpulver (ausgenomme Cortinariaceae). Fungicon-Verlag, Berlin.

Miller MA, Pfeiffer W, Schwartz T (2010). Creating the CIPRES Science Gateway for inference of large phylogenetic trees. In: Proceedings of the Gateway Computing Environments Workshop (GCE), 14 November 2010, New Orleans, LA: 1-8.

Morgan AP (1907). North American species of Agaricaceae. Journal of Mycology 13(91): 143-153.

Örstadius L, Knudsen H (2008). Psathyrella (Fr.) Quél. In: Funga Nordica -Agaricoid, boletoid, clavarioid, cyphelloid and gastroid genera. Vol.
1 (Knudsen H, Vesterholt J, eds). Nordsvamp, Copenhagen: 587-623. Örstadius L, Knudsen H (2012). Psathyrella (Fr.) Quél. In: Funga Nordica-Agaricoid, boletoid, clavarioid, cyphelloid and gastroid genera (2nd ed.). Vol. 1 (Knudsen $\mathrm{H}$, Vesterholt J, eds). Nordsvamp, Copenhagen: 692-728.

Örstadius L, Ryberg M, Larsson E (2015). Molecular phylogenetics and taxonomy in Psathyrellaceae (Agaricales) with focus on psathyrelloid species: introduction of three new genera and 18 new species. Mycological Progress 14: 25.

Osmundson T, Eyre C, Hayden K, et al. (2013). Back to basics: an evaluation of $\mathrm{NaOH}$ and alternative rapid DNA extraction protocols for DNA barcoding, genotyping, and disease diagnostics from fungal and oomycete samples. Molecular Ecology Resources 13: 66-74.

Pegler DN (1977). A preliminary agaric flora of East Africa. Kew bullettin additional series, 6. Her Majesty's Stationery Office.

Pérez-De-Gregorio MÀ, Roqué C, Carbó J (2010). Dos Psathyrella interesantes halladas en Girona. Micologia e Vegetazione Mediterranea 25: 23-32.

Posada D, Crandall KA (1998). Modeltest: testing the model of DNA substitution. Bioinformatics 14: 817-818.

Romagnesi H (1944). Classification du genre Drosophila Quélet. Bulletin Mensuel De La Societe Linneenne De Lyon 13: 51-54.

Ronquist F, Teslenko M, van der Mark P, et al. (2012). MrBayes 3.2: efficient Bayesian phylogenetic inference and model choice across a large model space. Systematic Biology 61: 539-542.

Schäffer JC (1771). Fungorum qui in Bavaria et Palatinatu circa Ratisbonam nascuntur Icones 3. Regensburg.

Schäffer JC (1774). Fungorum qui in Bavaria et Palatinatu circa Ratisbonam nascuntur Icones 4. Regensburg.

Schäffer JC (1800). Fungorum qui in Bavaria et Palatinatu circa Ratisbonam nascuntur Icones nativis coloribus expressae. Editio nova. Vol. 3-4. Erlangae, Apud J.J. Palmium.

Smith AH (1972). The North American species of Psathyrella. Memoirs of the New York Botanical Garden 24: 1-633.

Stamatakis A (2006). RAxML-VI-HPC: Maximum likelihood-based phylogenetic analyses with thousands of taxa and mixed models. Bioinformatics 22: 2688-2690.

Swofford DL (2003). PAUP*: phylogenetic analysis using parsimony. *and other methods). Version 4.0b10. Sinauer Associates, Sunderland.

Tassi G (2000). Le genre Psathyrella. Espèces rares ou intéressantes. II. Bulletin de la Société mycologique de France. 116: 343-384.

Vašutová M, Antonin V, Urban A (2008). Phylogenetic studies in Psathyrella focusing on sections Pennatae and Spadiceae - new evidence for the paraphyly of the genus. Mycological Research 112: 1153-1164.

Voto P (2007). Psathyrella bivelata, seconda stazione italiana e Psilocybe flocculosa, nuova per l'Italia. Rivista di Micologia 2: 145-157.

Voto $\mathrm{P}$ (2011). Psathyrella carinthiaca sp. nov. e nuove segnalazioni di $P$. bivelata. Rivista di Micologia 2: 121-133.

Voto P (2013). Note su Psathyrella candolleana e P. pseudogordonii. Rivista di Micologia 3: 247-261.

\section{Supplementary Material: http://fuse-journal.org/}

Fig. S1. Bayesian phylogram obtained from combined nrITS and Tef- $1 \alpha$ sequence alignment of Psathyrella spp. Bolbitius vitellinus was used as outgroup taxon. Only BPP values $\geq 0.95$ and MLB values $\geq 70 \%$ are given above clade branches. In addition to sequences generated by this study and to select GenBank accessions, most sequences published by Örstadius et al. (2015) are included in this tree. 